UNIVERSIDADE DE SÃO PAULO

INSTITUTO DE ASTRONOMIA, GEOFÍSICA E CIÊNCIAS ATMOSFÉRICAS

DEPARTAMENTO DE CIÊNCIAS ATMOSFÉRICAS

CINTHIA AVELLAR MARTINS

Estimativa da evapotranspiração no estado de São Paulo com o modelo da biosfera SiB2 


\section{Estimativa da evapotranspiração no estado de São Paulo com o modelo da biosfera SiB2}

Dissertação apresentada ao Departamento de Ciências Atmosféricas do Instituto de Astronomia, Geofísica e Ciências Atmosféricas da Universidade de São Paulo como parte dos requisitos para obtenção do título de Mestre em Ciências.

Área de Concentração: Meteorologia

Orientador: Prof. Dr. Humberto Ribeiro da Rocha

Versão corrigida. O original encontra-se no Instituto de Astronomia, Geofísica e Ciências Atmosféricas.

São Paulo 
Dedico este trabalho ao meu avô Luiz de Lima Avellar (in memoriam), um homem inteligente e trabalhador, que não teve a oportunidade de estudar, mas fez questão de apoiar suas filhas e netos para este fim. 


\section{AGRADECIMENTOS}

Agradeço a Deus que me abriu as portas e iluminou o meu caminho.

Ao Prof. Dr. Humberto Rocha, pela orientação presente e assistida, pela paciência, e por ter depositado em mim a confiança para executar este trabalho.

Aos meus pais, Solange Avellar e César Martins, que me apoiaram de diversas formas para que eu pudesse sair de casa e fazer o curso de mestrado em outro estado.

Ao meu irmão, Luis Augusto, pelos momentos compartilhados.

Ao meu amor, Iuri Nascimento, pela e compreensão nos anos em que estive ausente.

À minha família, em especial aos meus avós Aristéa, Deolinda e Augusto pela alegria em me verem conquistando tantas coisas.

Aos meus amigos do Rio de Janeiro, por não me deixarem de lado mesmo estando distante, e por aproveitarem os momentos em que eu estive presente para nos reunirmos.

Aos meus novos amigos do IAG, pela companhia e os bons momentos passados juntos.

Aos membros e ex-membros do Laboratório de Clima e Biosfera, em especial, Carlos Fagiolo, Emilia Brasilio, Jonathan Mota, Jônatan Tatsch, Marta Llopart, Mônica Queiroz e Ricardo Acosta, pela ajuda no desenvolvimento do trabalho.

Ao pessoal da informática, Samuel e Sebastião, pelo socorro rápido quando precisei.

Aos professores da pós-graduação pelo conhecimento adquirido, em especial à professora Rosmeri pela ajuda.

À Agritempo e Embrapa, nas figuras de Adriano Otavian e Eduardo Assad, pelos dados cedidos.

À CAPES (Coordenação de Aperfeiçoamento de Pessoal de Nível Superior) e ao CNPq (Conselho Nacional de Desenvolvimento Científico e Tecnológico), pelo apoio financeiro. 
Todos os rios vão para o mar, e, contudo o mar não se enche; ao lugar para onde os rios vão, para ali tornam eles a correr.

Eclesiastes 1:7 
RESUMO

MARTINS, C. A. Estimativa da evapotranspiração no estado de São Paulo com o modelo da biosfera SiB2. 2011. 130 f. Dissertação (Mestrado) - Instituto de Astronomia, Geofísica e Ciências Atmosféricas, Universidade de São Paulo, São Paulo, 2011.

Utilizamos um modelo físico-matemático de relações biosfera-atmosfera para estimar a climatologia da evapotranspiração regional (ETR) entre 1980 e 2009 no estado de São Paulo, o modelo SiB2 (Simple Biosphere model). Os cálculos utilizaram dados horários da reanálise CFSR, por meio de etapas de comparação das forçantes com dados observados de superfície, e com dados de fluxos de superfície observados no campo. Os padrões da reanálise mostraram-se satisfatórios no domínio do estado de São Paulo para caracterizar a climatologia de chuva e temperatura da região, com pequenos vieses no ciclo diurno e no total anual de precipitação. Foram utilizados 6 cenários com cobertura de superfície homogênea em todo o estado (floresta de mata atlântica, cerrado, eucalipto, cana-de-açúcar, pastagem, urbanização), além de dois outros cenários (vegetação nativa e vegetação atual), que produziram médias de ETR substancialmente distintas. No cenário de eucalipto obteve-se a maior média anual, de $3,7 \mathrm{~mm} \mathrm{dia}{ }^{-1}$, seguido pelos valores calculados para floresta atlântica e vegetação nativa, próximos entre si, e com máximos valores do saldo de radiação e fração evaporativa. $\mathrm{O}$ impacto da mudança do uso da terra nos totais de ETR no estado de São Paulo pode ser discutido a partir do cenário de vegetação nativa, com ETR média de $3,3 \mathrm{~mm} \mathrm{dia}{ }^{-1}, \sim 20 \%$ superior à ETR da vegetação atual. Obteve-se uma caracterização da climatologia da ETR real no estado de SP, com média de $930 \mathrm{~mm}^{\text {ano }}{ }^{-1}$, comparável com a climatologia do DAEE de $980 \mathrm{~mm} \mathrm{ano}^{-1}$ no estado como um todo, e bem comparada com a ETR em várias sub-bacias hidrográficas.

Palavras-chave: Evapotranspiração, modelo SiB2, climatologia, vegetação. 


\section{ABSTRACT}

\section{MARTINS, C. A. Evapotranspiration estimation in the State of São Paulo with SiB2}

biosphere model. 2011. 130 f. Dissertação (Mestrado) - Instituto de Astronomia, Geofísica e Ciências Atmosféricas, Universidade de São Paulo, São Paulo, 2010.

We have used a biosphere-atmosphere relationships physical-mathematical model in order to estimate the regional evapotranspiration (ETR) climatology between 1980 and 2009, the SiB2 model (Simple Biosphere Model). The calculations used hourly data from CFSR reanalysis, through the steps of comparing forcing data with observed surface data, and with surface fluxes data observed in site. The reanalysis patterns proved satisfactory to characterize the climatology of rainfall and temperature in São Paulo state area, with small biases in the diurnal cycle and in total annual precipitation. Six homogeneous coverage surface scenarios throughout the state were used (Atlantic forest, brasilian savannah, eucalyptus, sugar cane, pasture, urbanization), and two other scenarios (native vegetation and nowadays vegetation), which produced substantially different mean ETR. The eucalyptus scenario obtained the highest annual average of $3.7 \mathrm{~mm} \mathrm{day}^{-1}$, the greatest values were from eucalyptus, Atlantic forest and nowadays vegetation, close together, and with maximum values of net radiation and evaporative fraction. The land use change impact in the total ETR in São Paulo state can be discussed from the native vegetation scenario, with $3.3 \mathrm{~mm} \mathrm{day}^{-1}$ average value, $\sim 20 \%$ higher than nowadays vegetation. We obtained a characterization of real ETR climatology in São Paulo state, with an average of $930 \mathrm{~mm}_{\text {year }}{ }^{-1}$, comparable to DAEE climatology of 980 $\mathrm{mm}_{\text {year }}{ }^{-1}$ statewide, and well compared to ETR in various sub-basins.

Keywords: Evapotranspiration, biosphere model, climate. 


\section{LISTA DE FIGURAS}

Figura 1.1: Mapa do estado de São Paulo (cc 1910) com a cobertura vegetal dominante, onde aparece o café (verde escuro) no NE do estado, e a vegetação original de florestas em todo o o setor leste e no litoral com a Mata Atlântica.

Figura 2.1: Localização das estações do conjunto de dados observados com mais de 180 meses de dados no período de 1980 a 2009

Figura 2.2: A) Mapa político do estado de SP; B) Mapa do relevo do estado de SP. 24

Figura 2.3: Classes de vegetação encontradas no Estado de São Paulo, com $1 \mathrm{~km}$ de resolução. 28

Figura 2.4: Classes de vegetação atual no Estado de São Paulo, com 0,25 de espaçamento de grade.

Figura 2.5: Classificação da vegetação nativa sobre o Estado de São Paulo, escala de 1:5000000. 29

Figura 2.6: Classificação da vegetação nativa sobre o Estado de São Paulo, com $0,25^{\circ}$ de espaçamento de grade.

Figura 3.1: Forçantes do SiB2. Médias anuais entre 1980 e 2009. A) Irradiância Solar Incidente $\left[\mathrm{W} \mathrm{m}{ }^{-2}\right]$; B) Precipitação acumulada $\left[\mathrm{mm} \mathrm{dia}^{-1}\right]$; C) Pressão parcial de vapor d'água $[\mathrm{hPa}]$; D) Temperatura do ar $\left[{ }^{\circ} \mathrm{C}\right]$; E) Velocidade do vento $\left[\mathrm{m} \mathrm{s}^{-1}\right] .33$

Figura 3.2: Irradiância Solar Incidente $(\mathrm{Ki})\left[\mathrm{W} \mathrm{m} \mathrm{m}^{-2}\right]$. Médias sazonais climatológicas entre 1980 e 2009. A) trimestre Dezembro, Janeiro e Fevereiro; B) trimestre Junho, Julho e Agosto.

Figura 3.3: Precipitação Mensal Acumulada (Prc) $\left[\mathrm{mm} \mathrm{dia}^{-1}\right]$. Médias sazonais climatológicas entre 1980 e 2009. A) trimestre Dezembro, Janeiro e Fevereiro; B) trimestre Junho, Julho e Agosto.

Figura 3.4: Pressão Parcial do Vapor D’água (Pv) [hPa]. Médias sazonais climatológicas entre 1980 e 2009. A) trimestre Dezembro, Janeiro e Fevereiro; B) trimestre Junho, Julho e Agosto. 35

Figura 3.5: Temperatura Média do $\operatorname{Ar}(\operatorname{Tmp})\left[{ }^{\circ} \mathrm{C}\right]$. Médias sazonais climatológicas entre 1980 e 2009. A) trimestre Dezembro, Janeiro e Fevereiro; B) trimestre Junho, Julho e Agosto

Figura 3.6: Velocidade do Vento (Vnt) $\left[\mathrm{m} \mathrm{s}^{-1}\right]$. Médias sazonais entre 1980 e 2009. A) trimestre Dezembro, Janeiro e Fevereiro; B) trimestre Junho, Julho e Agosto...... 36 
Figura 3.7: Diferença entre Reanálise e dados observados. Médias anuais no período entre 1980 e 2009. A) Precipitação $\left[\mathrm{mm} \mathrm{dia}^{-1}\right]$; B) Temperatura Máxima $\left[{ }^{\circ} \mathrm{C}\right]$; C) Temperatura Mínima $\left[{ }^{\circ} \mathrm{C}\right]$.

Figura 3.8: Série temporal das forçantes do modelo Reg-SiB2. Média anual no domínio no período entre 1980 e 2009. A linha cheia preta representa os dados de reanálise, e a linha pontilhada vermelha, os dados observados. A) Irradiância Solar Incidente (Ki) $\left[\mathrm{W} \mathrm{m}{ }^{-2}\right]$; B) Precipitação acumulada (Prc) $\left[\mathrm{mm} \mathrm{dia}^{-1}\right]$; C) Pressão parcial de vapor d'água $(\mathrm{Pv})[\mathrm{hPa}]$; D) Temperatura média do ar (Tmp) $\left[{ }^{\circ} \mathrm{C}\right]$; E) Velocidade do vento $(\mathrm{Vnt})\left[\mathrm{m} \mathrm{s}^{-1}\right]$. 38

Figura 3.9: Série temporal das forçantes do modelo Reg-SiB2. Média mensal do domínio no período entre 1980 e 2009A linha cheia preta representa os dados de reanálise, e a linha pontilhada vermelha, os dados observados. A) Irradiância Solar Incidente (Ki) $\left[\mathrm{W} \mathrm{m}{ }^{-2}\right]$; B) Precipitação acumulada (Prc) $\left[\mathrm{mm} \mathrm{dia}^{-1}\right]$; C) Pressão parcial de vapor d'água $(\mathrm{Pv})[\mathrm{hPa}]$; D) Temperatura média do ar $(\mathrm{Tmp})\left[{ }^{\circ} \mathrm{C}\right]$; E) Velocidade do vento $(\mathrm{Vnt})\left[\mathrm{m} \mathrm{s}^{-1}\right]$.

Figura 3.10: Climatologia das forçantes do modelo Reg-SiB2. Média mensal no domínio no período entre 1980 e 2009. A linha cheia preta representa os dados de reanálise, e a linha pontilhada vermelha, os dados observados. A) Irradiância Solar Incidente (Ki) $\left[\mathrm{W} \mathrm{m}^{-2}\right]$; B) Precipitação acumulada (Prc) $\left[\mathrm{mm} \mathrm{dia}^{-1}\right]$; C) Pressão parcial de vapor d'água $(\mathrm{Pv})[\mathrm{hPa}]$; D) Temperatura média do ar $(\mathrm{Tmp})\left[{ }^{\circ} \mathrm{C}\right]$; E) Velocidade do vento $(\mathrm{Vnt})\left[\mathrm{m} \mathrm{s}^{-1}\right]$.

Figura 3.11: Saídas do modelo SiB2 para a cana-de-açúcar. Médias diárias no período entre 2006 e 2007. A) Saldo de Radiação (Rn) [W m ${ }^{-2}$; B) Fluxo de calor latente (LE) $\left[\mathrm{W} \mathrm{m}^{-2}\right]$; C) Fluxo de calor sensível $(\mathrm{H})\left[\mathrm{W} \mathrm{m}^{-2}\right]$; D) Fluxo de Calor no solo $(\mathrm{G})$

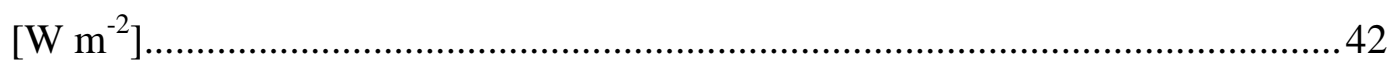

Figura 3.12: Saídas do modelo SiB2 para o cerrado. Médias diárias no período entre 2001e 2002. A) Saldo de Radiação (Rn) $\left[\mathrm{W} \mathrm{m}^{-2}\right]$; B) Fluxo de calor latente (LE) [W m ${ }^{2}$ ]; C) Fluxo de calor sensível $(\mathrm{H})\left[\mathrm{W} \mathrm{m}^{-2}\right]$; D) Fluxo de Calor no solo (G) [W m $\left.{ }^{2}\right]$

Figura 3.13: Saídas do modelo SiB2 para o eucalipto. Médias diárias no período entre 09/2006 e 08/2008. A) Saldo de Radiação (Rn) [W m ${ }^{-2}$; B) Fluxo de calor latente (LE) $\left[\mathrm{W} \mathrm{m}^{-2}\right]$; C) Fluxo de calor sensível (H) $\left[\mathrm{W} \mathrm{m}^{-2}\right]$; D) Fluxo de Calor no solo (G) $\left[\mathrm{W} \mathrm{m} \mathrm{m}^{-2}\right]$. 
Figura 3.14: Saídas do modelo SiB2 para a floresta atlântica. Médias diárias no período do ano de2008. A) Saldo de Radiação (Rn) $\left[\mathrm{W} \mathrm{m}^{-2}\right]$; B) Fluxo de calor latente (LE) [W $\left.\mathrm{m}^{-2}\right]$; C) Fluxo de calor sensível $(\mathrm{H})\left[\mathrm{W} \mathrm{m}^{-2}\right]$; D) Fluxo de Calor no solo (G)

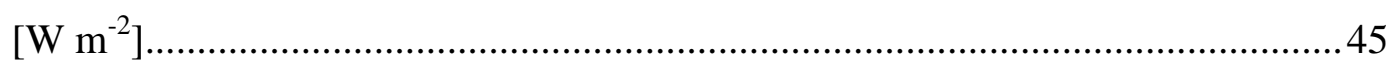

Figura 3.15: Saídas do modelo SiB2 para a pastagem. Médias diárias no período entre 2003 e 2004. A) Saldo de Radiação (Rn) [W m $\left.{ }^{-2}\right]$; B) Fluxo de calor latente (LE) [W m $\left.{ }^{2}\right]$; C) Fluxo de calor sensível $(\mathrm{H})\left[\mathrm{W} \mathrm{m}^{-2}\right]$; D) Fluxo de Calor no solo $(\mathrm{G})\left[\mathrm{W} \mathrm{m}^{-}\right.$ $\left.{ }^{2}\right]$ 46

Figura 3.16: Ciclo diurno em fevereiro e agosto das forçantes para a cana-de-açúcar. Média horária no período entre 2006 e 2007. A) Irradiância Solar Incidente (Ki) [W m ${ }^{-2}$; B) Precipitação acumulada (Prc) $\left[\mathrm{mm} \mathrm{dia}^{-1}\right]$; C) Pressão parcial de vapor d'água (Pv) $[\mathrm{hPa}]$; D) Temperatura média do ar (Tmp) $\left[{ }^{\circ} \mathrm{C}\right]$; E) Velocidade do vento (Vnt) $\left[\mathrm{m} \mathrm{s}^{-1}\right]$.

Figura 3.17: Ciclo diurno em fevereiro e agosto das forçantes para o cerrado. Média horária no período entre 2001 e 2002. A) Irradiância Solar Incidente (Ki) [W m²]; B) Precipitação acumulada (Prc) $\left[\mathrm{mm} \mathrm{dia}^{-1}\right]$; C) Pressão parcial de vapor d'água (Pv) [hPa]; D) Temperatura média do ar (Tmp) $\left[{ }^{\circ} \mathrm{C}\right]$; E) Velocidade do vento (Vnt) $[\mathrm{m}$ $\left.\mathrm{s}^{-1}\right]$.

Figura 3.18: Ciclo diurno em fevereiro e agosto das forçantes para o eucalipto. Média horária no período entre 2007 e 2008. A) Irradiância Solar Incidente (Ki) [W m²]; B) Precipitação acumulada (Prc) $\left[\mathrm{mm} \mathrm{dia}^{-1}\right]$; C) Pressão parcial de vapor d'água (Pv) [hPa]; D) Temperatura média do ar (Tmp) $\left[{ }^{\circ} \mathrm{C}\right]$; E) Velocidade do vento (Vnt) $[\mathrm{m}$ $\left.\mathrm{s}^{-1}\right]$.

Figura 3.19: Ciclo diurno em fevereiro e agosto das forçantes para a floresta atlântica. Média horária no ano de 2008. A) Irradiância Solar Incidente (Ki) [W $\left.\mathrm{m}^{-2}\right]$; B) Precipitação acumulada (Prc) $\left[\mathrm{mm} \mathrm{dia}^{-1}\right]$; C) Pressão parcial de vapor d'água (Pv) [hPa]; D) Temperatura média do $\operatorname{ar}(\mathrm{Tmp})\left[{ }^{\circ} \mathrm{C}\right]$; E) Velocidade do vento (Vnt) $[\mathrm{m}$ $\left.\mathrm{s}^{-1}\right]$.

Figura 3.20: Ciclo diurno em fevereiro e agosto das forçantes para a pastagem. Média horária no período entre 2003 e 2004. A) Irradiância Solar Incidente (Ki) [W m²]; B) Precipitação acumulada (Prc) $\left[\mathrm{mm} \mathrm{dia}^{-1}\right]$; C) Pressão parcial de vapor d'água (Pv) [hPa]; D) Temperatura média do ar (Tmp) $\left[{ }^{\circ} \mathrm{C}\right]$; E) Velocidade do vento (Vnt) [m $\left.\mathrm{s}^{-1}\right]$. 
Figura 3.21: Ciclo diurno em fevereiro e agosto dos fluxos de calor e componentes da evapotranspiração para a cana-de-açúcar. Média horária no período entre 2006 e 2007. A) Saldo de Radiação (Rn) $\left[\mathrm{W} \mathrm{m}^{-2}\right]$; B) Fluxo de calor latente (LE) [W m 2]; C) Fluxo de calor sensível $(\mathrm{H})\left[\mathrm{W} \mathrm{m}^{-2}\right]$; D) Fluxo de Calor no solo $(\mathrm{G})\left[\mathrm{W} \mathrm{m}{ }^{-}\right.$ 2]; E) Tranpiração (Tra) $\left[\mathrm{mm} \mathrm{dia}^{-1}\right]$; F) Evaporação do solo (Eso) $\left[\mathrm{mm} \mathrm{dia}^{-1}\right]$; G) Evaporação por interceptação (Ein) $\left[\mathrm{mm} \mathrm{dia}^{-1}\right]$.

Figura 3.22: Ciclo diurno em fevereiro e agosto dos fluxos de calor e componentes da evapotranspiração para o cerrado. Média horária no período entre 2001 e 2002. A) Saldo de Radiação (Rn) [W m${ }^{-2}$; B) Fluxo de calor latente (LE) [W $\mathrm{m}^{-2}$; C) Fluxo de calor sensível (H) $\left[\mathrm{W} \mathrm{m}^{-2}\right]$; D) Fluxo de Calor no solo (G) $\left[\mathrm{W} \mathrm{m}^{-2}\right]$; E) Tranpiração (Tra) $\left[\mathrm{mm} \mathrm{dia}^{-1}\right]$; F) Evaporação do solo (Eso) $\left[\mathrm{mm} \mathrm{dia}^{-1}\right]$; G)

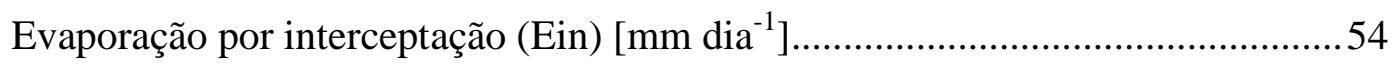

Figura 3.23: Ciclo diurno em fevereiro e agosto dos fluxos de calor e componentes da evapotranspiração para o eucalipto. Média horária entre 2007 e 2008. A) Saldo de Radiação (Rn) [W m ${ }^{-2}$; B) Fluxo de calor latente (LE) [W $\mathrm{W}^{-2}$; C) Fluxo de calor sensível (H) [W m $\left.{ }^{-2}\right]$; D) Fluxo de Calor no solo (G) $\left[\mathrm{W} \mathrm{m}^{-2}\right]$; E) Tranpiração (Tra) $\left[\mathrm{mm} \mathrm{dia}^{-1}\right]$; F) Evaporação do solo (Eso) $\left[\mathrm{mm} \mathrm{dia}^{-1}\right]$; G) Evaporação por interceptação (Ein) $\left[\mathrm{mm} \mathrm{dia}^{-1}\right]$. 55

Figura 3.24: Ciclo diurno em fevereiro e agosto dos fluxos de calor e componentes da evapotranspiração para a floresta atlântica. Média horária no ano de 2008. A) Saldo de Radiação (Rn) [W m${ }^{-2}$; B) Fluxo de calor latente (LE) [W $\left.\mathrm{m}^{-2}\right]$; C) Fluxo de calor sensível $(\mathrm{H})\left[\mathrm{W} \mathrm{m}^{-2}\right]$; D) Fluxo de Calor no solo $(\mathrm{G})\left[\mathrm{W} \mathrm{m} \mathrm{m}^{-2}\right]$; E) Tranpiração (Tra) $\left[\mathrm{mm} \mathrm{dia}^{-1}\right]$; F) Evaporação do solo (Eso) $\left[\mathrm{mm} \mathrm{dia}{ }^{-1}\right]$; G)

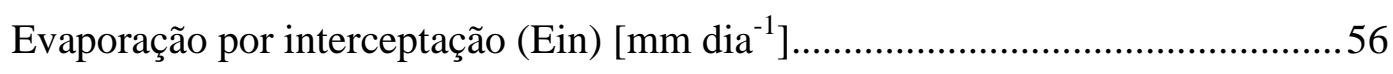

Figura 3.25: Ciclo diurno em fevereiro e agosto dos fluxos de calor e componentes da evapotranspiração para a pastagem. Média horária em 2003 e 2004. A) Saldo de Radiação (Rn) [W m ${ }^{-2}$; B) Fluxo de calor latente (LE) [W $\left.{ }^{-2}\right]$; C) Fluxo de calor sensível $(\mathrm{H})\left[\mathrm{W} \mathrm{m}{ }^{-2}\right]$; D) Fluxo de Calor no solo $(\mathrm{G})\left[\mathrm{W} \mathrm{m} \mathrm{m}^{-2}\right]$; E) Tranpiração (Tra) $\left[\mathrm{mm} \mathrm{dia}^{-1}\right]$; F) Evaporação do solo (Eso) $\left[\mathrm{mm} \mathrm{dia}^{-1}\right]$; G) Evaporação por interceptação (Ein) $\left[\mathrm{mm} \mathrm{dia}^{-1}\right]$.

Figura 3.26: Média mensal no domínio do Grau de Saturação de Umidade (W) [adim], escoamento superficial (Rs) $\left[\mathrm{mm} \mathrm{dia}^{-1}\right]$ e escoamento sub-superficial (Rsb) [mm $\left.\mathrm{dia}^{-1}\right]$ para a cana-de-açúcar, no período de 1980 a 2009. A) primeira etapa do

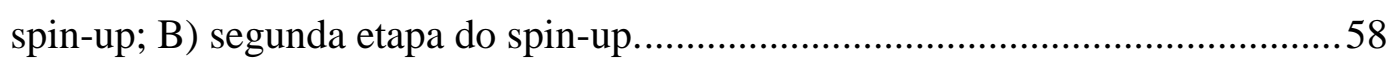


Figura 3.27: Média mensal no domínio do Grau de Saturação de Umidade (W) [adim], escoamento superficial (Rs) $\left[\mathrm{mm} \mathrm{dia}^{-1}\right]$ e escoamento sub-superficial (Rsb) [mm $\mathrm{dia}^{-1}$ ] para o cerrado, no período de 1980 a 2009. A) primeira etapa do spin-up; B) segunda etapa do spin-up.

Figura 3.28: Média mensal no domínio do Grau de Saturação de Umidade (W) [adim], escoamento superficial (Rs) $\left[\mathrm{mm} \mathrm{dia}^{-1}\right]$ e escoamento sub-superficial (Rsb) [mm $\mathrm{dia}^{-1}$ ] para o eucalipto, no período de 1980 a 2009. A) primeira etapa do spin-up; B) segunda etapa do spin-up.

Figura 3.29: Média mensal no domínio do Grau de Saturação de Umidade (W) [adim], escoamento superficial (Rs) $\left[\mathrm{mm} \mathrm{dia}^{-1}\right]$ e escoamento sub-superficial (Rsb) [mm $\mathrm{dia}^{-1}$ ] para a floresta, no período de 1980 a 2009. A) primeira etapa do spin-up; B) segunda etapa do spin-up......

Figura 3.30: Média mensal no domínio do Grau de Saturação de Umidade (W) [adim], escoamento superficial (Rs) $\left[\mathrm{mm} \mathrm{dia}^{-1}\right]$ e escoamento sub-superficial (Rsb) [mm $\mathrm{dia}^{-1}$ ] para a pastagem, no período de 1980 a 2009. A) primeira etapa do spin-up; B) segunda etapa do spin-up.

Figura 3.31: Média mensal no domínio do Grau de Saturação de Umidade (W) [adim], escoamento superficial (Rs) $\left[\mathrm{mm} \mathrm{dia}^{-1}\right]$ e escoamento sub-superficial (Rsb) [mm $\left.\mathrm{dia}^{-1}\right]$ para a área urbana, no período de 1980 a 2009. A) primeira etapa do spinup; B) segunda etapa do spin-up

Figura 3.32: Média mensal no domínio do Grau de Saturação de Umidade (W) [adim], escoamento superficial (Rs) $\left[\mathrm{mm} \mathrm{dia}^{-1}\right]$ e escoamento sub-superficial (Rsb) [mm dia $^{-1}$ ] para a vegetação atual, no período de 1980 a 2009. A) primeira etapa do spin-up; B) segunda etapa do spin-up.

Figura 3.33: Média mensal no domínio do Grau de Saturação de Umidade (W) [adim], escoamento superficial (Rs) $\left[\mathrm{mm} \mathrm{dia}^{-1}\right]$ e escoamento sub-superficial (Rsb) $[\mathrm{mm}$ $\operatorname{dia}^{-1}$ ] para a vegetação nativa, no período de 1980 a 2009. A) primeira etapa do spin-up; B) segunda etapa do spin-up. 62

Figura 3.34: Grau de Saturação de Umidade (W) [adim], escoamento superficial (Rs) [mm $\left.\mathrm{dia}^{-1}\right]$ e escoamento sub-superficial (Rsb) $\left[\mathrm{mm} \mathrm{dia}^{-1}\right]$ Média mensal no domínio entre 1980-2009. A) cana-de-açúcar; B) cerrado; C) eucalipto; D) floresta atlântica; E) pastagem; F) área urbana; G) vegetação atual; H) vegetação nativa.63 
Figura 3.35: Evapotranspiração média sazonal entre 1980 e 2009 para a cana-de-açúcar. A) trimestre Dezembro, Janeiro e Fevereiro; B) trimestre Junho, Julho e Agosto. [mm dia-1]

Figura 3.36: Evapotranspiração média sazonal entre 1980 e 2009 para o cerrado. A) trimestre Dezembro, Janeiro e Fevereiro; B) trimestre Junho, Julho e Agosto. [mm dia-1] 65

Figura 3.37: Evapotranspiração média sazonal entre 1980 e 2009 para o eucalipto. A) trimestre Dezembro, Janeiro e Fevereiro; B) trimestre Junho, Julho e Agosto. [mm dia-1]

Figura 3.38: Evapotranspiração média sazonal entre 1980 e 2009 para a floresta atlântica. A) trimestre Dezembro, Janeiro e Fevereiro; B) trimestre Junho, Julho e Agosto. [mm dia-1] 66

Figura 3.39: Evapotranspiração média sazonal entre 1980 e 2009 para a pastagem. A) trimestre Dezembro, Janeiro e Fevereiro; B) trimestre Junho, Julho e Agosto. [mm dia-1]

Figura 3.40: Evapotranspiração média sazonal entre 1980 e 2009 para a área urbana. A) trimestre Dezembro, Janeiro e Fevereiro; B) trimestre Junho, Julho e Agosto. [mm dia-1]

Figura 3.41: Evapotranspiração média sazonal entre 1980 e 2009 para a vegetação atual. A) trimestre Dezembro, Janeiro e Fevereiro; B) trimestre Junho, Julho e Agosto. [mm dia-1].

Figura 3.42: Evapotranspiração média sazonal entre 1980 e 2009 para a vegetação nativa. A) trimestre Dezembro, Janeiro e Fevereiro; B) trimestre Junho, Julho e Agosto. [mm dia-1]

Figura 3.43: Evapotranspiração média anual entre 1980 e 2009 [mm dia $\left.{ }^{-1}\right]$. A) cana-de-açúcar; B) cerrado; C) eucalipto; D) floresta atlântica; E) pastagem; F) área urbana; G) vegetação atual; H) vegetação nativa. ............................................................. 70

Figura 3.44: Saldo de radiação médio no domínio entre 1980 e 2009. [W m-2] ..................... 71

Figura 3.45: Fluxo de calor latente médio no domínio entre 1980 e 2009. [W m-2] ...............71

Figura 3.46: Fluxo de calor sensível médio no domínio entre 1980 e 2009. [W m-2].............72

Figura 3.47: Razão de Bowen média no domínio entre 1980 e 2009..................................... 73

Figura 3.48: Razão entre fluxo de calor latente e saldo de radiação média no domínio entre

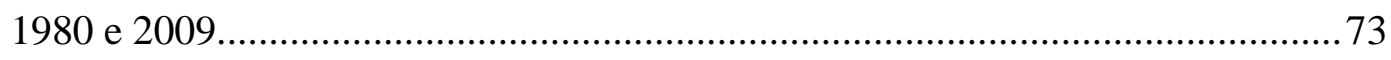

Figura 3.49: Razão entre evapotranspiração e precipitação média no domínio entre 1980 e 2009. 
Figura 3.50: ETR média anual calculada pelo modelo Reg-SiB2 em cada sub-bacia hidrográfica do estado de SP, e média anual do balanço hidrológico (DAEE, 1999). $\left[\mathrm{mm} \mathrm{ano}^{-1}\right]$

Figura A.1: Esquema de resistências do modelo SiB2. Adaptado de Sellers et al. (1996). ..... 86

Figura B.1: Irradiância Solar Incidente $(\mathrm{Ki})\left[\mathrm{W} \mathrm{m}^{-2}\right]$. Médias mensais climatológicas entre 1980 e 2009. A) Janeiro; B) Fevereiro; C) Março; D) Abril; E) Maio; F) Junho; G) Julho; H) Agosto; I) Setembro; J) Outubro; K) Novembro; L) Dezembro. 89

Figura B.2: Precipitação Mensal Acumulada (Prc) $\left[\mathrm{mm} \mathrm{dia}^{-1}\right]$. Médias mensais climatológicas entre 1980 e 2009. A) Janeiro; B) Fevereiro; C) Março; D) Abril; E) Maio; F) Junho; G) Julho; H) Agosto; I) Setembro; J) Outubro; K) Novembro; L) Dezembro

Figura B.3: Pressão Parcial do Vapor D’água (Pv) [hPa]. Médias mensais climatológicas entre 1980 e 2009. A) Janeiro; B) Fevereiro; C) Março; D) Abril; E) Maio; F) Junho; G) Julho; H) Agosto; I) Setembro; J) Outubro; K) Novembro; L) Dezembro. 93

Figura B.4: Temperatura Média do $\operatorname{Ar}(\mathrm{Tmp})\left[{ }^{\circ} \mathrm{C}\right]$. Médias mensais climatológicas entre 1980 e 2009. A) Janeiro; B) Fevereiro; C) Março; D) Abril; E) Maio; F) Junho; G) Julho; H) Agosto; I) Setembro; J) Outubro; K) Novembro; L) Dezembro. 95

Figura B.5: Velocidade do Vento (Vnt) $\left[\mathrm{m} \mathrm{s}^{-1}\right]$. Médias mensais entre 1980 e 2009. A) Janeiro; B) Fevereiro; C) Março; D) Abril; E) Maio; F) Junho; G) Julho; H) Agosto; I) Setembro; J) Outubro; K) Novembro; L) Dezembro. 97

Figura B.6: Diferença entre a precipitação mensal acumulada da Reanálise e do conjunto de dados observados [mm dia $\left.{ }^{-1}\right]$. Média no período entre 1980 e 2009. A) Janeiro; B) Fevereiro; C) Março; D) Abril; E) Maio; F) Junho; G) Julho; H) Agosto; I) Setembro; J) Outubro; K) Novembro; L) Dezembro

Figura B.7: Diferença entre a temperatura máxima média mensal da Reanálise e o conjunto de dados observados [ $\left.{ }^{\circ} \mathrm{C}\right]$. Média no período entre 1980 e 2009. A) Janeiro; B) Fevereiro; C) Março; D) Abril; E) Maio; F) Junho; G) Julho; H) Agosto; I) Setembro; J) Outubro; K) Novembro; L) Dezembro 101

Figura B.8: Diferença entre a temperatura mínima média mensal da Reanálise e o conjunto de dados observados [ ${ }^{\circ} \mathrm{C}$. Média no período entre 1980 e 2009. A) Janeiro; B) Fevereiro; C) Março; D) Abril; E) Maio; F) Junho; G) Julho; H) Agosto; I) Setembro; J) Outubro; K) Novembro; L) Dezembro 103 
Figura B.9: Evapotranspiração para a cana-de-açúcar [mm dia-1]. Média no período entre 1980 e 2009. A) Janeiro; B) Fevereiro; C) Março; D) Abril; E) Maio; F) Junho; G) Julho; H) Agosto; I) Setembro; J) Outubro; K) Novembro; L) Dezembro. 105

Figura B.10: Evapotranspiração para o cerrado [mm dia-1]. Média no período entre 1980 e 2009. A) Janeiro; B) Fevereiro; C) Março; D) Abril; E) Maio; F) Junho; G) Julho; H) Agosto; I) Setembro; J) Outubro; K) Novembro; L) Dezembro. 107

Figura B.11: Evapotranspiração para o eucalipto [mm dia-1]. Média no período entre 1980 e 2009. A) Janeiro; B) Fevereiro; C) Março; D) Abril; E) Maio; F) Junho; G) Julho; H) Agosto; I) Setembro; J) Outubro; K) Novembro; L) Dezembro. 109

Figura B.12: Evapotranspiração para a floresta atlântica $\left[\mathrm{mm} \mathrm{dia}^{-1}\right]$. Média no período entre 1980 e 2009. A) Janeiro; B) Fevereiro; C) Março; D) Abril; E) Maio; F) Junho; G) Julho; H) Agosto; I) Setembro; J) Outubro; K) Novembro; L) Dezembro. 111

Figura B.13: Evapotranspiração para a pastagem $\left[\mathrm{mm} \mathrm{dia}^{-1}\right]$. Média no período entre 1980 e 2009. A) Janeiro; B) Fevereiro; C) Março; D) Abril; E) Maio; F) Junho; G) Julho; H) Agosto; I) Setembro; J) Outubro; K) Novembro; L) Dezembro. 113

Figura B.14: Evapotranspiração para a área urbana $\left[\mathrm{mm} \mathrm{dia}^{-1}\right]$. Média no período entre $1980 \mathrm{e}$ 2009. A) Janeiro; B) Fevereiro; C) Março; D) Abril; E) Maio; F) Junho; G) Julho; H) Agosto; I) Setembro; J) Outubro; K) Novembro; L) Dezembro. 115

Figura B.15: Evapotranspiração para a vegetação atual $\left[\mathrm{mm} \mathrm{dia}^{-1}\right]$. Média no período entre 1980 e 2009. A) Janeiro; B) Fevereiro; C) Março; D) Abril; E) Maio; F) Junho; G) Julho; H) Agosto; I) Setembro; J) Outubro; K) Novembro; L) Dezembro. 117

Figura B.16: Evapotranspiração para a vegetação nativa $\left[\mathrm{mm} \mathrm{dia}^{-1}\right]$. Média no período entre 1980 e 2009. A) Janeiro; B) Fevereiro; C) Março; D) Abril; E) Maio; F) Junho; G) Julho; H) Agosto; I) Setembro; J) Outubro; K) Novembro; L) Dezembro. 119

Figura C.1: Conjunto de parâmetros calibrados para a simulação da cana-de-açúcar no modelo SiB2. 121

Figura C.2: Conjunto de parâmetros calibrados para a simulação do cerrado no modelo SiB2.

Figura C.3: Conjunto de parâmetros calibrados para a simulação do eucalipto no modelo SiB2.

Figura C.4: Conjunto de parâmetros calibrados para a simulação da floresta atlântica no modelo SiB2.

Figura C.5: Conjunto de parâmetros calibrados para a simulação da pastagem no modelo SiB2. 
Figura C.6: Conjunto de parâmetros calibrados para a simulação da área urbana no modelo SiB2.

Figura D.1: Teste t-Student para com a vegetação nativa como referência. A área sombreada indica onde o teste foi válido, séries compostas por 360 meses entre 1980 e 2009. A) cana-de-açúcar; B) cerrado; C) eucalipto; D) floresta atlântica; E) pastagem; F) área urbana; G) vegetação atual. 


\section{LISTA DE TABELAS}

Tabela 2.1: Localização dos sítios experimentais, pontos correspondentes da reanálise, e

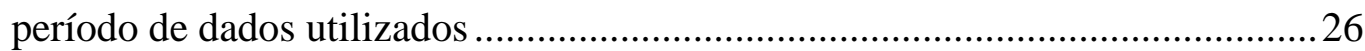

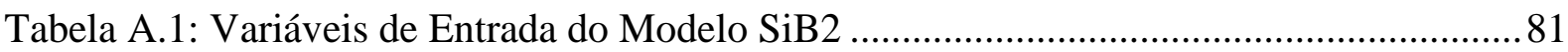

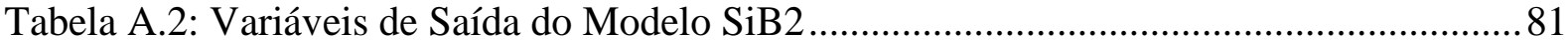

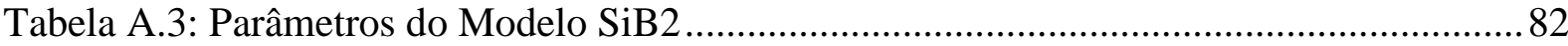

Tabela A.4: Fluxos, diferenças de potencial e resistências associados ao SiB2 ..................... 86 


\section{SUMÁRIO}

1 INTRODUÇÃO

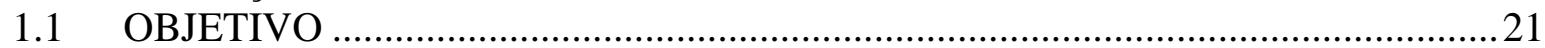

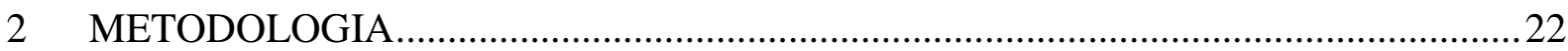

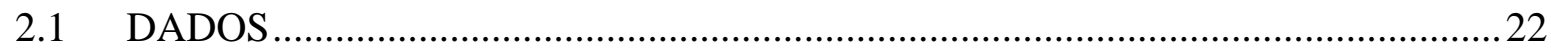

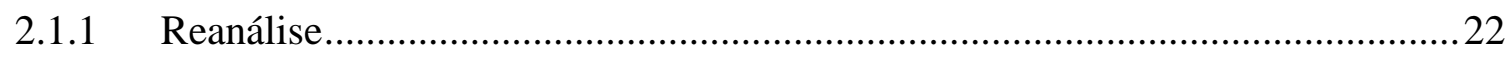

2.1.2 Dados meteorológicos de estações de superfície....................................................22

2.2 SIMULAÇÕES COM O MODELO SiB2 PONTUAL ………………………........2

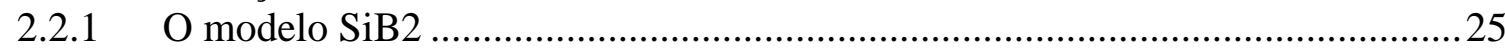

2.2.2 Desempenho do modelo com diferentes forçantes ................................................26

2.3 SIMULAÇÕES REGIONAIS COM O MODELO SiB2 ……….............................2

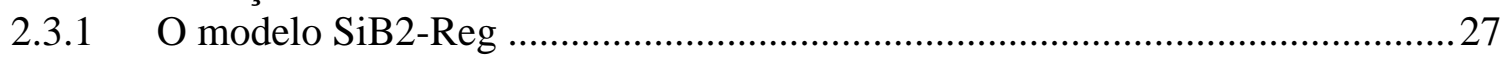

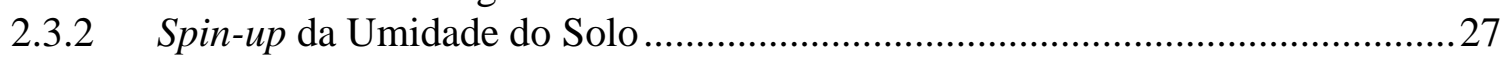

2.3.3 Cenários de Cobertura Vegetal....................................................................... 28

2.3.4 Comparação com dados observados..................................................................

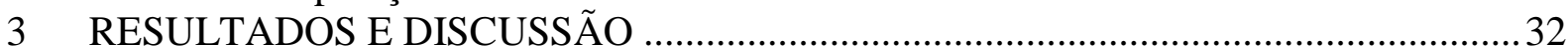

3.1 FORÇANTES CLIMÁTICAS PARA EVAPOTRANSPIRAÇÃO ............................ 32

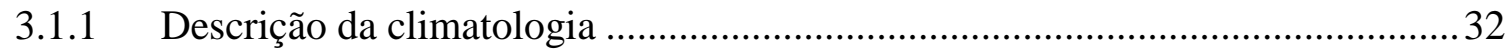

3.1.2 Comparação com observações.........................................................................36

3.1.3 Séries temporais das forçantes climatológicas ........................................................ 37

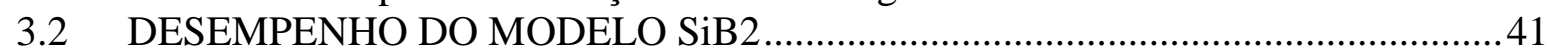

3.2.1 Variabilidade sazonal ............................................................................... 41

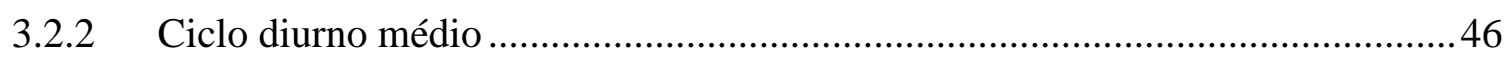

3.3 CENÁRIOS DE EVAPOTRANSPIRAÇÃO REGIONAL ………………….............58

3.3.1 Spin-up da umidade do solo ........................................................................

3.3.2 Campos de evapotranspiração ……………………………………………….......64

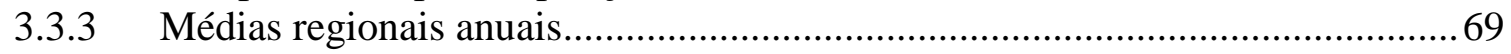

3.3.4 Comparação com a ETR das sub-bacias hidrográficas .........................................74

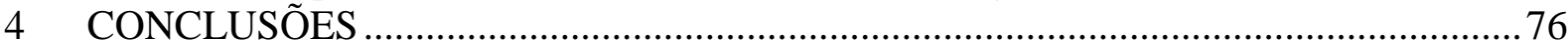

5 SUGESTÕES PARA TRABALHOS FUTUROS ……………………………….........

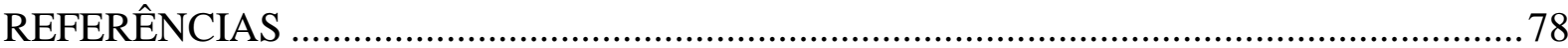

APÊNDICE A PARÂMETROS E EQUAÇÕES DO MODELO SiB2 ………………......81

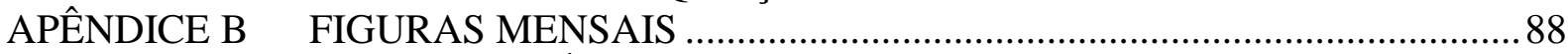

B.1 FORÇANTES CLIMÁTICAS PARA EVAPOTRANSPIRAÇÃO ……………..... 88

B.1.1 Descrição da climatologia ............................................................................ 88

B.1.2 Comparação com observações..........................................................................98

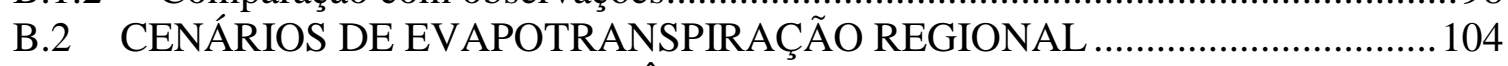

APÊNDICE C CONJUNTOS DE PARÂMETROS (data1) .............................................. 120

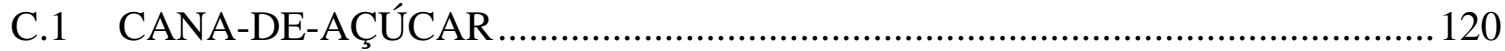

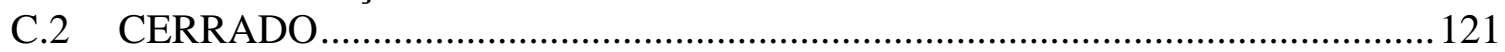

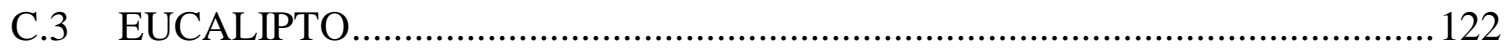

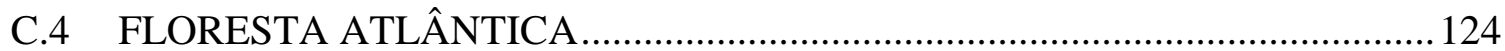

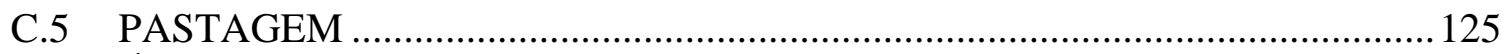

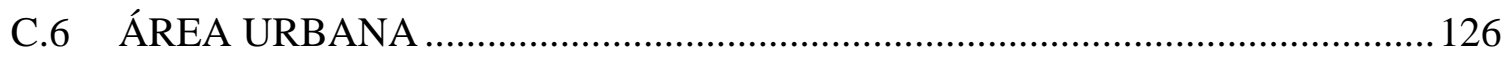

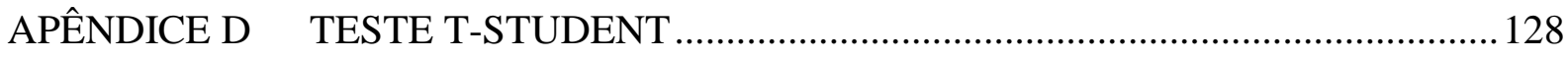




\section{INTRODUÇÃO}

A evapotranspiração envolve todos os processos de evaporação e transpiração que ocorram simultaneamente numa superfície vegetada, onde manifestam-se diferentes fontes de vapor d'água, como a água livre na superfície, o solo superficial úmido, a água da chuva interceptada pelos dosséis e a transpiração das plantas. É uma das etapas do ciclo hidrológico, que consiste na perpétua transferência de água da atmosfera para a superfície da terra pela precipitação, de onde ela escoa para o solo, rios, lagos e oceanos, formando um ciclo fechado no retorno da água evaporando para a atmosfera (Brutsaert, 1984).

O sistema climático terrestre é constituído, além da atmosfera, pelas componentes dos oceanos, criosfera, hidrosfera, biosfera e litosfera, tendo todos papel fundamental no clima do planeta pois proporcionam trocas de massa, energia e momentum com a atmosfera. A evapotranspiração (aqui referenciada como ETR) é um expressivo fenômeno destas trocas, que participa do balanço de energia à superfície, como o fluxo de calor latente, e da transferência de massa para a atmosfera pela oferta de água na fase vapor. A ETR continental é de $\sim 13 \%$ da evaporação global, mas também $~ 59 \%$ da precipitação continental (Oki \& Kanae, 2006), o que justifica sua relevância nos processos de formação de chuva, perda de água do solo e umedecimento da camada superficial. O cálculo da ETR é um elemento crucial para o bom desempenho dos modelos de circulação geral da atmosfera, na previsão do tempo e previsão climática, dos modelos agrometeorológicos de produtividade vegetal, balanço hídrico e irrigação, e dos modelos hidrológicos chuva-vazão, e é, por isso, um alvo de estudos com implicações socioeconômicas nos setores agrícola, florestal, energético e ecológico.

Na média global a perda por interceptação responde por aproximadamente por $16 \%$ da ETR continental, a evaporação do solo por $36 \%$ e a transpiração por $48 \%$ (Dirmeyer et al. 2006), o que indica o dominante papel da vegetação, embora o solo per se seja também significativo. A ETR é controlada por diversos fatores meteorológicos, como a temperatura do ar, do solo e da planta; a precipitação, que implica na oferta de água e na umidade do solo; a umidade do ar; a irradiância solar e consequentemente o saldo de radiação; e o vento. Os controles da ETR envolvem mais além os processos fisiológicos da planta intrinsecamente ligados à fotossíntese, que dependem da disponibilidade de nutrientes no solo.

Estudos acerca da ETR têm aplicações na Meteorologia, Hidrologia e Agronomia. Recentemente têm-se utilizado o termo água azul (blue water) como a água disponível 
máxima, equivalente à vazão regional, e água verde (green water) para a água removida pela ETR, devido à sua utilização efetiva no crescimento da vegetação (Oki \& Kanae, 2006). Em Agronomia foca-se a estimativa da evapotranspiração potencial, em especial a evapotranspiração de referência (ETR máxima da vegetação em crescimento, sem restrição hídrica) que por sua vez, em conjunto com o coeficiente de cultura $(\mathrm{Kc})$, provê a estimativa da ETR real. Em Climatologia ainda há muitas incertezas sobre as médias regionais e continentais da ETR, assim como a variabilidade interanual (Dirmeyer et al., 2006). Destacase mais além, que, nos prováveis efeitos do aquecimento global, espera-se a aceleração do ciclo hidrológico e em especial da ETR. Por exemplo, houve um aumento da ETR continental global de 1982 a 1998, mas com reversão da tendência (isto é, redução) de 1998 a 2008 explicada pela redução da umidade do solo, o que foi notado na Austrália, e no Brasil em particular para a região central (Jung et al. 2010).

Há métodos para se medir e estimar a evapotranspiração real diretamente no campo, mas a instrumentação específica é complexa e os métodos também restritos às pequenas áreas, além de demandarem um longo tempo de observação para se estimar a variabilidade sazonal. Muitos modelos físico-matemáticos abordam a transferência solo-planta-atmosfera de forma ampla, chamados de SVATs ou Surface-vegetation-transfer scheme, especialmente desenhados para o controle dos elementos climáticos, como o modelo SiB2 (Simple Biosphere Model) (Sellers et al.,1996), e que requerem calibração para cada ecossistema que se deseja simular. Loppart (2009) reporta o processo de calibração feito para alguns ecossistemas do Brasil.

As mudanças de uso da terra, devido à expansão agrícola e urbanização, podem trazer alterações no microclima e no clima de uma região. No Estado de SP, que possui uma área (IBGE, 2009) ${ }^{1}$ de $248.209 \mathrm{~km}^{2}$, com 645 municípios e população de 41 milhões de habitantes, segundo o censo agropecuário de 2006 tem 28\% da área com lavouras, e também 28\% com pastagem, o que ressalta a importância dos sistemas agropecuários para a economia da região. Em 1850 aproximadamente 81\% da área do estado eram cobertos pela vegetação original, segundo inventário do Instituto Florestal do Estado de SP, o que diminuiu para $13 \%$ na última década. Especificamente, no estado de SP as áreas originalmente de Mata Atlântica e Cerrado foram substituídas por diferentes agroecossistemas, como no século 20 o café nas $1^{\text {as }}$ décadas (Figura 1.1), o milho, a laranja e o algodão nas décadas posteriores, seguidos pelo expressivo cultivo da cana-de-açúcar a partir de 1970 nas regiões de Piracicaba

\footnotetext{
${ }^{1}$ IBGE - Instituto Brasileiro de Geografia e Estatística: http://www.ibge.gov.br/estadosat/perfil.php?sigla=sp acessado em Junho de 2010
} 
e Ribeirão Preto, e o aumento do plantio do eucalipto a partir de 1980 em áreas diversas. Tatsch (2006) discutiu a substituição da cobertura vegetal original do estado de SP por culturas, pastagens e florestas de rápido crescimento (eucalipto e pinus), e compara a evapotranspiração do cerrado com o eucalipto e a cana-de-açúcar, mostrando que "no período de clima úmido o eucalipto mostrou maior evapotranspiração $\left(5,2 \mathrm{~mm} \mathrm{~d}^{-1}\right)$ do que o cerrado e a cana-de-açúcar (3,1 e 2,5 $\mathrm{mm} \mathrm{d}^{-1}$, respectivamente)", indicando apesar disso que "o eucalipto foi sensível à condição de estresse hídrico, reduzindo a evapotranspiração abruptamente no final de agosto". O autor mostrou que a temperatura do ar na cana-de-açúcar foi significativamente mais quente que no Cerrado, e deste por sua vez mais quente que no eucalipto, em concordância com o balanço de energia. Adicionalmente, Negrón-Juárez (2004) utilizou o modelo atmosférico BRAMS para investigar a sensibilidade do clima devido ao desmatamento no Sudeste do Brasil, e sugeriu que a vegetação atual favorece o aumento da chuva em algumas áreas e a diminuição em outras, sem, todavia, um padrão dominante, mas indicou que a temperatura à superfície média diária foi $\sim 0,5^{\circ} \mathrm{C}$ mais quente no presente, e em especial nas áreas de cana-de-açúcar.

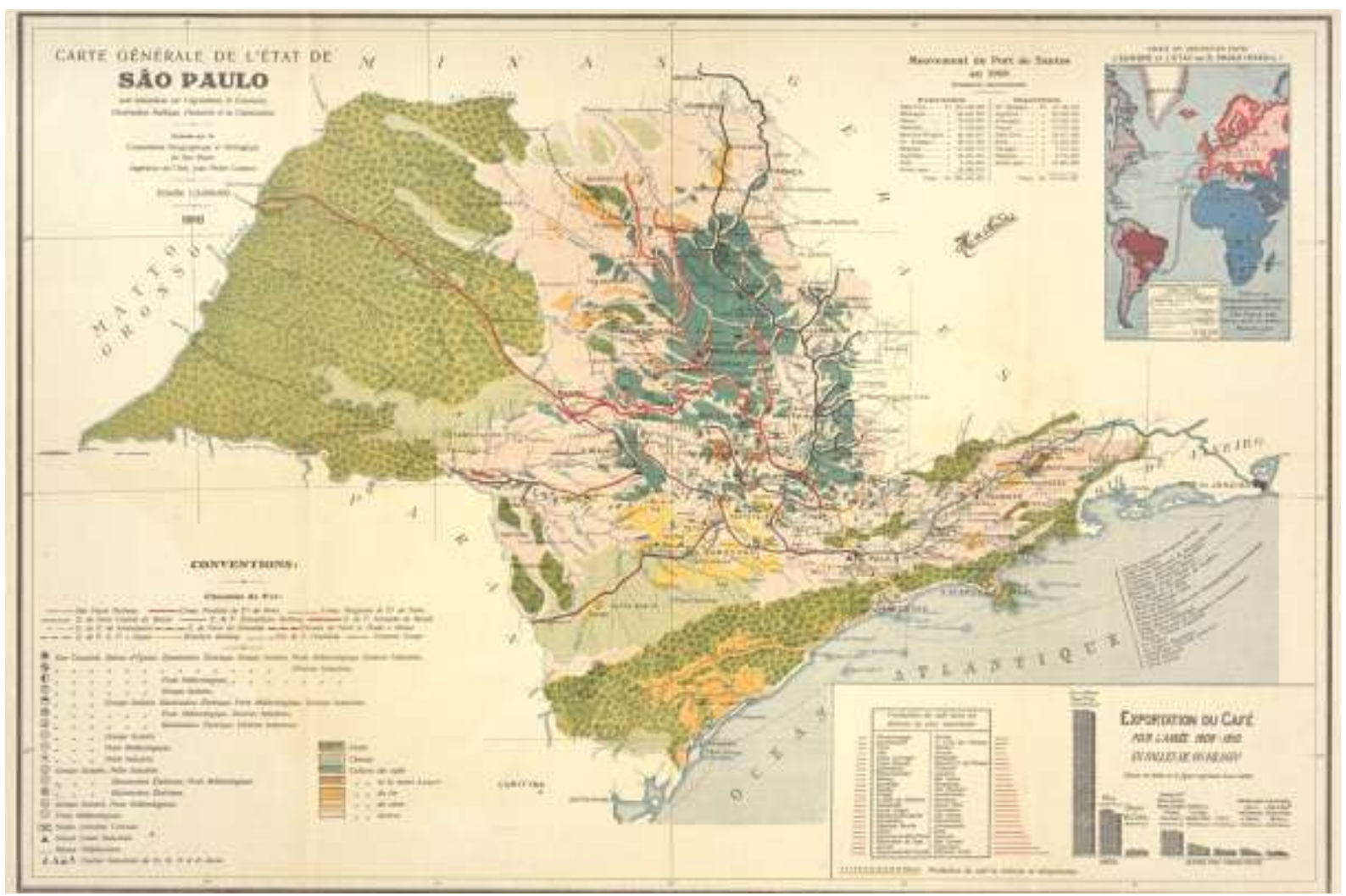

Figura 1.1: Mapa do estado de São Paulo (cc 1910) com a cobertura vegetal dominante, onde aparece o café (verde escuro) no NE do estado, e a vegetação original de florestas em todo o o setor leste e no litoral com a Mata Atlântica. 


\section{$1.1 \quad$ OBJETIVO}

O objetivo do trabalho é calcular uma climatologia da evapotranspiração no Estado de São Paulo, por meio de um modelo da biosfera (Simple Biosphere Model, SiB2), que possa representar os diferentes tipos de cobertura da vegetação, e com dados climáticos que possam cobrir a variabilidade interanual e a variabilidade espacial satisfatoriamente. 


\section{METODOLOGIA}

\subsection{DADOS}

\subsubsection{Reanálise}

Os dados meteorológicos utilizados para alimentar o modelo SiB2 foram os da Reanálise do Sistema de Previsão do Clima do NCEP (Saha et al. 2010), referido aqui como CFSR, obtidos pela combinação de simulação numérica do sistema global acoplado (atmosfera, oceano, superfície, gelo marítimo) e dados observacionais terrestres e de radiossondas, no período de 31 anos (1979 a 2009), com espaçamento de grade de $0,25^{\circ}$ no equador a $0,5^{\circ}$ nos extratrópicos. No domínio do estado de São Paulo o espaçamento é de aproximadamente $0,3^{\circ}$ e o período utilizado foi de 1980 a 2009 , ou seja, com 30 anos recomendados para se caracterizar a climatologia. Os dados não têm falhas, são horários, de superfície, e as variáveis utilizadas foram: temperatura média do ar, precipitação, componentes meridional e zonal do vento, irradiância solar incidente, umidade específica do ar e pressão atmosférica. Os dados foram interpolados espacialmente para o espaçamento de $0,25^{\circ}$, o que foi um requisito para o algoritmo de cálculo do modelo SiB2 (item 2.3) que utiliza apenas divisões inteiras de $1^{\circ}$, por meio de uma interpolação bilinear feita com a função regrid do aplicativo GrADS (Doty, 1995).

\subsubsection{Dados meteorológicos de estações de superfície}

Para avaliar os dados da reanálise foram feitas comparações com dados meteorológicos de estações de superfície coletados por várias instituições, principalmente INMET, CPTEC, Embrapa, CEMIG e SIMEPAR, reunidos pelo Sistema Agritempo 2, cedidos para o LCB $^{3}$, e coletados em São Paulo, Rio de Janeiro, Minas Gerais, Paraná, Mato

\footnotetext{
${ }^{2}$ Agritempo - Sistema de Monitoramento Agrometeorológico: http://www.agritempo.gov.br/

${ }^{3}$ LCB - Laboratório de Clima e Biosfera / IAG / USP
} 
Grosso do Sul e Goiás, na forma de médias diárias da temperatura máxima, temperatura mínima e precipitação. Foram feitas médias mensais, onde os meses com menos de 25 dias de dados foram descartados, e calculadas as médias climatológicas, onde foram consideradas apenas as estações com pelo menos 50\% dos meses no período de 30 anos (360 meses entre 1980 e 2009). As estações são apresentadas na Figura 2.1. Para a comparação com os dados em grade regular da reanálise os dados pontuais das estações foram interpolados com espaçamento horizontal e domínio iguais aos da reanálise. Foi utilizada a função oacres do GrADS (análise objetiva de Cressman) (Cressman, 1959) para obter a grade regular. A altitude de cada estação (Figura 2.2) não foi levada em conta na interpolação, por isso a comparação das duas fontes não é perfeitamente exata, pelo fato da reanálise ter dados médios em cada célula, negligenciando os extremos da topografia, como pela deficiência da cobertura de estações em vários setores do domínio.

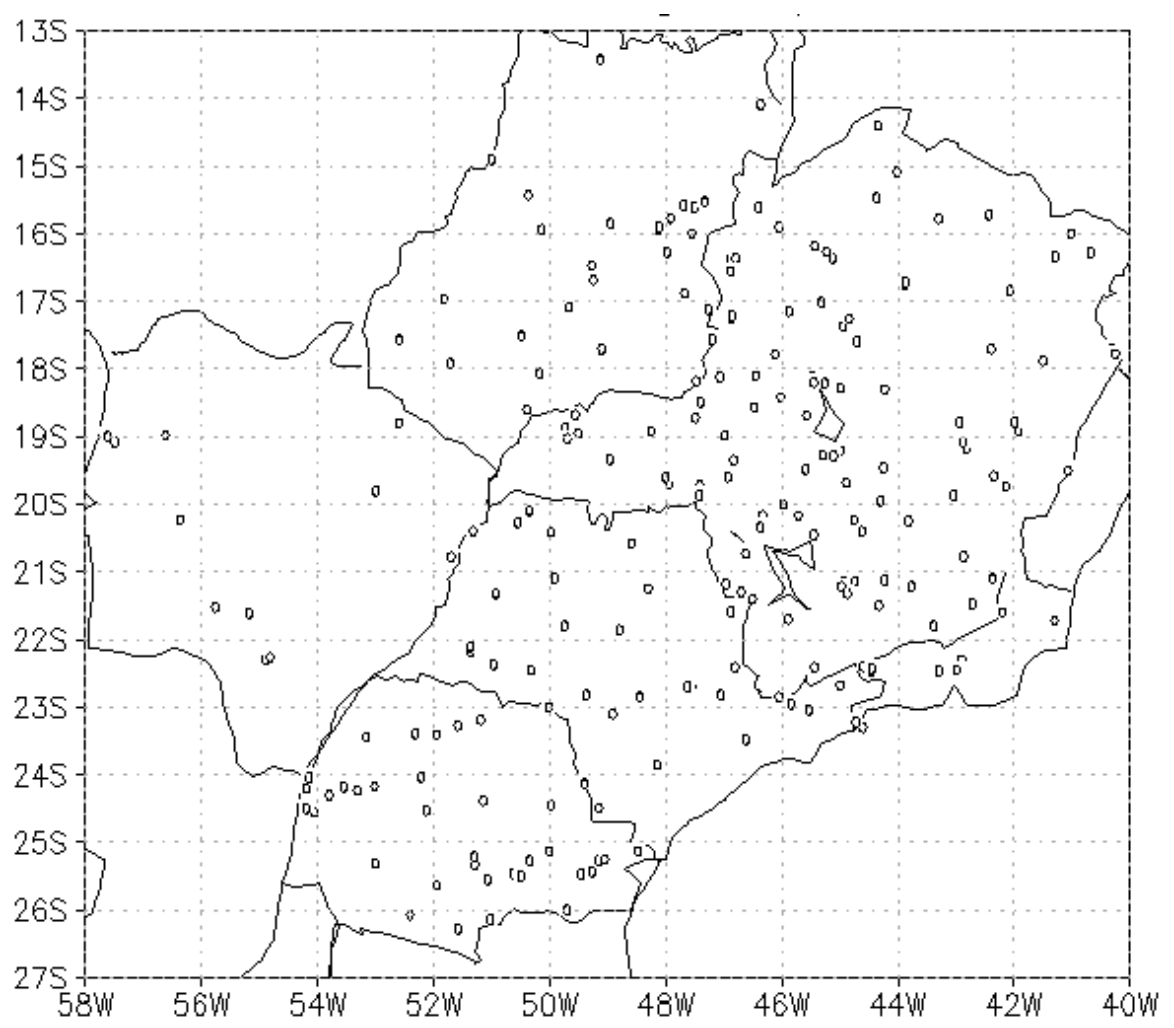

Figura 2.1: Localização das estações do conjunto de dados observados com mais de 180 meses de dados no período de 1980 a 2009.

No estado de SP destacam-se regiões de maior altitude (Fig. 2.2), como a Serra do Mar no litoral norte e a Serra da Mantiqueira no sul de MG, que juntas contornam o Vale do rio Paraíba do Sul; a Serra da Canastra (orientação norte-sul) na fronteira a leste com MG. A junção da Serra do Mar com a Serra da Mantiqueira, ao norte da região metropolitana de São 
Paulo, forma a pequena Serra do Japi. No interior do estado destacam-se as serras próximas à São Carlos (setor central), e a serra próxima à Avaré (setor centro-sudoeste), que juntas são intermediadas pelo vale do médio rio Tietê.

A

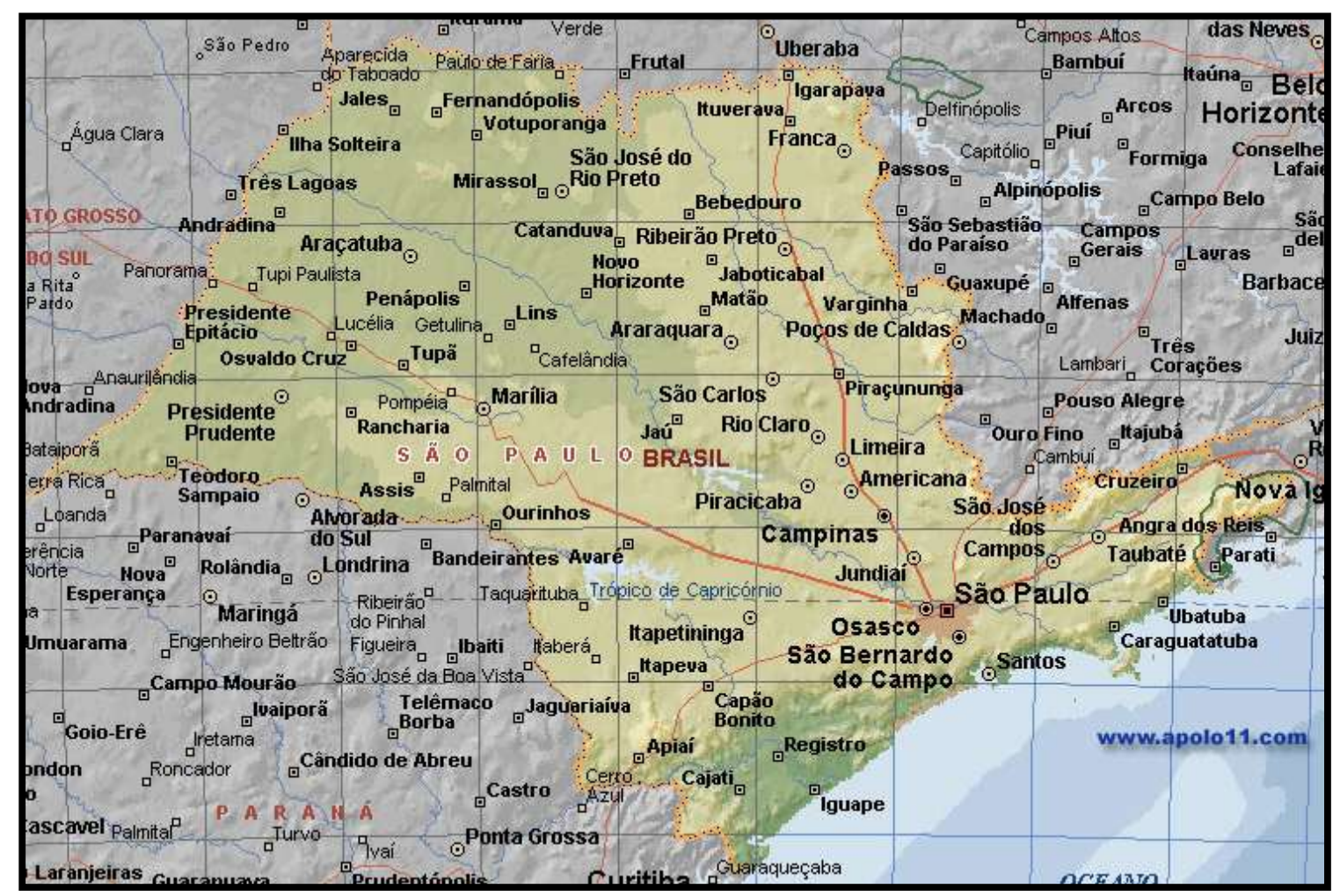

B

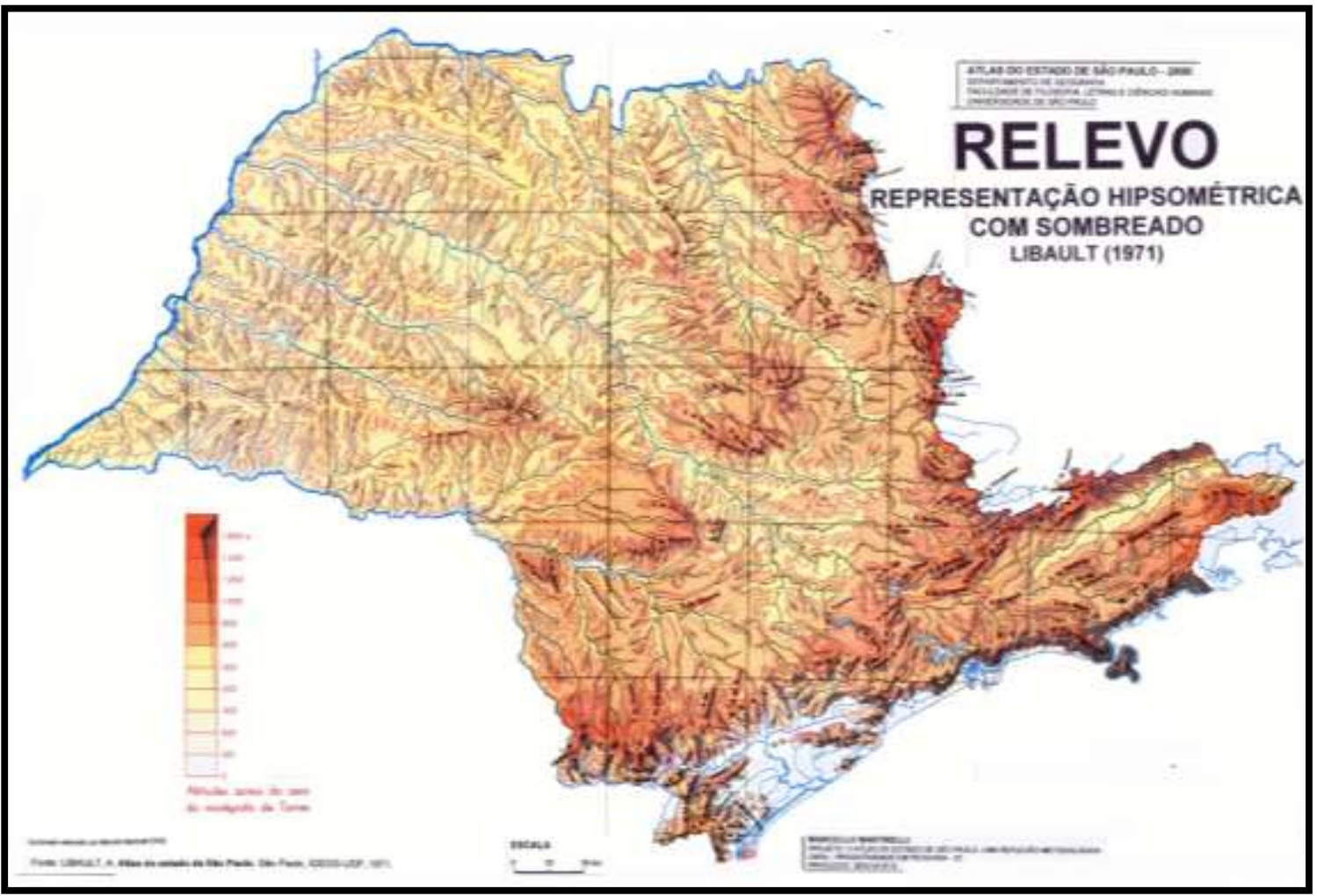

Figura 2.2: A) Mapa político do estado de SP; B) Mapa do relevo do estado de SP. 


\subsection{SIMULAÇÕES COM O MODELO SiB2 PONTUAL}

\subsubsection{O modelo SiB2}

O Simple Biosphere Model (modelo SiB2) é um modelo da biosfera terrestre desenvolvido para calcular as trocas ou fluxos de energia, massa e momentum entre a atmosfera e a superfície vegetada (Sellers et al., 1996). A versão utilizada tem alguns aperfeiçoamentos em relação à original, modificada para utilizar multicamadas de solo com parâmetros físicos heterogêneos (substituindo as três camadas fixas e homogêneas da versão original), permanecendo apenas fixas a $1^{\mathrm{a}}$ camada com $2 \mathrm{~cm}$ de espessura e a última com função de camada de drenagem, ambas sem raízes. A distribuição de raízes foi refeita prescrevendo-se as porcentagens distribuídas nas camadas intermediárias. Foram utilizadas 10 camadas para nossos cálculos. O índice de área foliar (IAF) e a fração de biomassa verde foram prescritos mensalmente (APÊNDICE C ).

O modelo SiB2 pontual (chamado também de off-line) é executado como um código fonte Fortran77 de 5000 linhas, que descreve os fluxos verticais sob a prescrição de um tipo de vegetação e solo e seus parâmetros biofísicos em uma área unitária de superfície, forçado (alimentado) com dados meteorológicos de superfície no passo de tempo horário, respectivamente os seguintes: irradiância solar incidente, temperatura e umidade do ar, velocidade do vento e precipitação. A cada passo de tempo o modelo calcula os fluxos atmosféricos de radiação solar refletida e radiação de onda longa emitida, fluxo de calor sensível, fluxo de calor latente (ETR e suas componentes de transpiração, evaporação do solo e perda por interceptação), fluxo de CO2 (produtividade primária bruta e líquida), fluxo de calor no solo, e os fluxos hidrológicos (escoamento superficial e drenagem para o freático). A descrição dos parâmetros e as principais equações do modelo SiB2 estão no APÊNDICE A

A calibração dos parâmetros do modelo SiB2 para os ecossistemas utilizados neste trabalho foi feita pela comparação dos fluxos simulados com os fluxos medidos nas torres micrometeorológicas (sítios experimentais) do LCB, ou seja, os fluxos de energia (calor latente, calor sensível e saldo de radiação), fluxo de $\mathrm{CO}$, albedo PAR e solar, além dos dados forçantes necessários para a simulação do modelo nesta etapa do estudo. As demais etapas de calibração foram as de transferência radiativa, difusão hidráulica do solo, fotossíntese e condutância estomática, conforme reportado em Llopart (2009). 
A calibração partiu com uma prescrição antecipada de parâmetros do módulo aerodinâmico, feita com o algoritmo SiBX/MOMOPT (Sellers et al., 1989), separado e antecipadamente ao modelo SiB2: utiliza-se nesta etapa como parâmetros de entrada os valores da morfologia da vegetação, como a altura da base, altura do topo do dossel e altura do ponto de máxima densidade foliar, comprimento de rugosidade do solo, fração de cobertura do dossel, comprimento e largura médios da folha. Foi utilizado um valor médio anual do IAF para obter os parâmetros aerodinâmicos no SiBX, o que foi uma simplificação. Os parâmetros calibrados e utilizados na prescrição de cada ecossistema estão descritos no APÊNDICE C .

\subsubsection{Desempenho do modelo com diferentes forçantes}

As simulações do modelo pontual na calibração foram feitas com dados forçantes observados em sítios experimentais (exceto para o ecossistema de pastagem onde não obtivemos dados de fluxos no estado de SP), e, alternativamente, com dados da reanálise CFSR, utilizando pontos de grade mais próximos aos dos sítios (Tabela 2.1). A calibração da pastagem foi baseada no desempenho do modelo para simular a pastagem na Amazônia (Rocha et al. 1996 a, b), feitas algumas adaptações para o caso de SP. Foram feitas comparações das séries temporais (médias diárias) durante 2 anos, e dos ciclos diurnos médios para o mês de fevereiro, representativo do verão, e agosto, representativo do inverno.

Tabela 2.1: Localização dos sítios experimentais, pontos correspondentes da reanálise, e período de dados utilizados

\begin{tabular}{|c|c|c|c|}
\hline Ecossistema & Sítio & Reanálise & Período \\
\hline $\begin{array}{l}\text { Cana-de- } \\
\text { açúcar }\end{array}$ & $21^{\circ} 38^{\prime} 13,40^{\prime \prime} \mathrm{S} ; 47^{\circ} 47^{\prime} 24,90^{\prime \prime} \mathrm{W}$ & $21,63 \mathrm{~S} ; 47,63 \mathrm{~W}$ & 2006-2007 \\
\hline Cerrado & $21^{\circ} 37^{\prime} 09,26^{\prime \prime} \mathrm{S} ; 47^{\circ} 37^{\prime} 56,38^{\prime \prime} \mathrm{W}$ & $21,63 \mathrm{~S} ; 47,63 \mathrm{~W}$ & 2001-2002 \\
\hline Eucalipto & $21^{\circ} 35^{\prime} 00,60^{\prime \prime} \mathrm{S} ; 47^{\circ} 36^{\prime} 08,30^{\prime \prime} \mathrm{W}$ & $21,63 \mathrm{~S} ; 47,63 \mathrm{~W}$ & 2006-2008* \\
\hline Floresta & $23^{\circ} 19^{\prime} 42,50^{\prime} \mathrm{S} ; 4^{\circ} 05^{\prime} 35,20^{\prime \prime} \mathrm{W}$ & $23,38 \mathrm{~S} ; 45,13 \mathrm{~W}$ & 2008 \\
\hline Pastagem** & $22^{\circ} 42^{\prime} 30,00^{\prime \prime} \mathrm{S} ; 47^{\circ} 38^{\prime} 00,00^{\prime \prime} \mathrm{W}$ & $22,63 \mathrm{~S} ; 47,63 \mathrm{~W}$ & 2003-2004 \\
\hline
\end{tabular}

* ano hidrológico com início em setembro e fim em agosto - dois anos de dados

** estação meteorológica automática da Esalq/USP em Piracicaba 


\subsection{SIMULAÇÕES REGIONAIS COM O MODELO SiB2}

\subsubsection{O modelo SiB2-Reg}

Um código computacional para simulações do modelo SiB2 em escala regional foi desenvolvido por Acosta (2007) para alimentar um modelo hidrológico na bacia dos rios Tocantins-Araguaia, o qual foi aqui adaptado para o Sudeste do Brasil (referenciado como SiB2-Reg), e que consiste simplesmente em um algoritmo que integra o modelo pontual em cada célula de uma grade horizontal regular, aqui definidos com espaçamento de $0,25^{\circ}$ (latitude e longitude), no passo de tempo de 1 h. Os fluxos são apenas verticais (não há trocas na direção horizontal), forçados por dados atmosféricos separadamente em cada célula com dados da reanálise CFSR. Os cálculos do modelo a cada passo de tempo para as variáveis prognósticas (grau de saturação da umidade e temperatura do solo) são guardados em uma matriz e servem como valores pretéritos no passo de tempo seguinte para o esquema numérico avançado implícito do SiB2 pontual.

\subsubsection{Spin-up da Umidade do Solo}

O spin-up de um modelo de superfície (para a umidade do solo) é o processo de ajuste da sua física às condições iniciais até que se atinja o estado de equilíbrio, caracterizando um comportamento sazonal médio (da umidade do solo), partindo de condições iniciais em circunstâncias anômalas e sem equilíbrio (da umidade do solo) (Yang et al. 1995). Para estabilizar a média anual da umidade do solo, integramos o modelo pelo período de 60 anos nas simulações regionais, o que foi feito em duas etapas, replicando-se os 30 anos de dados existentes da reanálise sequencialmente. $\mathrm{Na} 1^{\mathrm{a}}$ etapa o grau de saturação de umidade inicial foi de $90 \%$ para todas as camadas do solo, em todo o domínio. $\mathrm{Na} 2^{\mathrm{a}}$ etapa as condições iniciais foram recuperadas do final da $1^{\mathrm{a}}$ etapa. A umidade do solo final serviu de condição inicial equilibrada para as simulações propriamente ditas da climatologia de ETR. O spin-up foi feito individualmente para todos os cenários de cobertura de superfície (item 2.3.3). 


\subsubsection{Cenários de Cobertura Vegetal}

Foram elaborados oito cenários de cobertura vegetal para a simulação no domínio do estado de SP:

a) o cenário de cobertura vegetal atual foi elaborado a partir do mapa de classes de vegetação no Estado de São Paulo (Figura 2.3) com dados do INPE ${ }^{4}$ (Vieira et al., 2010), referentes ao ano de 2005, de informações da presença de floresta de mata atlântica, pastagem, cana-deaçúcar, área urbana e florestas plantadas (eucalipto e pinus), enquanto as informações de cerrado, com base no ano de 2001, foram obtidas do Instituto Florestal ${ }^{5}$, ambos com resolução de $1 \mathrm{~km}$. O mapa de resolução de $1 \mathrm{~km}$ foi reamostrado para $0,25^{\circ}$ no software ArcGIS $^{6}$ (Figura 2.4). Somente a Região Metropolitana de São Paulo (RMSP) foi classificada como Cobertura Urbana na escala de $0,25^{\circ}$, as demais áreas urbanas foram reclassificadas pela segunda classe de cobertura vegetal mais frequente ao seu redor, no mapa de $1 \mathrm{~km}$.

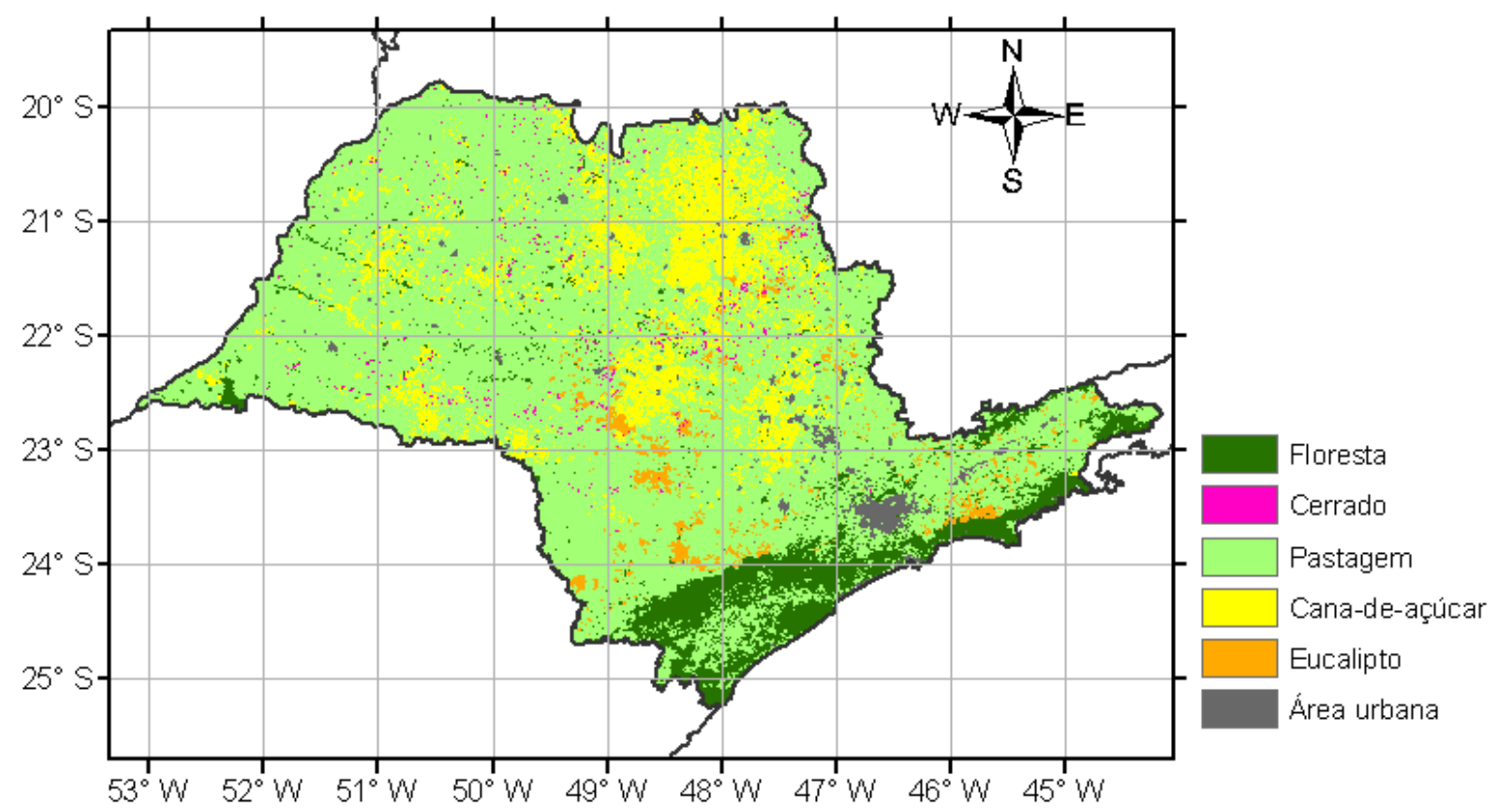

Figura 2.3: Classes de vegetação encontradas no Estado de São Paulo, com 1 km de resolução.

\footnotetext{
${ }^{4}$ INPE - Instituto Nacional de Pesquisas Espaciais: http://www.inpe.br/

${ }^{5}$ IF - Instituto Florestal: http://www.iflorestal.sp.gov.br/

${ }^{6}$ ArcGIS - http://www.arcgis.com/
} 


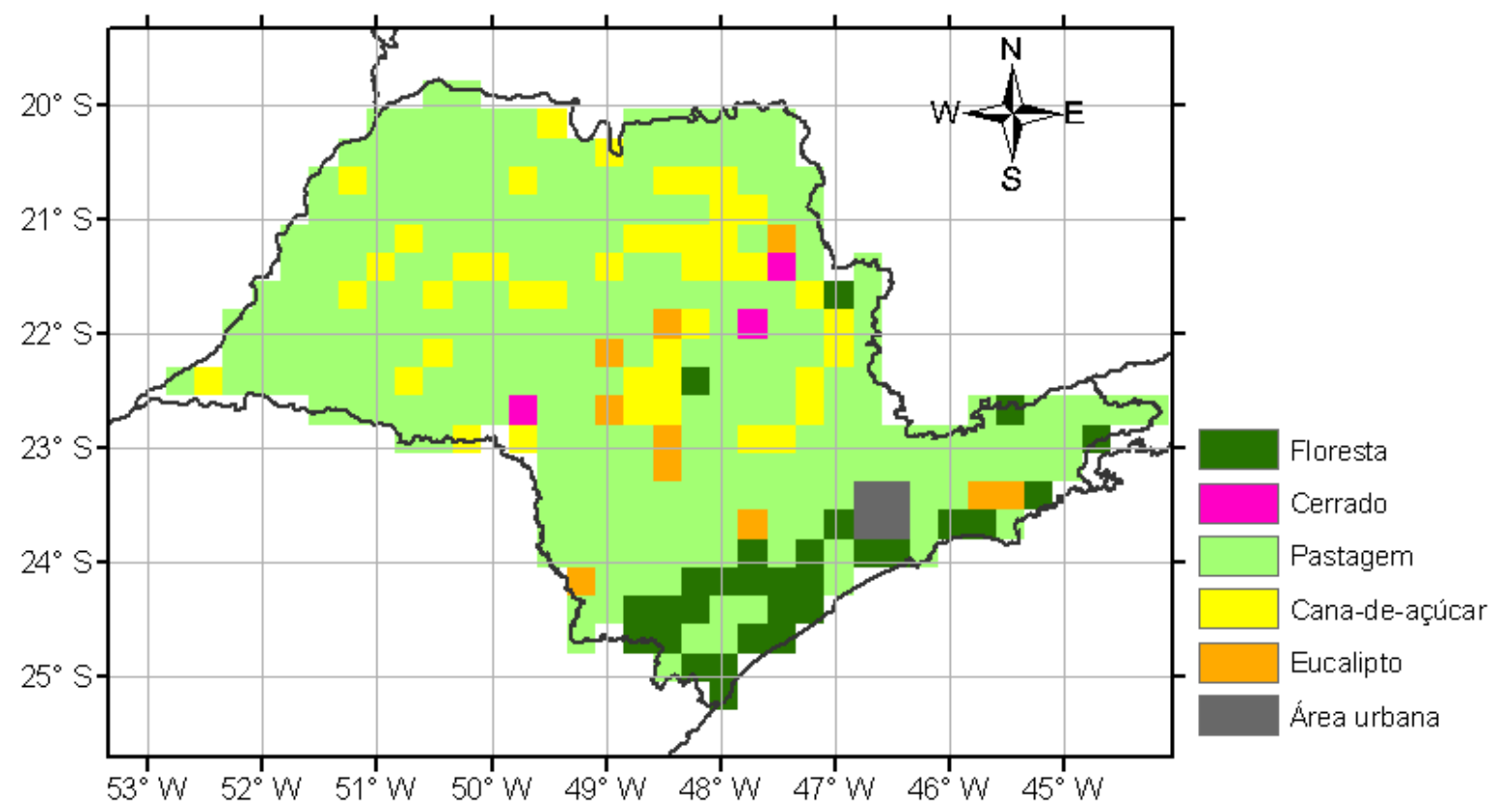

Figura 2.4: Classes de vegetação atual no Estado de São Paulo, com 0,25 ${ }^{\circ}$ de espaçamento de grade.

b) o cenário de cobertura da vegetação nativa do estado de SP utilizou as informações de Veloso, Filho \& Lima (1991), a partir do qual as classes de floresta ombrófila (densa e mista) e floresta estacional semidecidual foram convertidas, por simplicidade, para Floresta de Mata Atlântica, e as áreas de tensão ecológica e savanas foram convertidas para Cerrado, obtendose um mapa final (Figura 2.5) reamostrado para 0,25 (Figura 2.6).

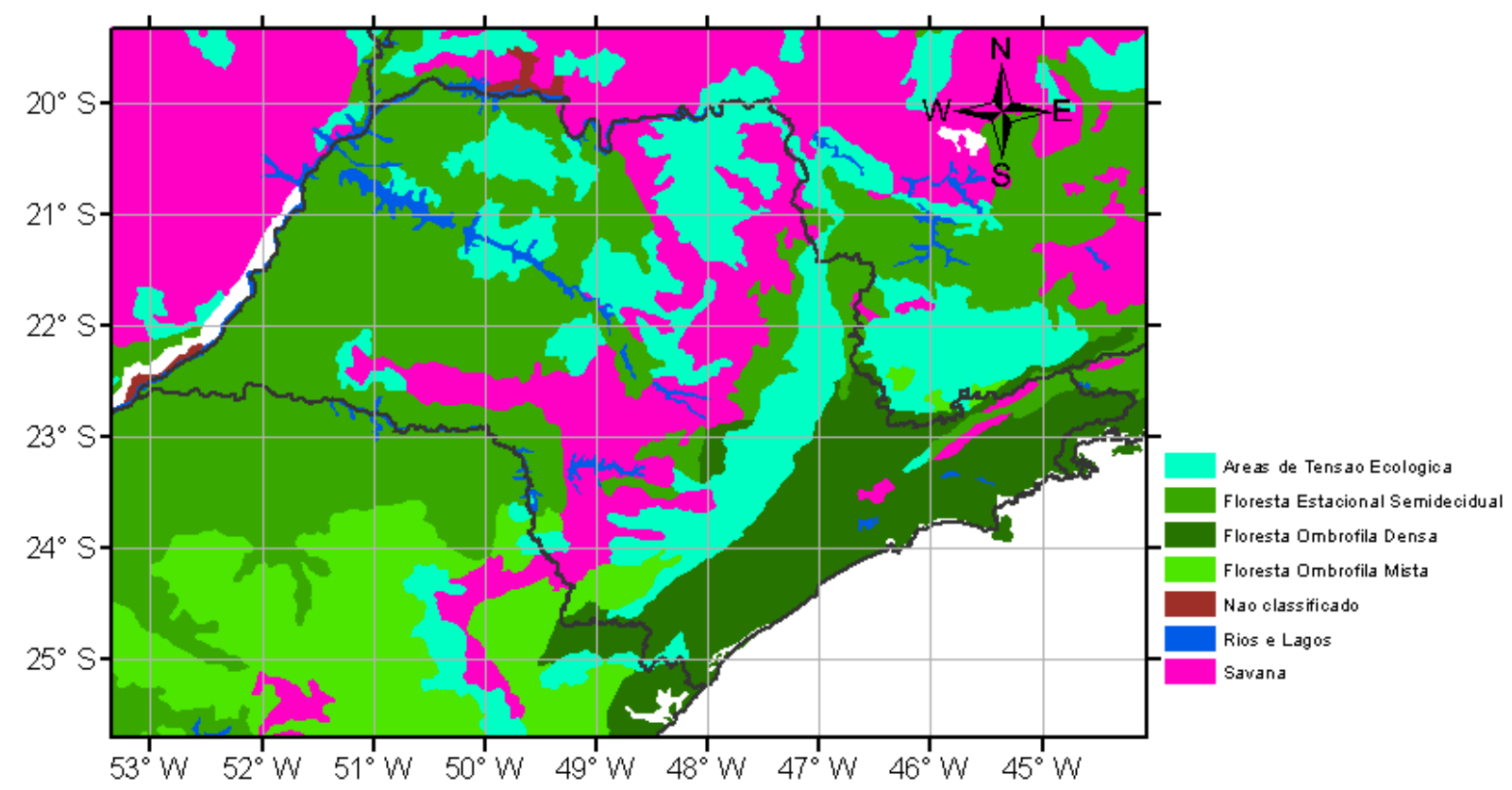

Figura 2.5: Classificação da vegetação nativa sobre o Estado de São Paulo, escala de 1:5000000. 


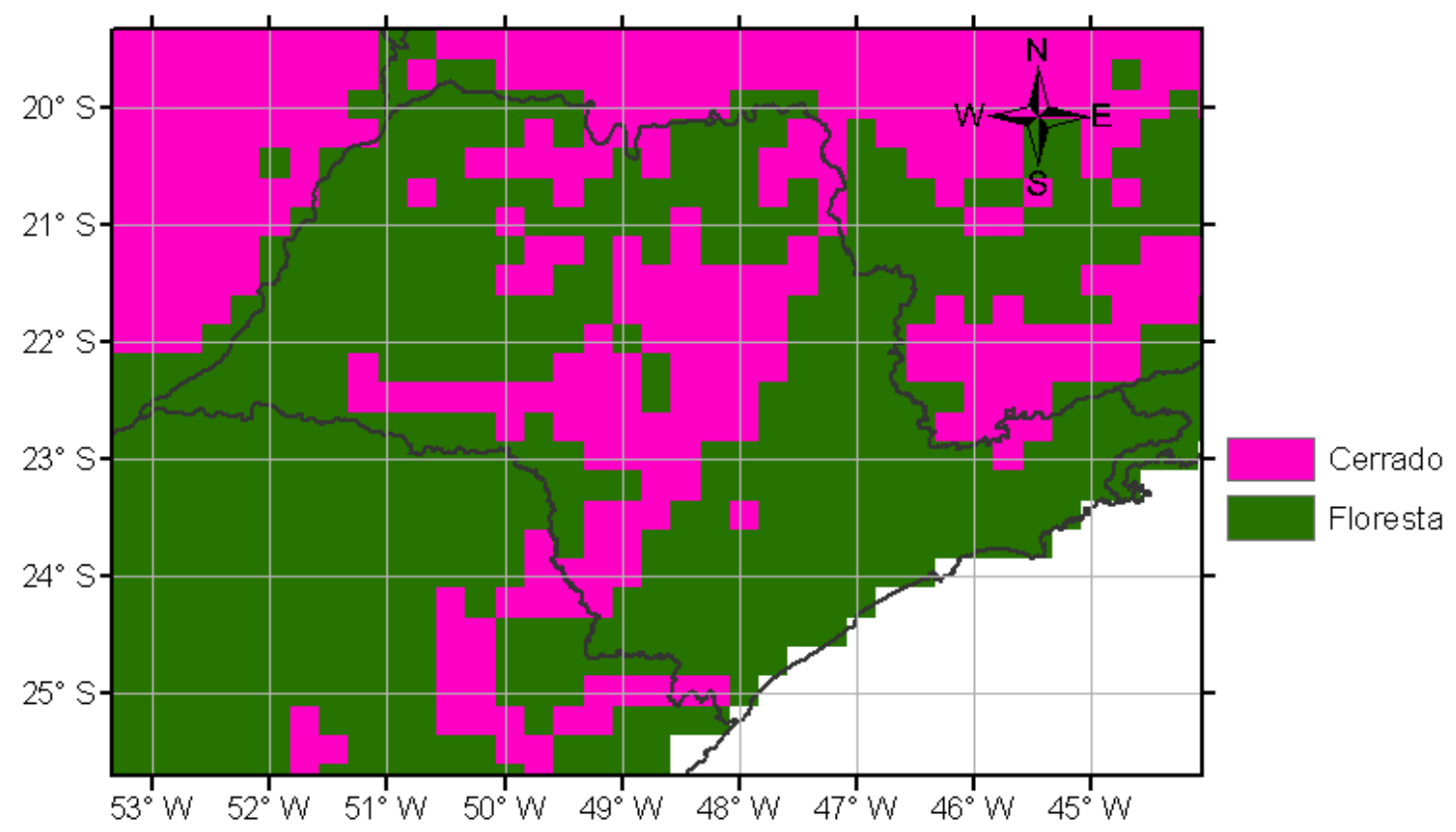

Figura 2.6: Classificação da vegetação nativa sobre o Estado de São Paulo, com $0,25^{\circ}$ de espaçamento de grade.

c) os demais 6 cenários prescreveram, individualmente, uma cobertura vegetal homogênea em todo o domínio do estado de SP, ou seja, são cenários idealizados e irrealistas, úteis exclusivamente para os testes de sensibilidade do modelo às forçantes estabelecidas, que supõem toda a área coberta apenas por uma cobertura vegetal, que foram respectivamente as seguintes: Cana-de-açúcar, Cerrado, Eucalipto, Floresta (de mata atlântica), Pastagem e Urbanizada.

\subsubsection{Comparação com dados observados}

Os dados do Relatório de Situação dos Recursos Hídricos do Estado de São Paulo (CRH/CORHI/DAEE, 1999) são médias de evapotranspiração anual calculadas como a diferença entre a precipitação acumulada e o escoamento básico que aflui dos corpos d'água após percolar aquíferos subterrâneos. Os valores são divididos por bacia da região. As coletas foram feitas em 444 postos pluviométricos para a confecção de isoietas médias anuais, 219 estações fluviométricas medindo séries de descargas mensais e 88 postos fluviométricos com séries históricas de vazões diárias.

Esses dados por bacia foram confrontados com valores médios ponderados nos pixels resultados da saída climatológica anual do modelo SiB2-Reg para o caso com vegetação atual. 
Após a confecção de uma tabela contendo uma lista de todas as bacias e os valores correspondentes calculados pelo modelo e observados pelo DAEE, foi plotado um gráfico a fim de analisar a tendência do modelo em subestimar ou superestimar a evapotranspiração para cada bacia. 


\section{RESULTADOS E DISCUSSÃO}

\subsection{FORÇANTES CLIMÁTICAS PARA EVAPOTRANSPIRAÇÃO}

\subsubsection{Descrição da climatologia}

As forçantes da reanálise estão apresentadas como médias climatológicas trimestrais (período chuvoso - dezembro, janeiro e fevereiro; e período seco - junho, julho e agosto) e médias anuais, no período 1980 a 2009. As médias mensais climatológicas estão disponíveis no APÊNDICE B . Nas médias anuais (Figura 3.1) notamos semelhanças entre as figuras da irradiância solar incidente (aqui referenciada como Ki), pressão de vapor (aqui referenciada como Pv) e temperatura (aqui referenciada como Tmp), com máximos no setor noroeste do estado, onde ocorrem também os mínimos de precipitação (aqui referenciada como Prc). Quanto à velocidade do vento (aqui referenciada como Vnt), os máximos estão no Paraná, provavelmente pela dinâmica dos sistemas transientes que atingem mais frequentemente a região, e um mínimo no sul de SP, coincidente com a área de depressão regional da altitude no vale do Ribeira.
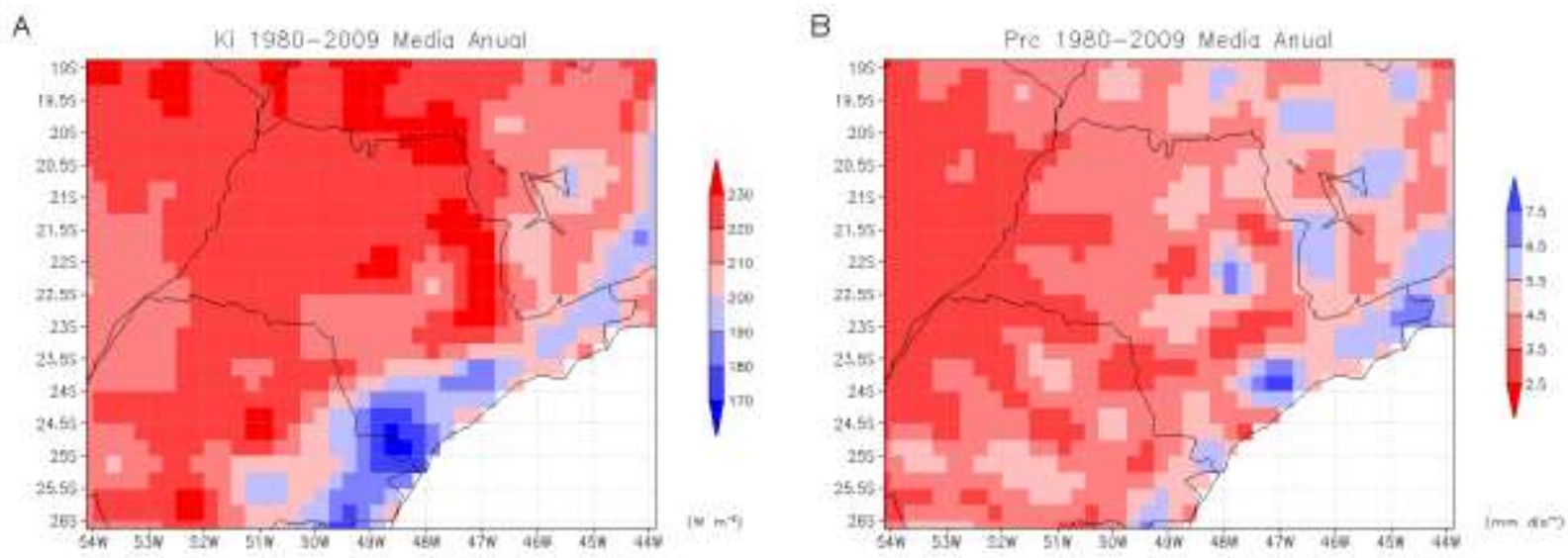

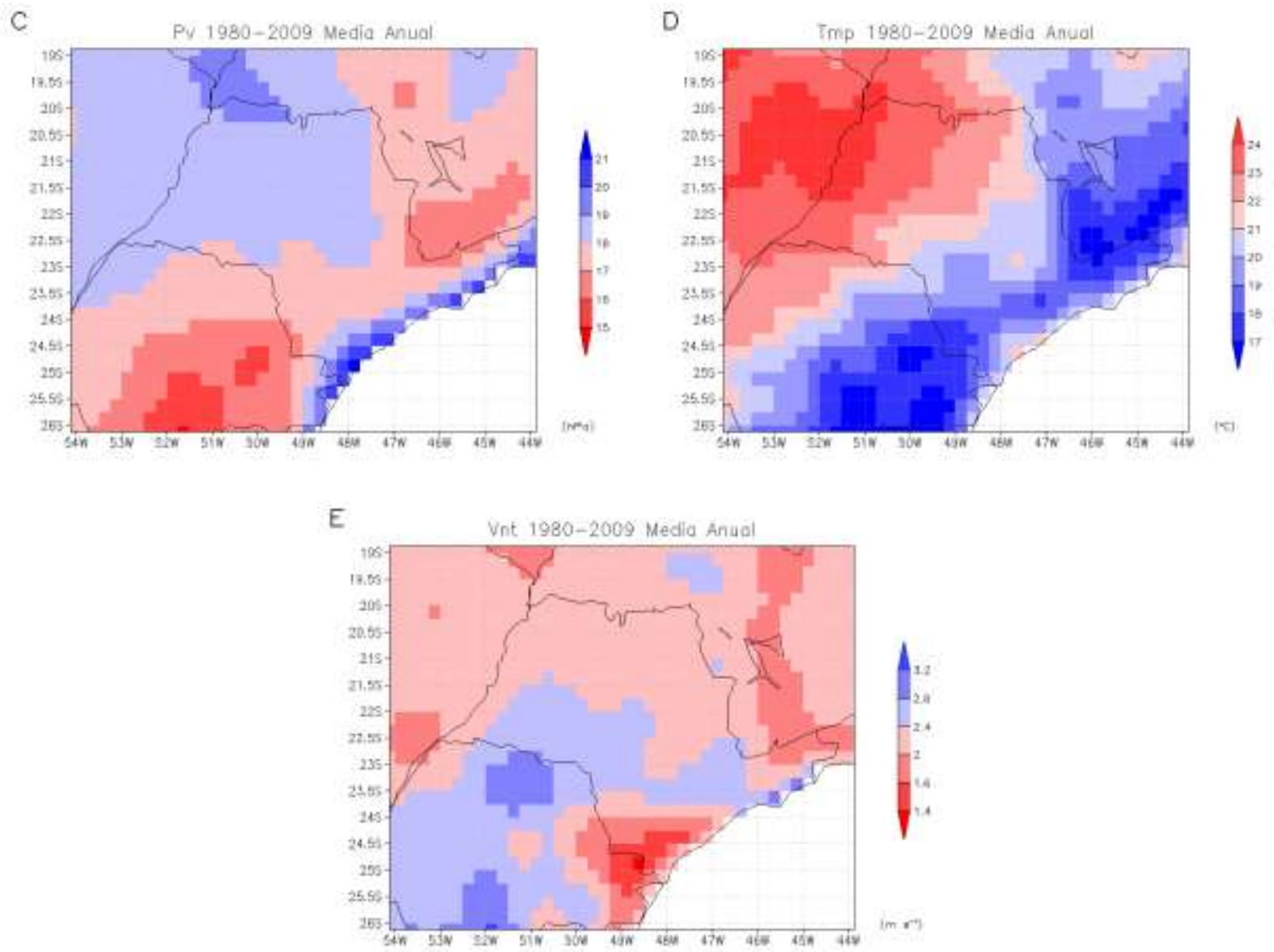

Figura 3.1: Forçantes do SiB2. Médias anuais entre 1980 e 2009. A) Irradiância Solar Incidente [W $\mathrm{m}^{-2}$; B) Precipitação acumulada $\left[\mathrm{mm} \mathrm{dia}^{-1}\right]$; C) Pressão parcial de vapor d'água $[\mathrm{hPa}]$; D) Temperatura do ar $\left[{ }^{\circ} \mathrm{C}\right]$; E) Velocidade do vento $\left[\mathrm{m} \mathrm{s}^{-1}\right]$.

A Figura 3.2 ilustra a sazonalidade da irradiância Solar incidente (Ki), onde no inverno (JJA) são encontrados máximos ao norte e mínimos ao sul, devido ao controle do ângulo solar. No verão (DJF) ocorrem mínimos devidos ao efeito orográfico da Serra do Mar, Serra da Mantiqueira e Serra da Canastra, que se estendem também às regiões baixas do Vale do Ribeira. No interior em especial há um mínimo de Ki na serra de São Carlos, coincidente com um máximo de precipitação (Figura 3.3.a). A média espacial de Ki no trimestre DJF foi de $239 \mathrm{~W} \mathrm{~m}^{-2}$, e no trimestre JJA de $169 \mathrm{~W} \mathrm{~m}^{-2}$. 

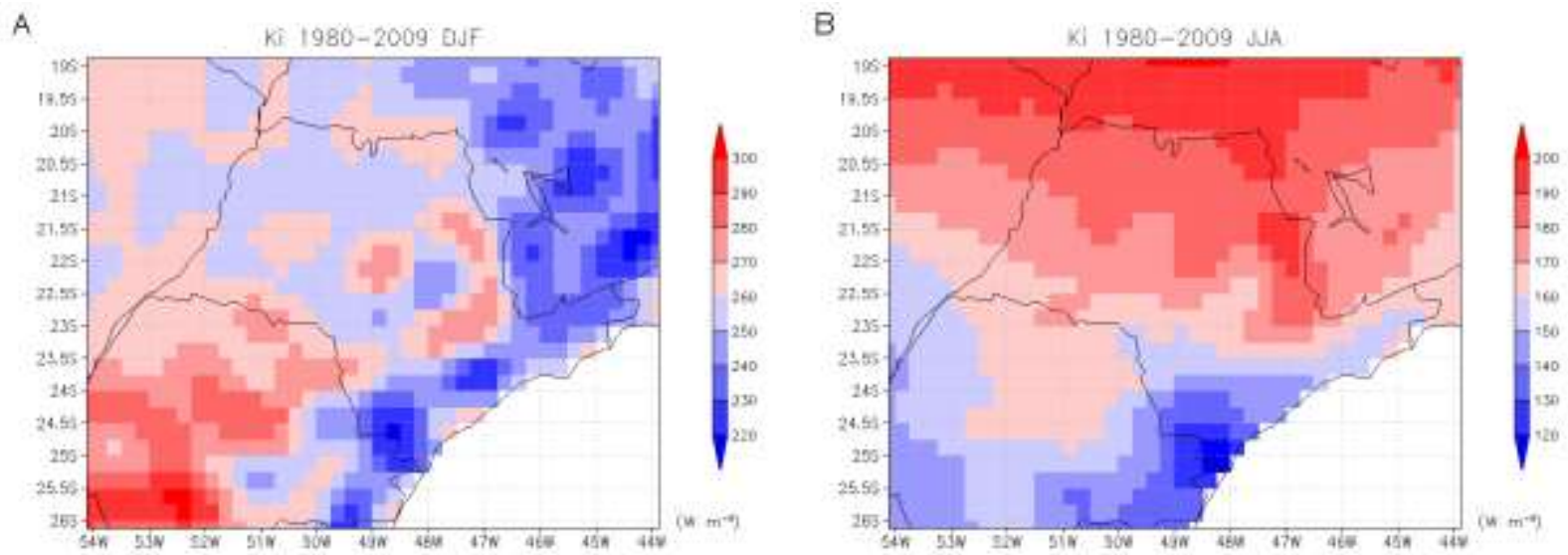

Figura 3.2: Irradiância Solar Incidente (Ki) [W $\left.\mathrm{m}^{-2}\right]$. Médias sazonais climatológicas entre 1980 e 2009. A) trimestre Dezembro, Janeiro e Fevereiro; B) trimestre Junho, Julho e Agosto.

Outros máximos de precipitação no Verão (Figura 3.3) ocorreram no litoral de SP, associados à brisa marítima e efeito orográfico e na Serra da Canastra. Os máximos de precipitação no Inverno concentraram-se no Paraná devido às frentes frias, responsáveis pela chuva nesta época, que provocam menos chuva nas latitudes mais ao norte. Há um viés da precipitação no Verão com o máximo de chuva na Serra de São Carlos e outro ao sul na Serra do Mar, estabelecendo um mínimo entre eles. A média espacial da precipitação no período chuvoso foi de 7,9 $\mathrm{mm} \mathrm{dia}^{-1}$, e no período seco, de $1,4 \mathrm{~mm} \mathrm{dia}^{-1}$.

A

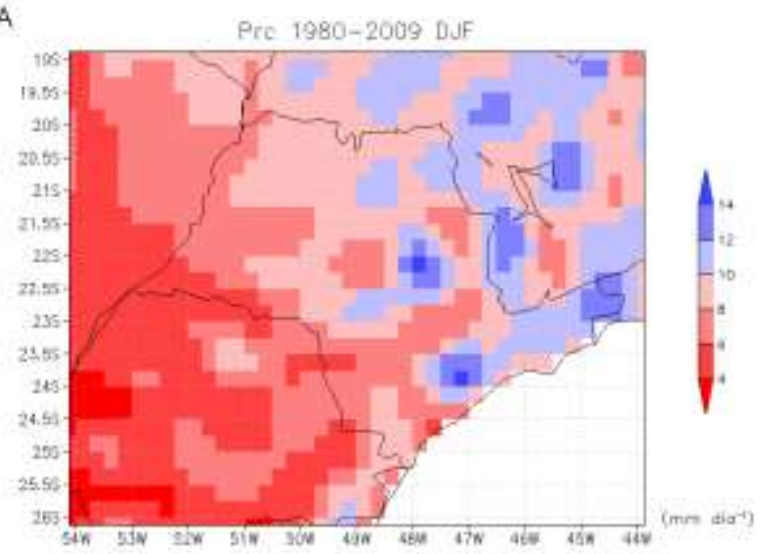

B

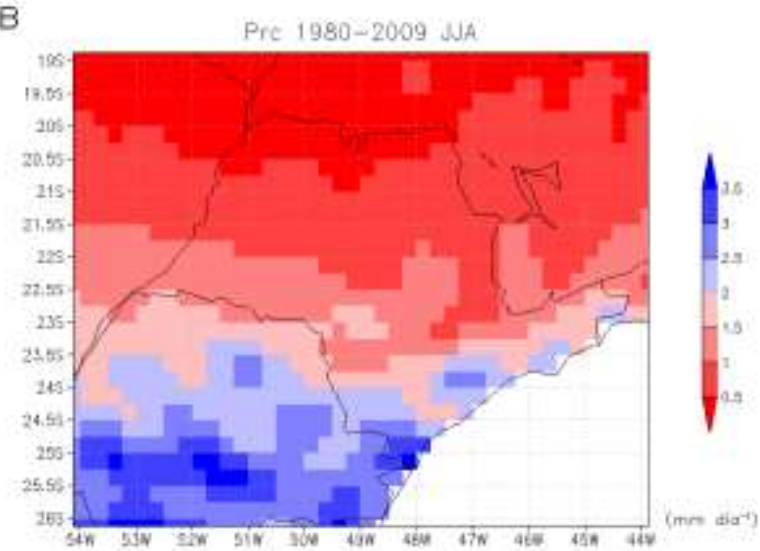

Figura 3.3: Precipitação Mensal Acumulada (Prc) $\left[\mathrm{mm} \mathrm{dia}^{-1}\right]$. Médias sazonais climatológicas entre 1980 e 2009. A) trimestre Dezembro, Janeiro e Fevereiro; B) trimestre Junho, Julho e Agosto.

No período chuvoso as faixas de maior umidade ocorrem no litoral e no setor noroeste, devido às altas temperaturas, e os mínimos na Serra da Mantiqueira e Serra da Canastra devido à altitude (Figura 3.4). Nos meses secos a redução da umidade é generalizada. 

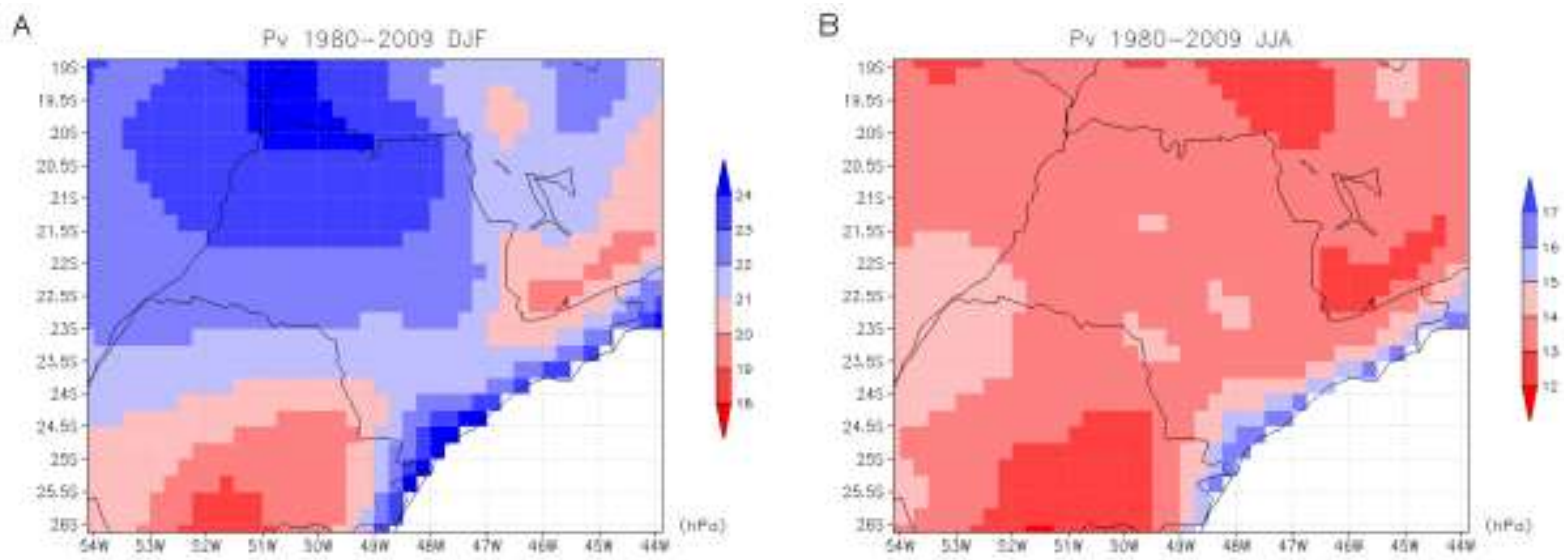

Figura 3.4: Pressão Parcial do Vapor D’água (Pv) [hPa]. Médias sazonais climatológicas entre 1980 e 2009. A) trimestre Dezembro, Janeiro e Fevereiro; B) trimestre Junho, Julho e Agosto.

A Figura 3.5 apresenta a temperatura sazonal climatológica, com máximos que se estabelecem no interior na direção noroeste, devido à variação latitudinal e ao efeito de continentalidade. Em especial nas Serras do Mar, Mantiqueira e da Canastra ocorrem as temperaturas mais baixas.

A

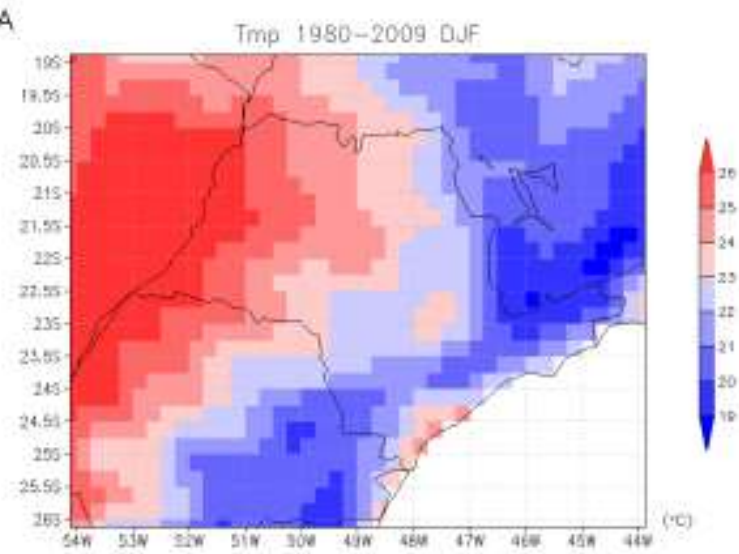

B

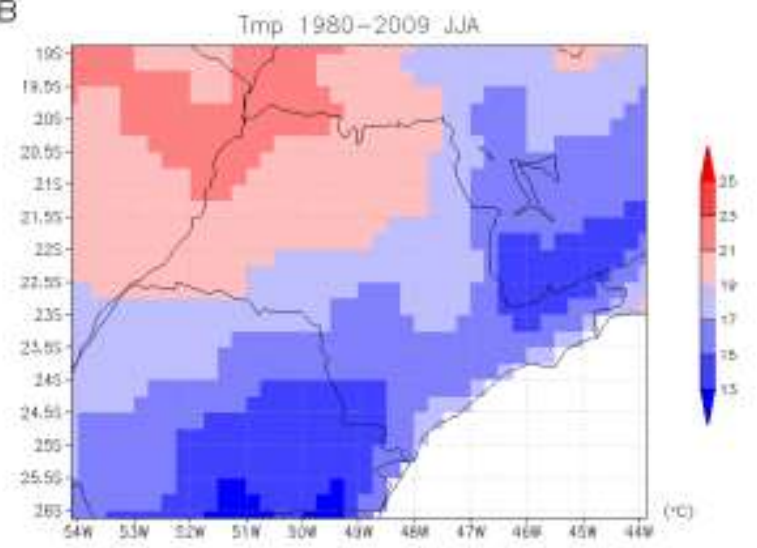

Figura 3.5: Temperatura Média do Ar (Tmp) $\left[{ }^{\circ} \mathrm{C}\right]$. Médias sazonais climatológicas entre 1980 e 2009. A) trimestre Dezembro, Janeiro e Fevereiro; B) trimestre Junho, Julho e Agosto.

A velocidade do vento (Figura 3.6) mostra pouca variação no estado de SP, havendo, todavia, máximos no PR devido à influência das frentes frias que lá estão mais intensas, principalmente no Inverno. Há um mínimo de vento no Vale do Ribeira, em ambas as estações, possivelmente devido à obstrução do vento de norte pela Serra do Mar. As médias de velocidade do vento foram de $2,1 \mathrm{~m} \mathrm{~s}^{-1}$ no verão e $2,4 \mathrm{~m} \mathrm{~s}^{-1}$ no inverno. 

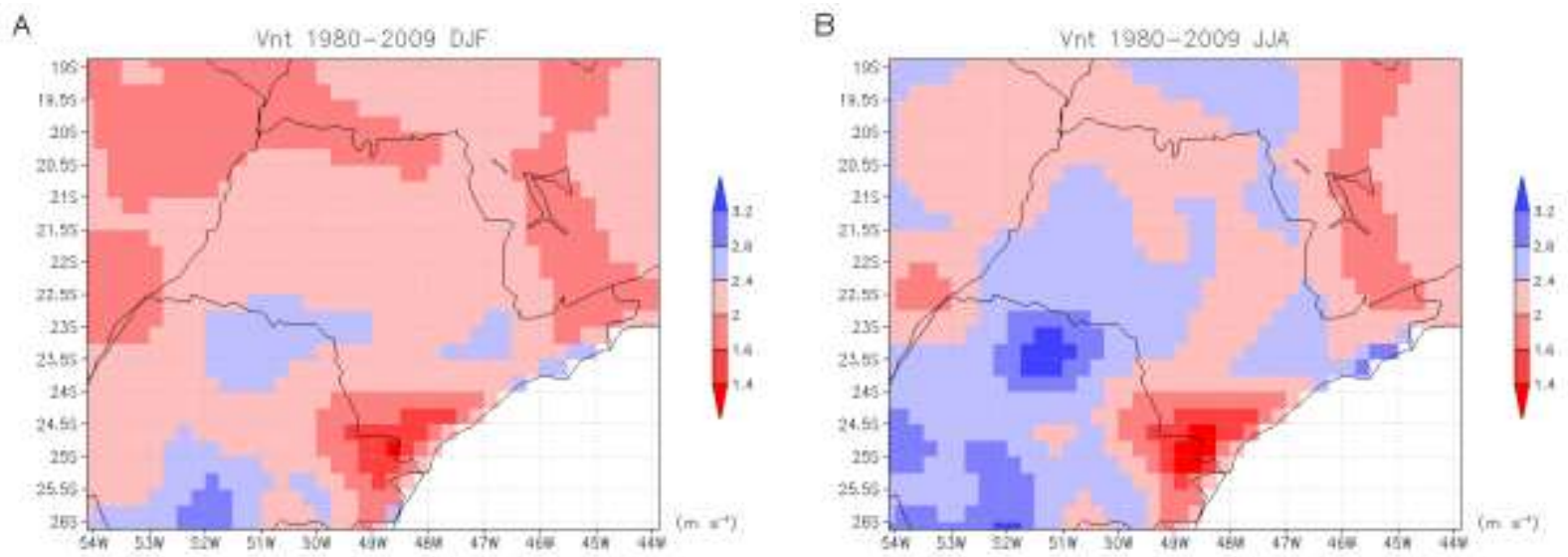

Figura 3.6: Velocidade do Vento (Vnt) [ $\mathrm{m} \mathrm{s}^{-1}$. Médias sazonais entre 1980 e 2009. A) trimestre Dezembro, Janeiro e Fevereiro; B) trimestre Junho, Julho e Agosto.

\subsubsection{Comparação com observações}

A comparação das médias sazonais dos dados da reanálise com as estações de superfície são mostradas a seguir. As figuras mensais constam no APÊNDICE B . A Figura 3.7 mostra as diferenças de precipitação e temperaturas máxima e mínima médias anuais. Para a precipitação a reanálise foi mais chuvosa (diferença positiva) na Serra do Mar e na Serra de São Carlos, o que pode ter sido pela interpolação das observações que não considerou a altitude, embora o máximo de chuva na região de São Carlos tenha sido representado na reanálise. Outro fator importante que pode alterar a análise de Cressman é a ausência de dados no oceano que deforma o campo nesta região. A precipitação média anual da reanálise foi 0,63 $\mathrm{mm} \mathrm{dia}^{-1}$ maior que as observações. Para as temperaturas máximas e mínimas, a reanálise mostra-se expressivamente mais fria que as observações ao longo da Serra do Mar e vale do Ribeira, de até $-3^{\circ} \mathrm{C}$, e levemente mais quente na fronteira oeste do estado. A comparação de precipitação e temperatura no verão e inverno foi de natureza semelhante às das médias anuais (não mostradas por simplicidade). 

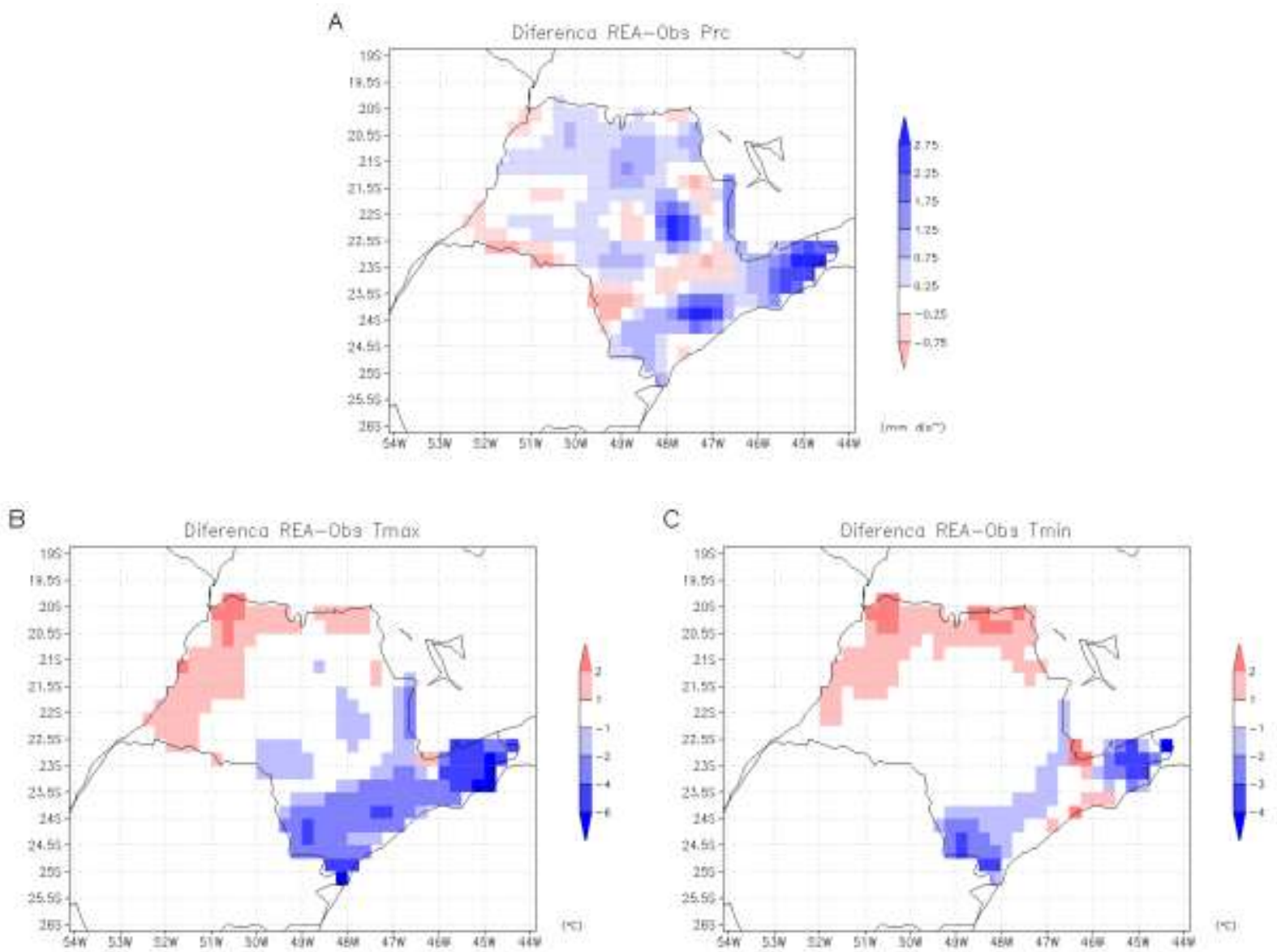

Figura 3.7: Diferença entre Reanálise e dados observados. Médias anuais no período entre 1980 e 2009. A) Precipitação $\left[\mathrm{mm}\right.$ dia $\left.^{-1}\right]$; B) Temperatura Máxima $\left[{ }^{\circ} \mathrm{C}\right]$; C) Temperatura Mínima $\left[{ }^{\circ} \mathrm{C}\right]$.

\subsubsection{Séries temporais das forçantes climatológicas}

As médias das variáveis atmosféricas da reanálise, em todo o domínio das forçantes (área compreendida entre 19S e 26S, 44W e 54W; com máscara para o estado de SP), estão dispostas na Figura 3.8 como série temporal da média mensal, na Figura 3.9 como série temporal da média anual, e na Figura 3.10 como a média climatológica mensal. Nelas notamos mais facilmente os vieses da reanálise em relação ao conjunto observado. A reanálise tende a superestimar alguns picos de precipitação nos meses chuvosos, subestimar a temperatura máxima e acompanhar bem a curva da temperatura mínima, conforme observado na Figura 3.8, e mais claramente nas Figura 3.9 e Figura 3.10. 


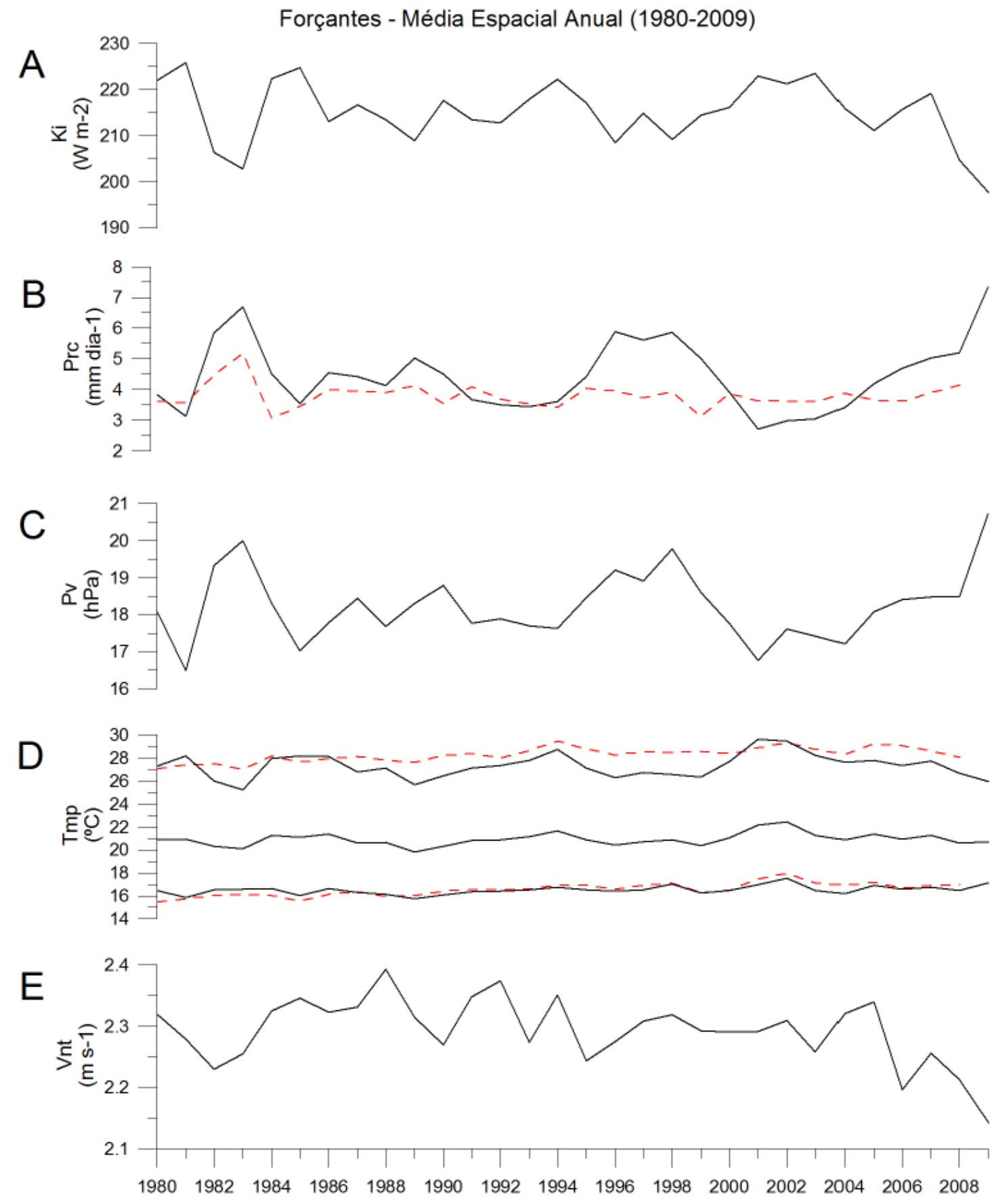

Figura 3.8: Série temporal das forçantes do modelo Reg-SiB2. Média anual no domínio no período entre 1980 e 2009. A linha cheia preta representa os dados de reanálise, e a linha pontilhada vermelha, os dados observados. A) Irradiância Solar Incidente (Ki) $\left[\mathrm{W} \mathrm{m}^{-2}\right]$; B) Precipitação acumulada (Prc) $\left[\mathrm{mm} \mathrm{dia}^{-1}\right]$; C) Pressão parcial de vapor d'água (Pv) [hPa]; D) Temperatura média do ar (Tmp) [ $\left.{ }^{\circ} \mathrm{C}\right]$; E) Velocidade do vento (Vnt) $\left[\mathrm{m} \mathrm{s}^{-1}\right]$. 


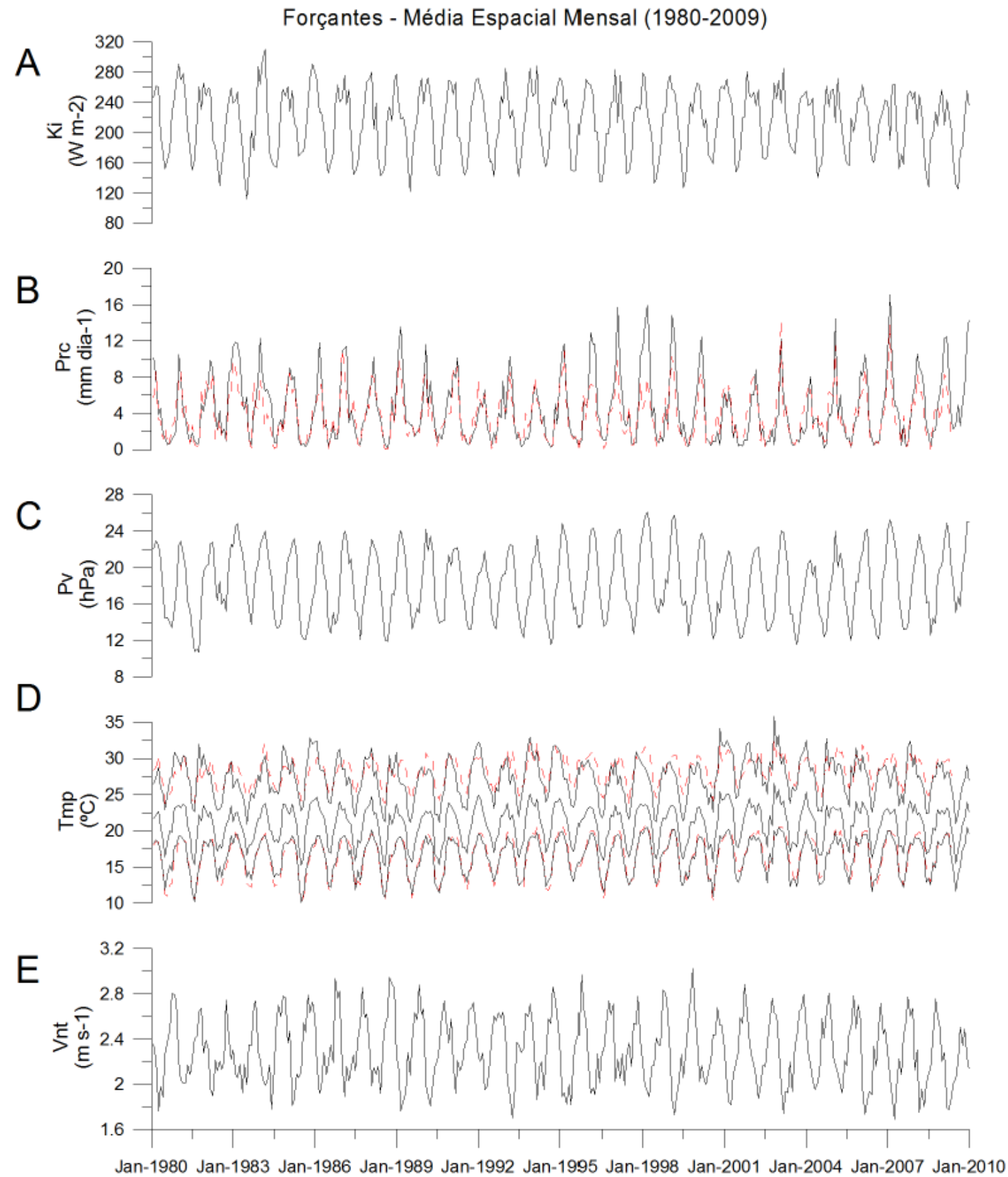

Figura 3.9: Série temporal das forçantes do modelo Reg-SiB2. Média mensal do domínio no período entre 1980 e 2009A linha cheia preta representa os dados de reanálise, e a linha pontilhada vermelha, os dados observados. A) Irradiância Solar Incidente (Ki) $\left[\mathrm{W} \mathrm{m}^{-2}\right]$; B) Precipitação acumulada (Prc) $\left[\mathrm{mm} \mathrm{dia}^{-1}\right]$; C) Pressão parcial de vapor d'água (Pv) $[\mathrm{hPa}]$; D) Temperatura média do ar $(\mathrm{Tmp})\left[{ }^{\circ} \mathrm{C}\right]$; E) Velocidade do vento (Vnt) $\left[\mathrm{m} \mathrm{s}^{-1}\right]$.

A Figura 3.10 indica maiores diferenças entre os dois conjuntos de dados no primeiro semestre, quando a precipitação é superestimada e a temperatura máxima é subestimada. A propósito, a discrepância da comparação é coerente em si, indicando um clima mais chuvoso 
e consistentemente mais frio da reanálise. A comparação da reanálise é melhor para a temperatura mínima.

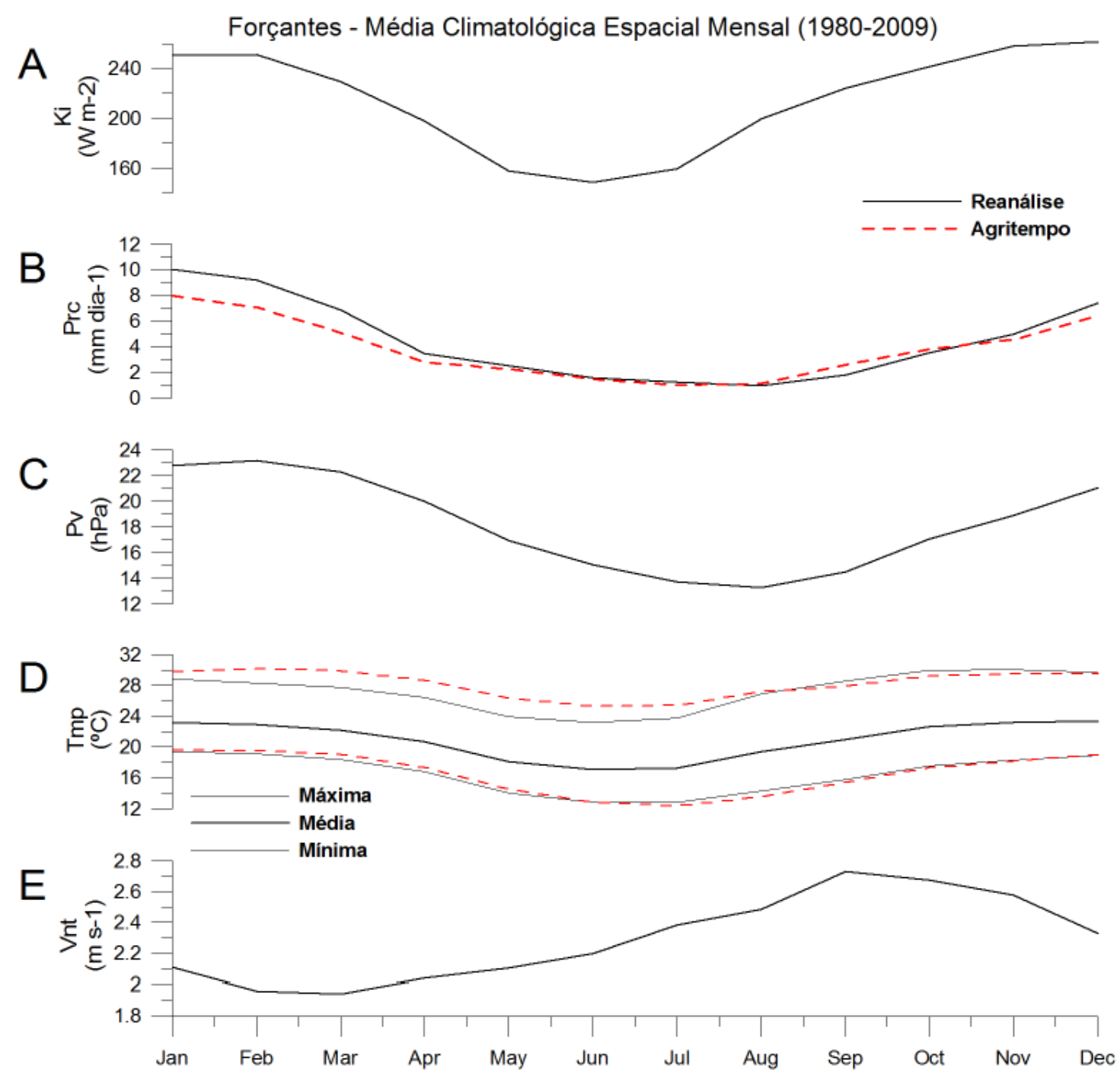

Figura 3.10: Climatologia das forçantes do modelo Reg-SiB2. Média mensal no domínio no período entre 1980 e 2009. A linha cheia preta representa os dados de reanálise, e a linha pontilhada vermelha, os dados observados. A) Irradiância Solar Incidente (Ki) $\left[\mathrm{W} \mathrm{m}^{-2}\right]$; B) Precipitação acumulada (Prc) $\left[\mathrm{mm} \mathrm{dia}^{-1}\right]$; C) Pressão parcial de vapor d'água $(\mathrm{Pv})[\mathrm{hPa}]$; D) Temperatura média do ar $(\mathrm{Tmp})\left[{ }^{\circ} \mathrm{C}\right]$; E) Velocidade do vento (Vnt) $\left[\mathrm{m} \mathrm{s}^{-1}\right]$.

Em uma estimativa inicial, podemos esperar máximos de ETR nas regiões com maior oferta de radiação solar, portanto, no centro, oeste e norte do estado de SP. 


\subsection{DESEMPENHO DO MODELO SiB2}

Neste tópico é discutido o desempenho dos fluxos calculados pelo modelo SiB2 pontual em confronto com as observações de campo, por duas formas ou duas diferentes forçantes (as locais ou observadas nas torres micrometeorológicas, versus as da reanálise), o que é per se uma forma de avaliação da calibração do modelo; e que permitirá verificar como se preservam os padrões dos fluxos de escala local quando a escala e a característica do forçamento se alteram.

\subsubsection{Variabilidade sazonal}

A Figura 3.11 mostra as médias diárias dos fluxos de energia para a cana-de-açúcar. De forma geral a variabilidade sazonal é bem representada para todos os fluxos. As diferenças das simulações com as duas forçantes são pequenas. Ambas as simulações tendem a superestimar o saldo de radiação (Rn) no Inverno e Primavera, consequentemente os fluxos de calor latente (LE) e sensível $(\mathrm{H})$ foram também superestimados naquelas circunstâncias. Neste aspecto, é interessante notar que o fechamento do balanço de energia nos sítios experimentais situou-se entre $78 \%$ e $90 \%$, portanto com uma tendência de subestimativa dos fluxos LE e H. A superestimativa dos fluxos pelo modelo compensou artificialmente uma esta subestimativa da ETR das observações de campo. O fluxo de calor no solo (termo G) foi bem simulado, inclusive na forma de variabilidade intrasazonal ou simplesmente no dia-a-dia. 


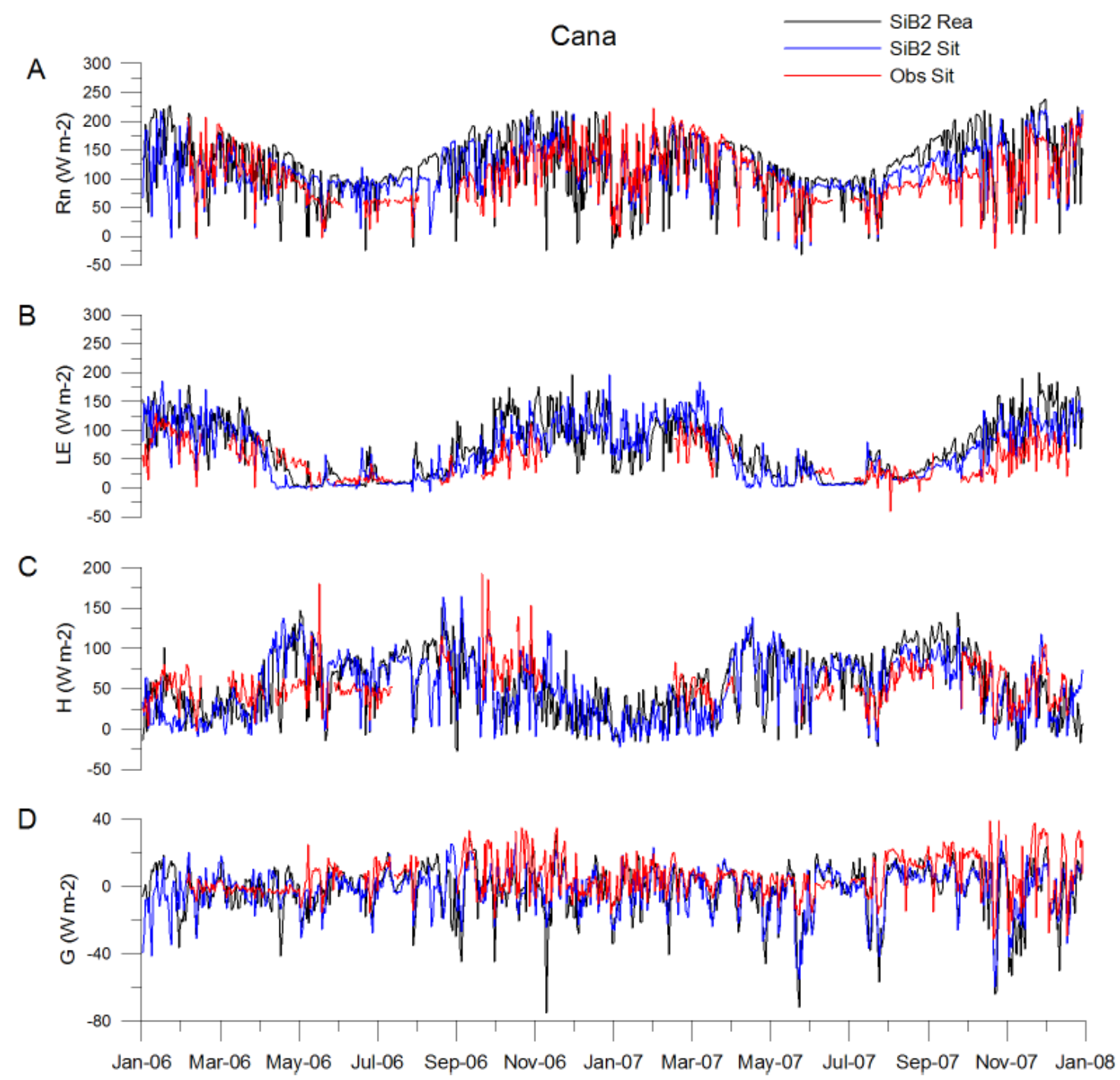

Figura 3.11: Saídas do modelo SiB2 para a cana-de-açúcar. Médias diárias no período entre 2006 e 2007. A) Saldo de Radiação (Rn) [W $\left.{ }^{-2}\right]$; B) Fluxo de calor latente (LE) [W $\left.\mathrm{m}^{-2}\right]$; C) Fluxo de calor sensível (H) [W m $\left.{ }^{-2}\right]$; D) Fluxo de Calor no solo (G) [W $\left.\mathbf{~ m}^{-2}\right]$.

As comparações para o cerrado (Figura 3.12) mostraram uma concordância do cálculo do saldo de radiação $(\mathrm{Rn})$ para as duas forçantes, e ambas superestimaram as observações principalmente no $2^{\circ}$ semestre do $1^{\circ}$ ano, mas não no ano seguinte. Para o fluxo de calor latente (LE) as comparações foram satisfatórias, e também para o fluxo de calor sensível (H) calculado com as duas forçantes, havendo, todavia, para o termo H uma certa superestimativa das observações de campo no Inverno. As observações de campo do fluxo de calor no solo (G) foram bem representadas pelo modelo na média como um todo, mas o modelo tende a amplificar a oscilação na escala dia-a-dia, que geralmente decorre dos eventos de chuva. 


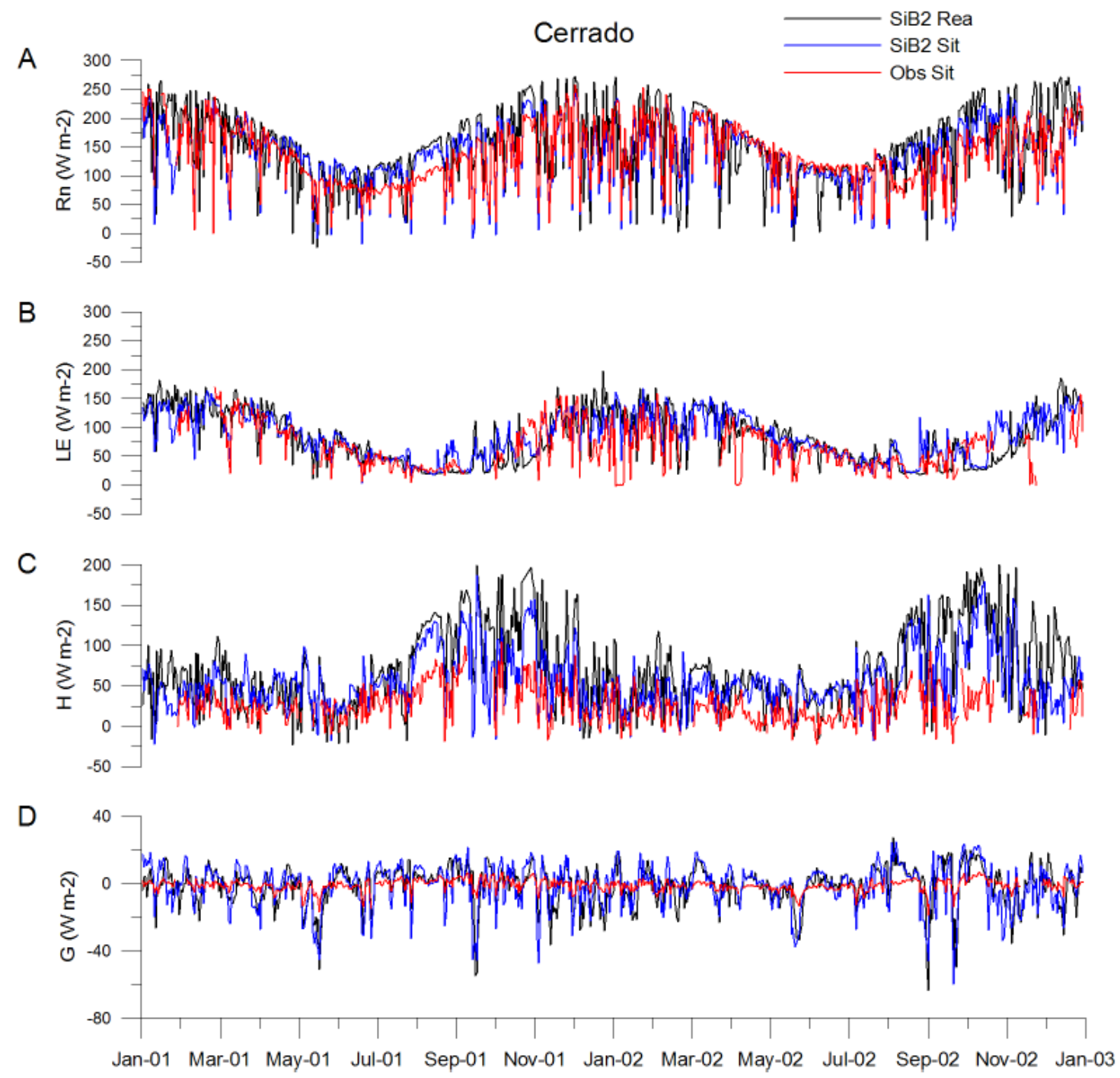

Figura 3.12: Saídas do modelo SiB2 para o cerrado. Médias diárias no período entre 2001e 2002. A) Saldo de Radiação (Rn) $\left[\mathrm{W} \mathrm{m}^{-2}\right]$; B) Fluxo de calor latente (LE) $\left[\mathrm{W} \mathrm{m}^{-2}\right]$; C) Fluxo de calor sensível (H) [W m $\left.^{-2}\right]$; D) Fluxo de Calor no solo (G) $\left[\mathrm{W} \mathrm{m}^{-2}\right]$.

Os cálculos do saldo de radiação (Rn) para o eucalipto (Figura 3.13) representaram bem a sazonalidade anual mas também mostraram uma notável superestimativa durante o Inverno, e mais próximos no verão. A sazonalidade dos termos LE e H também foi bem caracterizada e a média bem representada, tendo havido uma certa tendência da forçante da reanálise em aumentar o termo $\mathrm{H}$. As comparações do fluxo de calor no solo $(\mathrm{G})$ foram semelhantes às do Cerrado. 


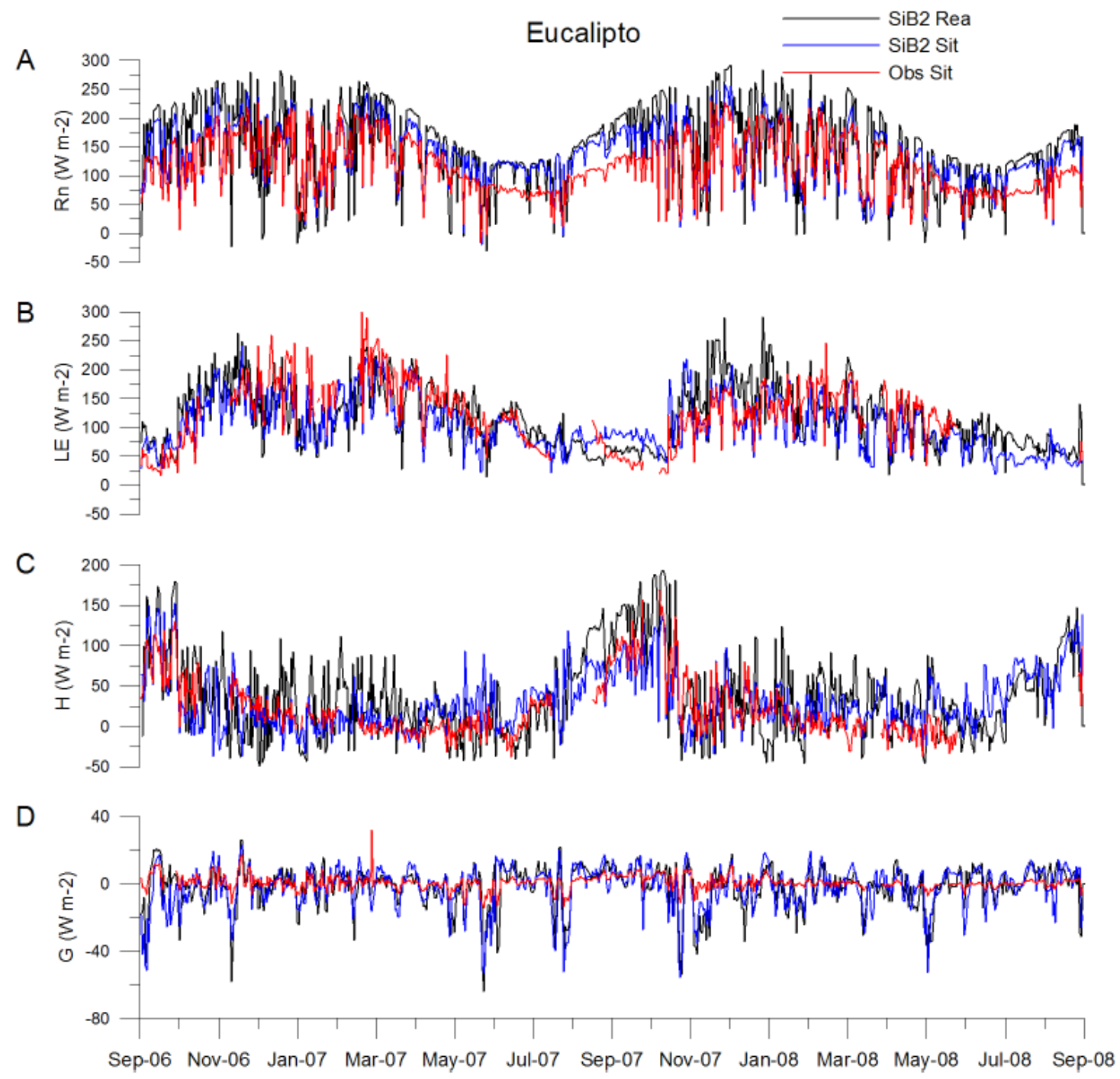

Figura 3.13: Saídas do modelo SiB2 para o eucalipto. Médias diárias no período entre 09/2006 e 08/2008. A) Saldo de Radiação (Rn) [W $\left.{ }^{-2}\right]$; B) Fluxo de calor latente (LE) [W $\left.\mathrm{m}^{-2}\right]$; C) Fluxo de calor sensível (H) [W m $\left.{ }^{-2}\right]$; D) Fluxo de Calor no solo (G) [W $\left.\mathbf{~ m}^{-2}\right]$.

Na Figura 3.14 são mostradas as comparações para a floresta de mata atlântica, onde o saldo de radiação $(\mathrm{Rn})$ foi bem simulado pelas duas formas de forçante. O fluxo de calor latente LE foi melhor simulado pela forçante da reanálise, havendo todavia em ambas as simulações um padrão de subestimativa, enquanto o fluxo de calor sensível $\mathrm{H}$ foi, de forma oposta, superestimado. Em termos de médias, as simulações do fluxo de calor no solo (G) foram bastante razoáveis. 


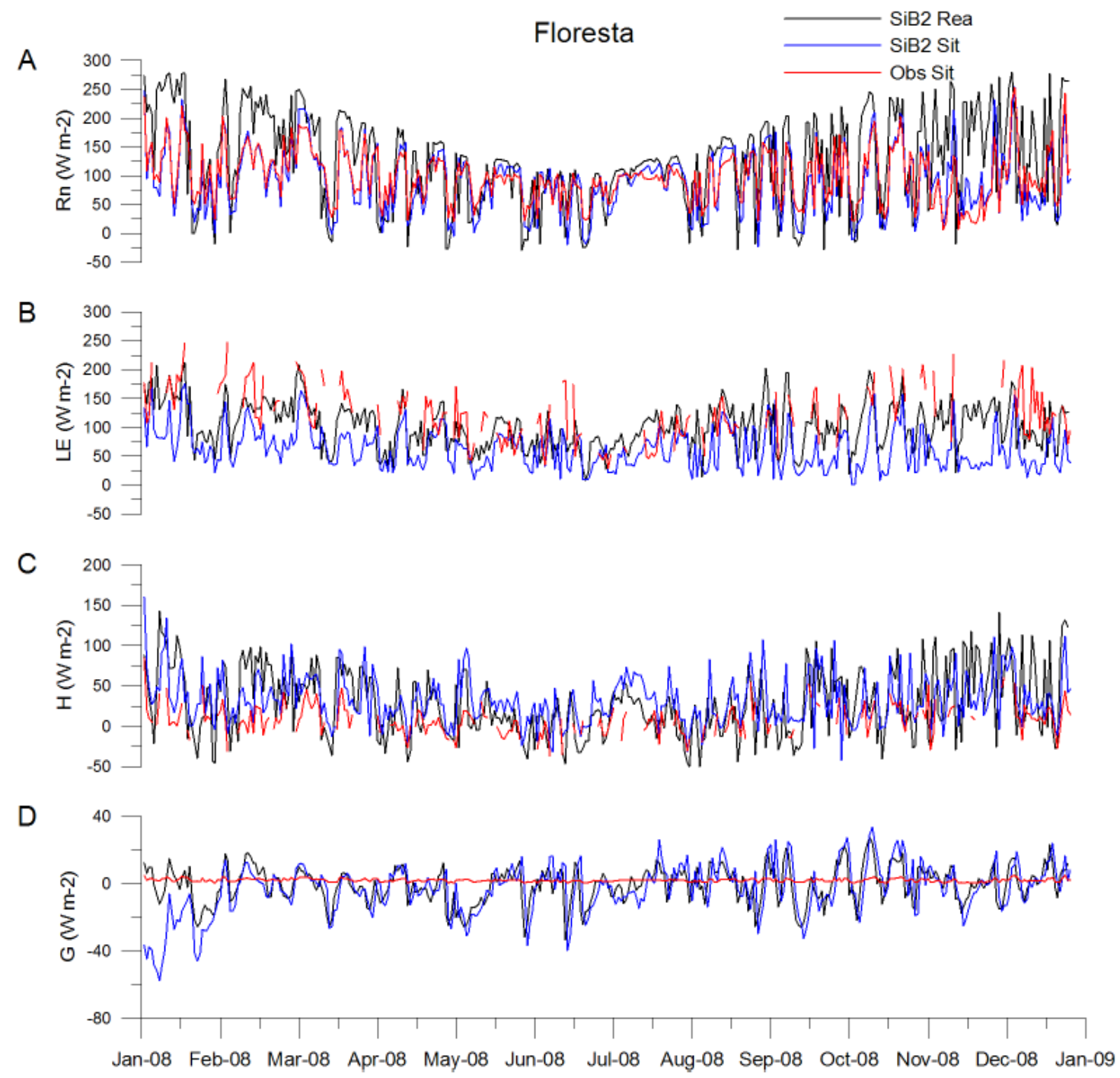

Figura 3.14: Saídas do modelo SiB2 para a floresta atlântica. Médias diárias no período do ano de2008. A) Saldo de Radiação (Rn) [W m $\left.{ }^{-2}\right]$; B) Fluxo de calor latente (LE) [W $\left.\mathbf{~ m}^{-2}\right]$; C) Fluxo de calor sensível (H) [W

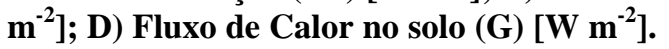

A simulação da pastagem será discutida apenas com os dados calculados (Figura 3.15), mas as duas simulações mostraram-se bastante próximas, reforçando aceitar a hipótese de que os resultados não foram penalizados pela escolha da reanálise como a fonte de dados meteorológicos forçantes. Há discrepâncias notáveis em alguns períodos, como, por exemplo, na Primavera de 2003, onde a simulação do termo H com a reanálise foi bem superior, e o termo LE compensadamente inferior, o que, todavia, não se repetiu no mesmo período dos outro ano. 


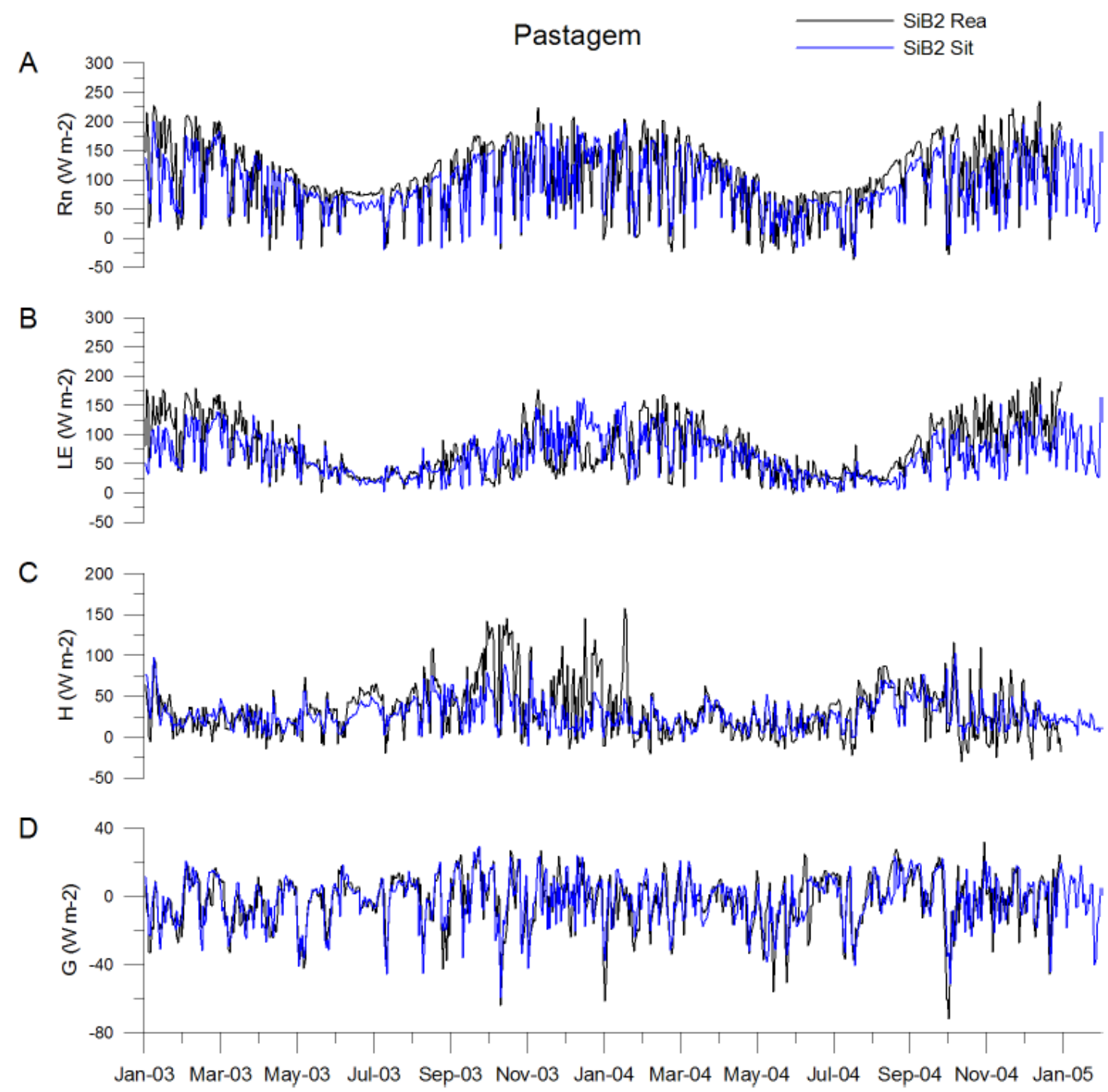

Figura 3.15: Saídas do modelo SiB2 para a pastagem. Médias diárias no período entre 2003 e 2004. A) Saldo de Radiação (Rn) $\left[\mathrm{W} \mathrm{m}^{-2}\right]$; B) Fluxo de calor latente (LE) $\left[\mathrm{W} \mathrm{m}^{-2}\right]$; C) Fluxo de calor sensível (H) [W $\left.\mathbf{m}^{-2}\right]$; D) Fluxo de Calor no solo $(G)\left[\mathrm{W} \mathrm{m}^{-2}\right]$.

\subsubsection{Ciclo diurno médio}

O desempenho do modelo e a comparação das forçantes na escala do ciclo diurno foram aqui discutidos para fevereiro e agosto. Especialmente, são mostradas as componentes calculadas da ETR total (transpiração, evaporação do solo e da água interceptada).

Um viés da reanálise é representar a irradiância solar incidente (Ki) ao longo do dia menos suavemente que as observações, o que controla algumas variáveis diretamente 
dependentes desta forçante sob um padrão semelhante (Figura 3.16). Adicionalmente, notouse nos dados da reanálise o nascer do Sol $\sim 1$ h mais tarde e o ocaso $\sim 2$ horas mais tarde que as observações locais, mas com os máximos próximos de $12 \mathrm{~h}$ local, coincidente com o observado, assim como a temperatura máxima e mínima coincidiram razoavelmente.

Este viés é sistemático em todas as células de grade da reanálise, e vão gerar consequentemente discrepâncias na comparação do ciclo diurno entre simulação e observação, que promovem defasagem.

No caso da cana-de-açúcar, como final de todas estas diferenças, há uma leve superestimativa da reanálise em relação às observações de campo. Na cana-de-açúcar, a precipitação observada (Figura 3.16) foi subestimada em fevereiro em 1,4 mm dia ${ }^{-1}$, e não houve chuva registrada localmente em agosto. Para fevereiro, a pressão de vapor é levemente superestimada pela reanálise $(\sim 1 \mathrm{hPa})$, enquanto é subestimada em agosto $(\sim 1 \mathrm{hPa})$, no entanto, os valores são bastante próximos nas médias em todo o período. As curvas de temperatura têm variações semelhantes em fevereiro, exceto por um padrão mais frio à tarde na reanálise $\left(\sim 1^{\circ} \mathrm{C}\right)$, enquanto para agosto há também leve superestimativa da reanálise à noite e de manhã. O ciclo diurno da velocidade do vento em geral não é bem capturado na reanálise, com certa superestimativa $\left(\sim 1 \mathrm{~m} \mathrm{~s}^{-1}\right)$ em fevereiro durante todo o dia, e à noite em agosto, período este último em que a reanálise subestima o vento diurno em $\sim 1 \mathrm{~m} \mathrm{~s}^{-1}$. 


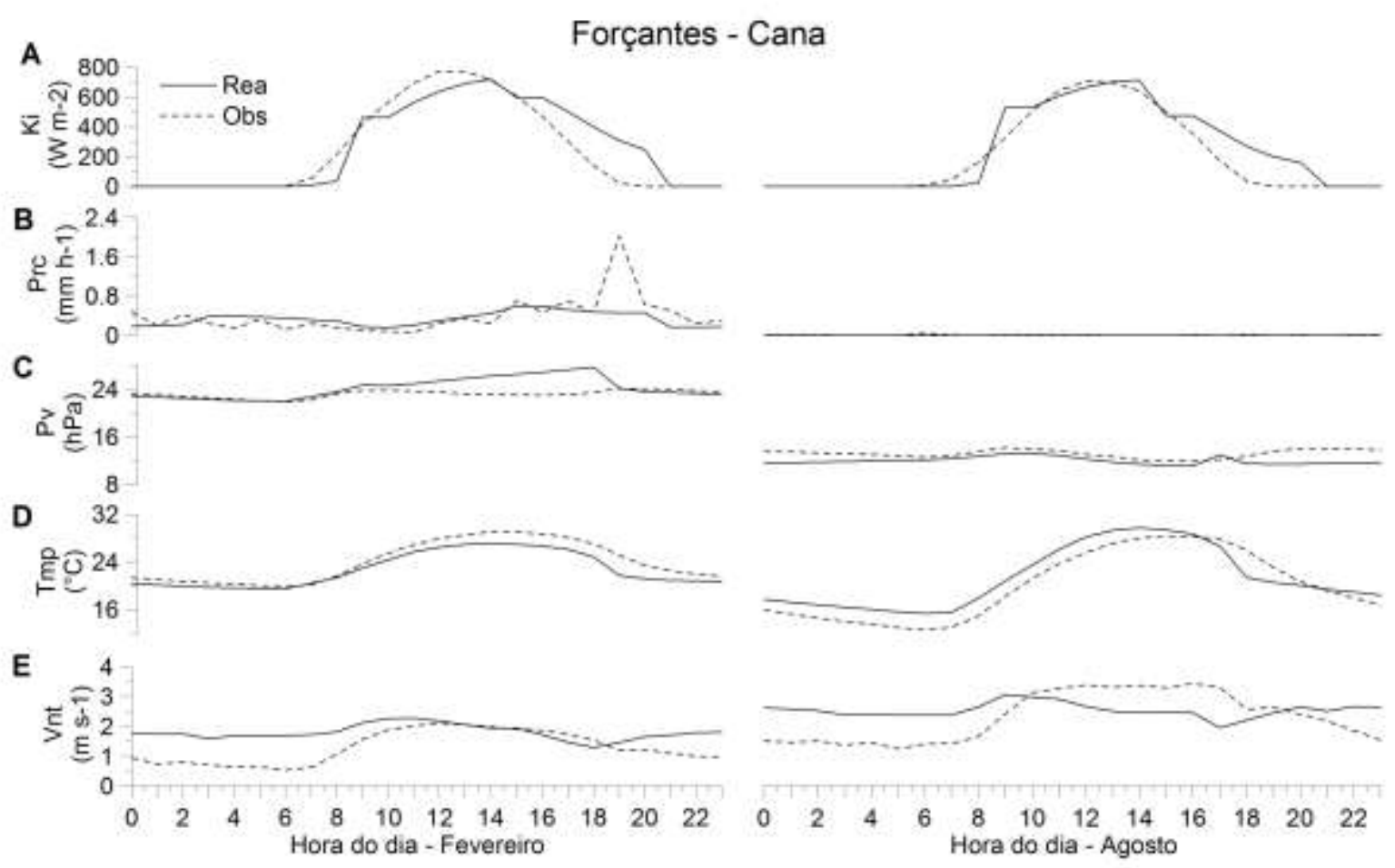

Figura 3.16: Ciclo diurno em fevereiro e agosto das forçantes para a cana-de-açúcar. Média horária no período entre 2006 e 2007. A) Irradiância Solar Incidente (Ki) [W m ${ }^{-2}$; B) Precipitação acumulada (Prc) $\left[\mathrm{mm} \mathrm{dia}^{-1}\right]$; C) Pressão parcial de vapor d'água (Pv) [hPa]; D) Temperatura média do ar (Tmp) $\left[{ }^{\circ} \mathrm{C}\right]$; E) Velocidade do vento (Vnt) $\left[\mathrm{m} \mathrm{s}^{-1}\right]$.

No caso da simulação do cerrado (Figura 3.16) o termo Ki também mostrou padrões de comparação semelhantes aos da cana-de-açúcar, mesmo por que a célula da reanálise é a mesma, apenas o dado observado e o período de análise são diferentes. Para a precipitação a superestimativa da reanálise foi de 4,5 $\mathrm{mm} \mathrm{dia}^{-1}$ em fevereiro, os resultados estiveram muito próximos em agosto. A comparação da pressão de vapor foi boa em fevereiro, e uma certa subestimativa no período diurno de $2,2 \mathrm{hPa}$ em agosto. Em fevereiro a reanálise comparou muito bem a temperatura, e em agosto notou-se uma superestimativa de $\sim 2{ }^{\circ} \mathrm{C}$ durante a manhã. A velocidade do vento foi de forma geral subestimada pela reanálise nos dois meses, mas de $\sim 1 \mathrm{~ms}^{-1}$ apenas. 


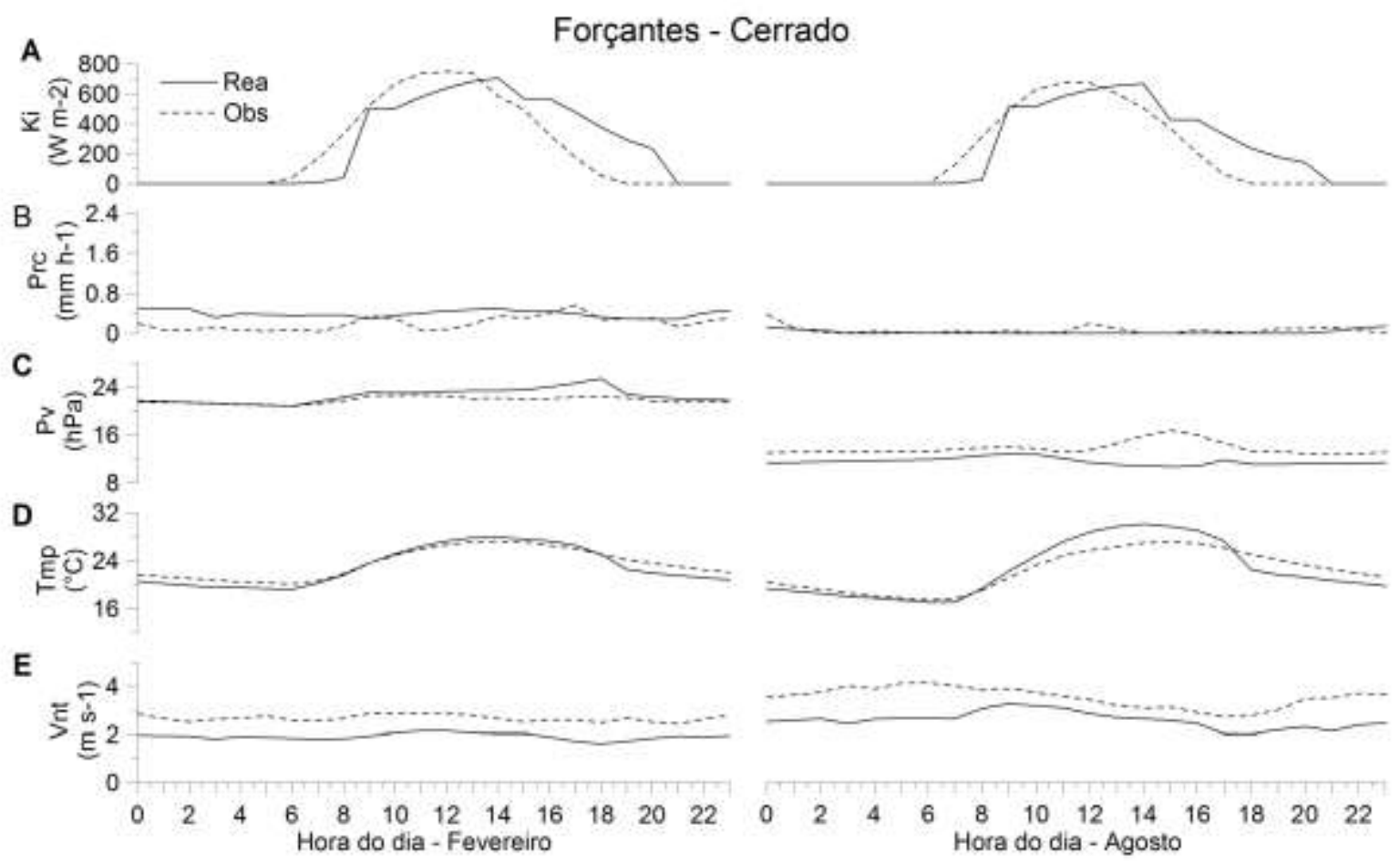

Figura 3.17: Ciclo diurno em fevereiro e agosto das forçantes para o cerrado. Média horária no período entre 2001 e 2002. A) Irradiância Solar Incidente (Ki) $\left[\mathrm{W} \mathrm{m}^{-2}\right]$; B) Precipitação acumulada (Prc) [mm dia ${ }^{-}$ $\left.{ }^{1}\right]$; C) Pressão parcial de vapor d'água (Pv) $[\mathrm{hPa}]$; D) Temperatura média do ar $\left.(\mathrm{Tmp})\left[{ }^{\circ} \mathrm{C}\right] ; \mathrm{E}\right)$ Velocidade do vento (Vnt) [ $\left.\mathrm{m} \mathrm{s}^{-1}\right]$.

No caso da simulação do eucalipto (Figura 3.16) o termo Ki também mostrou padrões de comparação semelhantes aos da cana-de-açúcar e cerrado, por que a célula da reanálise é coincidente. Para a precipitação a reanálise subestimou a precipitação em $0,5 \mathrm{~mm} \mathrm{dia}{ }^{-1} \mathrm{em}$ fevereiro e subestimou em $0,1 \mathrm{~mm} \mathrm{dia}^{-1}$ em agosto. A comparação da pressão de vapor foi boa em agosto, e houve uma certa superestimativa no período diurno em agosto. Em fevereiro a reanálise acompanhou muito bem a temperatura, e em agosto notou-se uma superestimativa de $\sim 2^{\circ} \mathrm{C}$ durante a manhã. A velocidade do vento foi de forma geral bem simulada nos dois meses. 


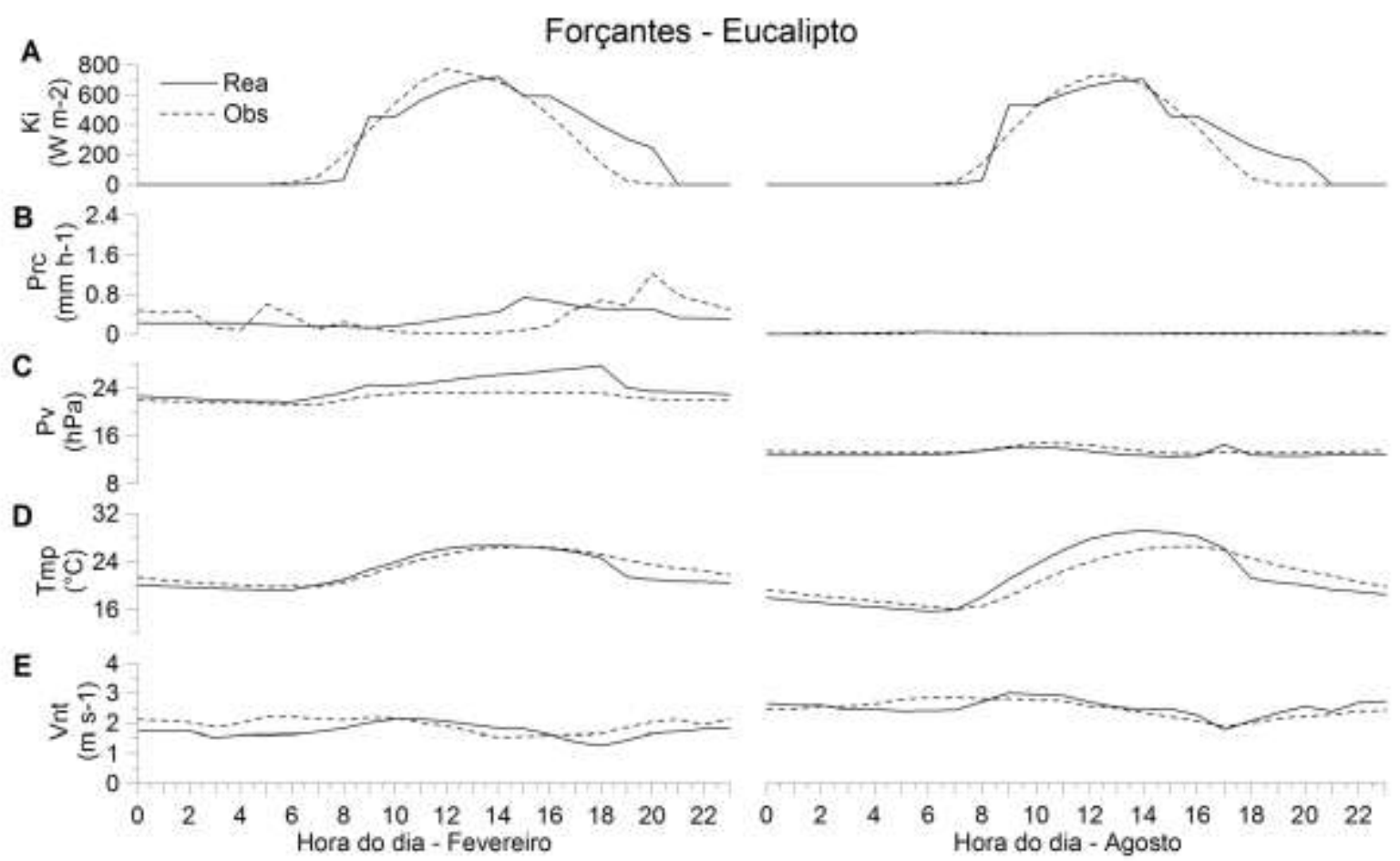

Figura 3.18: Ciclo diurno em fevereiro e agosto das forçantes para o eucalipto. Média horária no período entre 2007 e 2008. A) Irradiância Solar Incidente (Ki) $\left[\mathrm{W} \mathrm{m}^{-2}\right]$; B) Precipitação acumulada (Prc) [mm dia $\left.{ }^{1}\right]$; C) Pressão parcial de vapor d'água (Pv) [hPa]; D) Temperatura média do ar (Tmp) $\left[{ }^{\circ} \mathrm{C}\right]$; E) Velocidade do vento (Vnt) [ $\left.\mathrm{m} \mathrm{s}^{-1}\right]$.

As simulações das forçantes da reanálise no caso da floresta de mata atlântica foram as mais discrepantes das observações (Figura 3.16), dentre todos os sítios experimentais discutidos. As diferenças da temperatura média do ar nos dois meses foram de $\sim 4^{\circ} \mathrm{C}$ e da pressão de vapor d'água de $\sim 5 \mathrm{hPa}$. A diferença pode decorrer da resolução espacial mais grosseira da reanálise, que não diferencia aspectos regionais oceano-continente, e a abrupta diferença de altitude na transição da Serra do Mar no litoral norte. As diferenças para o termo $\mathrm{Ki}$ foram as maiores dentre todos os casos, com superestimativa. A velocidade do vento foi levemente superestimada à noite em geral, por $\sim 1 \mathrm{~ms}^{-1}$ e o ciclo diurno com aumento do vento diurno não foi adequadamente representado. 


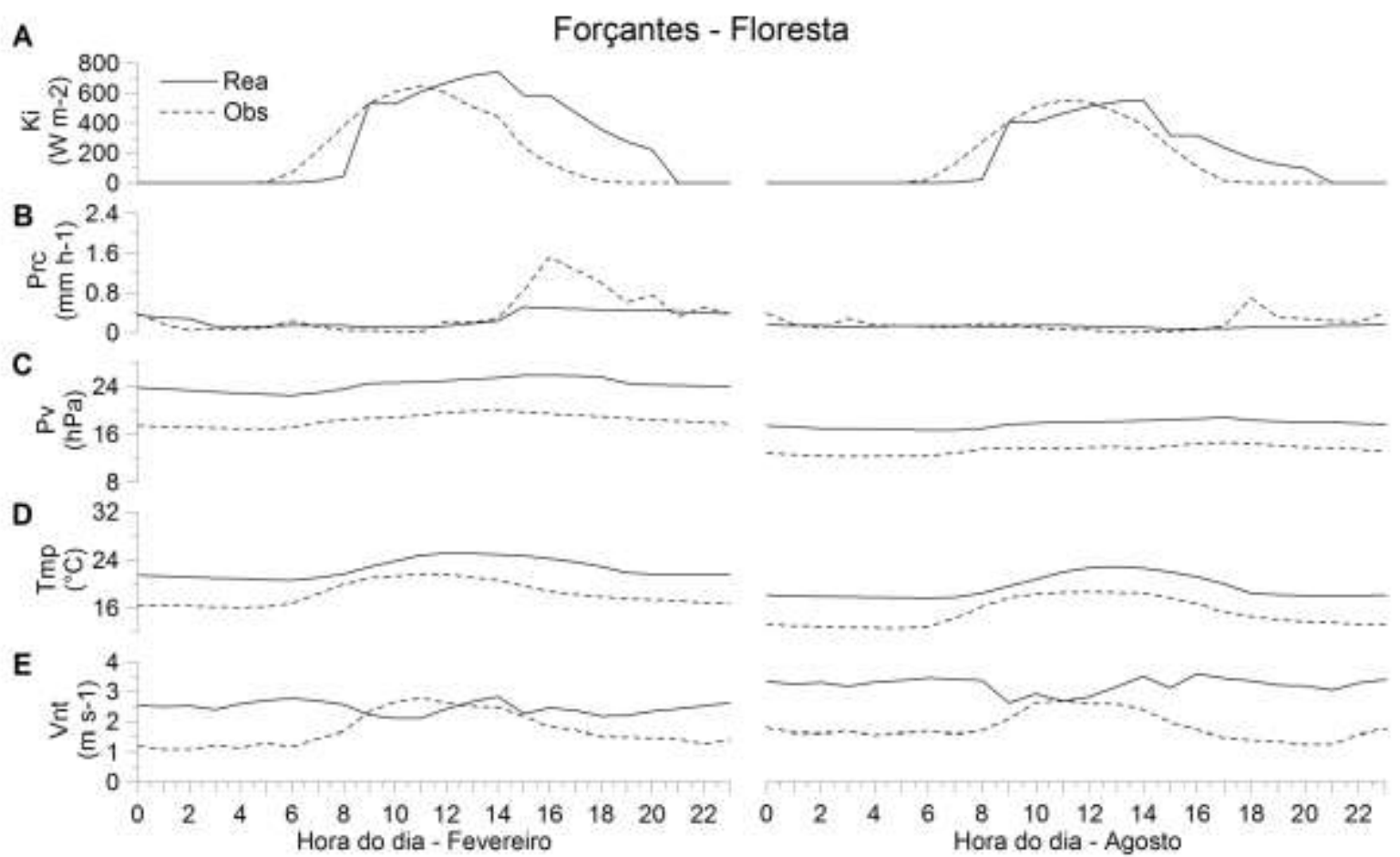

Figura 3.19: Ciclo diurno em fevereiro e agosto das forçantes para a floresta atlântica. Média horária no ano de 2008. A) Irradiância Solar Incidente (Ki) $\left[\mathrm{W} \mathrm{m}^{-2}\right]$; B) Precipitação acumulada (Prc) $\left.\left[\mathrm{mm} \mathrm{dia}^{-1}\right] ; \mathbf{C}\right)$ Pressão parcial de vapor d'água (Pv) $[\mathrm{hPa}]$; D) Temperatura média do ar (Tmp) $\left[{ }^{\circ} \mathrm{C}\right]$; E) Velocidade do vento (Vnt) $\left[\mathrm{m} \mathrm{s}^{-1}\right]$.

As diferenças para a pastagem foram calculadas em relação às observações da estação automática de Piracicaba, SP (Figura 3.16). O termo Ki mostrou padrões de comparação semelhantes aos da cana-de-açúcar e cerrado, com leve superestimativa e defasagem do ciclo diurno. Para a precipitação houve tendência dominante de leve superestimativa em fevereiro. A pressão de vapor foi em geral subestimada, de $\sim 1 \mathrm{hPa}$ nos dois meses. A reanálise comparou muito bem a temperatura de forma geral nos dois meses. A velocidade do vento da reanálise foi superestimada de $\sim 1 \mathrm{~ms}^{-1}$, com representação do ciclo diurno mas de forma atenuada 


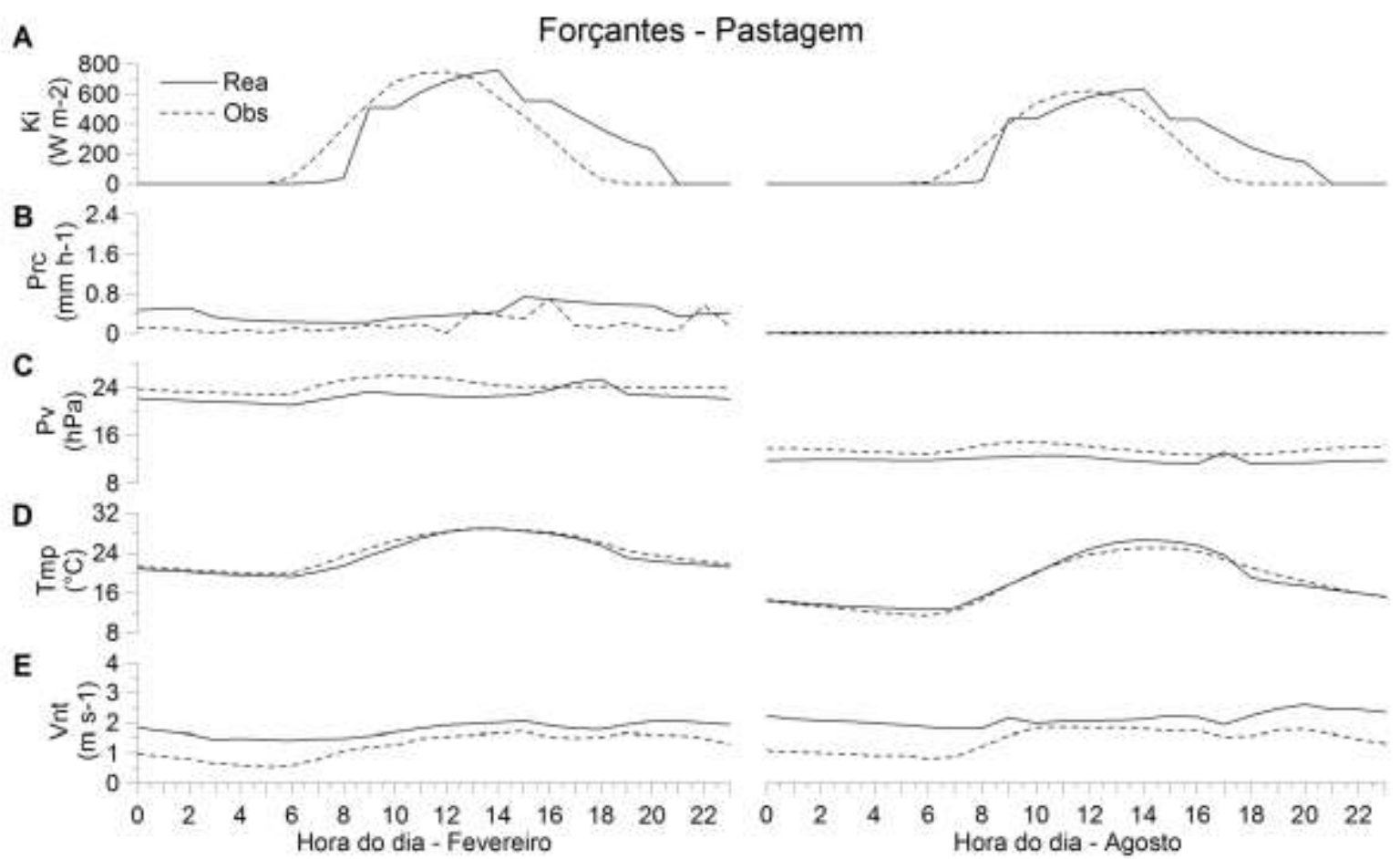

Figura 3.20: Ciclo diurno em fevereiro e agosto das forçantes para a pastagem. Média horária no período entre 2003 e 2004. A) Irradiância Solar Incidente (Ki) $\left[\mathrm{W} \mathrm{m}^{-2}\right]$; B) Precipitação acumulada (Prc) [mm dia ${ }^{-}$ ${ }^{1}$; C) Pressão parcial de vapor d'água (Pv) [hPa]; D) Temperatura média do ar (Tmp) [ $\left.{ }^{\circ} \mathrm{C}\right]$; E) Velocidade do vento (Vnt) [ $\left.\mathrm{m} \mathrm{s}^{-1}\right]$.

As próximas discussões serão sobre a comparação dos fluxos radiativos e fluxos de energia, calculados com as duas forçantes e observados no campo, como médias do ciclo diurno.

Na Figura 3.21 as comparações para a cana mostraram o desempenho do modelo para representar o saldo de radiação (diferenças médias de $-9 \mathrm{~W} \mathrm{~m}^{-2}$ em fevereiro, embora pela compensação da manhã com o início da noite), e com razoável superestimativa ( $47 \mathrm{~W} \mathrm{~m}^{-2}$ ) em agosto. Para fevereiro o modelo superestimou o fluxo de calor latente $\left(37 \mathrm{~W} \mathrm{~m}^{-2}\right)$, e subestimou o fluxo de calor sensível $\left(21 \mathrm{~W} \mathrm{~m}^{-2}\right)$, e para agosto mostrou menores vieses positivos para LE e $\mathrm{H}\left(9 \mathrm{~W} \mathrm{~m} \mathrm{~m}^{-2}, 23 \mathrm{~W} \mathrm{~m}^{-2}\right)$, padrão este já discutido na análise da variabilidade sazonal discutida anteriormente. O fluxo de calor no solo foi bem representado em fevereiro, mas com subestimativa em agosto.

As componentes da ETR simulada mostram de forma concordante nos dois conjuntos de forçantes o termo de transpiração como dominante, e a evaporação do solo como a de menor expressão. Há certas discrepâncias entre eles: a reanálise produz substancialmente maior transpiração e evaporação da água interceptada em fevereiro, e menor evaporação do solo. Em agosto as discrepâncias são desprezíveis. 


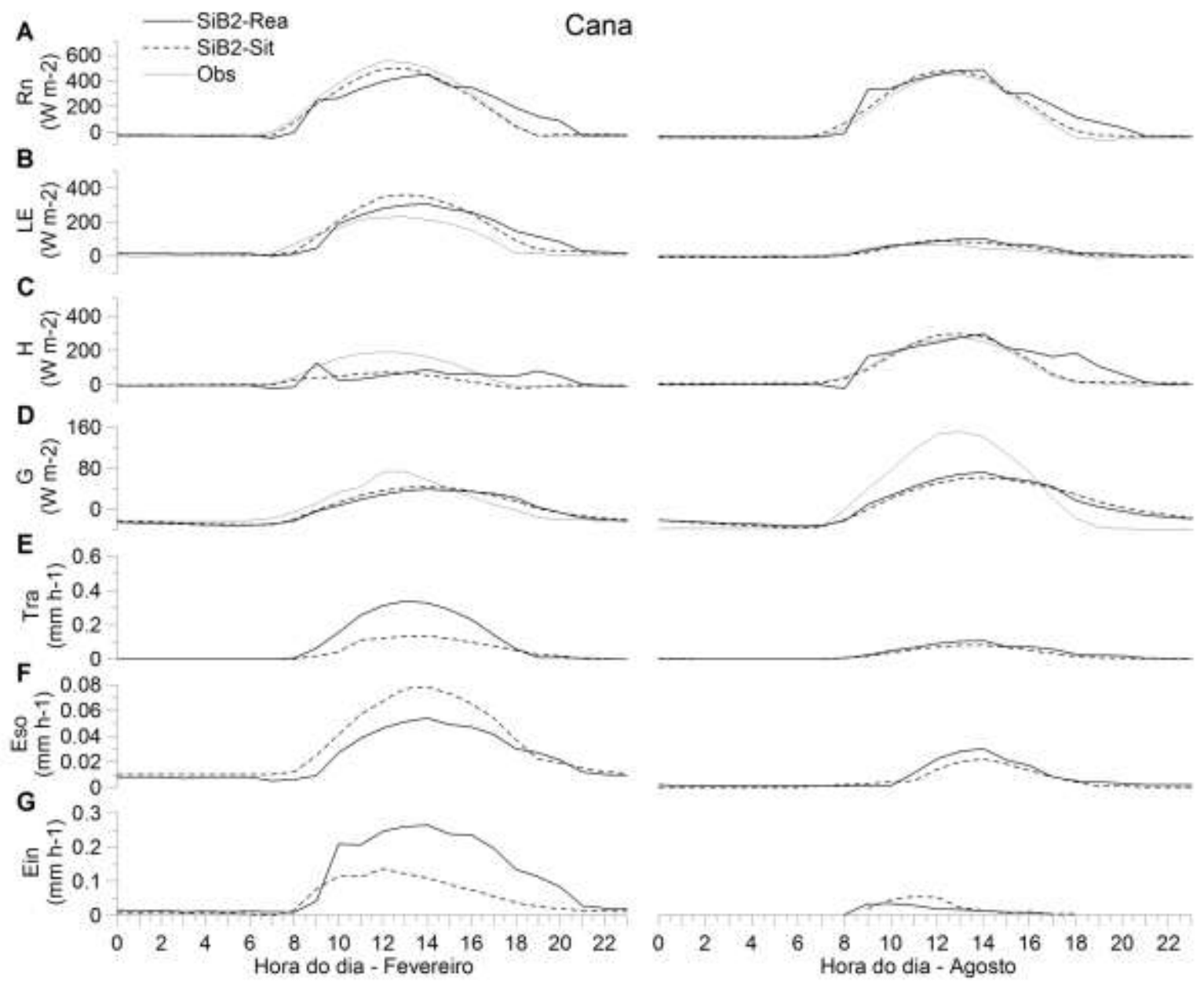

Figura 3.21: Ciclo diurno em fevereiro e agosto dos fluxos de calor e componentes da evapotranspiração para a cana-de-açúcar. Média horária no período entre 2006 e 2007. A) Saldo de Radiação (Rn) [W m ${ }^{-2}$;

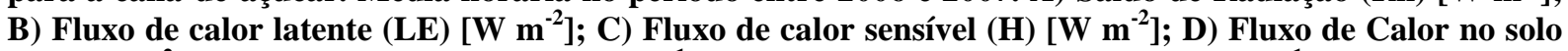

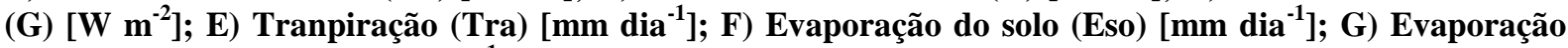
por interceptação (Ein) $\left[\mathrm{mm} \mathrm{dia}^{-1}\right]$.

Na Figura 3.22 as comparações para o cerrado mostraram o desempenho do modelo para representar o saldo de radiação com diferenças médias de $-3 \mathrm{~W} \mathrm{~m}^{-2}$ em fevereiro (embora pela compensação da manhã com o início da noite), e com razoável superestimativa ( $29 \mathrm{~W} \mathrm{~m}$ ${ }^{2}$ ) em agosto, ambos semelhante ao desempenho da cana-de-açúcar. Para fevereiro o modelo superestimou o fluxo de calor latente $\left(29 \mathrm{~W} \mathrm{~m}^{-2}\right.$ para reanálise e $15 \mathrm{~W} \mathrm{~m}^{-2}$ para o sítio) e para agosto mostrou menores vieses positivos de LE $\left(-2 \mathrm{~W} \mathrm{~m}^{-2}\right.$ para a reanálise e $9 \mathrm{~W} \mathrm{~m}^{-2}$ para o sítio); e superestimou o fluxo de calor sensível ( $29 \mathrm{~W} \mathrm{~m}^{-2}$ e locais de $15 \mathrm{~W} \mathrm{~m}^{-2}$ em fevereiro), e em agosto nos dados locais de $62 \mathrm{~W} \mathrm{~m}^{-2}$ e $36 \mathrm{~W} \mathrm{~m}^{-2}$ para a reanálise), padrão este já discutido na análise da variabilidade sazonal discutida anteriormente. O fluxo de calor no solo foi bem representado nos dois meses em geral.

A comparação das componentes da ETR simulada foi em natureza de forma geral semelhante à discutida para a cana-de-açúcar. 


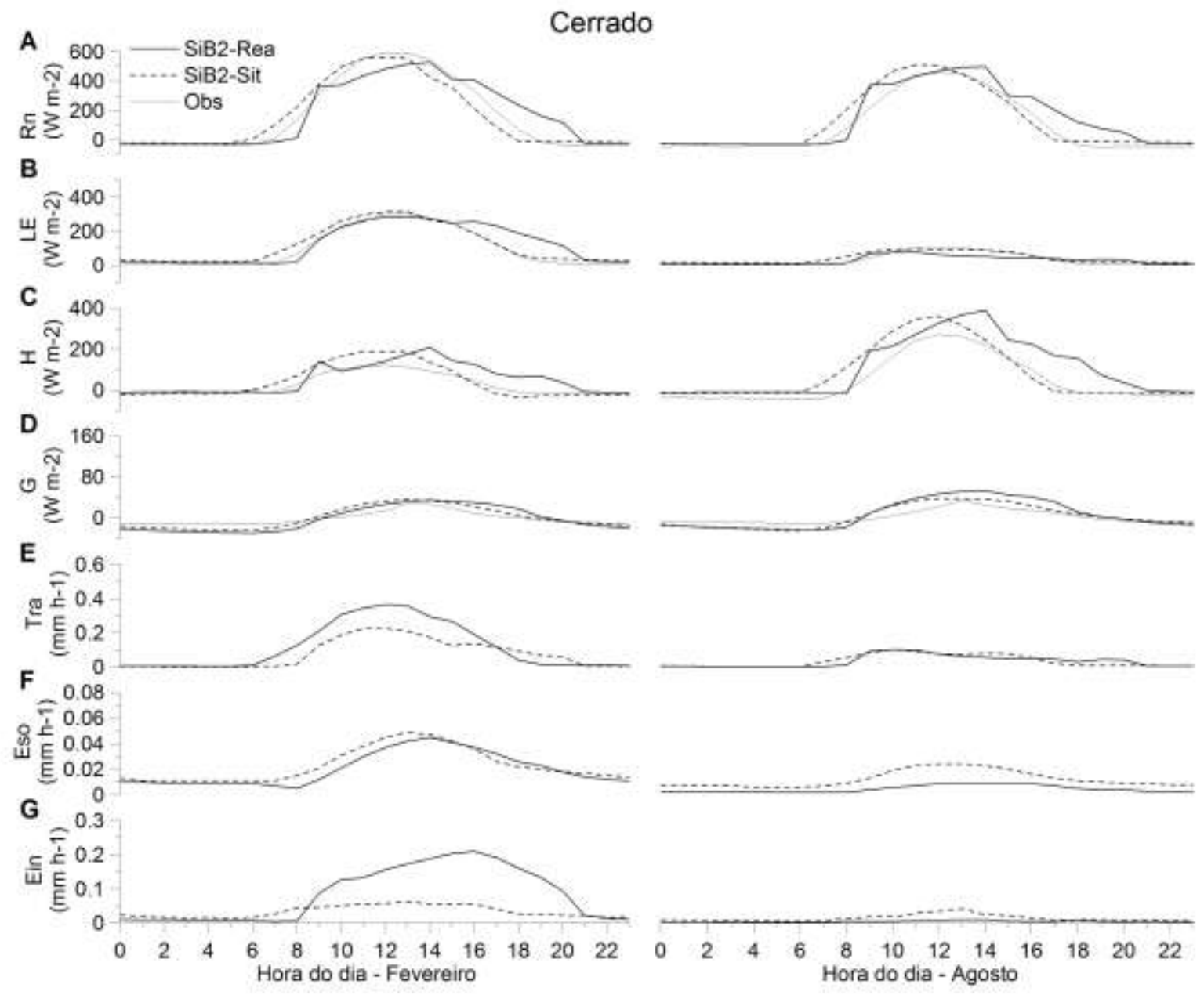

Figura 3.22: Ciclo diurno em fevereiro e agosto dos fluxos de calor e componentes da evapotranspiração para o cerrado. Média horária no período entre 2001 e 2002. A) Saldo de Radiação (Rn) [W m $\left.{ }^{-2}\right]$; B) Fluxo

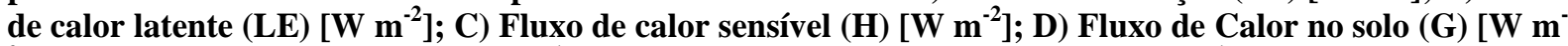

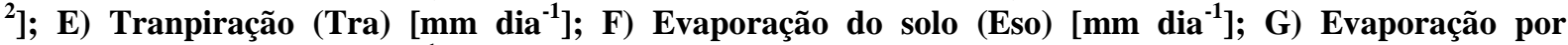
interceptação (Ein) $\left[\mathrm{mm} \mathrm{dia}^{-1}\right]$.

As simulações para o eucalipto (Figura 3.23) indicaram melhor destreza das forçantes locais do sítio para simular o termo $\mathrm{Rn}$ (diferenças de -1 e $39 \mathrm{~W} \mathrm{~m}^{-2}$, contra 24 e $55 \mathrm{~W} \mathrm{~m}^{-2}$ resultados da reanálise, para fevereiro e agosto respectivamente). As simulações de LE foram parecidas em fevereiro, com diferenças das observações de $35 \mathrm{~W} \mathrm{~m}^{-2}$ (reanálise) e $-38 \mathrm{~W} \mathrm{~m}^{-2}$ (sítio), enquanto as diferenças em agosto foram menores $\left(-10 \mathrm{~W} \mathrm{~m}^{-2} \mathrm{e}-4 \mathrm{~W} \mathrm{~m}^{-2}\right)$. As simulações com dados de torre também descreveram melhor os fluxos de calor sensível e no solo quando comparadas à reanálise.

A comparação das componentes da ETR simulada foi em natureza de forma geral semelhante à discutida para a cana-de-açúcar e cerrado. 


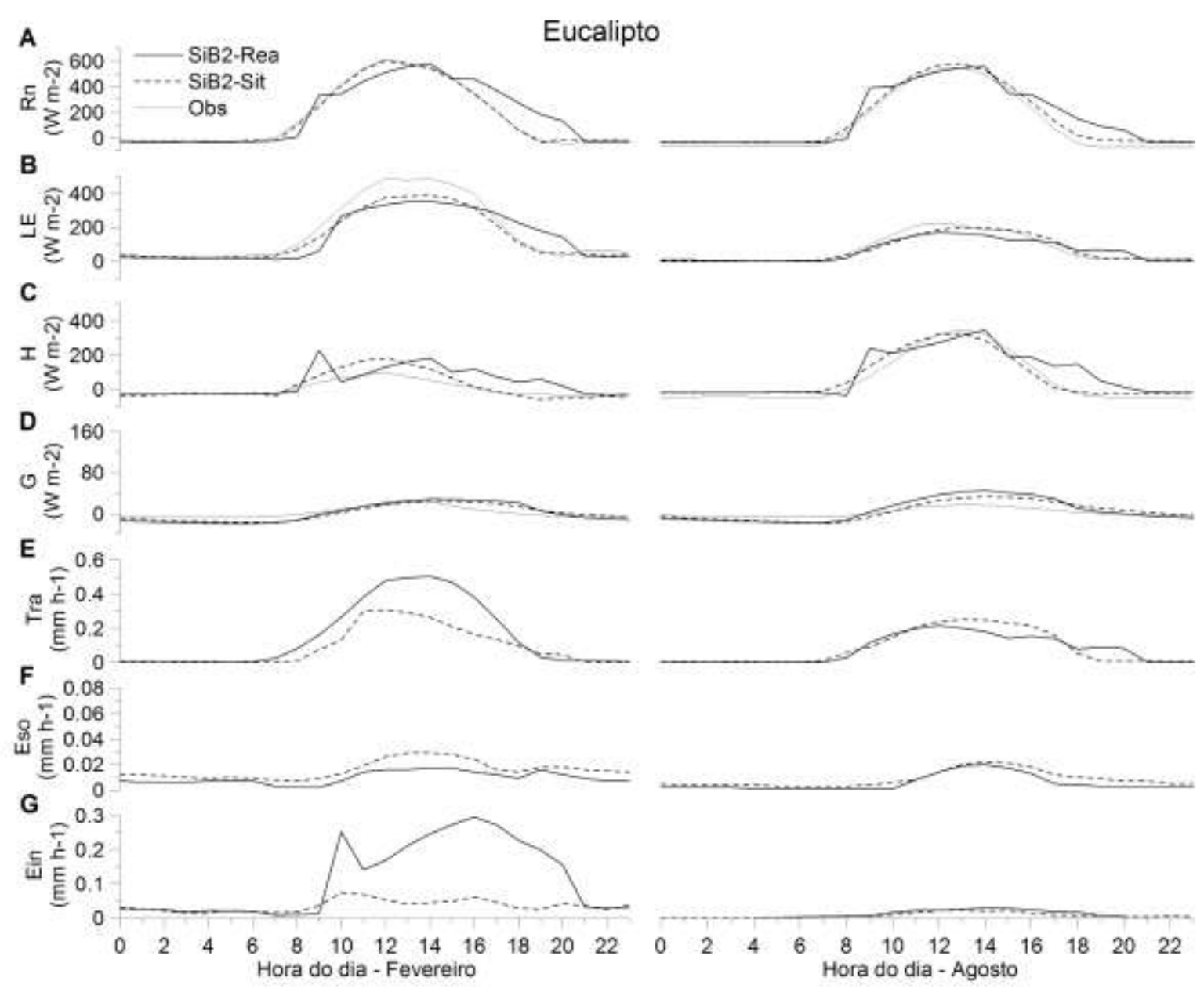

Figura 3.23: Ciclo diurno em fevereiro e agosto dos fluxos de calor e componentes da evapotranspiração para o eucalipto. Média horária entre 2007 e 2008. A) Saldo de Radiação (Rn) $\left[\mathrm{W} \mathrm{m}^{-2}\right]$; B) Fluxo de calor

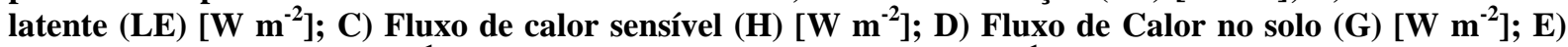
Tranpiração (Tra) $\left[\mathrm{mm} \mathrm{dia}^{-1}\right]$; F) Evaporação do solo (Eso) $\left[\mathrm{mm} \mathrm{dia}^{-1}\right]$; G) Evaporação por interceptação (Ein) $\left[\mathrm{mm} \mathrm{dia}^{-1}\right]$.

As simulações no caso da floresta de mata atlântica (Figura 3.24) mostraram que as forçantes locais compararam bem melhor o termo Rn. Todavia a comparação do termo LE foi melhor na reanálise, com diferenças de $-40 \mathrm{~W} \mathrm{~m}^{-2}$ em fevereiro e $-23 \mathrm{~W} \mathrm{~m}^{-2}$ em agosto, enquanto as diferenças com relação ao sítio foram de -90 e $-60 \mathrm{~W} \mathrm{~m}^{-2}$, respectivamente. As simulações com dados de sítio tiveram melhor comportamento para $\mathrm{H}$ em fevereiro, com diferença de 29 contra $49 \mathrm{~W} \mathrm{~m}^{-2}$ para a reanálise, já para agosto a diferença para a reanálise foi de apenas $2 \mathrm{~W} \mathrm{~m}^{-2}$ para a reanálise, mas de $20 \mathrm{~W} \mathrm{~m}^{-2}$ para o sítio.

As componentes da evapotranspiração simulada mostram de forma concordante nos dois conjuntos de forçantes o termo de transpiração (inclusive entre as simulações) e a perda por interceptação como dominantes e a evaporação do solo como a de menor expressão. A reanálise produz substancialmente maior evaporação da água interceptada em fevereiro. Em agosto as discrepâncias são desprezíveis. 


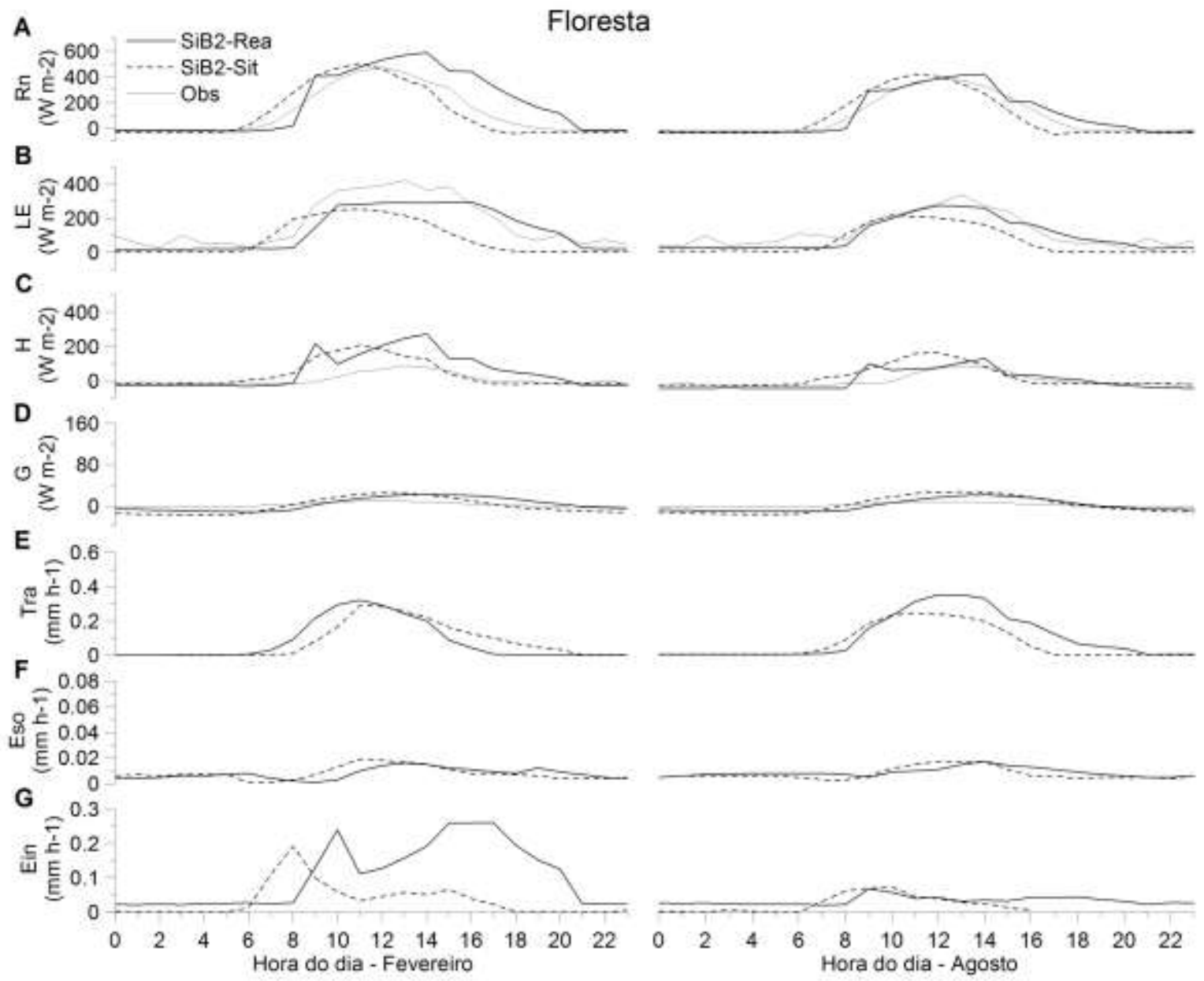

Figura 3.24: Ciclo diurno em fevereiro e agosto dos fluxos de calor e componentes da evapotranspiração para a floresta atlântica. Média horária no ano de 2008. A) Saldo de Radiação (Rn) [W $\left.\mathbf{m}^{-2}\right]$; B) Fluxo de

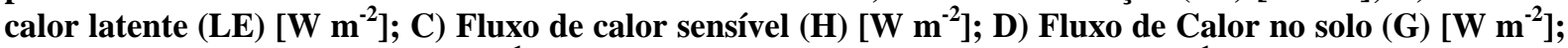
E) Tranpiração (Tra) $\left[\mathrm{mm} \mathrm{dia}{ }^{-1}\right]$; F) Evaporação do solo (Eso) $\left[\mathrm{mm} \mathrm{dia}{ }^{-1}\right]$; G) Evaporação por interceptação (Ein) [mm dia $\left.{ }^{-1}\right]$.

$\mathrm{Na}$ ausência de fluxos medidos da pastagem, apresentamos as duas fontes de dados forçantes (Figura 3.25). Os fluxos estão bastante próximos nos casos reanálise e sítio, as diferenças entre as componentes de ETR diferem pela maior precipitação da reanálise. As diferenças entre os resultados das duas fontes foram de $18 \mathrm{~W} \mathrm{~m}^{-2}$ em fevereiro e $20 \mathrm{~W} \mathrm{~m}^{-2}$ em agosto para o saldo de radiação, $25 \mathrm{~W} \mathrm{~m}^{-2}$ e $11 \mathrm{~W} \mathrm{~m}^{-2}$ para o fluxo de calor latente, $-6 \mathrm{~W} \mathrm{~m}^{-2} \mathrm{e}$ $8 \mathrm{~W} \mathrm{~m}^{-2}$ para o fluxo de calor sensível, -1 e $1 \mathrm{~W} \mathrm{~m}^{-2}$ para o fluxo de calor no solo. As diferenças nas médias de evaporação do solo foram insignificantes nos dois períodos, para a evaporação da água interceptada foram de 1,2 $\mathrm{mm} \mathrm{dia}^{-1} \mathrm{em}$ fevereiro e desprezível em agosto. 


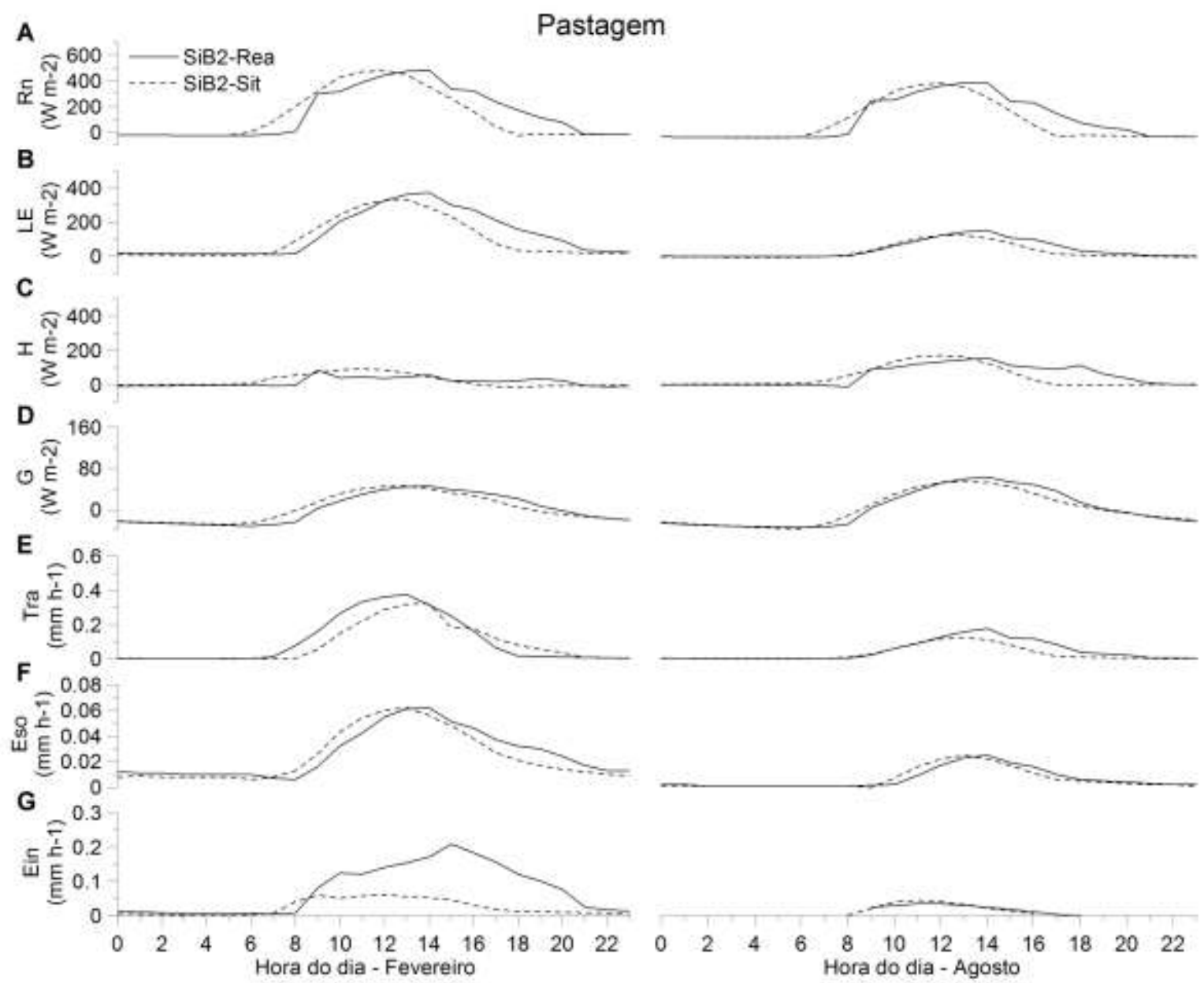

Figura 3.25: Ciclo diurno em fevereiro e agosto dos fluxos de calor e componentes da evapotranspiração para a pastagem. Média horária em 2003 e 2004. A) Saldo de Radiação (Rn) [W m ${ }^{-2}$ ]; B) Fluxo de calor

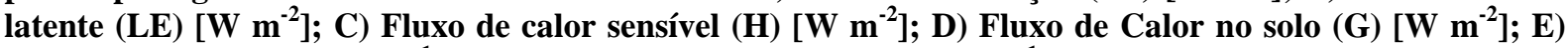
Tranpiração (Tra) $\left[\mathrm{mm} \mathrm{dia}^{-1}\right]$; F) Evaporação do solo (Eso) $\left[\mathrm{mm} \mathrm{dia}^{-1}\right]$; G) Evaporação por interceptação (Ein) $\left[\mathrm{mm} \mathrm{dia}^{-1}\right]$.

É interessante observar como diferenças entre as forçantes fornecidas pela reanálise e pelas torres micrometeorológicas em sítios experimentais foram mais importantes que as encontradas entre os fluxos calculados com os dois conjuntos distintos de dados. Esta análise é uma avaliação das características que o modelo imprime nos seus resultados. Como notamos em discussões anteriores, o modelo não parece tão sensível aos dados observados quanto aos parâmetros fornecidos pelo usuário, assim, a calibração do modelo se torna imprescindível. 


\subsection{CENÁRIOS DE EVAPOTRANSPIRAÇÃO REGIONAL}

\subsubsection{Spin-up da umidade do solo}

Aqui apresentamos os resultados do spin-up da umidade do solo para os oito cenários de cobertura vegetal, simulados durante 60 anos em duas etapas, ambas com 30 anos de simulação. Os últimos 30 anos foram inicializados com o estado final dos primeiros 30 anos.

As duas etapas não diferem muito no caso da cana (Figura 3.26) e da pastagem (Figura 3.30). A depleção da umidade manifesta-se recorrentemente até $\sim 60 \mathrm{~cm}$ devido à profundidade rasa das raízes, havendo um secamento dominante em $\sim 50 \mathrm{~cm}$ de profundidade. Os picos de Rs acompanham os máximos de chuva, enquanto os valores de Rsb têm comportamento parecido com a umidade na última camada, e permaneceram próximos de zero nas duas etapas do spin-up da cana.
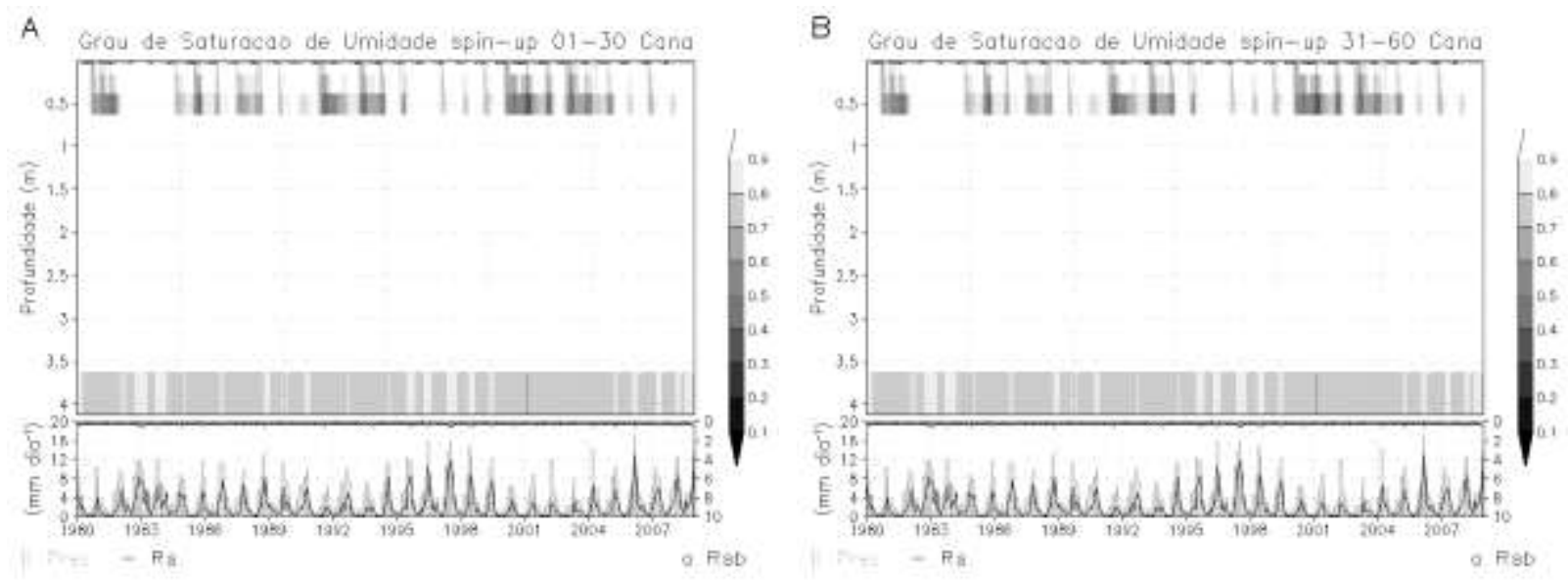

Figura 3.26: Média mensal no domínio do Grau de Saturação de Umidade (W) [adim], escoamento superficial (Rs) $\left[\mathrm{mm} \mathrm{dia}^{-1}\right]$ e escoamento sub-superficial (Rsb) $\left[\mathrm{mm}\right.$ dia $\left.^{-1}\right]$ para a cana-de-açúcar, no período de 1980 a 2009. A) primeira etapa do spin-up; B) segunda etapa do spin-up.

Para o cerrado (Figura 3.27) a extração de umidade ocorreu em camadas mais profundas do solo, até $\sim 5,5 \mathrm{~m}$, assim como nos outros padrões florestais (extração até $\sim 10 \mathrm{~m}$ no eucalipto, Figura 3.28, e até $\sim 13 \mathrm{~m}$ na floresta atlântica, Figura 3.29) devido à grande profundidade das raízes. Os valores de Rs estiveram mais baixos que os reportados para a cana-de-açúcar, não ultrapassando o valor de $4 \mathrm{~mm} \mathrm{dia}^{-1}$, em compensação Rsb esteve maior, passando de $4 \mathrm{~mm} \mathrm{dia}^{-1}$ nos casos em que o grau de saturação de umidade na última camada esteve superior a 0,9. Não se observaram diferenças significativas entre as duas etapas do 
spin-up, por isso o intervalo de 60 anos para a estabilização da umidade no solo foi mais que suficiente.
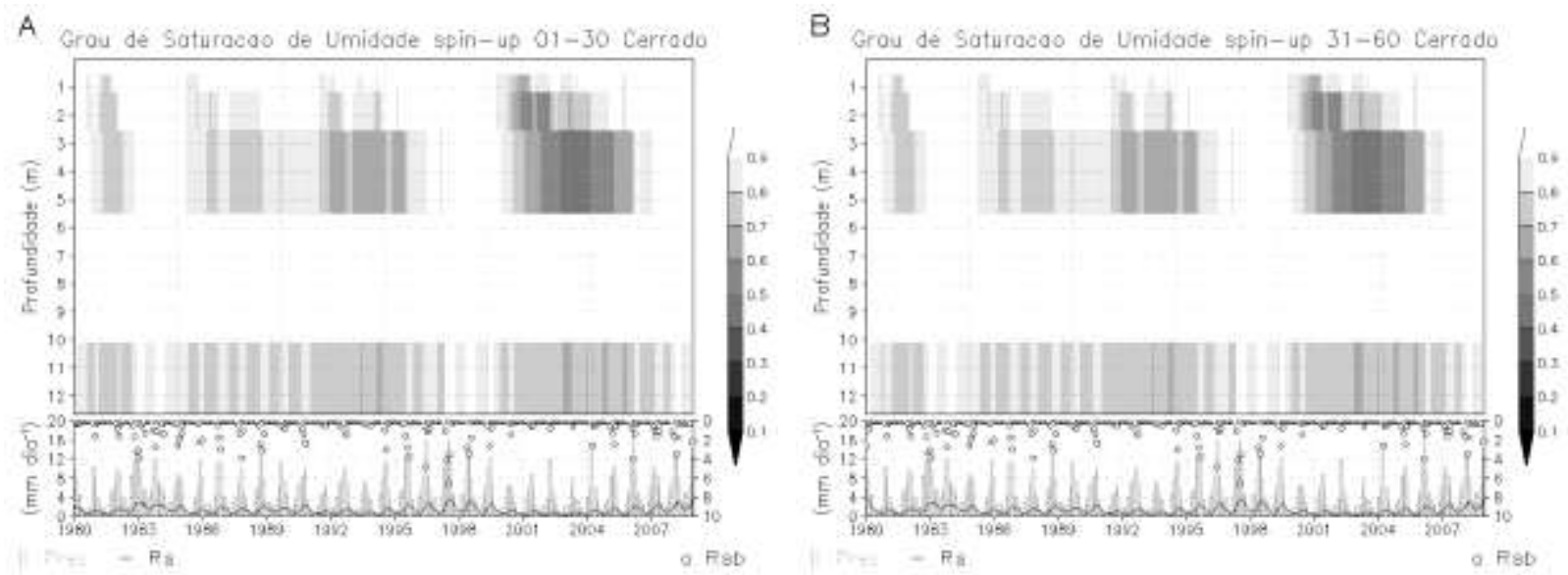

Figura 3.27: Média mensal no domínio do Grau de Saturação de Umidade (W) [adim], escoamento superficial (Rs) $\left[\mathrm{mm} \mathrm{dia}^{-1}\right]$ e escoamento sub-superficial $(\mathrm{Rsb})\left[\mathrm{mm} \mathrm{dia}{ }^{-1}\right]$ para o cerrado, no período de 1980 a 2009. A) primeira etapa do spin-up; B) segunda etapa do spin-up.

O período de 60 anos também foi suficiente para o spin-up no eucalipto (Figura 3.28). Este ecossistema é muito eficiente na extração de água nas camadas de raízes para a transpiração, além da porção perdida por interceptação no dossel, por isso o ressecamento do solo a valores de 0,4 entre 4 e $10 \mathrm{~m}$ de profundidade. Ambos os fluxos de água no solo, Rs e Rsb, tiveram valores baixos, por volta de $1 \mathrm{~mm} \mathrm{dia}^{-1}$.
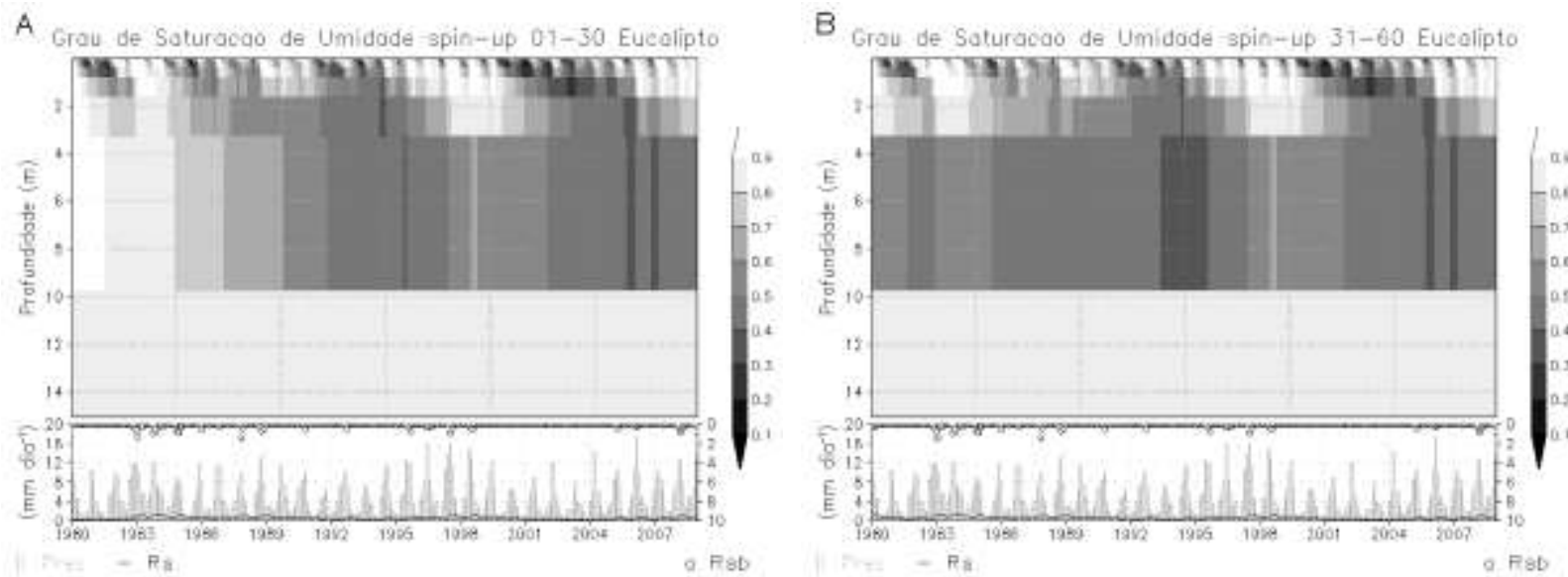

Figura 3.28: Média mensal no domínio do Grau de Saturação de Umidade (W) [adim], escoamento superficial (Rs) $\left[\mathrm{mm} \mathrm{dia}^{-1}\right]$ e escoamento sub-superficial (Rsb) $\left[\mathrm{mm} \mathrm{dia}^{-1}\right]$ para o eucalipto, no período de 1980 a 2009. A) primeira etapa do spin-up; B) segunda etapa do spin-up.

Os padrões observados para o eucalipto se repetem na análise da umidade no solo para a floresta atlântica (Figura 3.29), isso se deve ao fato de os conjuntos de parâmetros utilizados 
serem parecidos para ambos os casos. Para a floresta, os valores de Rs também não ultrapassaram $1 \mathrm{~mm} \mathrm{dia}^{-1}$, mas os de Rsb chegaram a $3 \mathrm{~mm} \mathrm{dia}^{-1}$ nos meses mais chuvosos.
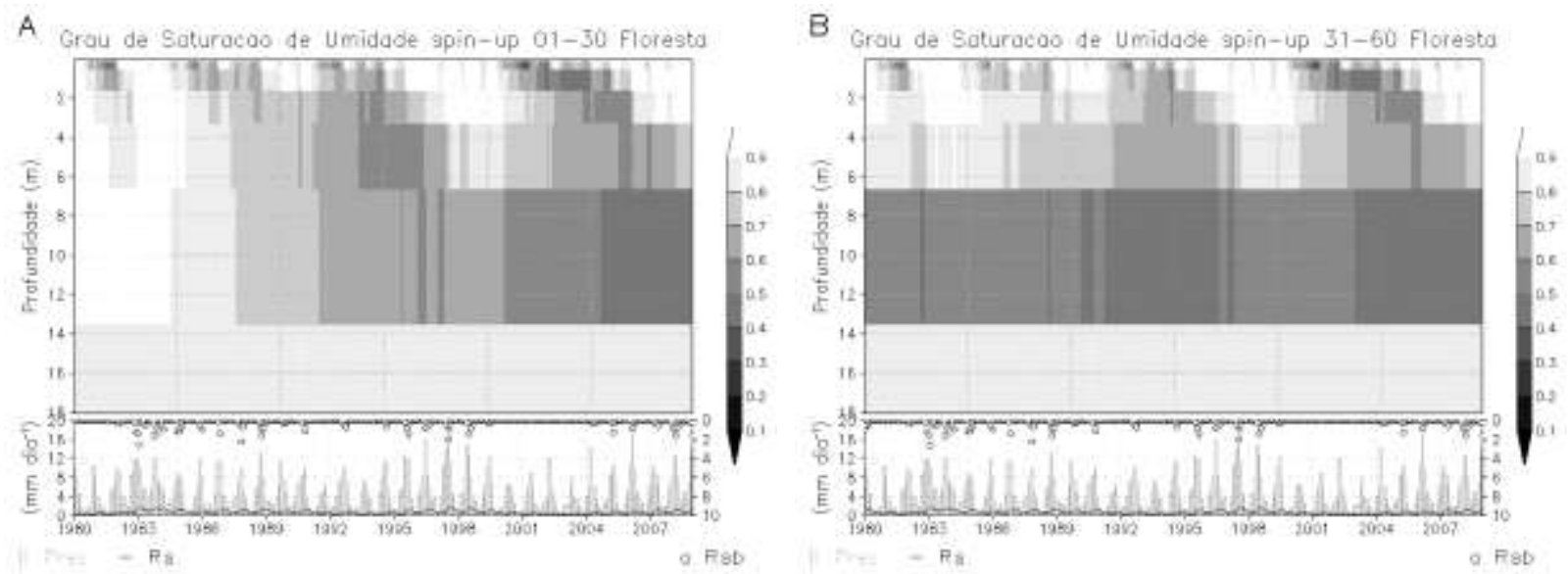

Figura 3.29: Média mensal no domínio do Grau de Saturação de Umidade (W) [adim], escoamento superficial (Rs) $\left[\mathrm{mm} \mathrm{dia}^{-1}\right]$ e escoamento sub-superficial (Rsb) $\left[\mathrm{mm} \mathrm{dia}{ }^{-1}\right]$ para a floresta, no período de 1980 a 2009. A) primeira etapa do spin-up; B) segunda etapa do spin-up.

A depleção para a pastagem (Figura 3.30), conforme discutido para a cana-de-açúcar, ocorre em camadas mais rasas por conta da distribuição das raízes. Também neste caso não houve diferença significativa entre a primeira e a segunda simulação.
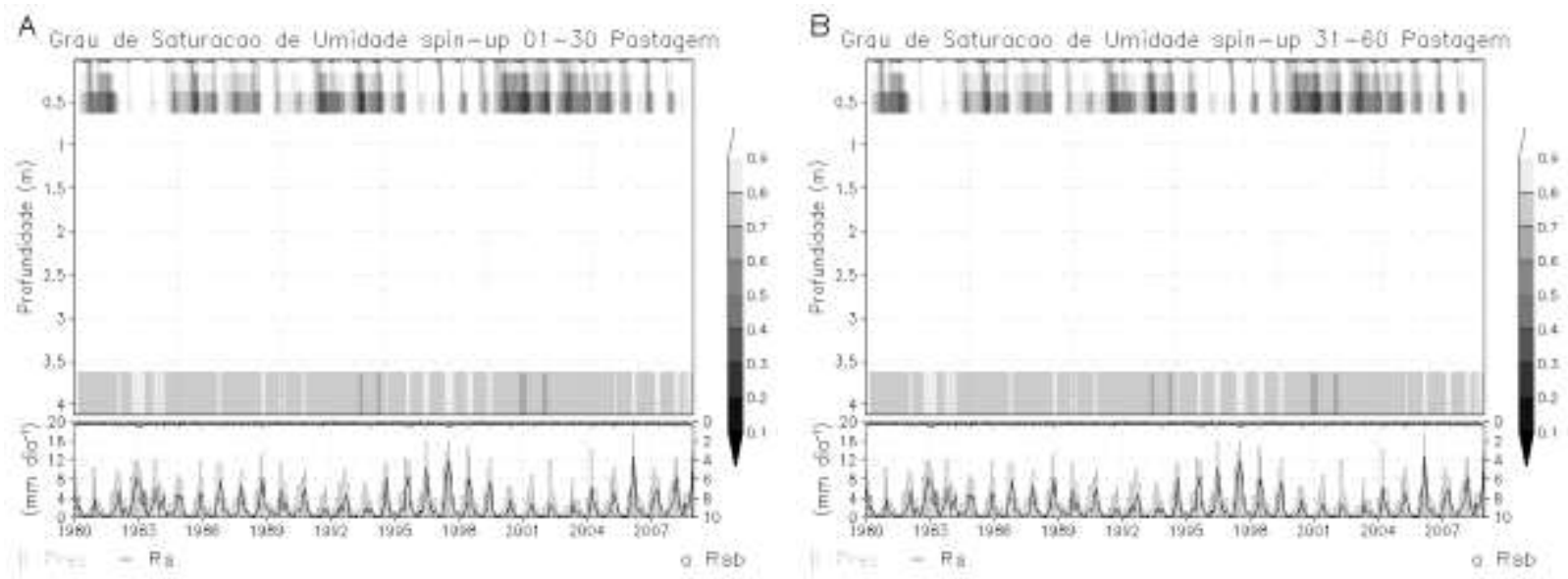

Figura 3.30: Média mensal no domínio do Grau de Saturação de Umidade (W) [adim], escoamento superficial (Rs) $\left[\mathrm{mm} \mathrm{dia}^{-1}\right]$ e escoamento sub-superficial $(\mathrm{Rsb})\left[\mathrm{mm} \mathrm{dia}{ }^{-1}\right]$ para a pastagem, no período de 1980 a 2009. A) primeira etapa do spin-up; B) segunda etapa do spin-up.

O grau de saturação de umidade para área urbana esteve acima de 0,9 para todo o período, em quase todas as camadas. Isto pelo artifício utilizado para reduzir os valores da ETR calculada no modelo, onde aumentamos o valor prescrito de resistência no solo. Isto se 
refletiu nos valores de Rsb, já que a água disponível não retornou como transpiração, pela extração das raízes, ou como evaporação do solo.
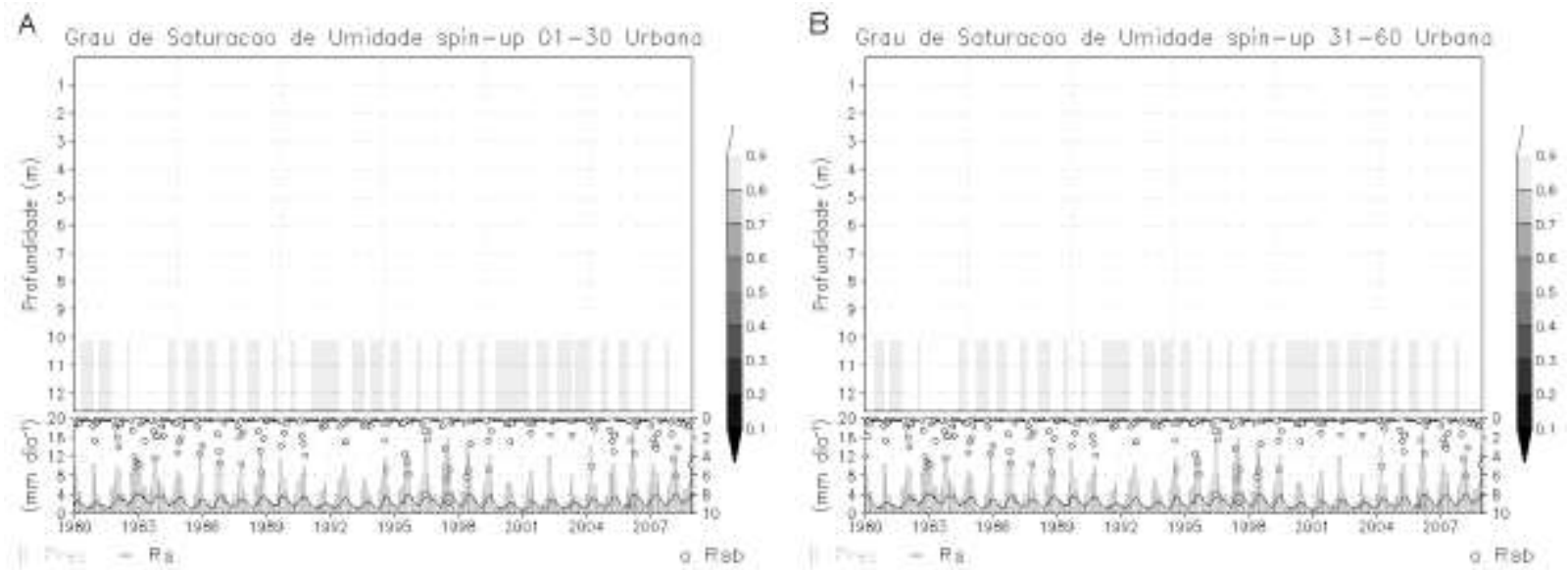

Figura 3.31: Média mensal no domínio do Grau de Saturação de Umidade (W) [adim], escoamento superficial (Rs) $\left[\mathrm{mm} \mathrm{dia}^{-1}\right]$ e escoamento sub-superficial $(\mathrm{Rsb})\left[\mathrm{mm} \mathrm{dia}^{-1}\right]$ para a área urbana, no período de 1980 a 2009. A) primeira etapa do spin-up; B) segunda etapa do spin-up.

As simulações do cenário de vegetação atual (Figura 3.32) são semelhantes às da pastagem, devido à predominância desta cobertura. Da mesma forma, a simulação do cenário de vegetação nativa (Figura 3.33) foi semelhante à da floresta atlântica.
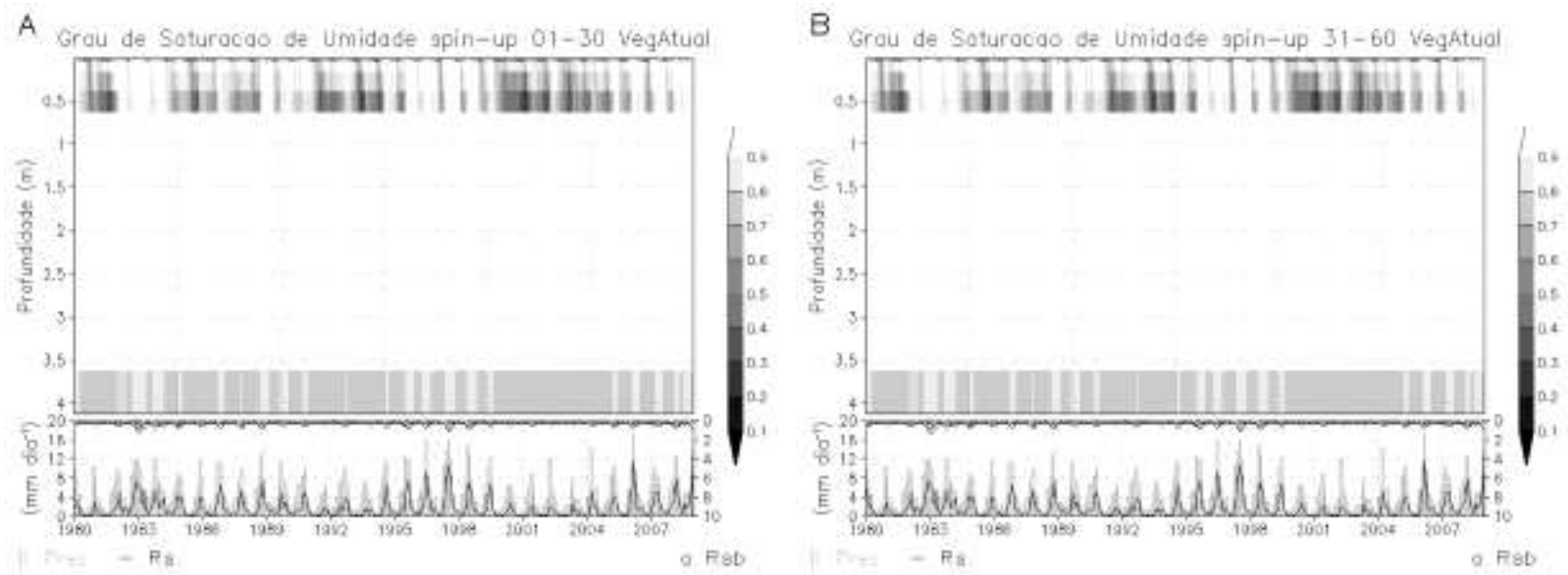

Figura 3.32: Média mensal no domínio do Grau de Saturação de Umidade (W) [adim], escoamento superficial $(\mathbf{R s})\left[\mathrm{mm} \mathrm{dia}^{-1}\right]$ e escoamento sub-superficial $(\mathbf{R s b})\left[\mathrm{mm} \mathrm{dia}^{-1}\right]$ para a vegetação atual, no período de 1980 a 2009. A) primeira etapa do spin-up; B) segunda etapa do spin-up. 

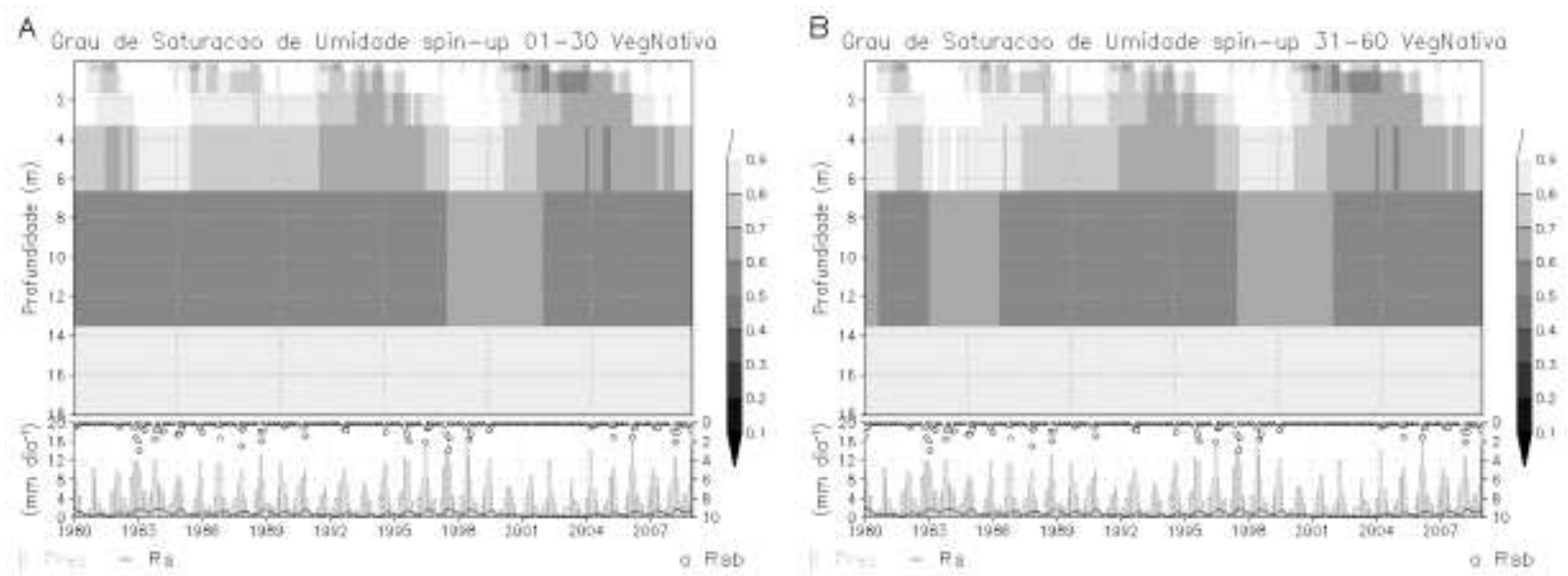

Figura 3.33: Média mensal no domínio do Grau de Saturação de Umidade (W) [adim], escoamento superficial (Rs) $\left[\mathrm{mm} \mathrm{dia}{ }^{-1}\right]$ e escoamento sub-superficial (Rsb) $\left[\mathrm{mm} \mathrm{dia}^{-1}\right]$ para a vegetação nativa, no período de 1980 a 2009. A) primeira etapa do spin-up; B) segunda etapa do spin-up.

As simulações finais dos 30 anos, inicializadas pelos produtos do spin-up estão ilustradas na Figura 3.34, para todos os cenários simulados.

Em todos os casos os perfis finais de W, Rs e Rsb praticamente não diferiram dos calculados para a última etapa do spin-up, indicando que a estabilização pretendida foi alcançada com sucesso pelo o processo escolhido.
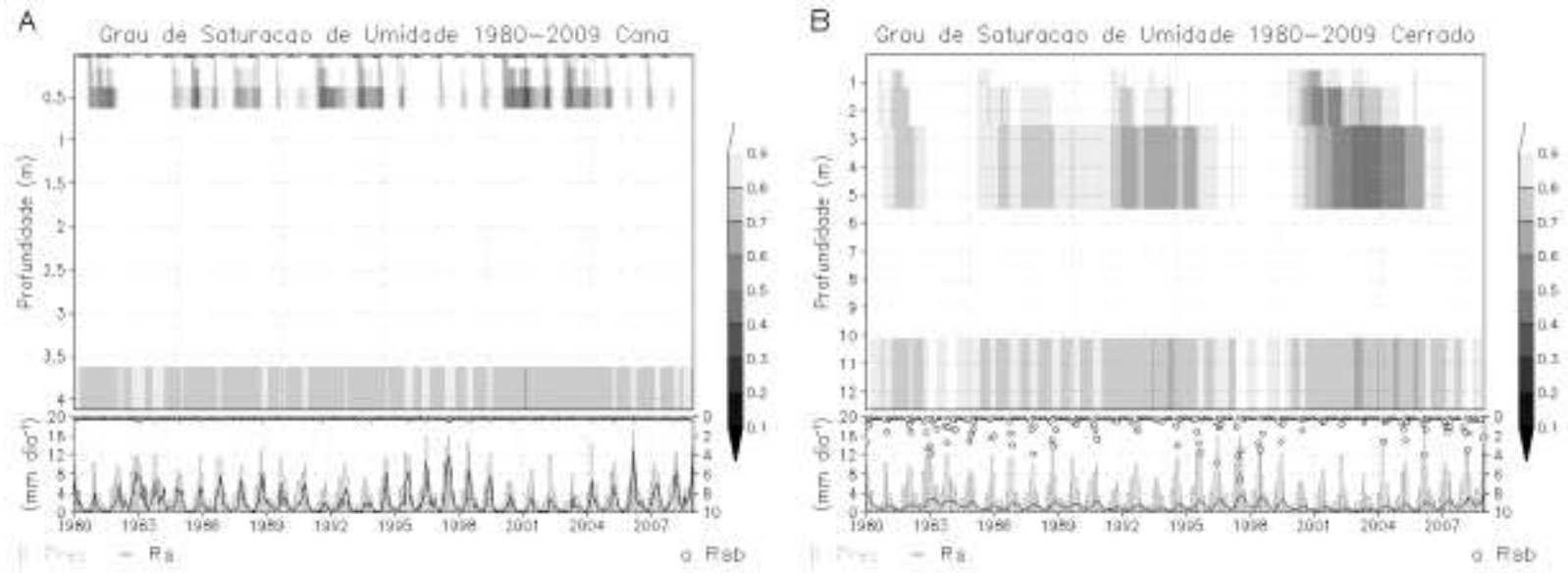
C

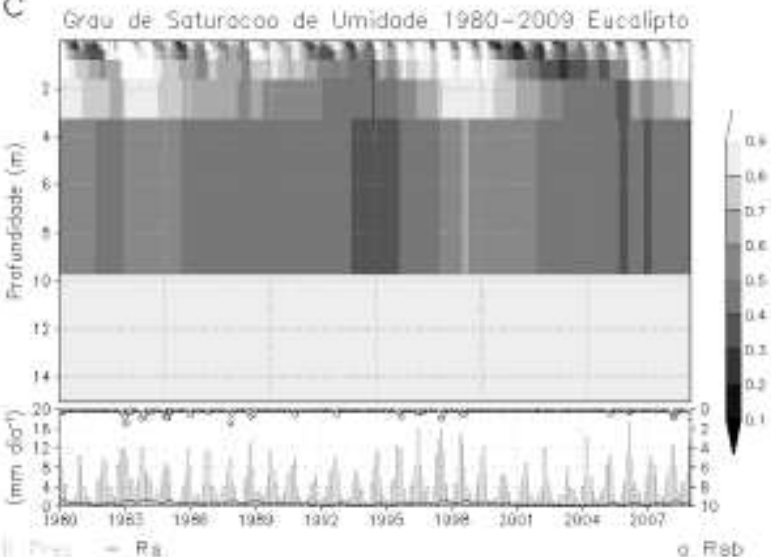

E

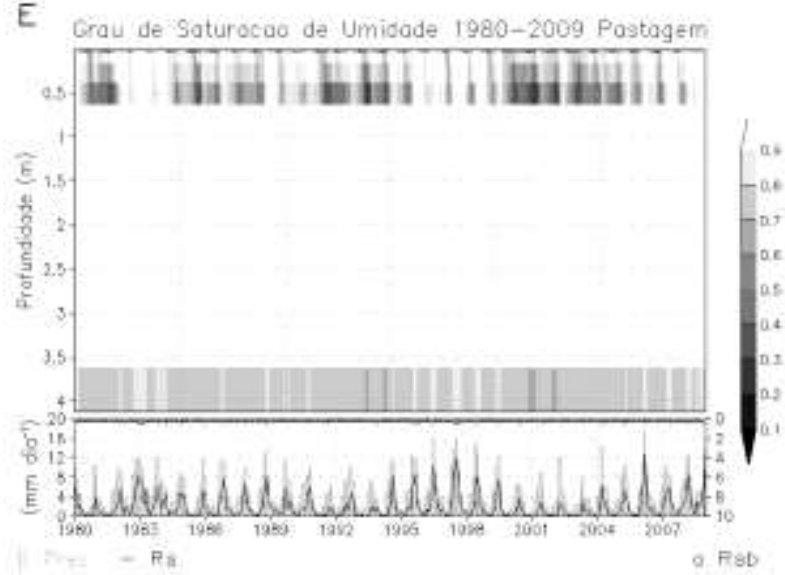

G

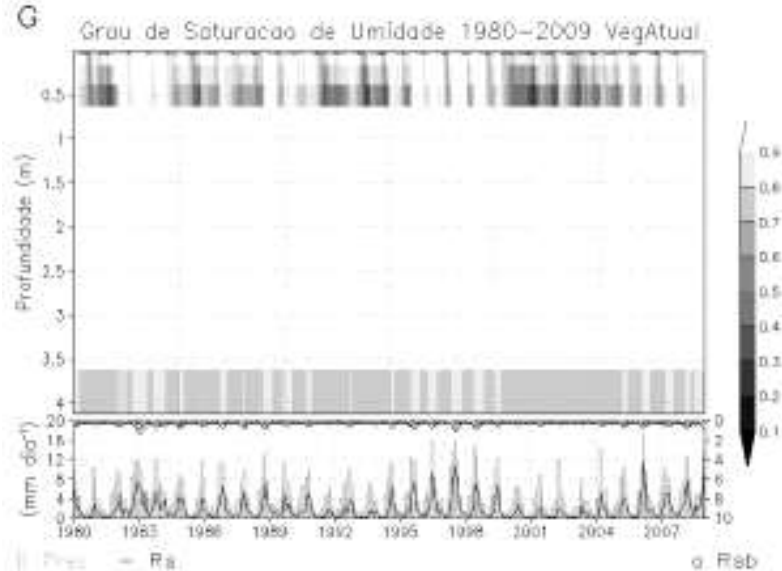

D

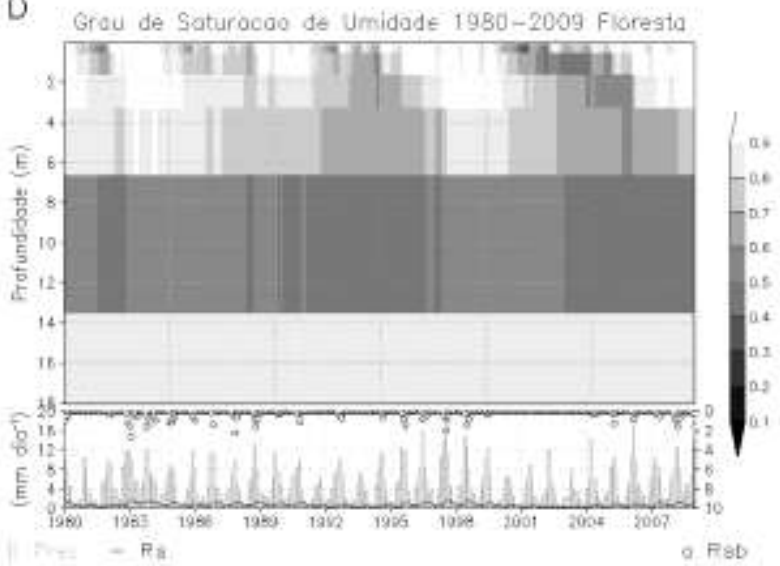

$\mathrm{F}$

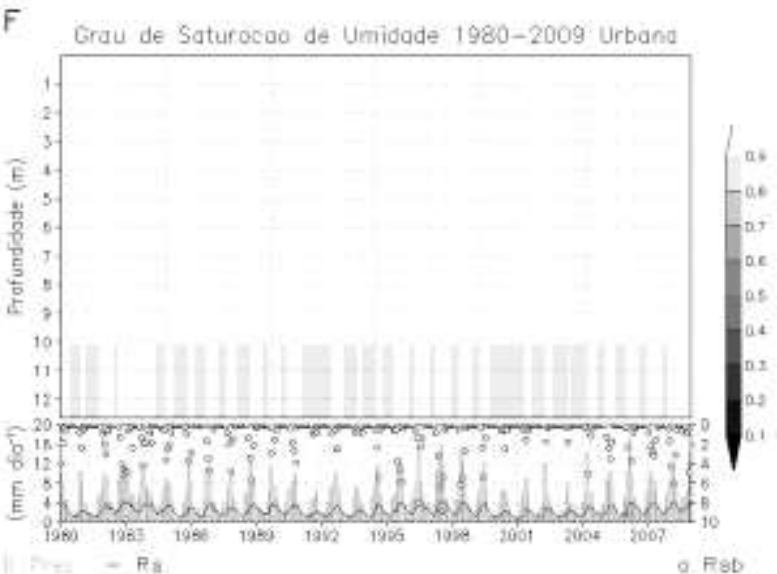

H

H Grau de Saturacoo de Umidode 1980-2009 Veonfativa

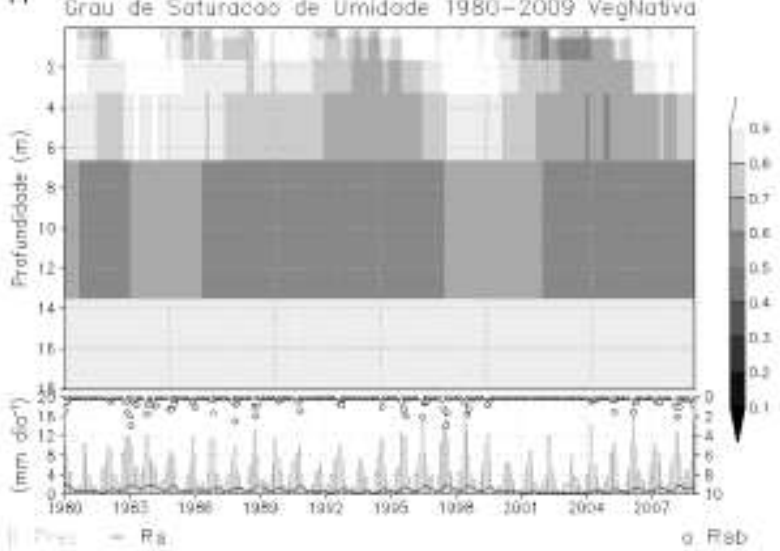

Figura 3.34: Grau de Saturação de Umidade (W) [adim], escoamento superficial (Rs) $\left[\mathrm{mm}\right.$ diaa $\left.^{-1}\right]$ e escoamento sub-superficial (Rsb) $\left[\mathrm{mm} \mathrm{dia}^{-1}\right]$ Média mensal no domínio entre 1980-2009. A) cana-deaçúcar; B) cerrado; C) eucalipto; D) floresta atlântica; E) pastagem; F) área urbana; G) vegetação atual; H) vegetação nativa. 


\subsubsection{Campos de evapotranspiração}

Serão discutidos aqui os campos médios da ETR calculada, para os 8 diferentes cenários de cobertura de superfície.

O cenário de cana-de-açúcar (Figura 3.35) mostra mínimos no verão situados ao longo das Serras do Mar e da Mantiqueira, padrão este que se assemelha muito com o campo da irradiância solar e da pressão de vapor d'água no verão, com médias de $\sim 3,5 \mathrm{~mm} \mathrm{dia}^{-1}$, e máximos deslocados homogeneamente no centro e noroeste do estado com médias de 4 a 4,5 $\mathrm{mm} \mathrm{dia}^{-1}$. No inverno a ETR é de forma geral homogênea espacialmente, ao redor de $\sim 1,5$ $\mathrm{mm} \mathrm{dia}^{-1}$, e de forma detalhada um pouco menor na faixa norte do estado, de $\sim 1 \mathrm{~mm} \mathrm{dia}^{-1}$.

A

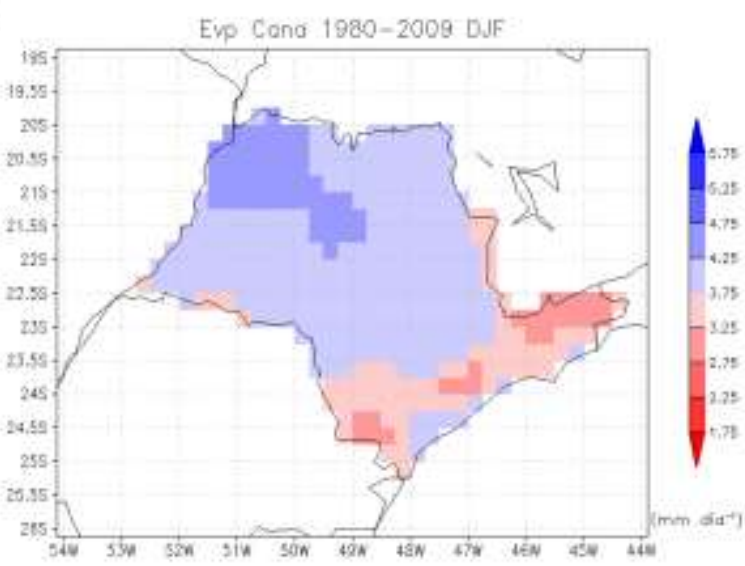

B

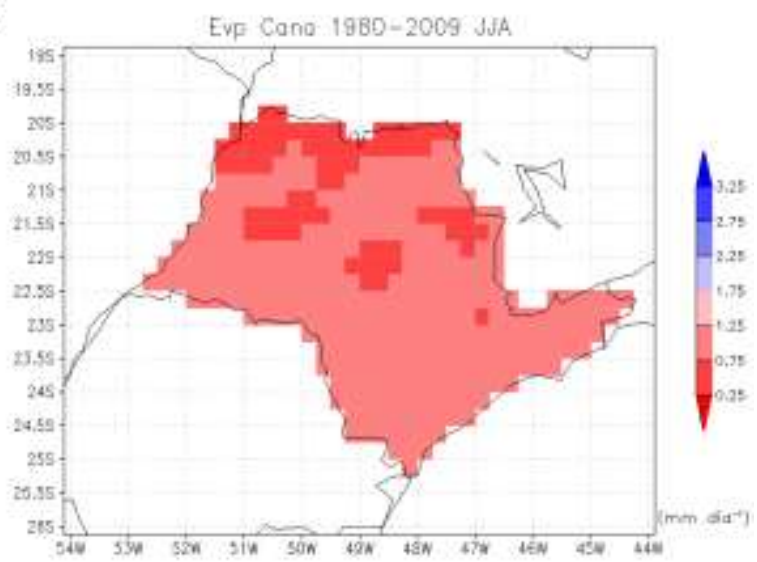

Figura 3.35: Evapotranspiração média sazonal entre 1980 e 2009 para a cana-de-açúcar. A) trimestre Dezembro, Janeiro e Fevereiro; B) trimestre Junho, Julho e Agosto. [mm dia-1]

Para o cerrado (Figura 3.36) a distribuição regional da ETR é semelhante à do cenário da cana-de-açúcar, com máximos no centro e noroeste no Verão, de $\sim 4,5 \mathrm{~mm} \mathrm{dia}^{-1}$, e no inverno as médias são igualmente homogêneas de $\sim 1,5 \mathrm{~mm} \mathrm{dia}^{-1}$. 

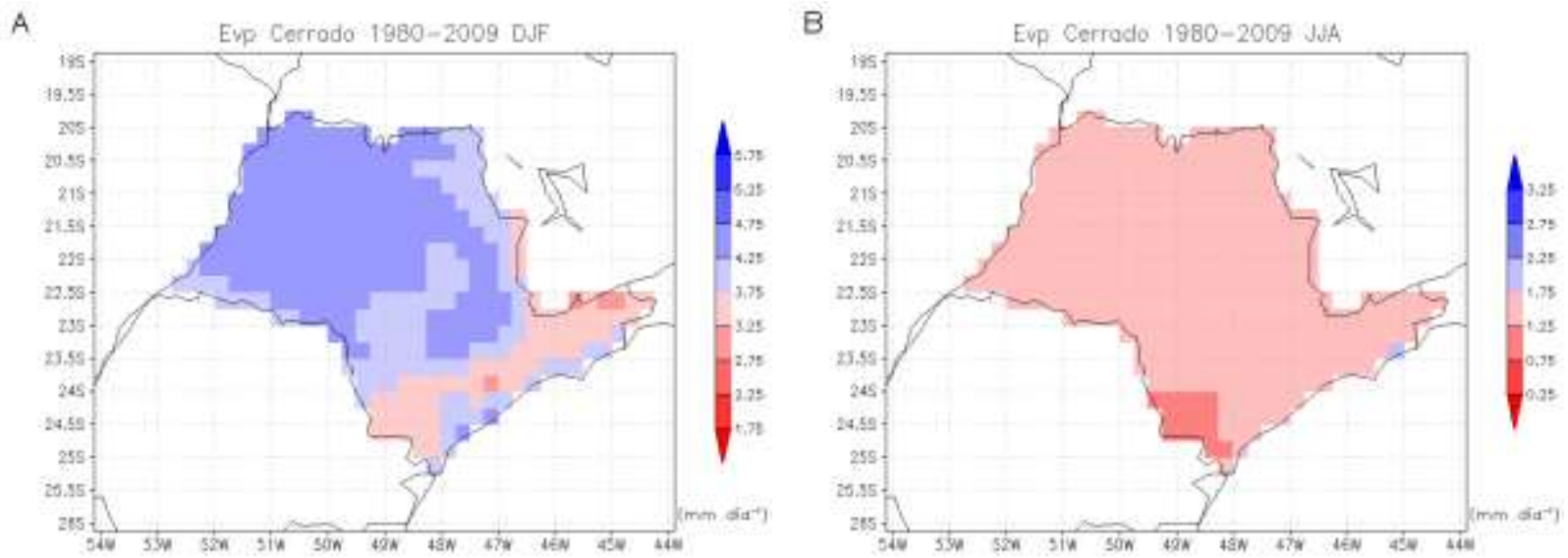

Figura 3.36: Evapotranspiração média sazonal entre 1980 e 2009 para o cerrado. A) trimestre Dezembro, Janeiro e Fevereiro; B) trimestre Junho, Julho e Agosto. [mm dia-1]

Para o cenário de eucalipto (Figura 3.37) foram obtidos os máximos extremos com relação aos outros cenários, com dominância de áreas entre $\sim 4$ e $5,5 \mathrm{~mm} \mathrm{dia}{ }^{-1}$ bem distribuídas regionalmente no verão. No trimestre seco a ETR variou entre $\sim 1,5$ a $3 \mathrm{~mm} \mathrm{dia}{ }^{-1}$, onde curiosamente notou-se uma distribuição regional semelhante à da precipitação no trimestre chuvoso, como por exemplo os máximos na serra de São Carlos, na Serra do mar, e os mínimos entre estas regiões, o que sugere um controle de memória da umidade do solo em sustentar a ETR durante a estiagem. Além deste fator, a maior precipitação induz maiores perdas por interceptação em ambientes florestais, que podem também responder parcialmente pelos máximos.

A

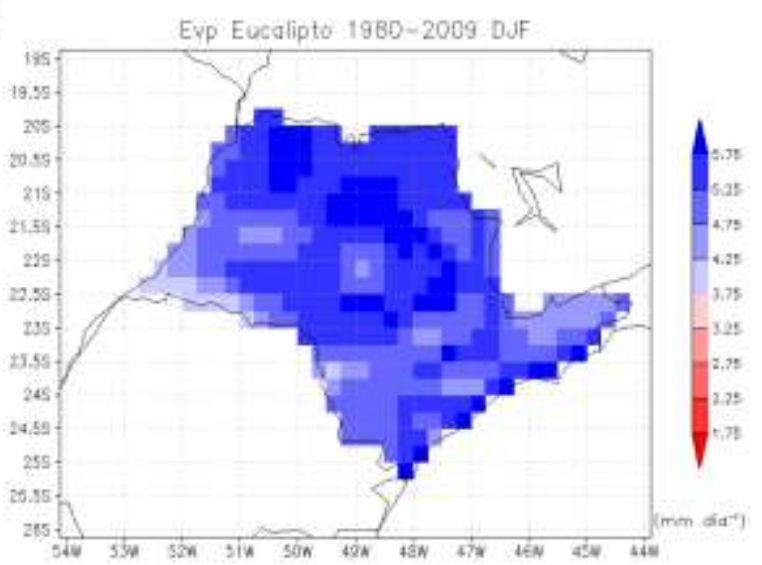

B

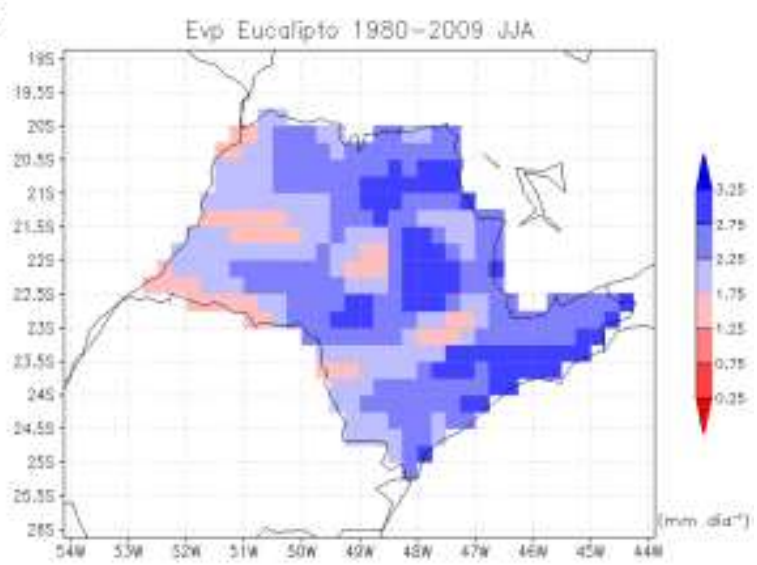

Figura 3.37: Evapotranspiração média sazonal entre 1980 e 2009 para o eucalipto. A) trimestre Dezembro, Janeiro e Fevereiro; B) trimestre Junho, Julho e Agosto. [mm dia-1]

O cenário de ETR da floresta de mata atlântica (Figura 3.38) sugere uma grande semelhança de distribuição regional com o cenário do eucalipto, no verão e no inverno. As 
médias no cenário da floresta são aparentemente próximas às do eucalipto no verão, e levemente superiores no trimestre seco, principalmente em setores do interior do estado onde fica sempre acima de $2 \mathrm{~mm} \mathrm{dia}^{-1}$. De forma geral a grande semelhança daqueles reforça como os dois ecossistemas foram modelados com uma alta eficiência de padrões florestais para extrair água de camadas profundas do solo, utilizando água armazenada no solo para a transpiração.

A

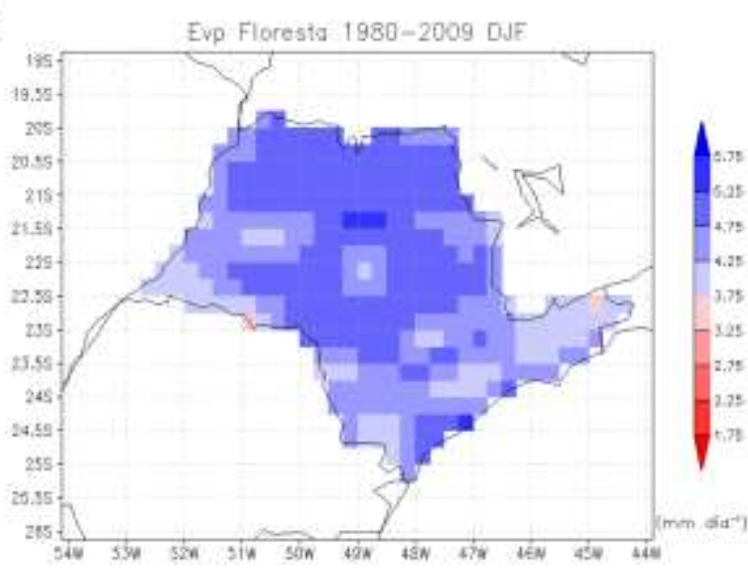

B

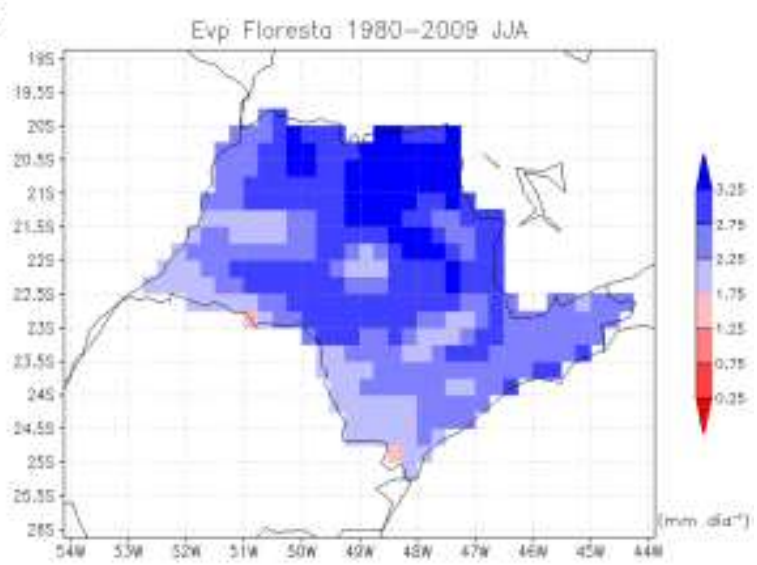

Figura 3.38: Evapotranspiração média sazonal entre 1980 e 2009 para a floresta atlântica. A) trimestre Dezembro, Janeiro e Fevereiro; B) trimestre Junho, Julho e Agosto. [mm dia-1]

Os campos de ETR no cenário da pastagem (Figura 3.39) mostram notável semelhança com os cenários da cana-de-açúcar na distribuição regional, principalmente nos aspectos de diferenças sazonais, onde a variação espacial de irradiância solar e pressão de vapor d’água são semelhantes. A ETR da pastagem no inverno mostrou-se levemente superior à cana-deaçúcar, com mínimos de $\sim 1 \mathrm{~mm} \operatorname{dia}^{-1}$. As médias foram de $\sim 4,5 \mathrm{~mm} \mathrm{dia}^{-1}$ no verão, que reduziram-se na faixa da Serra do Mar e da Mantiqueira para $\sim 3 \mathrm{~mm} \mathrm{dia}^{-1}$.

A

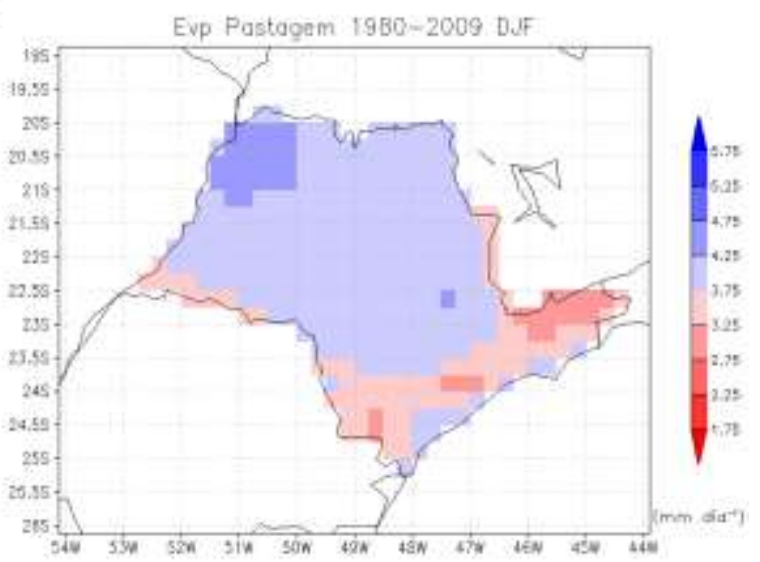

B

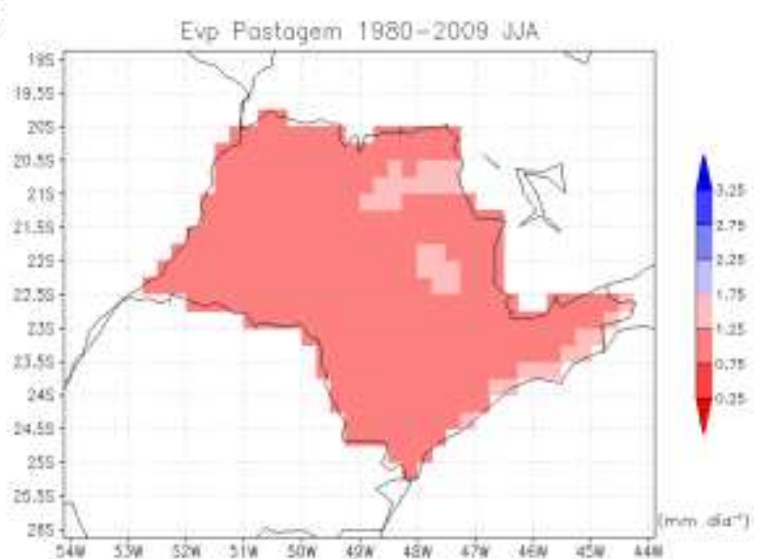

Figura 3.39: Evapotranspiração média sazonal entre 1980 e 2009 para a pastagem. A) trimestre Dezembro, Janeiro e Fevereiro; B) trimestre Junho, Julho e Agosto. [mm dia-1] 
Os resultados da ETR do cenário de urbanização (Figura 3.40) foram os menores dentre todos cenários, como esperado, que variou de 2 a $1,5 \mathrm{~mm} \mathrm{dia}^{-1}$ no verão e se manteve abaixo de $0,25 \mathrm{~mm} \mathrm{dia}^{-1}$ no inverno. Estes padrões foram controlados pela precipitação, pois a fonte dominante de evaporação decorre da perda por interceptação. Nota-se no período chuvoso que os máximos situaram-se no interior do estado, onde os padrões de temperatura foram mais quentes e provavelmente controlaram o processo.
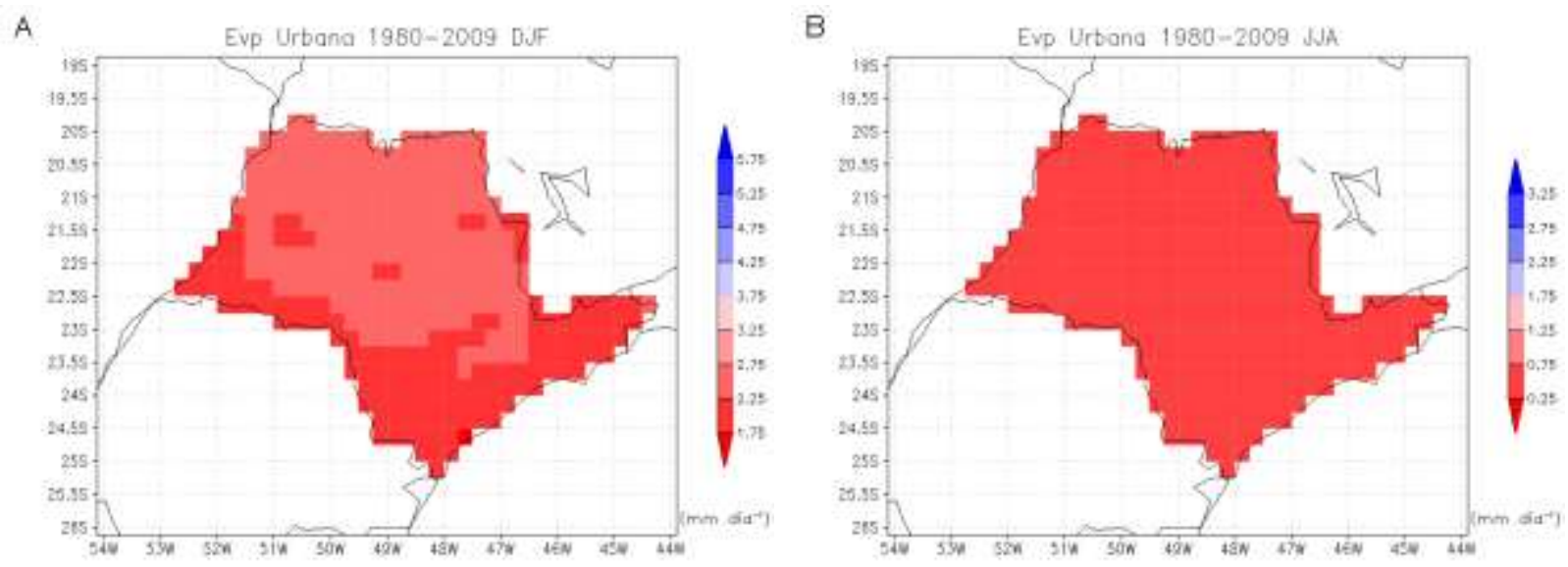

Figura 3.40: Evapotranspiração média sazonal entre 1980 e 2009 para a área urbana. A) trimestre Dezembro, Janeiro e Fevereiro; B) trimestre Junho, Julho e Agosto. [mm dia-1]

Para o cenário da vegetação atual (Figura 3.41) a distribuição espacial da ETR foi bastante controlada pela heterogeneidade do mapa de cobertura vegetal, inclusive na escala sazonal. Pela dominância da cobertura de pastagem no centro, oeste e sudoeste do estado, as médias no verão e no inverno nestes setores situam-se dominantemente em torno de $\sim 4$ e 1 $\mathrm{mm} \mathrm{dia}{ }^{-1}$, respectivamente. Nota-se, todavia, a presença de outros tipos de cobertura. A ocorrência do eucalipto, nos meses secos e úmidos, coincide com os extremos máximos destacados no interior do estado e no vale do Paraíba, e, da mesma forma, a presença de floresta de mata atlântica destaca-se no sul do estado e na faixa do litoral. A região metropolitana de SP também se destaca com valores mínimos. A presença da cana-de-açúcar é também notável, no caso do Inverno, em alguns pontos de mínimos na região de Piracicaba e no oeste do estado. A presença de cerrado também se destaca discretamente, mas é pouco relevante para a média total uma vez que foram apenas 3 células em todo o mapa. 
A

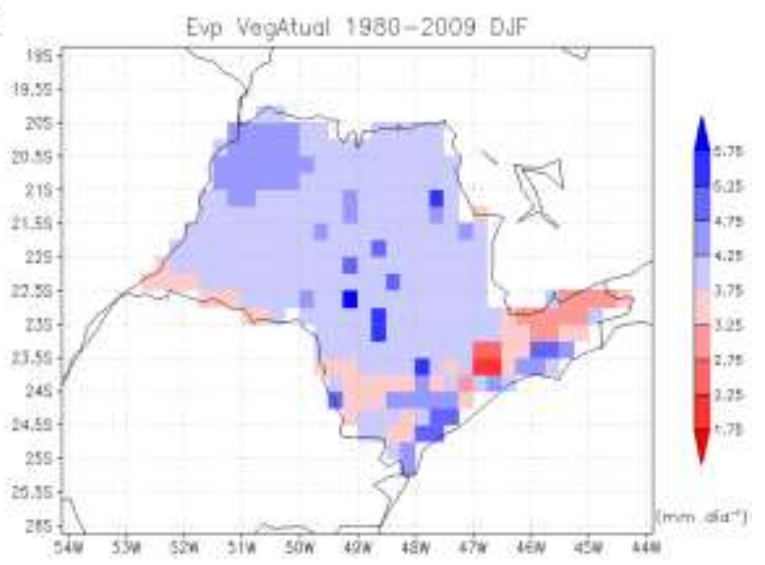

$B$

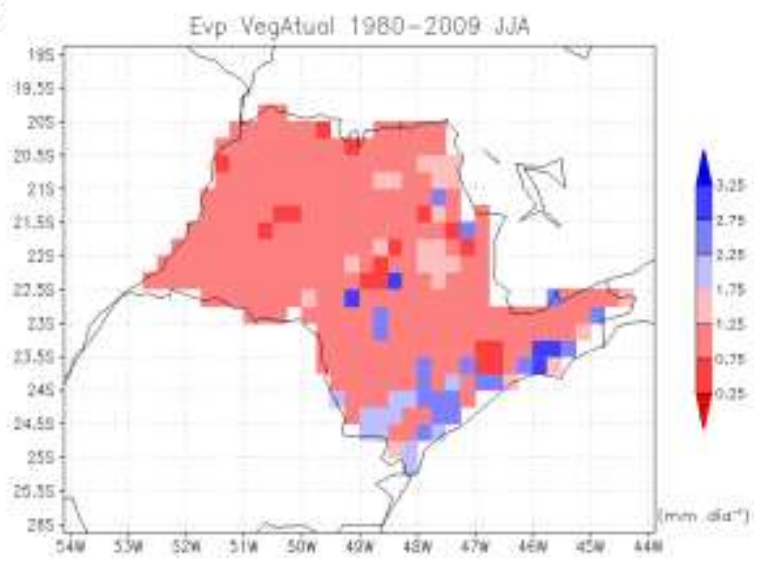

Figura 3.41: Evapotranspiração média sazonal entre 1980 e 2009 para a vegetação atual. A) trimestre Dezembro, Janeiro e Fevereiro; B) trimestre Junho, Julho e Agosto. [mm dia-1]

No cenário da vegetação nativa (Figura 3.42) as diferenças entre as áreas de floresta e de cerrado são aparentemente mais evidentes nos meses secos, quando a restrição hídrica controla a ETR no cerrado, embora a ETR no cerrado tenha sido menor que da floresta também no período chuvoso, o que, portanto, marcam diferenças do tipo de cobertura vegetal em ambas as estações.

A

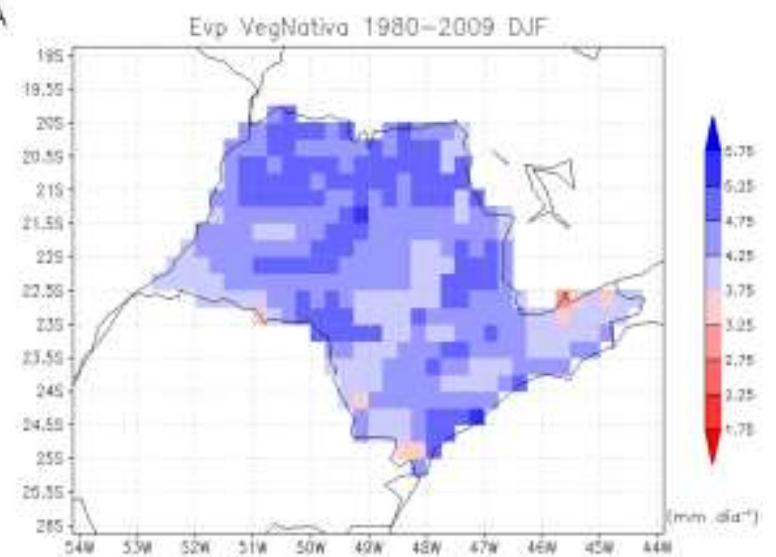

B

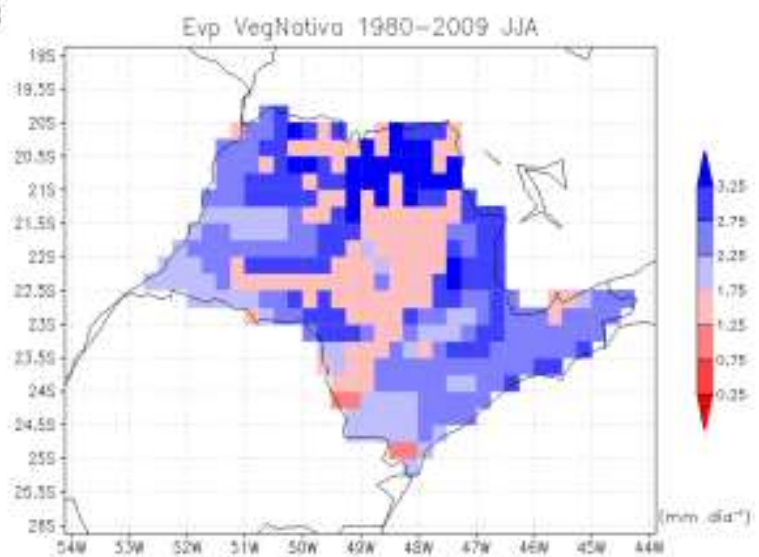

Figura 3.42: Evapotranspiração média sazonal entre 1980 e 2009 para a vegetação nativa. A) trimestre Dezembro, Janeiro e Fevereiro; B) trimestre Junho, Julho e Agosto. [mm dia-1]

O teste-t comparando o cenário de cobertura primitiva do solo com os outros sete casos está apresentado no APÊNDICE D. Foi possível verificar que as séries para a vegetação atual foram estatisticamente diferentes das calculadas para a vegetação nativa, embasando a teoria de que as mudanças no uso da terra respondem com alterações na evapotranspiração local. 


\subsubsection{Médias regionais anuais}

São discutidas aqui as médias anuais do balanço de energia e água nos oito cenários. Nos campos espaciais médios anuais de ETR (Figura 3.43), exceto no cenário de urbanização, os campos mostram-se mais homogêneos nos cenários de menor ETR, ou seja, cana-deaçúcar, pastagem e o cerrado, respectivamente. Os cenários de floresta e eucalipto mostram máximos localizados que se deram em função da oferta de energia solar e da precipitação, como discutido anteriormente. As médias espaciais anuais dos cenários variaram na seguinte ordem decrescente: eucalipto $\left(3,7 \mathrm{~mm} \mathrm{dia}{ }^{-1}\right)$, floresta de mata atlântica $\left(3,5 \mathrm{~mm} \mathrm{dia}^{-1}\right)$, vegetação nativa $\left(3,3 \mathrm{~mm} \mathrm{dia}^{-1}\right)$, cerrado $\left(2,6 \mathrm{~mm} \mathrm{dia}^{-1}\right)$, vegetação atual e pastagem $(2,5 \mathrm{~mm}$ $\left.\operatorname{dia}^{-1}\right)$, cana-de-açúcar $\left(2,3 \mathrm{~mm} \mathrm{dia}^{-1}\right)$ e urbanização $\left(1,2 \mathrm{~mm} \mathrm{dia}^{-1}\right)$.

A

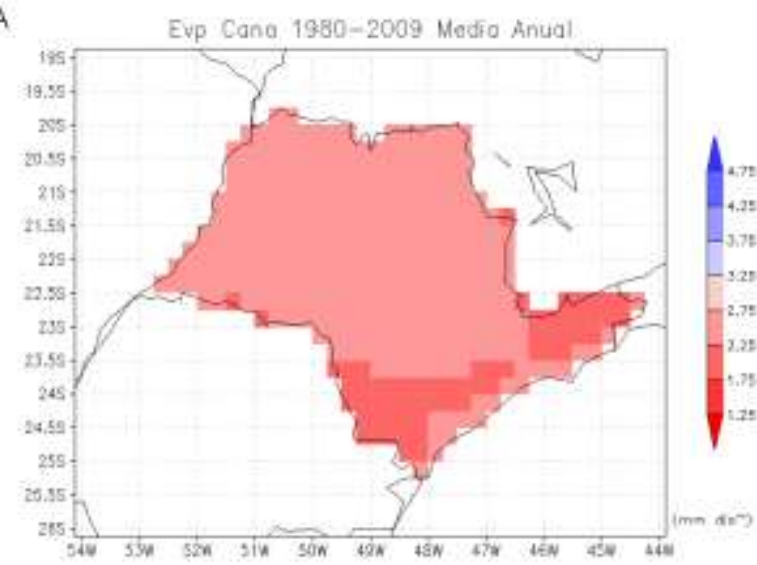

C

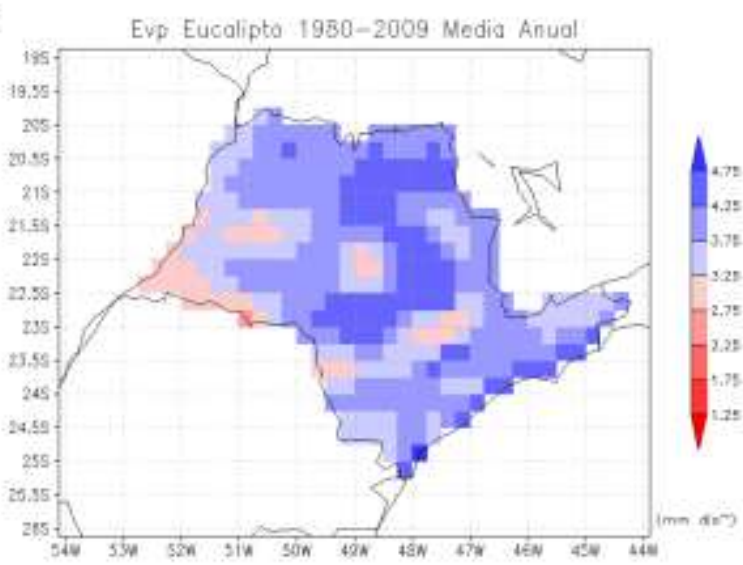

$B$

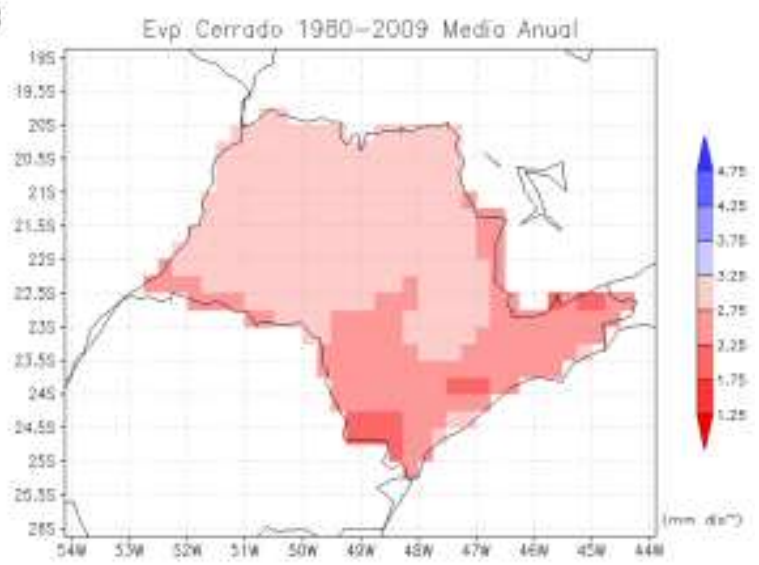

D

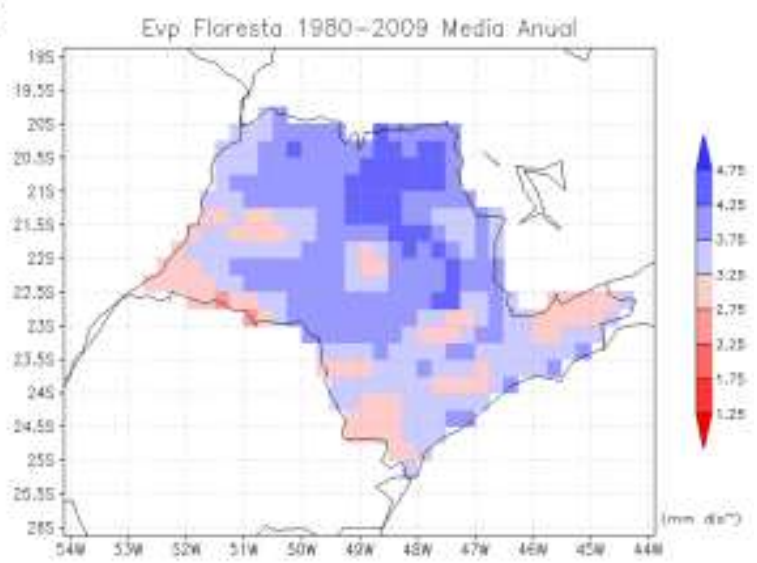


E

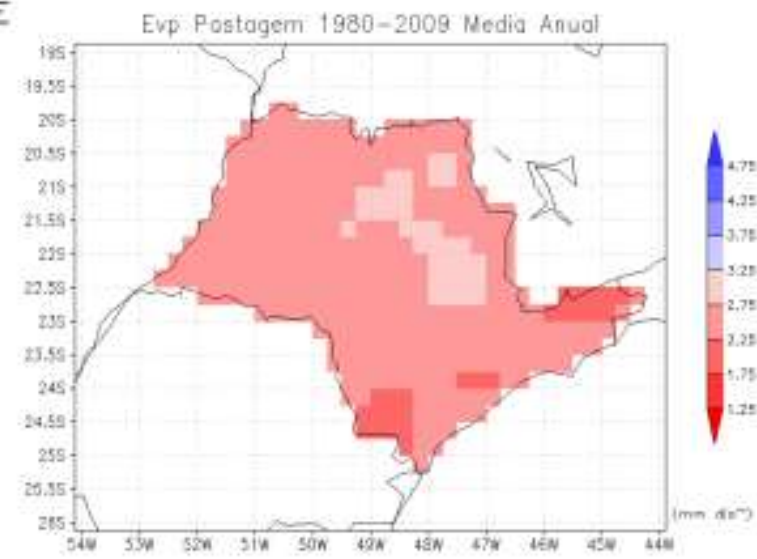

G

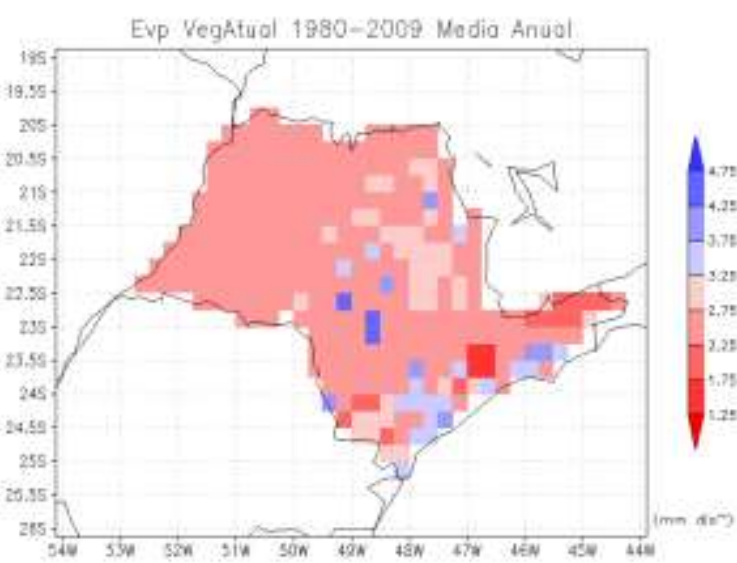

F

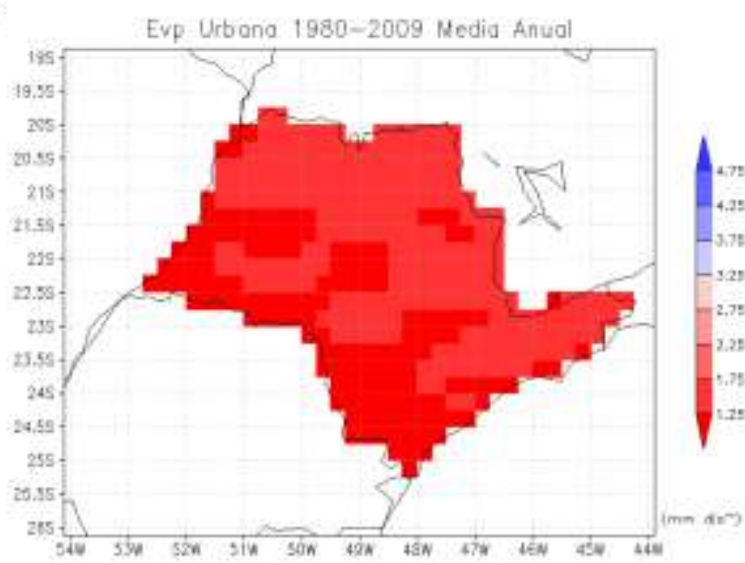

H

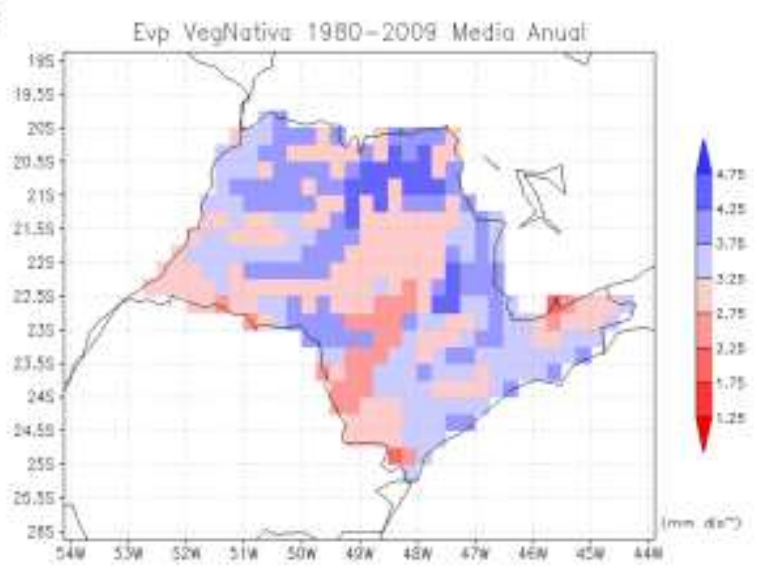

Figura 3.43: Evapotranspiração média anual entre 1980 e 2009 [mm dia $\left.{ }^{-1}\right]$. A) cana-de-açúcar; B) cerrado; C) eucalipto; D) floresta atlântica; E) pastagem; F) área urbana; G) vegetação atual; H) vegetação nativa.

Serão comparadas a seguir as médias anuais dos termos de maior escala do balanço de energia (Rn, H e LE) para os cenários de cobertura homogênea. O cenário de urbanização será justaposto nas figuras seguintes, mas não será comparado com os demais cenários por não ter sido elaborado para este fim. Finalmente, será feita uma comparação entre os cenários de vegetação nativa e vegetação atual, em especial.

Para o saldo de radiação médio anual, Rn, (Figura 3.44), os cenários situam-se em ordem decrescente a partir dos padrões florestais de Floresta Mata Atlântica e Eucalipto (muito próximos e ao redor de $142 \mathrm{~W} \mathrm{~m}^{-2}$ ), seguidos do Cerrado (134 $\mathrm{W} \mathrm{m}^{-2}$ ), Cana (112 W $\left.\mathrm{m}^{-2}\right)$ e Pastagem $\left(104 \mathrm{~W} \mathrm{~m}^{-2}\right)$. 
Rn - 1980-2009 (W m-2)

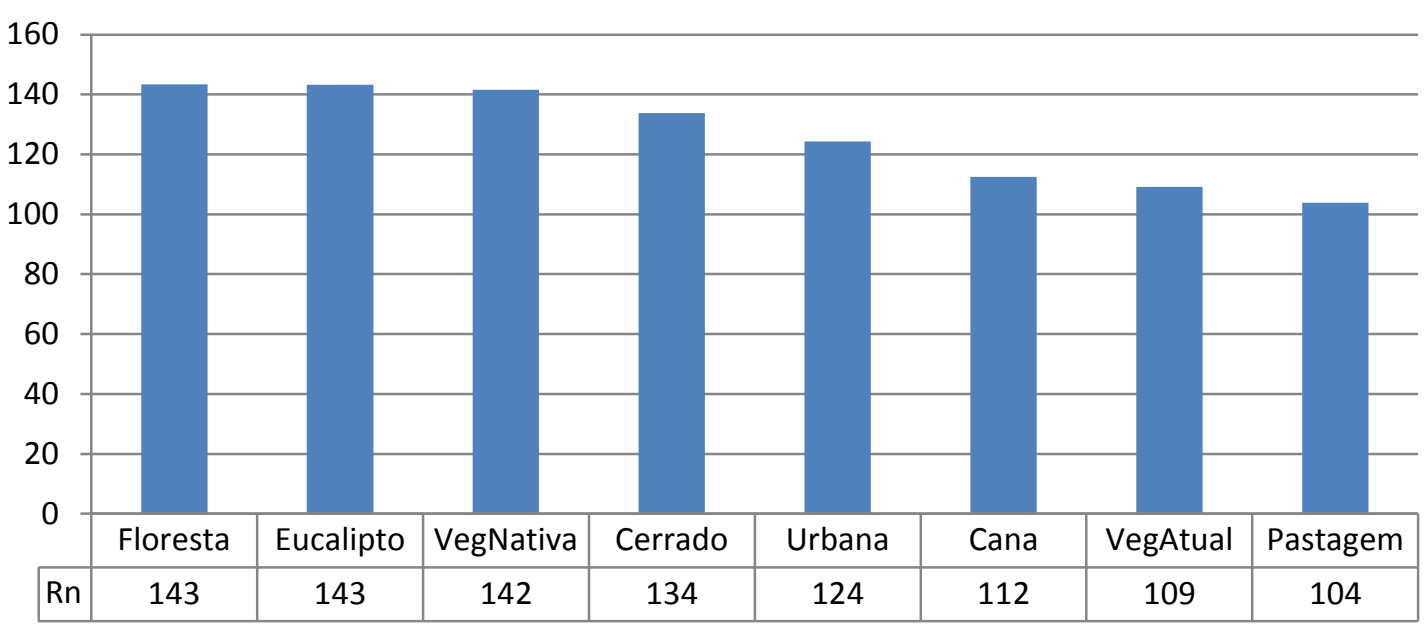

Figura 3.44: Saldo de radiação médio no domínio entre 1980 e 2009. [W m-2]

As médias anuais do fluxo de calor latente, LE, (Figura 3.45) seguem exatamente a mesma ordem de comparação das médias discutidas na Figura 3.43, e em especial destaca-se a ordem decrescente a partir do Eucalipto e Floresta (muito próximos), seguidos do Cerrado, Pastagem e Cana. Há grande semelhança desta ordem com a ordem do saldo de radiação, Rn, mas com algumas diferenças: nos cenários de maior LE, o eucalipto supera significativamente a floresta; a pastagem supera a cana, o que era oposto na ordem de Rn.

\section{LE - 1980-2009 (W m-2)}

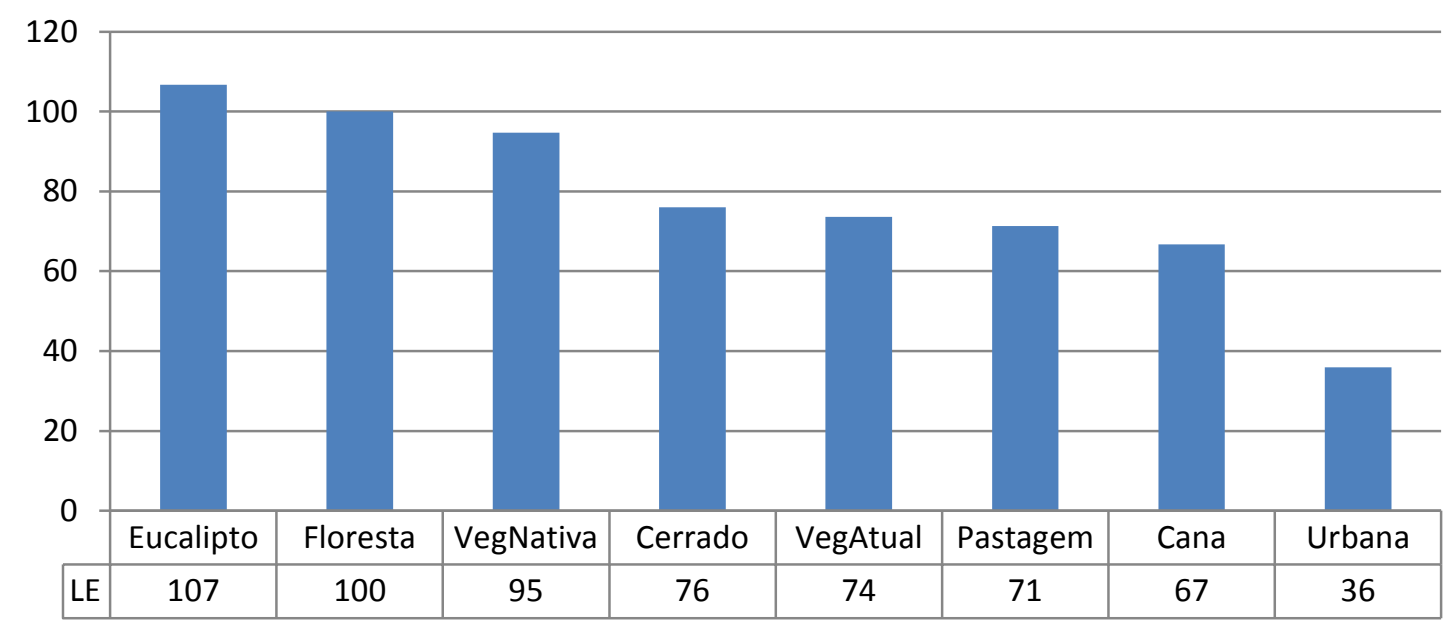

Figura 3.45: Fluxo de calor latente médio no domínio entre 1980 e 2009. [W m-2] 
A média anual do fluxo de calor sensível (H - Figura 3.46) foi maior no cenário de urbanização, o que era esperado. Nos cenários com vegetação homogênea, o cerrado teve o máximo $\mathrm{H}$, seguido da cana-de-açúcar, floresta, eucalipto e pastagem. Esta ordem não é a ordem inversa do termo LE, pois há diferenças de $\mathrm{Rn}$ entre os cenários, e a própria funcionalidade intrínseca da partição de energia de cada um dos ecossistemas, que será discutida a seguir. Entre os extremos da sequência do termo H, na pastagem é 57\% ou 25 $\mathrm{W} \mathrm{m}^{-2}$ menor que no Cerrado, o que é em parte explicado pela diferença do saldo de radiação, que é $30 \mathrm{~W} \mathrm{~m}^{-2}$ menor na pastagem.

\section{H - 1980-2009 (W m-2)}

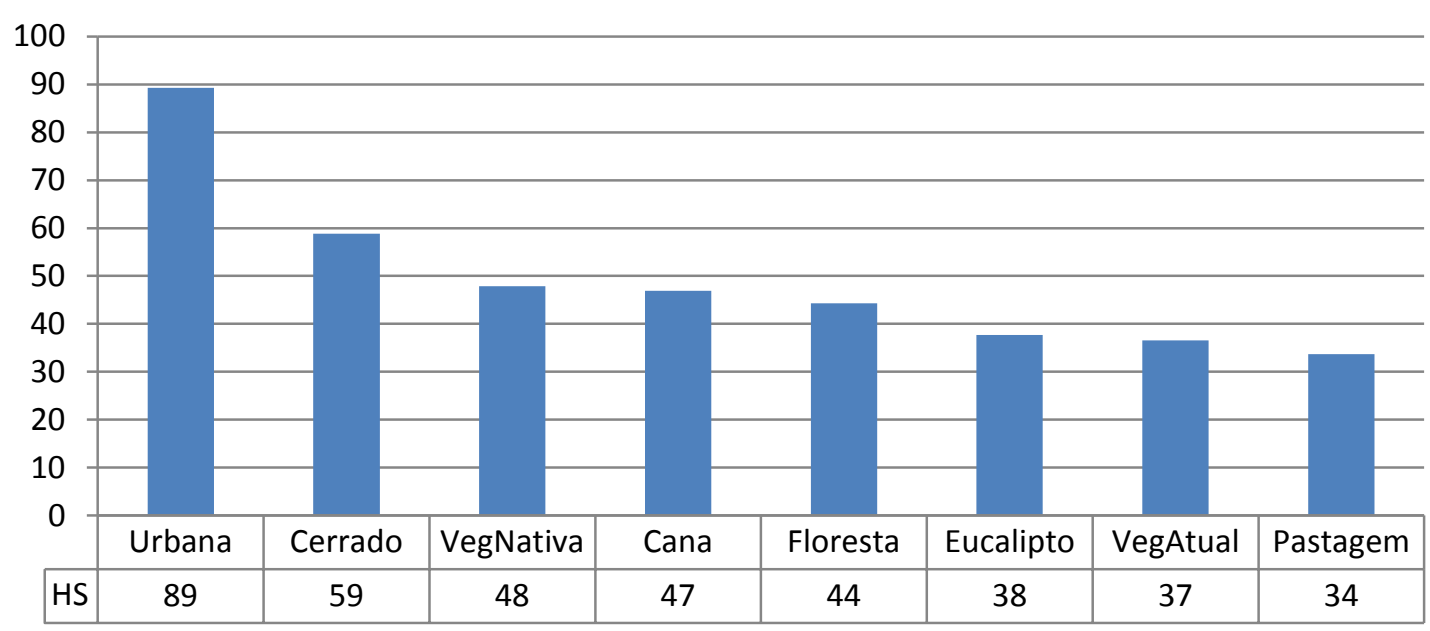

Figura 3.46: Fluxo de calor sensível médio no domínio entre 1980 e 2009. [W m-2]

Para a razão de Bowen média anual (H/LE) (Figura 3.47) o único valor superior a 1 é o cenário da área urbanização. Nos cenários com vegetação homogênea, o cerrado é o maior $(0,77)$, seguido da cana-de-açúcar $(0,74)$, até aqui na mesma ordem do termo $\mathrm{H}$, seguidos por pastagem, floresta e eucalipto, estes dois últimos os mesmos com os maiores termos LE. 


\section{H/LE - 1980-2009}

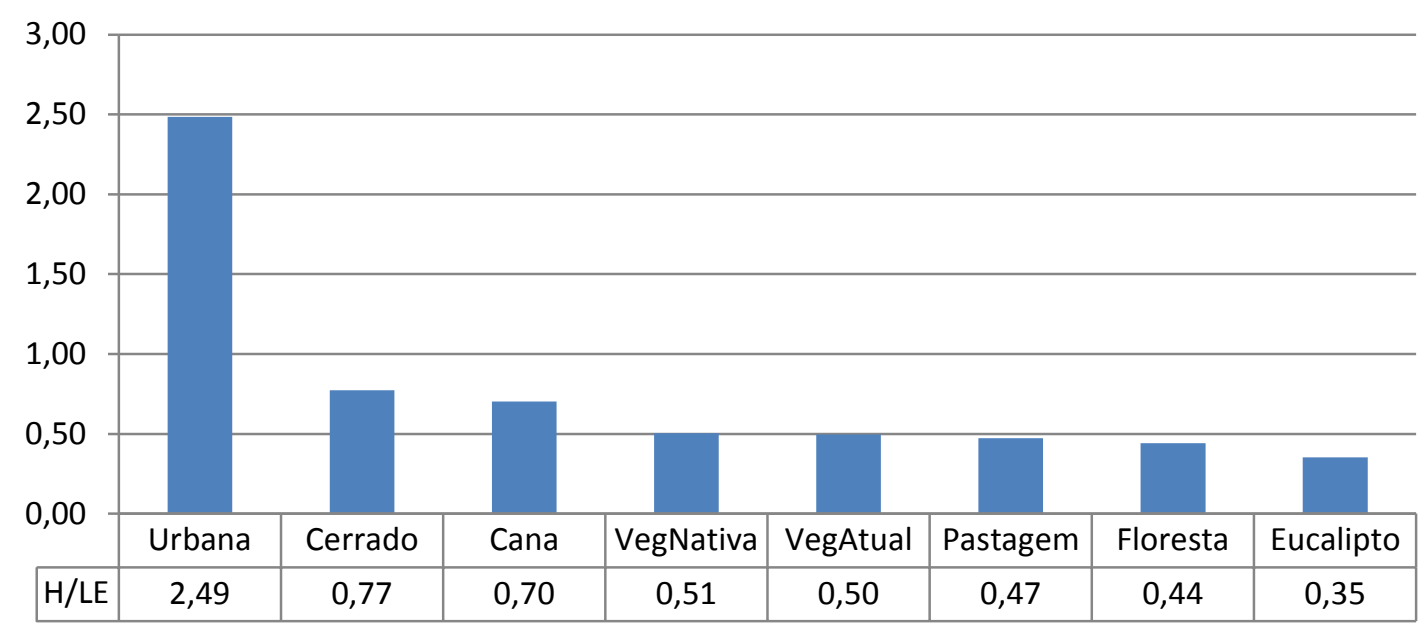

Figura 3.47: Razão de Bowen média no domínio entre 1980 e 2009.

Para fração evaporativa média anual (LE/Rn - Figura 3.47), nos cenários com vegetação homogênea, o eucalipto e a floresta são os maiores $(0,75$ e 0,70 respectivamente), seguidos pela pastagem $(0,69)$, cana $(0,59)$ e cerrado $(0,57)$.

\section{LE/Rn - 1980-2009}

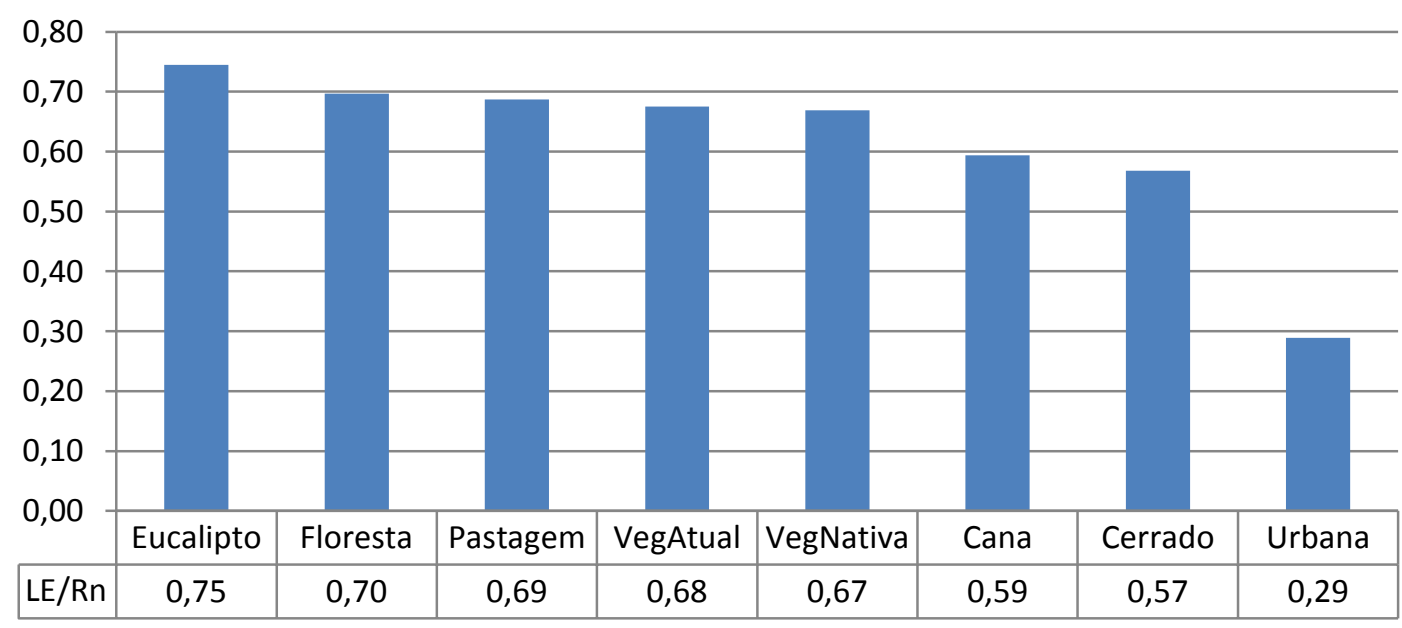

Figura 3.48: Razão entre fluxo de calor latente e saldo de radiação média no domínio entre 1980 e 2009.

A razão entre a ETR e a precipitação (Figura 3.49) tem a mesma sequência do termo LE, uma vez que a chuva média anual é igual para todos. Em grandes ecossistemas como a Amazônia, este termo é de $\sim 0,60$, valor este abaixo do estimado para eucalipto e floresta de 
mata atlântica em SP $(0,85$ e 0,80 , respectivamente), igual ao cerrado, e acima da pastagem e cana.

\section{$E / P-1980-2009$}

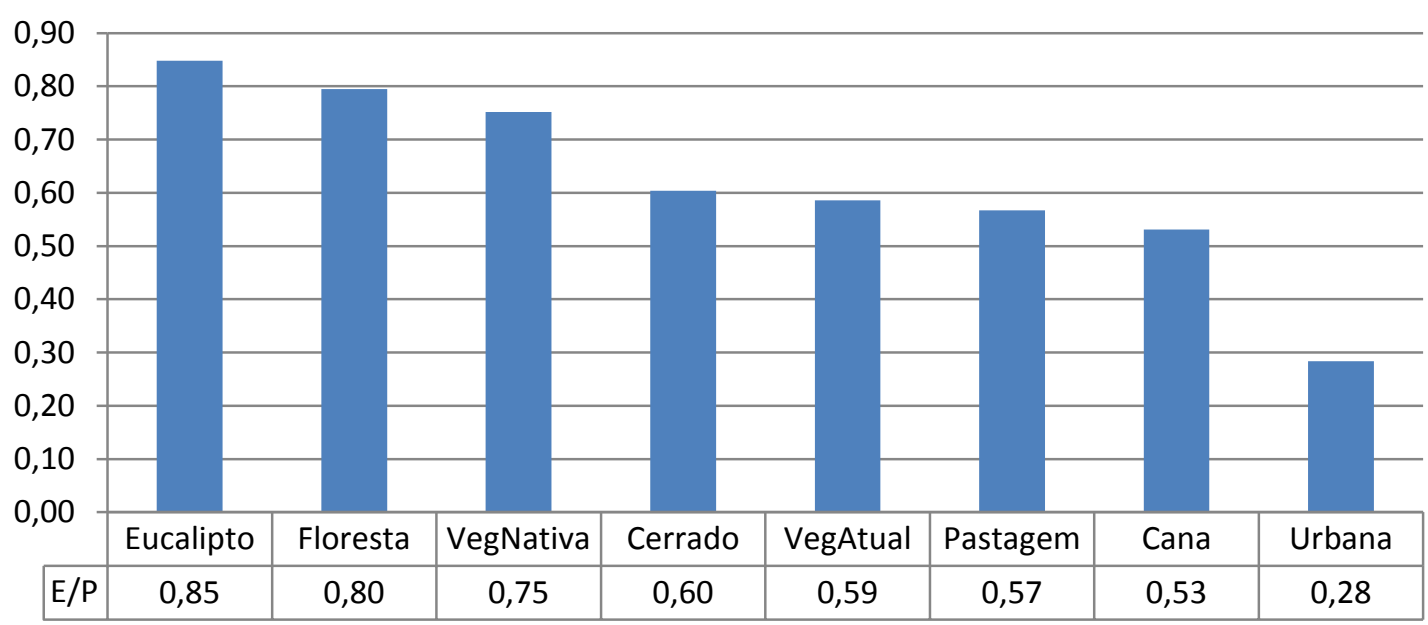

Figura 3.49: Razão entre evapotranspiração e precipitação média no domínio entre 1980 e 2009.

\subsubsection{Comparação com a ETR das sub-bacias hidrográficas}

Será feita a comparação da ETR média calculada pelo modelo em cada sub-bacia hidrográfica do estado de SP, com a média anual de longo prazo estimada pelo balanço hidrológico igual à chuva menos à vazão (CRH/CORHI/DAEE, 1999).

A caracterização da climatologia da ETR real no estado de SP mais adequadamente proposta por este trabalho é a do cenário da vegetação atual, com média de $930 \mathrm{~mm} \mathrm{ano}^{-1}$, que mostrou-se bem comparável com a climatologia do DAEE de $980 \mathrm{~mm} \mathrm{ano}^{-1}$ (Figura 3.50). Apesar desta razoável comparação, houve uma discrepância da precipitação média anual da Reanálise, de $1630 \mathrm{~mm} \mathrm{ano}^{-1}$, muito superior à estimada do DAEE, de $1380 \mathrm{~mm}$ ano $^{-1}$. 


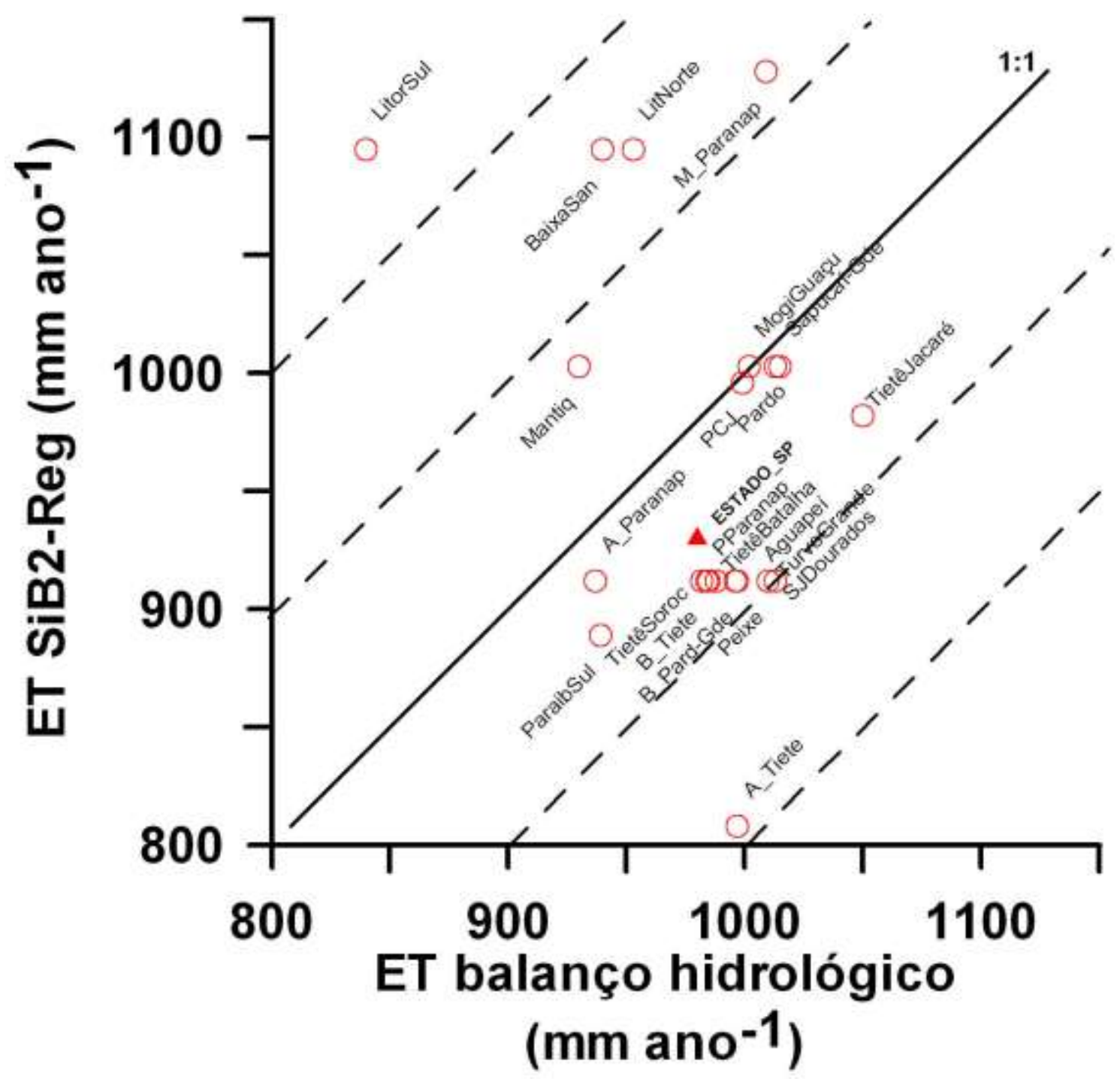

Figura 3.50: ETR média anual calculada pelo modelo Reg-SiB2 em cada sub-bacia hidrográfica do estado de SP, e média anual do balanço hidrológico (DAEE, 1999). [ $\left.\mathrm{mm} \mathrm{ano}^{-1}\right]$

O cálculo da ETR em várias sub-bacias aproximou-se muito bem (muito próximo da linha 1:1) dos dados do DAEE, como as bacias do Mogi-Guaçú, PCJ, Pardo, Sapucaí-Grande, e Alto Paranapanema. Para o maior conjunto de sub-bacias, o cálculo da ETR foi ligeiramente menor, mas não menos que $100 \mathrm{~mm}^{\mathrm{ano}}{ }^{-1}$, como as bacias do Tietê-Jacarei, Paraiba do Sul, Tietê-Sorocaba, Baixo Tietê, Baixo Pardo-Grande, Tietê-Batalha, Aguapeí, Turvo-Grande, SJDourados e Peixe. Finalmente, para um conjunto menor, a ETR calculada mostrou-se maior, acima de $100 \mathrm{~mm} \mathrm{ano}^{-1}$, como as bacias da Baixada Santista, Litoral Norte, Médio Paranapanema e Litoral Sul. 


\section{CONCLUSÕES}

A reanálise CFSR conseguiu representar satisfatoriamente as variáveis requeridas pelo SiB2 no domínio do estado de São Paulo, caracterizando a climatologia da região. Através desta fonte é possível enxergar os sistemas mais importantes que atuam nas diferentes as épocas do ano. Os vieses observados nas comparações com os dados observacionais não parecem depreciar a importância dos resultados das simulações com o modelo Reg-SiB2.

O maior prejuízo na escolha da reanálise como fonte de dados parece estar na caracterização do ciclo diurno para algumas variáveis, onde os dados de sítios acompanharam melhor a observação na maioria dos casos. A maior eficiência das variáveis observadas nos sítios já era esperada, já que a mesma torre que mede os dados forçantes mede também os dados de fluxos de calor utilizados na comparação, eliminando as diferenças por conta do microclima local e variações na elevação do terreno. De qualquer forma, as médias mensais não parecem depreciadas por esta deficiência da reanálise.

Foram utilizados 6 cenários com cobertura de superfície homogênea em todo o estado (floresta de mata atlântica, cerrado, eucalipto, cana-de-açúcar, pastagem, urbanização), além de dois outros cenários (vegetação nativa e vegetação atual), que produziram médias de ETR substancialmente distintas. No cenário de eucalipto obteve-se a maior média anual, de 3,7 mm $\operatorname{dia}^{-1}$, sendo maiores os cenários de eucalipto e floresta atlântica e vegetação nativa, próximos entre si, e com máximos valores do saldo de radiação e fração evaporativa. $O$ impacto na mudança do uso da terra nos totais de ETR no estado de São Paulo pode ser discutido a partir do cenário de vegetação nativa, com ETR média de 3,3 $\mathrm{mm} \mathrm{dia}^{-1}, \sim 20 \%$ superior à ETR da vegetação atual. Por meio do teste de significância estatística realizado, observou-se a importância da caracterização da vegetação neste estudo e o impacto na mudança do uso da terra nos totais de ETR no estado de São Paulo, já que a média calculada para o cenário com vegetação nativa resultou em $3,3 \mathrm{~mm} \mathrm{dia}^{-1}$ enquanto o resultado para vegetação atual foi menor, com $2,5 \mathrm{~mm} \mathrm{dia}^{-1}, \sim 20 \%$ inferior.

O produto final deste estudo é então uma caracterização da climatologia da ETR real no estado de SP, com média calculada de $930 \mathrm{~mm}$ ano $^{-1}$ no domínio, enquanto a climatologia medida pelo DAEE é de $980 \mathrm{~mm} \mathrm{ano}^{-1}$. O resultado é menor que o observado pelo DAEE, mesmo com o viés chuvoso da Reanálise, que resultou em $1630 \mathrm{~mm} \mathrm{ano}^{-1}$, enquanto o resultado do DAEE foi menor, $1380 \mathrm{~mm}^{2} \mathrm{ano}^{-1}$.

Portanto, os resultados são apresentados como a melhor representação da ETR calculada no estado de SP. 


\section{SUGESTÕES PARA TRABALHOS FUTUROS}

São várias as frentes nas quais este trabalho pode se estender para que novos benefícios sejam incorporados, e cálculos mais acurados sejam levantados:

a) Modificações do modelo da biosfera per se:

- introdução de processos de dinâmica do índice de área foliar, em especial para os ecossistemas nativos fortemente sazonais (cerrado) e os agroecossistemas;

- reavaliação do fechamento de energia dos fluxos de calor e água nos dados de campo, para avaliar mais adequadamente a calibração e o desempenho do modelo;

- sincronização dos parâmetros aerodinâmicos com o índice de área foliar;

- discussão da utilização de mapas e parâmetros de solo que reflitam melhor os dados de inventários regionais.

b) Correção da defasagem do ciclo diurno da irradiância solar incidente nos dados forçantes da reanálise CFSR;

c) Aumento da resolução espacial no caso do contorno próximo ao oceano e regiões de grande altitude, e em especial das sub-bacias hidrográficas onde o desempenho médio não foi muito satisfatório, inclusive do ponto de vista da descrição da cobertura vegetal. 


\section{REFERÊNCIAS}

ACOSTA, R. Um modelo biosfera-hidrosfera para a bacia do Tocantins-Araguaia. 2007. Dissertação (Mestrado em Meteorologia) - Instituto de Astronomia, Geofísica e Ciências Atmosféricas, Universidade de São Paulo, São Paulo, 2007.

BRUTSAERT, W. Evaporation into the atmosphere; theory, history and applications. Dordrecht, D Reidel, 1984

CRESSMAN, G. P. An Operational Objective Analysis System. U.S. Weather Bureau, Washington, D.C., 1959.

CABRAL, O. M. R. et al. The energy and water balance of a Eucalyptus plantation in southeast Brazil. Journal of Hydrology, 388. 208-216. 10.1016/jhydrol.2010.04.041, 2010 a.

CONSELHO ESTADUAL DE RECURSOS HÍDRICOS. Comitê Coordenador do Plano Estadual de Recursos Hídricos. Relatório de situação dos recursos hídricos do Estado de São Paulo. São Paulo, 1999.

DA ROCHA, H. R; et al. A vegetation atmosphere interaction study for Amazonian deforestation using field data and a single column model. Quarterly Journal Royal Meteorological Society, 122: 567-594. 1996a.

DA ROCHA, H. R. et al. Calibration and use of SiB2 model to estimate $\mathrm{H}_{2} \mathrm{O}$ and $\mathrm{CO}_{2}$ exchanges in Abracos forest sites. In Amazon Deforestation and Climate, eds. J. Gash, C. Nobre, J. Roberts and R. Victória. J. Wiley \& Sons, Chichester, UK, p. 459-472. 1996b.

DA ROCHA, H. R. et al. Measurements of CO2 exchange over a woodland savanna (Cerrado Sensu stricto) in southeast Brasil. Biota Neotropica (English ed.), Campinas, SP, v. 2, n. 1, 2002.

DIRMEYER, P. et al. GSWP-2 multi-model analysis and implications for our perception of the land surface. B. Am. Meteorol. Soc, 87, 1381-1397. 2006.

DOTY, B. The Grid Analysis and Display System - GrADS. Institute of Global Environment and Society (IGES), 2005. 
FREITAS, E. D. Circulações locais em São Paulo e sua influência sobre a dispersão de poluentes. 2003. Tese (Doutorado em Meteorologia) - Instituto de Astronomia, Geofísica e Ciências Atmosféricas, Universidade de São Paulo, São Paulo, 2003.

JUNG, M. et al. Recent decline in the global land evapotranspiration trend due to limited moisture supply. Nature, 467, doi:10.1038/nature09396 (2010)

LLOPART, M. P. Calibração do modelo SiB2 em módulos sequenciais para a Floresta Tropical Amazônica. 2009. Dissertação (Mestrado em Meteorologia) - Instituto de Astronomia, Geofísica e Ciências Atmosféricas, Universidade de São Paulo, São Paulo, 2009.

NEGRON-JUAREZ, R. I. Variabilidade climática regional e controle da vegetação de observações sobre cerrado e cana-de-açúcar e modelagem numérica da atmosfera. 2004. Tese (Doutorado em Meteorologia) - Instituto de Astronomia, Geofísica e Ciências Atmosféricas, Universidade de São Paulo, São Paulo, 2004.

OKI, T.; S. KANAE. Global hydrological cycles and world water resources. Science, 313, 1068-1072 (2006).

$\mathrm{SAAD}, \mathrm{S}$. et al. Can the deforestation breeze change the rainfall in Amazonia? A case estudy for the BR-163 highway region. Earth Interactions, V. 14, p. 1-23 (2010).

SAHA, S. et al. The NCEP Climate Forecast System Reanalysis. Submitted to the Bulletin s the American Meteorological Society, 2010.

SELLERS, P. J.; MINTZ, Y.; DALCHER, A. A simple biosphere model (SiB) for use within circulation models. Journal of the Atmospheric Sciences, vol. 43, no. 6, 1986.

SELLERS, P. J. et al. A Revised Land Surface Parameterization (SiB2) for Atmospheric GCMS. Part I: Model Formulation. USRA, NASA/GSFC, Greenbelt, Maryland, 1996.

SELLERS, P. J, SHUTTLEWORTH, W. J.; DORMAN J. Calibrating the Simple Biosphere Model for Amazonian Tropical Forest using field and remote sensing data. Part I: Average calibration with field data. Journal of Applied Meteorology, 28: 727-759, 1989.

TATSCH, J. D. Uma análise dos fluxos de superfície e do microclima sobre cerrado, cana-de-açúcar e eucalipto, com implicações para mudanças climáticas regionais. 2006. Dissertação (Mestrado em Meteorologia) - Instituto de Astronomia, Geofísica e Ciências Atmosféricas, Universidade de São Paulo, São Paulo, 2006. 
YANG, Z.-L., R. E. et al. Preliminary study of spin-up processes in land surface models with the first stage data of Project for Intercomparison of Land Surface Parameterization Schemes Phase. 1(a), J. Geophys. Res., 100(D8), 16,553-16,578, doi:10.1029/95JD01076. 1995.

VELOSO, H. P.; FILHO, A. L. R. R.; LIMA, J. C. A. Classificação da vegetação brasileira, adaptada a um sistema universal. Fundação Instituto Brasileiro de Geografia e Estatística IBGE, 1991.

VIEIRA, R. M. S. P. et al. Mapa de uso e cobertura da terra do Estado de São Paulo. São José dos Campos: INPE, 2010

Disponível em: http://urlib.net/sid.inpe.br/mtc-m19@80/2010/01.22.12.32 


\section{APÊNDICE A PARÂMETROS E EQUAÇÕES DO MODELO SiB2}

O SiB2 necessita de uma série de parâmetros e forçantes meteorológicas fornecidos pelo usuário, requer dados de entrada horários, listados na Tabela A.1, mas também possui a opção de utilizar o saldo de radiação calculado pelo próprio modelo para que o usuário não precise deste conjunto de dados observados nem sempre disponível. Esta opção foi escolhida, já que a reanálise CFSR não contém dados de saldo de radiação, e utilizou-se a equação de Swinbank (1963), Equação A.1, com correção de Jacobs (1978), Equação A.2, que se mostrou a parametrização que melhor aproxima o valor simulado da observação nos testes para o cerrado.

Tabela A.1: Variáveis de Entrada do Modelo SiB2

\begin{tabular}{|c|c|c|}
\hline Nome & Variável & Umidade \\
\hline $\mathrm{Ki}$ & irradiância de onda curta incidente observada & $\left(\mathrm{W} \mathrm{m}^{-2}\right)$ \\
\hline $\mathrm{Rn}$ & saldo de radiação observado & $\left(\mathrm{W} \mathrm{m}^{-2}\right)$ \\
\hline em & pressão de vapor d'água observada & $(\mathrm{hPa})$ \\
\hline $\operatorname{tm}$ & temperatura do ar observada & $(\mathrm{K})$ \\
\hline um & velocidade horizontal do vento observado & [m s-1] \\
\hline prec & precipitação observada & $(\mathrm{mm})$ \\
\hline
\end{tabular}

Fonte: Adaptado de Sellers et al. (1996)

$$
\begin{aligned}
& L_{d=} 9,2 \cdot 10^{-6} \sigma T^{4} \\
& L_{d}=L_{d} \cdot(1+0,26 c)
\end{aligned}
$$

Onde: $L_{d}=$ Onda Longa Incidente

$\sigma=$ constante de Stefan-Boltzmann

$T=$ temperatura média do ar

$c=$ fração de cobertura de nuvens

A cada passo de tempo o modelo retorna as variáveis de saída listadas na Tabela A.2, outras podem ser impressas à escolha do usuário.

Tabela A.2: Variáveis de Saída do Modelo SiB2

\begin{tabular}{lll}
\multicolumn{1}{c}{ Nome } & \multicolumn{1}{c}{ Variável } & \multicolumn{1}{c}{ Umidade } \\
\hline Alb & albedo de superfície & $($ adim $)$ \\
Ldwn & irradiância de onda longa incidente & $\left(\mathrm{W} \mathrm{m}^{-2}\right)$
\end{tabular}




\begin{tabular}{|c|c|c|}
\hline Lupw & irradiância de onda longa emergente & $\left(\mathrm{W} \mathrm{m} \mathrm{m}^{-2}\right)$ \\
\hline $\mathrm{Rn} \_\mathrm{C}$ & saldo de radiação calculado & $\left(\mathrm{W} \mathrm{m}^{-2}\right)$ \\
\hline H_C & fluxo de calor sensível calculado & $\left(\mathrm{W} \mathrm{m} \mathrm{m}^{-2}\right)$ \\
\hline LE_C & fluxo de calor latente calculado & $\left(\mathrm{W} \mathrm{m} \mathrm{m}^{-2}\right)$ \\
\hline G_C & fluxo de calor no solo calculado & $\left(\mathrm{W} \mathrm{m}^{-2}\right)$ \\
\hline Fc_C & fluxo total de $\mathrm{CO}_{2}$ calculado & $\left(\mu \mathrm{mol} \mathrm{CO} \mathrm{Cm}^{2} \mathrm{~s}^{-1}\right)$ \\
\hline Rsc_C & efluxo de $\mathrm{CO}_{2}$ no solo & $\left(\mu \mathrm{mol} \mathrm{CO} \mathrm{CO}^{2} \mathrm{~s}^{-1}\right)$ \\
\hline An_C & assimilação liquida de $\mathrm{CO}_{2}$ & $\left(\mu \mathrm{mol} \mathrm{CO} 2 \mathrm{~m}^{2} \mathrm{~s}^{-1}\right)$ \\
\hline $\mathrm{Td}$ & temperatura do solo & $(\mathrm{K})$ \\
\hline Wn_C & grau de saturação da umidade do solo $\mathrm{n}^{\mathrm{a}}$ camada & $\left(\mathrm{m}^{3} \mathrm{~m}^{-3}\right)$ \\
\hline $\mathrm{u}^{*} \_\mathrm{C}$ & velocidade de atrito calculada & [m s-1] \\
\hline Croff & escoamento de superfície & $(\mathrm{mm})$ \\
\hline Qng & escoamento por drenagem vertical para aquífero & $(\mathrm{mm})$ \\
\hline PARidir & irradiância PAR incidente direta & $\left(\mathrm{W} \mathrm{m}^{-2}\right)$ \\
\hline PARidif & irradiância PAR incidente difusa & $\left(\mathrm{W} \mathrm{m} \mathrm{m}^{-2}\right)$ \\
\hline albPARdir & albedo PAR de radiação direta & (adim) \\
\hline albPARdif & albedo PAR de radiação difusa & (adim) \\
\hline
\end{tabular}

Fonte: Adaptado de Sellers et al. (1996)

Para cada ecossistema considerado foi preciso prescrever um conjunto de parâmetros variantes e invariantes no tempo, listados na Tabela A.3.

Tabela A.3: Parâmetros do Modelo SiB2

\begin{tabular}{llc} 
Símbolo & Definição & \multicolumn{1}{c}{ Parâmetros invariantes com o tempo } \\
& \multicolumn{1}{c}{ (a) Parâmetros morfológicos } \\
$\mathrm{Z}_{2}$ & Altura do topo do dossel & $\mathrm{m}$ \\
$\mathrm{Z}_{1}$ & Altura da base do dossel & $\mathrm{m}$ \\
$\mathrm{Z}_{\mathrm{c}}$ & Altura de inflexão IAF & $\mathrm{m}$ \\
$\mathrm{Z}_{\mathrm{s}}$ & Comprimento de rugosidade do chão & $\mathrm{m}$ \\
$\mathrm{V}_{\mathrm{c}}$ & Fração de cobertura do dossel & - \\
$\chi_{\mathrm{L}}$ & Fator de distribuição angular da folha & - \\
$\mathrm{G}_{\mathrm{n}} ;$ & Coeficientes de transferência de momentum & - \\
$\mathrm{l}_{\mathrm{w}}$ & Largura da folha & $\mathrm{m}$ \\
$\mathrm{l}_{1}$ & Comprimento da folha & $\mathrm{m}$ \\
$\mathrm{Dl}_{1}$ & Espessura da camada superficial do solo & $\mathrm{m}$ \\
$\mathrm{D}_{\mathrm{r}}$ & Espessura da camada de raízes, $\left(\mathrm{D}_{1}+\mathrm{D}_{2}\right)$ & $\mathrm{m}$ \\
$\mathrm{D}_{\mathrm{T}}$ & Espessura da camada de drenagem, $\left(\mathrm{D}_{1}+\mathrm{D}_{2}+\mathrm{D}_{3}\right)$ & $\mathrm{m}$ \\
$\mathrm{C}_{1}$ & Coeficiente da resistência $\mathrm{r}_{\mathrm{b}}$ & $\left(\mathrm{s} . \mathrm{m}^{-1}\right)^{1 / 2}$ \\
& & \\
$\alpha_{\mathrm{v}, 1}$ & refletância folha, VIS, viva & - \\
$\alpha_{\mathrm{v}, \mathrm{d}}$ & refletância folha, VIS, morta & - \\
$\alpha_{\mathrm{N}, \mathrm{l}}$ & refletância folha, NIR, viva & - \\
$\alpha_{\mathrm{N}, \mathrm{d}}$ & refletância folha, NIR, morta & - \\
$\delta_{\mathrm{V}, 1}$ & transmitância folha, VIS, viva & -
\end{tabular}




\begin{tabular}{|c|c|c|}
\hline$\delta_{\mathrm{V}, \mathrm{d}}$ & transmitância folha, VIS, morta & - \\
\hline$\delta_{\mathrm{N}, 1}$ & transmitância folha, NIR, viva & - \\
\hline$\delta_{\mathrm{N}, \mathrm{d}}$ & transmitância folha, NIR, morta & - \\
\hline $\mathrm{a}_{\mathrm{Sv}}$ & refletância do solo, VIS & - \\
\hline $\mathrm{a}_{\mathrm{Sn}}$ & $\begin{array}{l}\text { refletância do solo, NIR } \\
\text { (c) Parâmetros fisiológicos }\end{array}$ & - \\
\hline $\mathrm{V}_{\max 0}$ & Máxima capacidade de fotossíntese & $\mathrm{mol} \mathrm{m}^{-2}$ \\
\hline$\varepsilon$ & Eficiência quantum intrínseca & $\mathrm{mol} \mathrm{mol}^{-1}$ \\
\hline $\mathrm{m}$ & Coeficiente angular estomático & 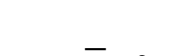 \\
\hline $\mathrm{B}$ & Condutância estomática mínima & $\mathrm{mol} \mathrm{m}^{-2} \mathrm{~s}$ \\
\hline$\beta_{\mathrm{ce}}$ & Coeficiente de acoplamento da fotossíntese & - \\
\hline $\mathrm{S}_{2}$ & Fator de estresse, alta temperatura & $\mathrm{K}$ \\
\hline $\mathrm{S}_{4}$ & Fator de estresse, baixa temperatura & $\mathrm{K}$ \\
\hline$\psi_{\mathrm{c}}$ & Fator $1 / 2$ inibição potencial água & $\mathrm{m}$ \\
\hline$f_{d}$ & $\begin{array}{l}\text { Fator de respiração da folha } \\
\text { (d) Parâmetros físicos do solo }\end{array}$ & - \\
\hline$\psi_{\mathrm{s}}$ & Potencial de umidade do solo saturado & $\mathrm{m}$ \\
\hline $\mathrm{K}_{\mathrm{s}}$ & Condutividade hidráulica do solo saturado & $\mathrm{m} \cdot \mathrm{s}^{-1}$ \\
\hline B & Parâmetro do potencial de umidade do solo & \\
\hline$\Theta_{\mathrm{s}}$ & Porosidade do solo na saturação & $\mathrm{m}^{3} \cdot \mathrm{m}^{-3}$ \\
\hline d & Deslocamento do plano zero & $\mathrm{m}$ \\
\hline $\mathrm{C}_{2}$ & $\begin{array}{l}\text { Coeficiente da resistência } r_{d} \\
\text { Parâmetros variantes com o tempo }\end{array}$ & - \\
\hline $\begin{array}{l}\mathrm{N} \\
\mathrm{IAF}\end{array}$ & $\begin{array}{l}\text { Fração de folhas verdes do dossel } \\
\text { Índice de área foliar }\end{array}$ & $\mathrm{m}^{2} \cdot \mathrm{m}^{-2}$ \\
\hline
\end{tabular}

Fonte: Adaptado de Llopart (2009)

As equações governantes das variáveis prognósticas do SiB2 determinam as temperaturas do dossel (Equação A.3), da superfície do solo (Equação A.4) e a temperatura do solo à uma certa profundidade (Equação A.5). O subscrito "c" se refere ao dossel, "g" a superfície do solo, "d" à profundidade do solo.

$$
\begin{aligned}
& C_{c} \frac{\partial T_{c}}{\partial t}=R n_{c}-H_{c}-\lambda E_{c}-\xi_{c s} \\
& C_{g} \frac{\partial T_{g}}{\partial t}=R n_{g}-H_{g}-\lambda E_{g}-\frac{2 \pi C_{d}}{\tau_{d}}\left(T_{g}-T_{d}\right)-\xi_{g s} \\
& C_{d} \frac{\partial T_{d}}{\partial t}=\frac{1}{2(365 \pi)^{1 / 2}}\left(R n_{g}-H_{g}-\lambda E_{g}\right)
\end{aligned}
$$

Onde: $T_{c}, T_{g}, T_{d}=$ temperatura $(\mathrm{K})$

$$
\begin{aligned}
& R n_{c}, T n_{g}=\text { radiação líquida absorvida }\left(\mathrm{W} \mathrm{m}^{-2}\right) \\
& H_{c}, H_{g}=\text { fluxo de calor sensível }\left(\mathrm{W} \mathrm{m}^{-2}\right)
\end{aligned}
$$


$E_{c}, E_{g}=$ taxas de evapotranspiração $\left(\mathrm{kg} \mathrm{m}^{-2} \mathrm{~s}^{-1}\right)$

$C_{c}, C_{g}, C_{d}=$ capacidades térmicas efetivas $\left(\mathrm{J} \mathrm{m}^{-2} \mathrm{~K}^{-1}\right)$

$\lambda=$ calor latente de vaporização $\left(\mathrm{J} \mathrm{kg}^{-1}\right)$

$\tau_{d}=$ duração do dia (s)

$\xi_{c s}, \xi_{g s}=$ energias de transferência de mudanças de fase de $M_{c}$ e $M_{g}$ respectivamente $\left(\mathrm{W} \mathrm{m}^{-2}\right)$

O segundo conjunto de equações se refere ao armazenamento por interceptação (Equações A.6 e A.7).

$$
\begin{aligned}
& \frac{\partial M_{c w, s}}{\partial t}=P-D_{d}-D_{c}-E_{c i} / \rho_{w} \\
& \frac{\partial M_{g w, s}}{\partial t}=D_{d}+D_{c}-E_{g i} / \rho_{w}
\end{aligned}
$$

Onde: $M_{c w, s}, M_{g w, s}=$ água ou neve estocada no dossel ou na superfície (m)

$P=P_{c}+P_{i}=$ taxa de precipitação $[\mathrm{m} \mathrm{s}-1]$

$D_{d}=$ taxa de escoamento pelo dossel [m s-1]

$D_{c}=$ taxa de drenagem no dossel [m s-1]

$E_{c i}, E_{g i}=$ taxa de evaporação do estoque por interceptação $\left(\mathrm{kg} \mathrm{m}^{-2} \mathrm{~s}^{-1}\right)$

$\rho_{w}=$ densidade da água $\left(\mathrm{Kg} \mathrm{m}^{-3}\right)$

As Equações A.8, A.9 e A.10 calculam o armazenamento da umidade do solo para um modelo com 10 camadas de solo, onde as camadas intermediárias (2 a 9) são calculadas pela Equação A.9.

$$
\begin{aligned}
& \frac{\partial W_{1}}{\partial t}=\frac{1}{\theta_{s} D_{1}}\left[P_{W 1}-Q_{1,2}-\frac{1}{\rho_{w}} E_{g s}\right] \\
& \frac{\partial W_{n}}{\partial t}=\frac{1}{\theta_{s} D_{n}}\left[Q_{n-1, n}-Q_{n, n+1}-\frac{1}{\rho_{w}} E_{c t}\right] \\
& \frac{\partial W_{10}}{\partial t}=\frac{1}{\theta_{s} D_{10}}\left[Q_{9,10}-Q_{10}\right]
\end{aligned}
$$

Onde: $W_{n}=\theta_{i} / \theta_{s}=$ umidade do solo na camada $n$

$$
\theta_{i}=\text { umidade volumétrica do solo na camada } \mathrm{i}\left(\mathrm{m}^{3} \mathrm{~m}^{-3}\right)
$$


$\theta_{s}=$ valor de $\theta$ na saturação $\left(\mathrm{m}^{3} \mathrm{~m}^{-3}\right)$

$D_{t}=$ espessura da camada do solo $(\mathrm{m})$

$Q_{i, i+1}=$ escoamento entre as camadas $i$ e $i+1$ [m s-1]

$Q_{3}=$ drenagem gravitacional para recarga do armazenamento da umidade do solo

$P_{W 1}=D_{c}+D_{d}+R_{O I}=$ infiltração da precipitação dentro do armazenamento superior da umidade do solo

$R_{O i}=$ infiltração excedente da taxa de runoff da superfície

A última Equação A.11 calcula a condutância no dossel do vapor d'água:

$$
\frac{\partial g_{c}}{\partial t}=-k_{g}\left(g_{c}-g_{\text {Cinf }}\right)
$$

Onde: $g_{c}=$ condutância do dossel [m s-1]

$$
\begin{aligned}
& k_{g}=\text { constante temporal }\left(\mathrm{s}^{-1}\right) \\
& g_{\text {Cinf }}=\text { estimativa de } g_{c} \text { em } t \rightarrow \infty\left[\mathrm{m} \mathrm{s}^{-1}\right]
\end{aligned}
$$

O modelo faz analogia à Lei de Ohm (Equação A.12 e Figura A.1) para calcular os fluxos de massa e calor listados da Tabela A.4.

$$
\text { fluxo }=\frac{d d p}{r}
$$

Onde: $d d p=$ diferença de potencial $r=$ resistência 


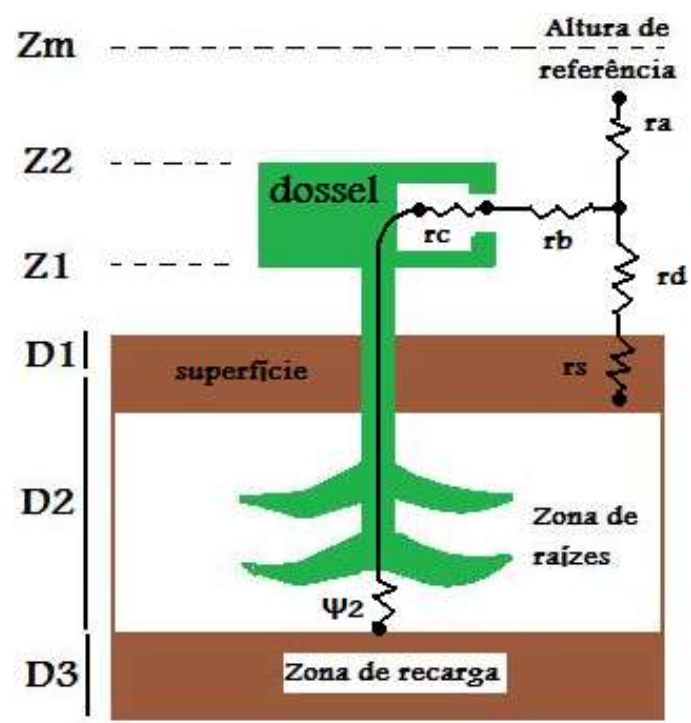

Figura A.1: Esquema de resistências do modelo SiB2. Adaptado de Sellers et al. (1996).

Tabela A.4: Fluxos, diferenças de potencial e resistências associados ao SiB2

\begin{tabular}{lll}
\hline \multicolumn{1}{c}{ Fluxo } & \multicolumn{1}{c}{ Diferença de potencial } & \multicolumn{1}{c}{ Resistência } \\
\hline $\mathrm{H}_{\mathrm{c}}$ & $\rho \mathrm{c}_{\mathrm{p}}\left(\mathrm{T}_{\mathrm{c}}-\mathrm{T}_{\mathrm{a}}\right)$ & $\mathrm{r}_{\mathrm{b}}$ \\
$\mathrm{H}_{\mathrm{g}}$ & $\rho \mathrm{c}_{\mathrm{p}}\left(\mathrm{T}_{\mathrm{g}}-\mathrm{T}_{\mathrm{a}}\right)$ & $\mathrm{r}_{\mathrm{d}}$ \\
$\mathrm{H}_{\mathrm{c}}+\mathrm{H}_{\mathrm{g}}$ & $\rho \mathrm{c}_{\mathrm{p}}\left(\mathrm{T}_{\mathrm{a}}-\mathrm{T}_{\mathrm{m}}\right)$ & $\mathrm{r}_{\mathrm{a}}$ \\
$\lambda \mathrm{E}_{\mathrm{ct}}$ & $\rho \mathrm{c}_{\mathrm{p}} / \gamma\left[\mathrm{e}_{\mathrm{s}}\left(\mathrm{T}_{\mathrm{c}}\right)-\mathrm{e}_{\mathrm{a}}\right]$ & $\left(\mathrm{r}_{\mathrm{c}}+2 \mathrm{r}_{\mathrm{b}}\right) /\left(1-\mathrm{W}_{\mathrm{c}}\right)$ \\
$\lambda \mathrm{E}_{\mathrm{ci}}$ & $\rho \mathrm{c}_{\mathrm{p}} / \gamma\left[\mathrm{e}_{\mathrm{s}}\left(\mathrm{T}_{\mathrm{c}}\right)-\mathrm{e}_{\mathrm{a}}\right]$ & $2 \mathrm{r}_{\mathrm{b}} / \mathrm{W}_{\mathrm{c}}$ \\
$\lambda \mathrm{E}_{\mathrm{gi}}$ & $\rho \mathrm{c}_{\mathrm{p}} / \gamma\left[\mathrm{e}_{\mathrm{s}}\left(\mathrm{T}_{\mathrm{g}}\right)-\mathrm{e}_{\mathrm{a}}\right]$ & $\mathrm{r}_{\mathrm{d}} / \mathrm{W}_{\mathrm{g}}$ \\
$\lambda \mathrm{E}_{g \mathrm{~s}}$ & $\rho \mathrm{c}_{\mathrm{p}} / \gamma\left[\mathrm{h}_{\text {soil }} \mathrm{e}_{\mathrm{s}}\left(\mathrm{T}_{\mathrm{g}}\right)-\mathrm{e}_{\mathrm{a}}\right]$ & $\left(\mathrm{r}_{\text {solo }}+\mathrm{r}_{\mathrm{d}}\right) /\left(1-\mathrm{W}_{\mathrm{g}}\right)$ \\
$\lambda \mathrm{E}_{\mathrm{ct}}+\lambda \mathrm{E}_{\mathrm{ci}}+\lambda \mathrm{E}_{\mathrm{gs}}+\lambda \mathrm{E}_{\mathrm{gi}}$ & $\rho \mathrm{c}_{\mathrm{p}} / \gamma\left(\mathrm{e}_{\mathrm{a}}-\mathrm{e}_{\mathrm{m}}\right)$ & $\mathrm{r}_{\mathrm{a}}$ \\
$\mathrm{R}_{\mathrm{D}}-\mathrm{A}_{\mathrm{c}}$ & $\mathrm{p}\left(\mathrm{c}_{\mathrm{a}}-\mathrm{c}_{\mathrm{l}}\right)$ & $1,6 \mathrm{r}_{\mathrm{a}}+2,8 \mathrm{r}_{\mathrm{b}}$ \\
\hline
\end{tabular}

Fonte: Adaptado de Sellers et al. (1996).

Onde: $\gamma=$ constante psicrométrica $\left(\mathrm{Pa} \mathrm{K}^{-1}\right)$

$\rho, c_{p}=$ densidade e calor específico do ar $\left(\mathrm{Kg} \mathrm{m}^{-3}, \mathrm{~J} \mathrm{Kg}^{-1} \mathrm{~K}^{-1}\right)$

$T_{a}, e_{a}=$ temperatura e pressão de vapor d'água no espaço aéreo do dossel (K,

$\mathrm{Pa})$

$T_{m}, e_{m}=$ temperatura e pressão de vapor d'água no nível de referência $z_{m}(\mathrm{~K}$,

$\mathrm{Pa})$

$$
\begin{aligned}
& r_{d}=\text { resistência aerodinâmica entre o solo e o espaço aéreo do dossel }\left(\mathrm{s} \mathrm{m}^{-1}\right) \\
& r_{a}=\text { resistência aerodinâmica entre o espaço aéreo do dossel e o nível de }
\end{aligned}
$$

referência $z_{m}\left(\mathrm{~s} \mathrm{~m}^{-1}\right)$

$r_{c}=$ resistência estomática do nível superior do dossel $\left(\mathrm{s} \mathrm{m}^{-1}\right)$ 


$$
\begin{aligned}
& r_{\text {solo }}=\text { resistência de superfície do solo nu }\left(\mathrm{s} \mathrm{m}^{-1}\right) \\
& r_{b}=\text { resistência da camada limite do dossel }\left(\mathrm{s} \mathrm{m}^{-1}\right) \\
& h_{\text {solo }}=\text { umidade relativa nos poros da superfície do solo } \\
& e_{S}(T)=\text { pressão de vapor de saturação à temperatura } T(\mathrm{~Pa}) \\
& W_{c}=\text { fração de cobertura de umidade e neve do dossel } \\
& W_{g}=\text { fração de cobertura de umidade e neve do solo } \\
& c_{a}=\text { pressão parcial de } \mathrm{CO}_{2} \text { no espaço aéreo do dossel }(\mathrm{Pa}) \\
& c_{I}=\text { pressão parcial de } \mathrm{CO}_{2} \text { “bulk" interna das folhas }(\mathrm{Pa})
\end{aligned}
$$

O código do $\mathrm{SiB} 2$ é aberto e permite modificações pelo usuário, portanto é possível encontrar outras versões do modelo descritas em literatura. O código utilizado neste estudo é o mesmo de Llopart (2009), com exceção da equação da resistência do solo substituída para resultar em uma curva exponencial com valor máximo em $1000 \mathrm{~s} \mathrm{~m}^{-1}$ (Equação A.13). As simulações para área urbana foram feitas utilizando um valor constante de resistência do solo, de $3000 \mathrm{~s} \mathrm{~m}^{-1}$.

$$
\text { rsoil }=\text { máximo }\left(0,1 ; 1001-e^{(W .6,686)}\right)
$$

Onde: $r$ soil $=$ resistência da superfície do solo

$$
W=\text { grau de saturação da umidade no solo }
$$




\section{APÊNDICE B FIGURAS MENSAIS}

\section{B.1 FORÇANTES CLIMÁTICAS PARA EVAPOTRANSPIRAÇÃO}

\section{B.1.1 Descrição da climatologia}

A

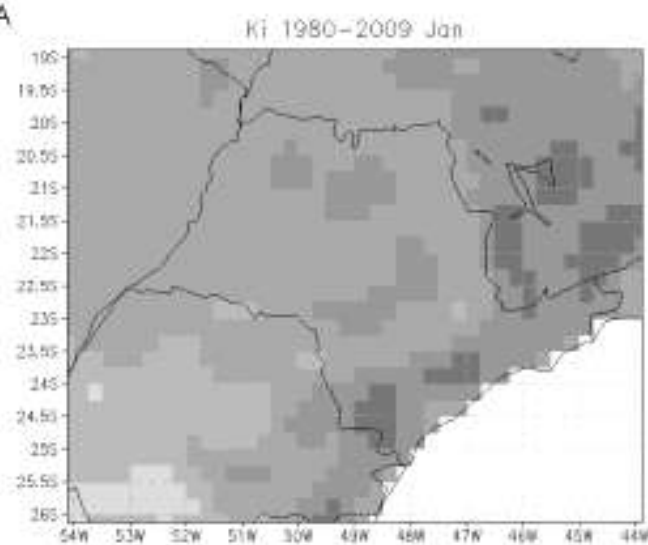

C

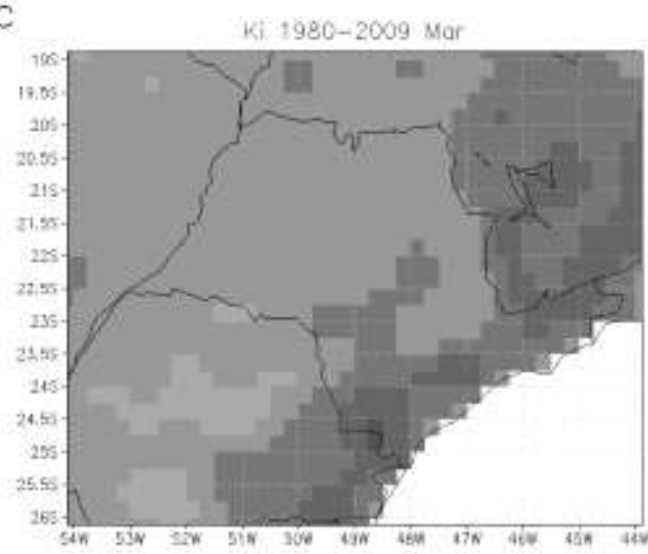

E

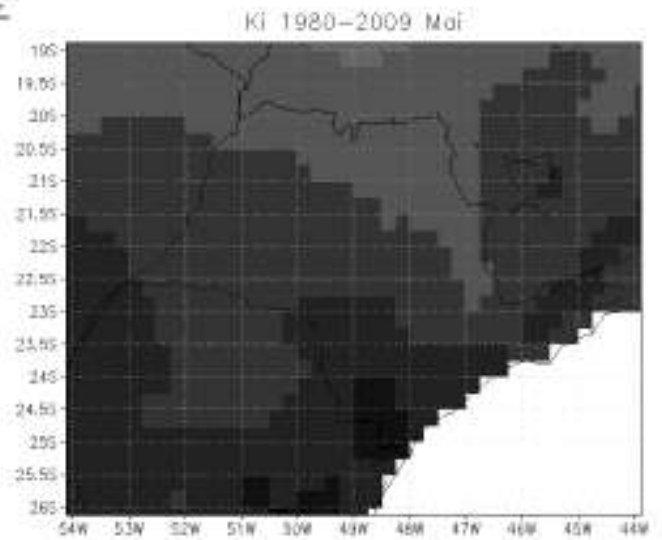

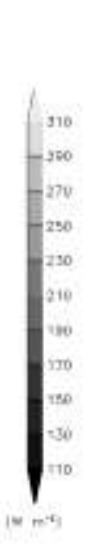

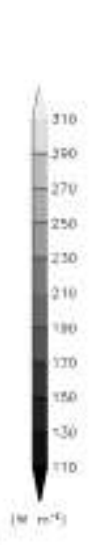

D

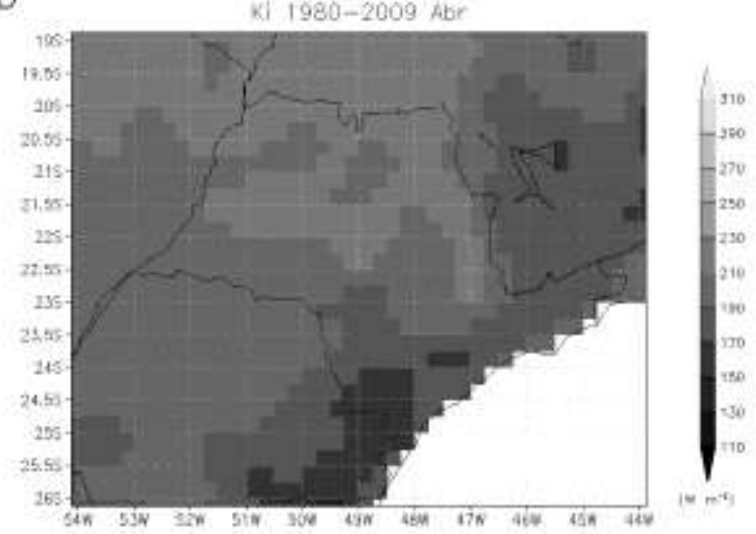

F
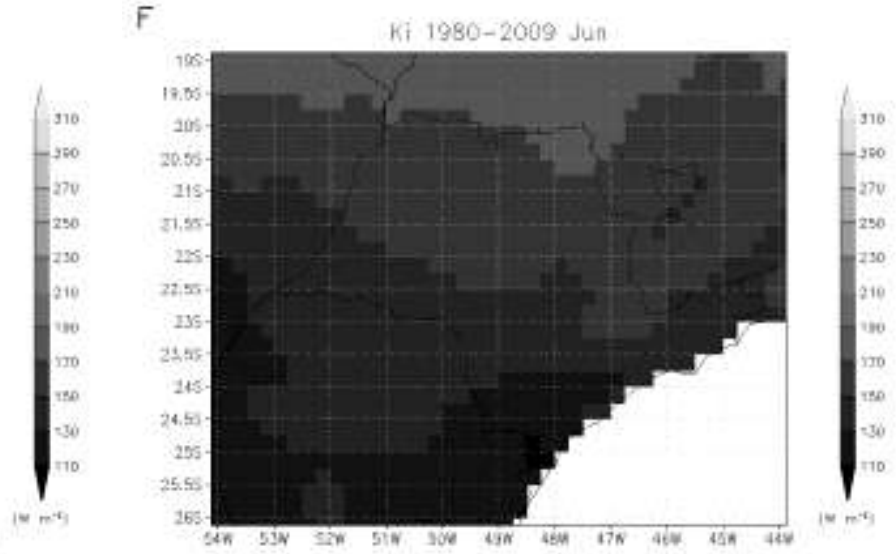

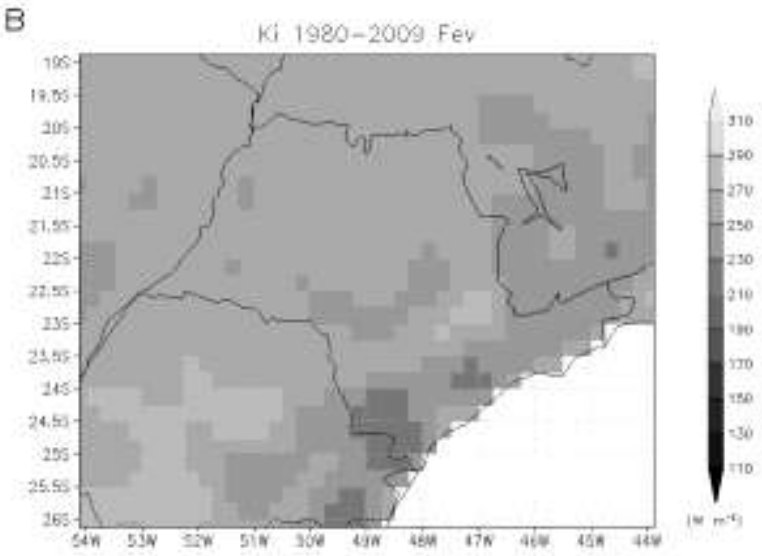

B

ki $1980-2009$ Abi 
G

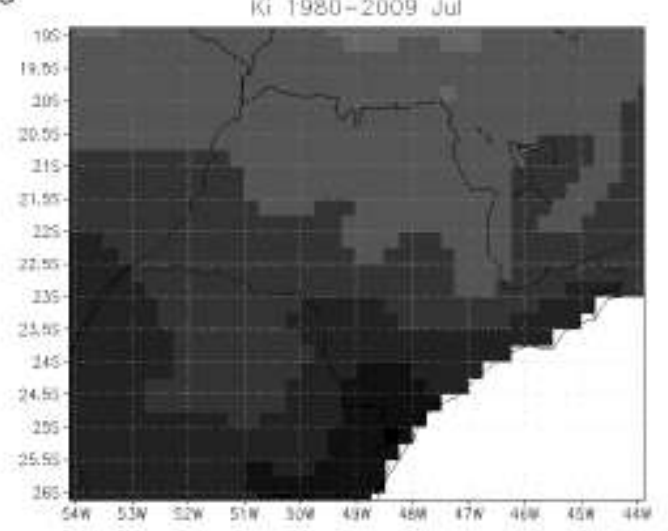

1

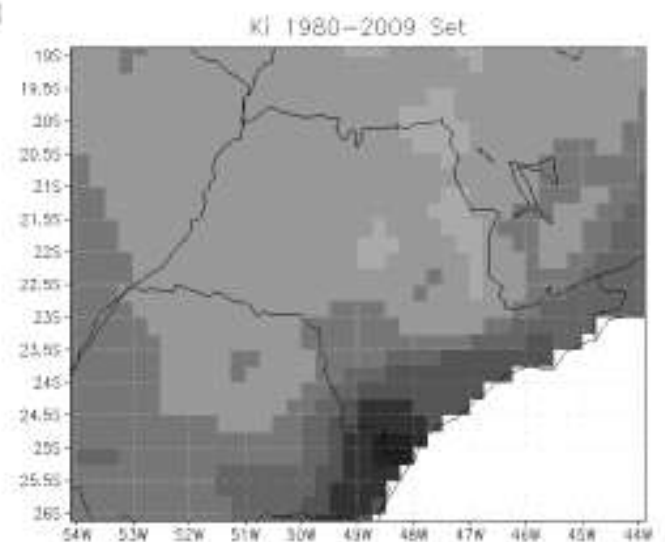

K

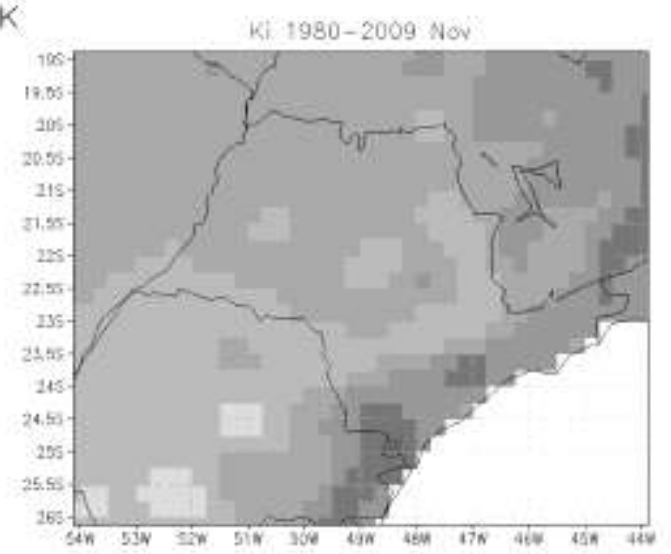

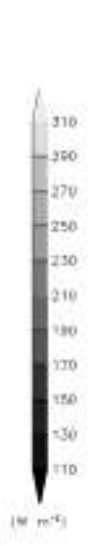

$\mathrm{H}$

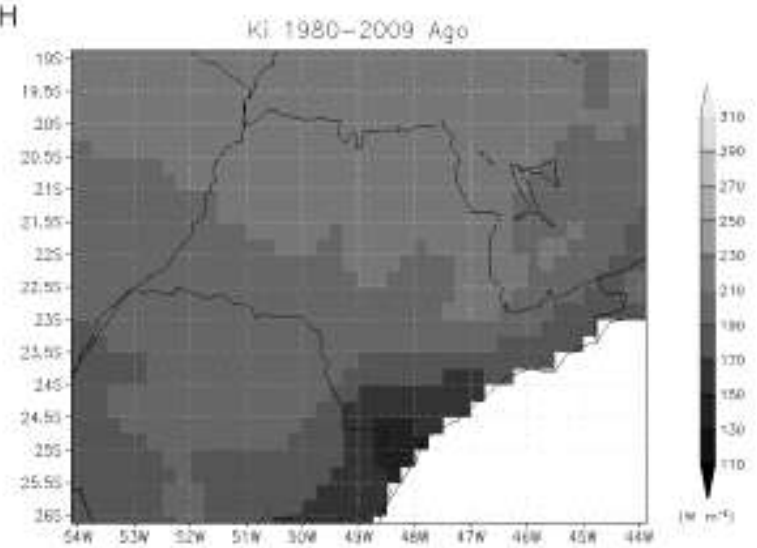

J

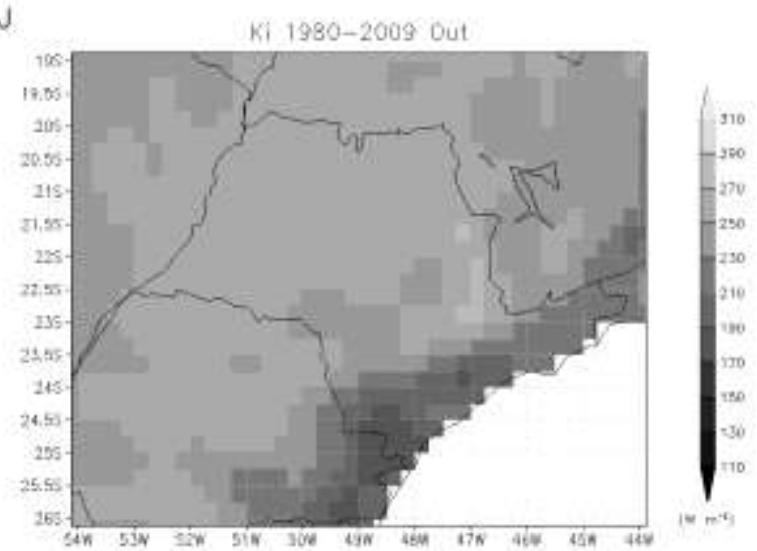

L

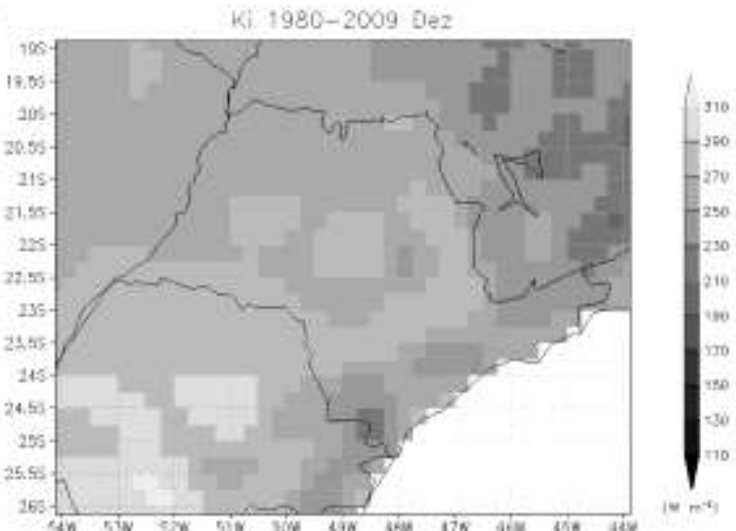

Figura B.1: Irradiância Solar Incidente (Ki) $\left[\mathrm{W} \mathrm{m}^{-2}\right]$. Médias mensais climatológicas entre 1980 e 2009. A) Janeiro; B) Fevereiro; C) Março; D) Abril; E) Maio; F) Junho; G) Julho; H) Agosto; I) Setembro; J) Outubro; K) Novembro; L) Dezembro. 
A

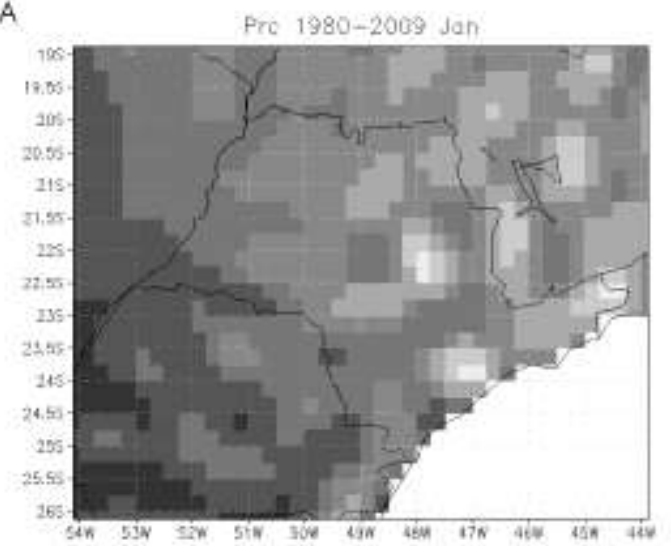

c

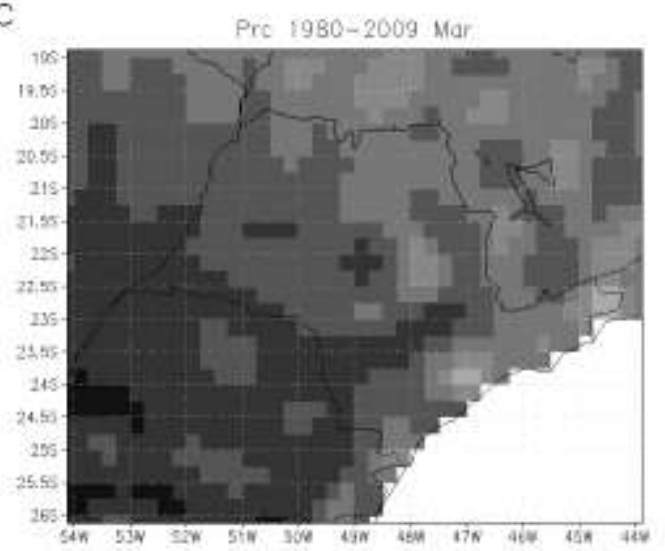

E

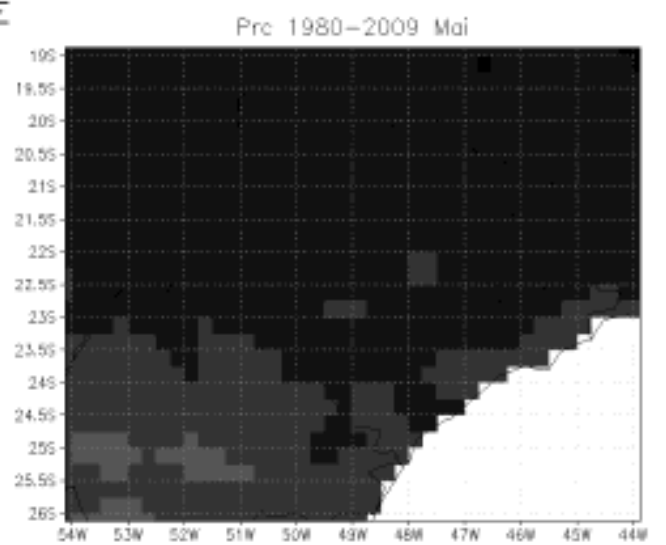

B

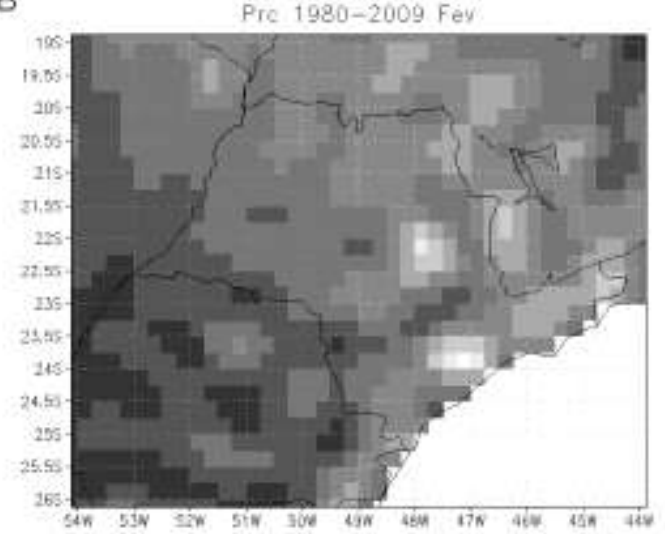

D
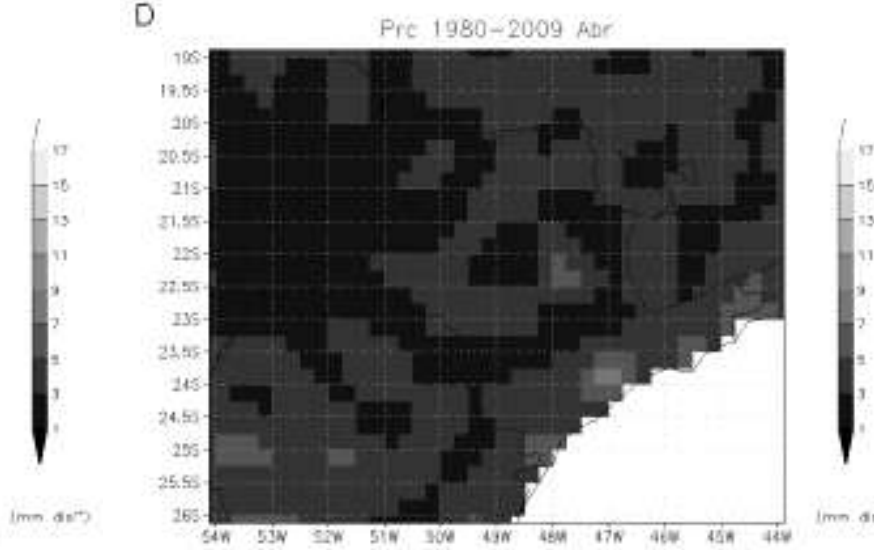

F

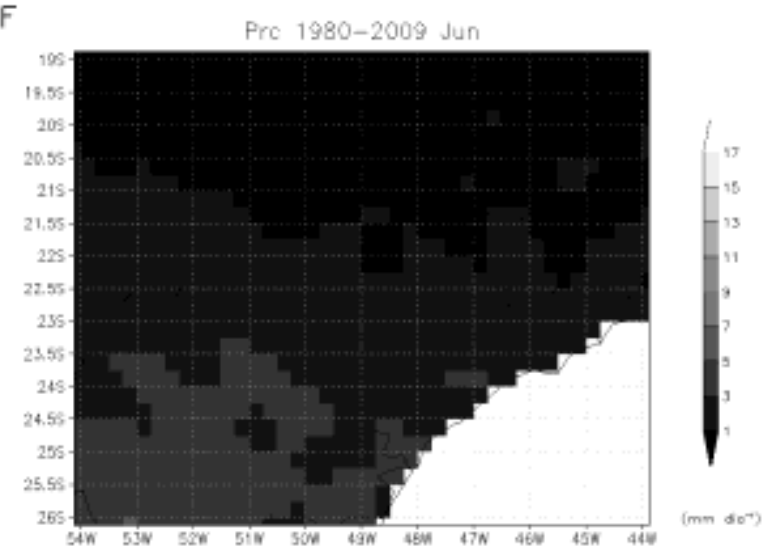


G

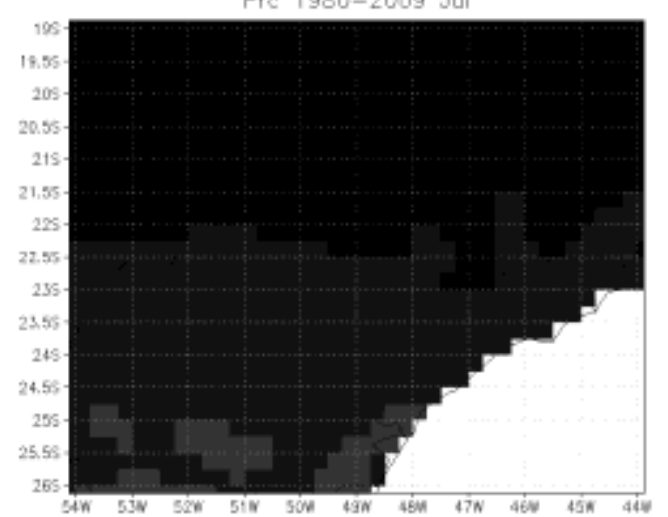

Pre 1980-2009

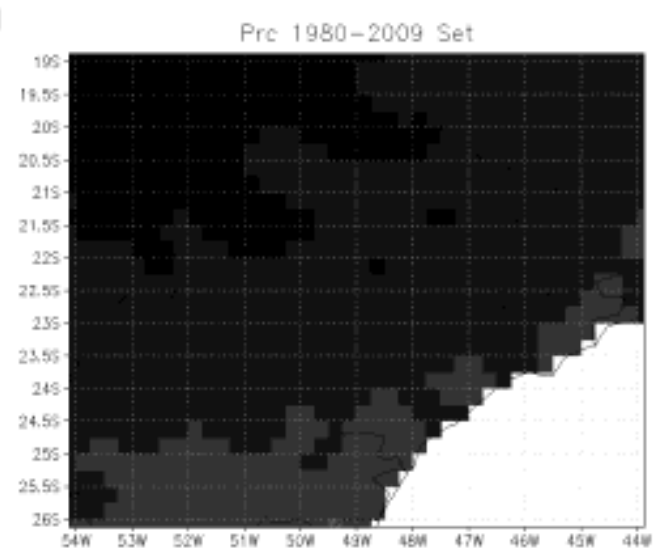

K

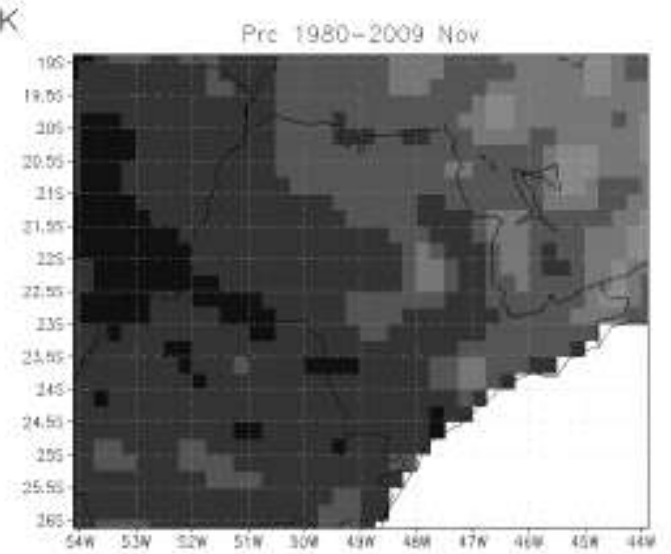

$\mathrm{H}$

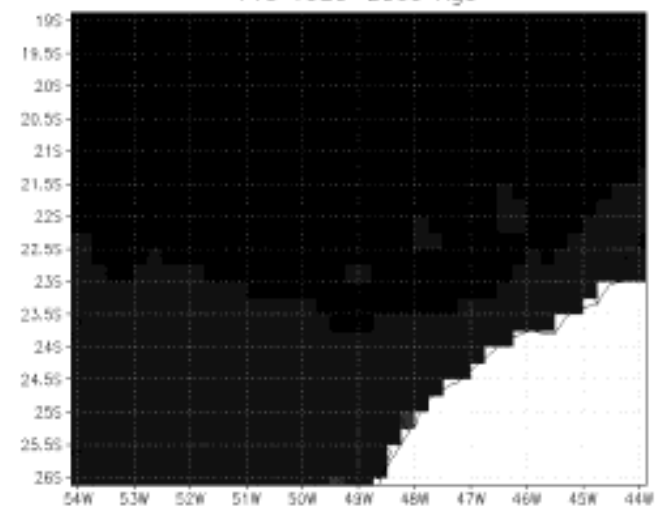

Prs 1980-2009 Ag

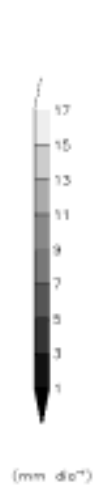

J

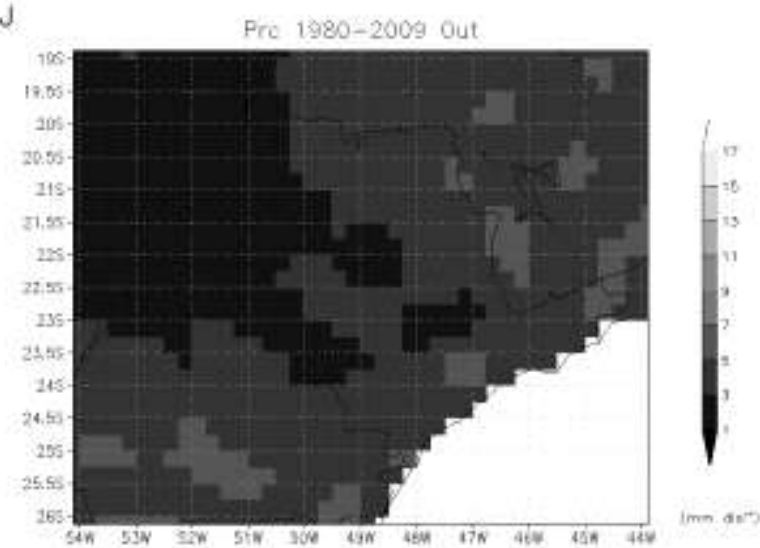

L

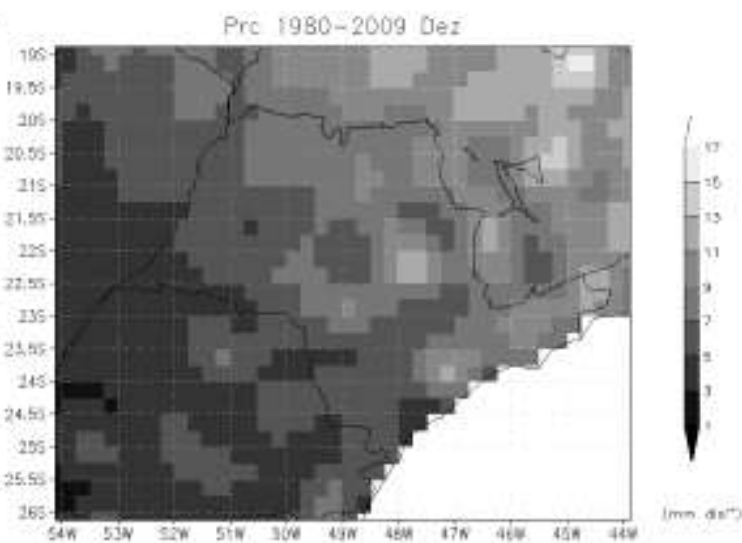

Figura B.2: Precipitação Mensal Acumulada (Prc) $\left[\mathrm{mm} \mathrm{dia}^{-1}\right]$. Médias mensais climatológicas entre 1980 e 2009. A) Janeiro; B) Fevereiro; C) Março; D) Abril; E) Maio; F) Junho; G) Julho; H) Agosto; I) Setembro; J) Outubro; K) Novembro; L) Dezembro. 
A

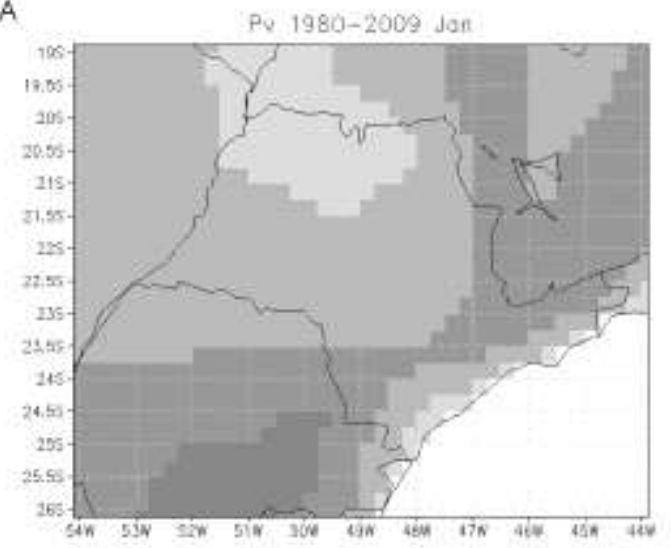

C

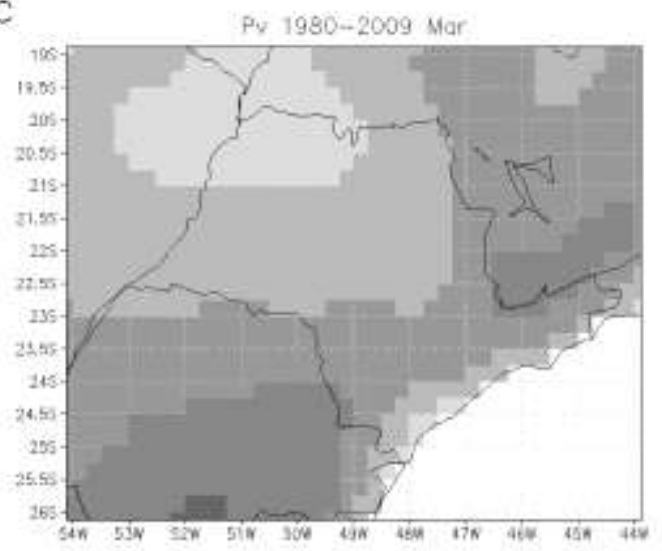

E

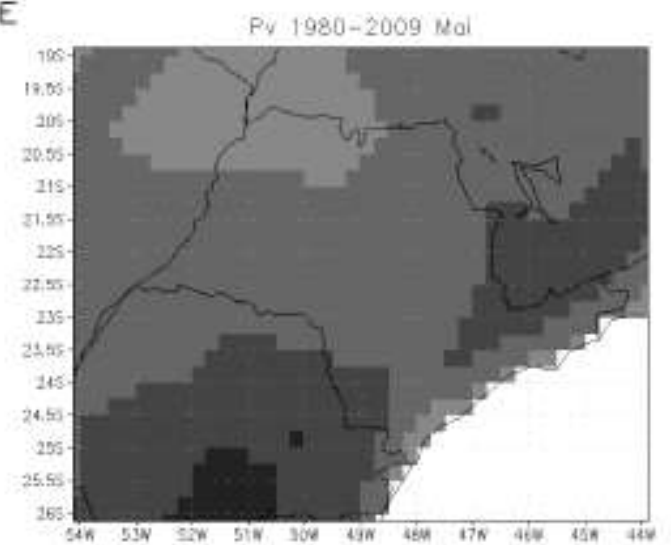

B
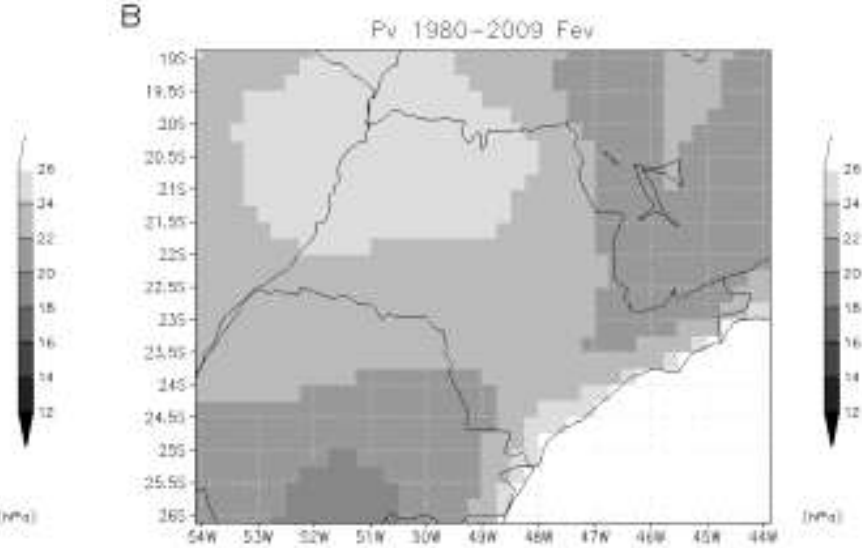

D

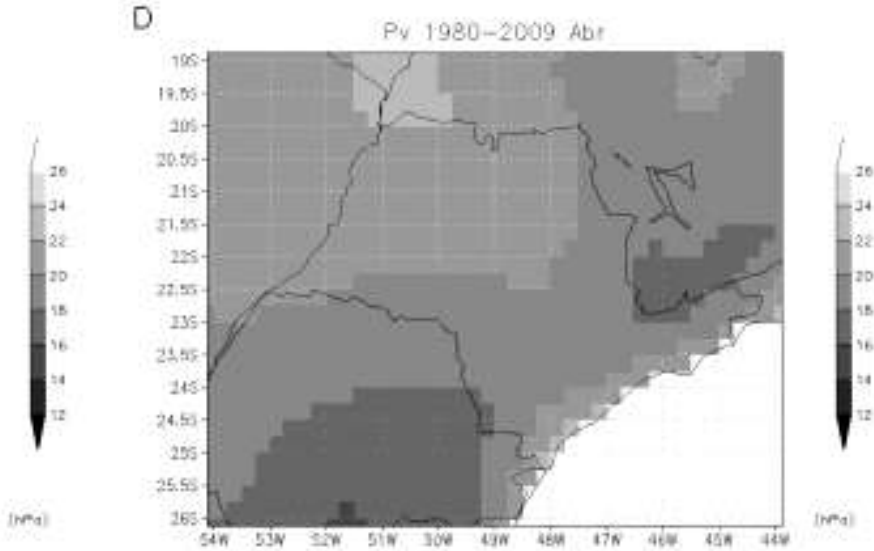

F

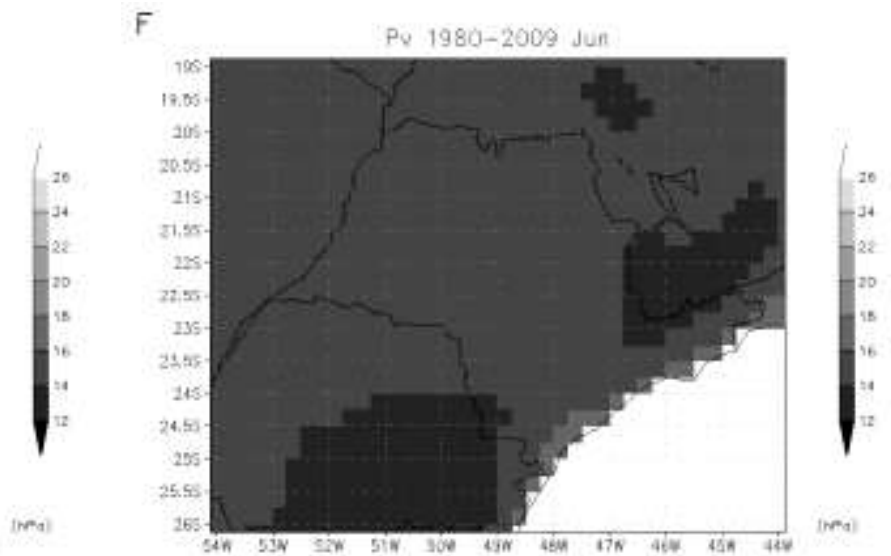


G

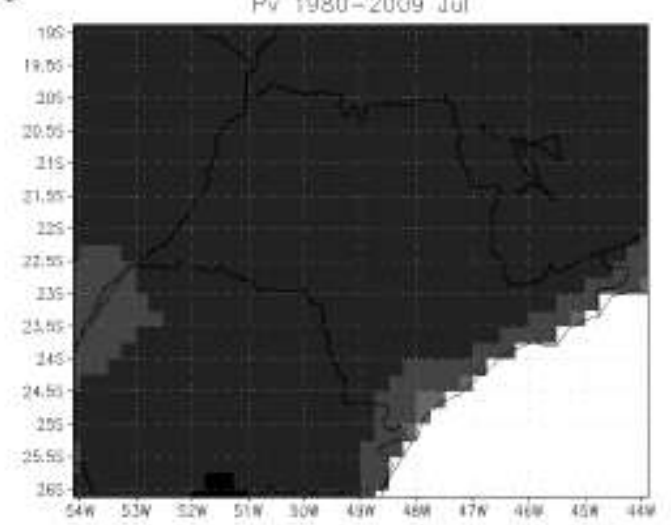

1

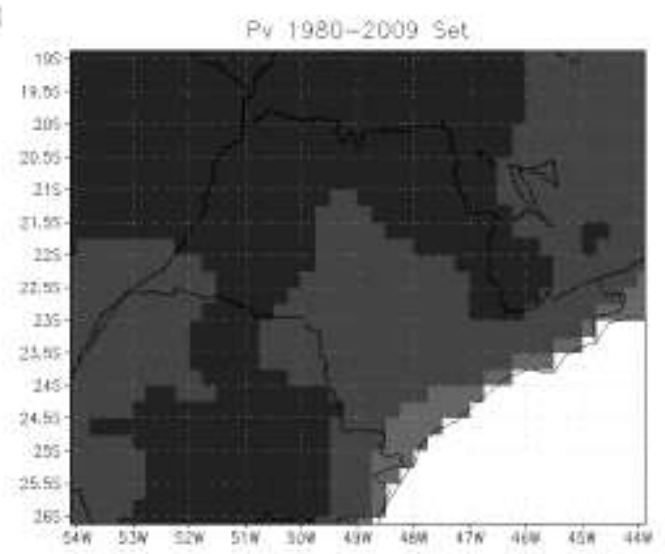

K

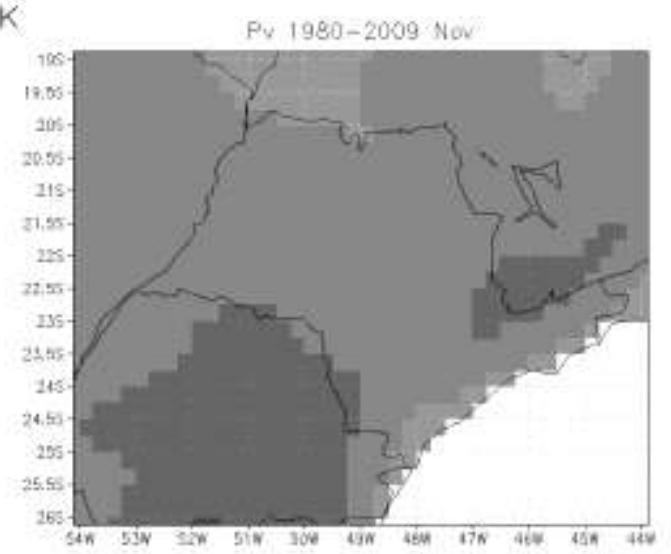

H

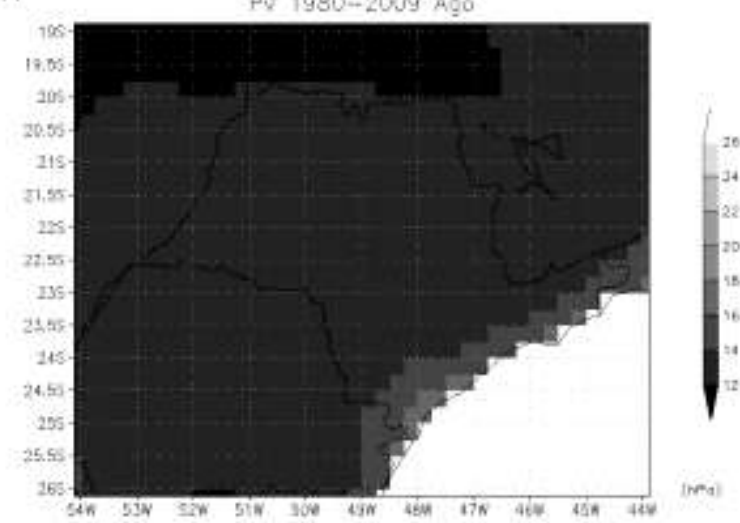

J

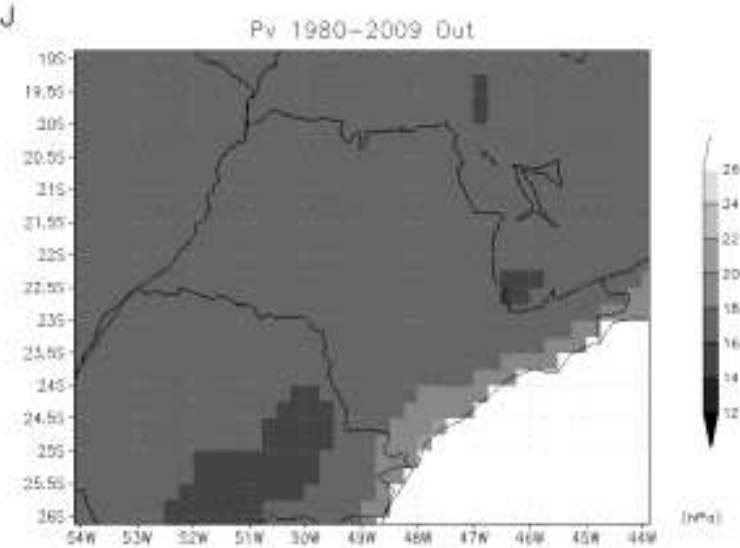

L

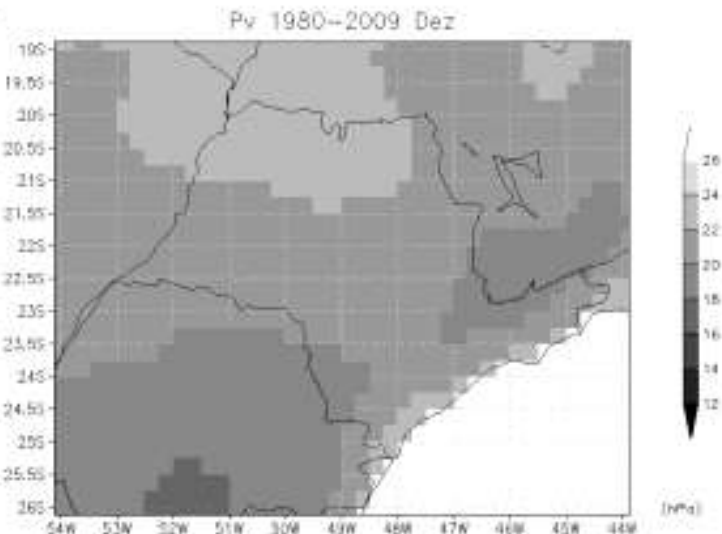

Figura B.3: Pressão Parcial do Vapor D’água (Pv) [hPa]. Médias mensais climatológicas entre 1980 e 2009. A) Janeiro; B) Fevereiro; C) Março; D) Abril; E) Maio; F) Junho; G) Julho; H) Agosto; I) Setembro; J) Outubro; K) Novembro; L) Dezembro. 
A

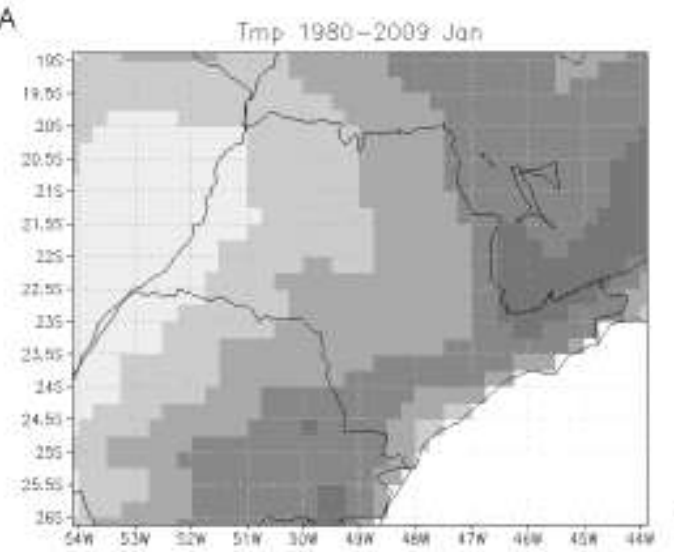

c

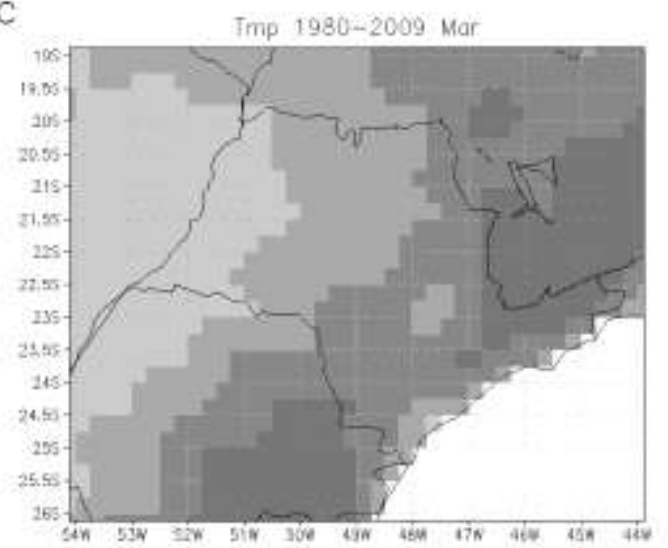

E

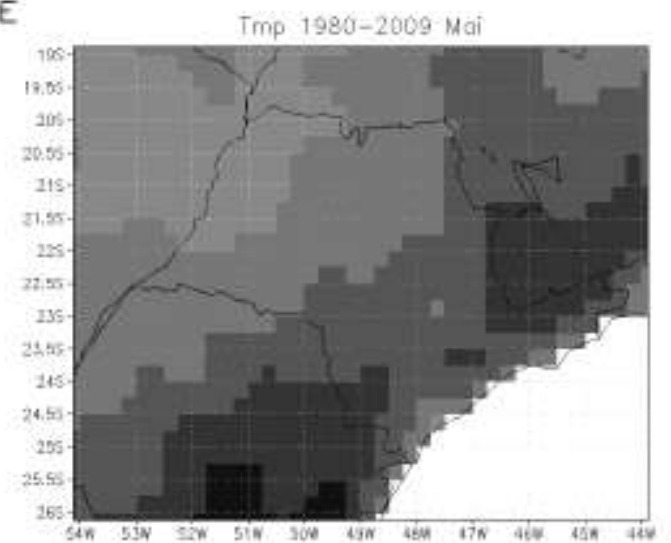

B

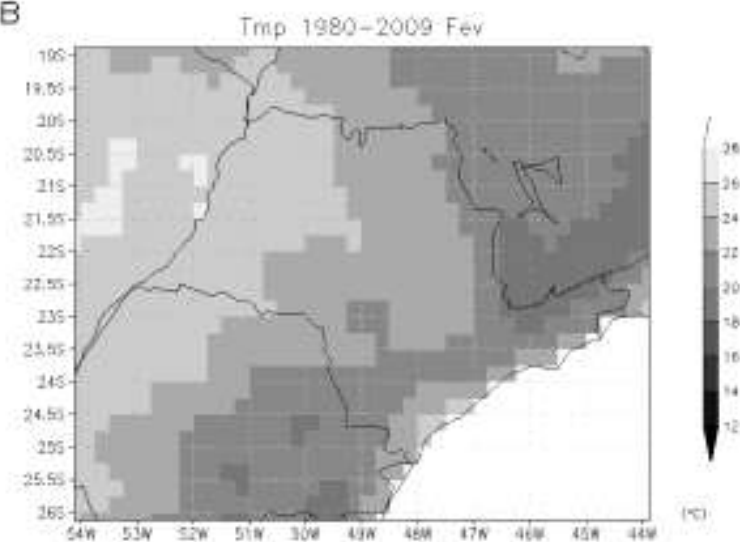

D

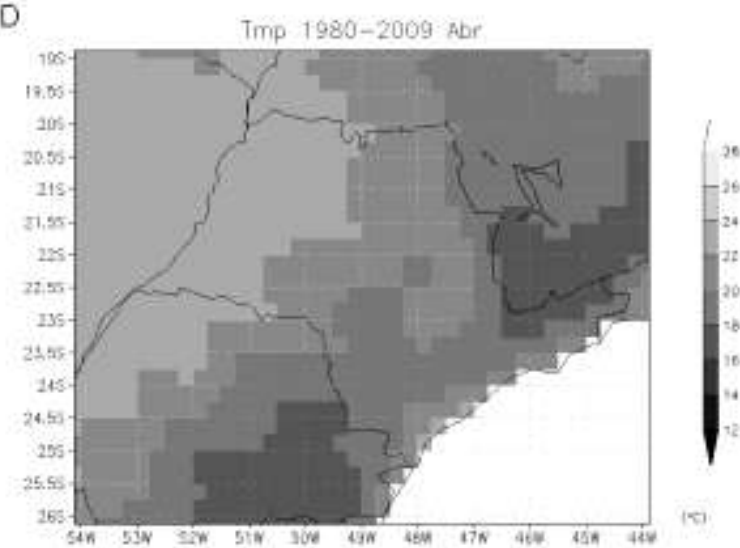

F

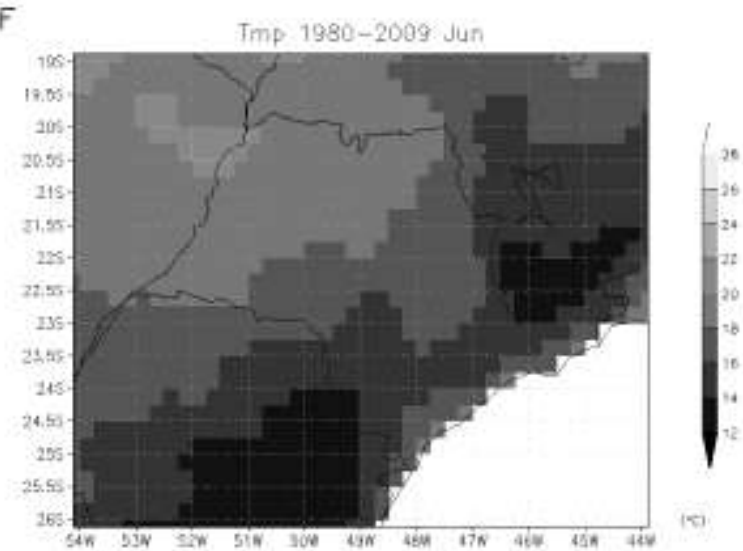


G

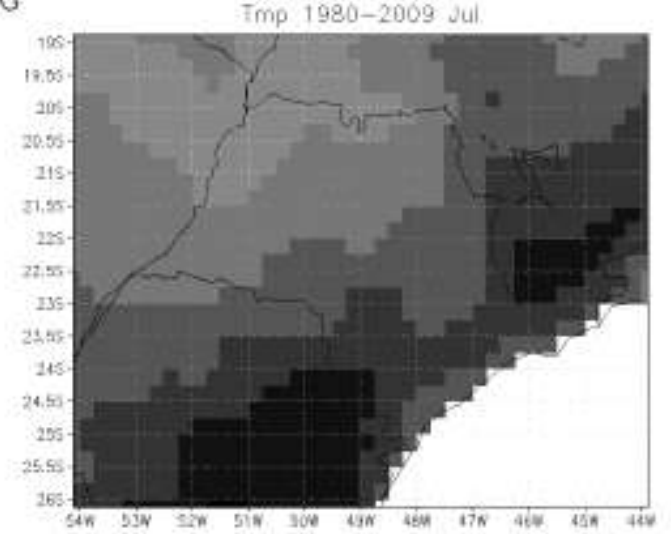

I

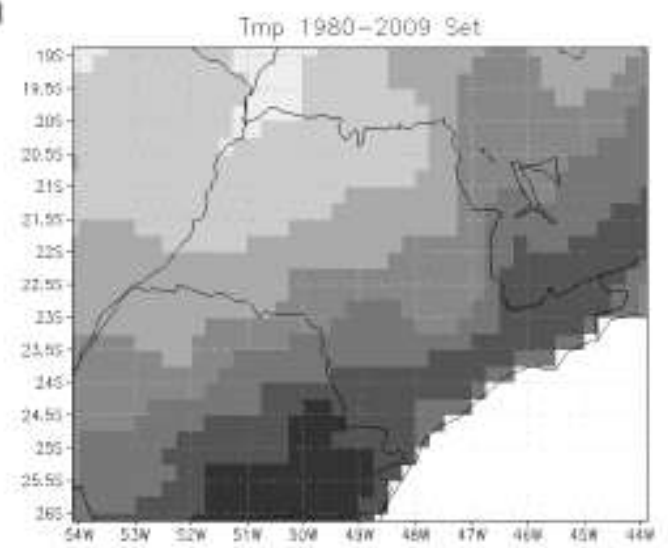

K

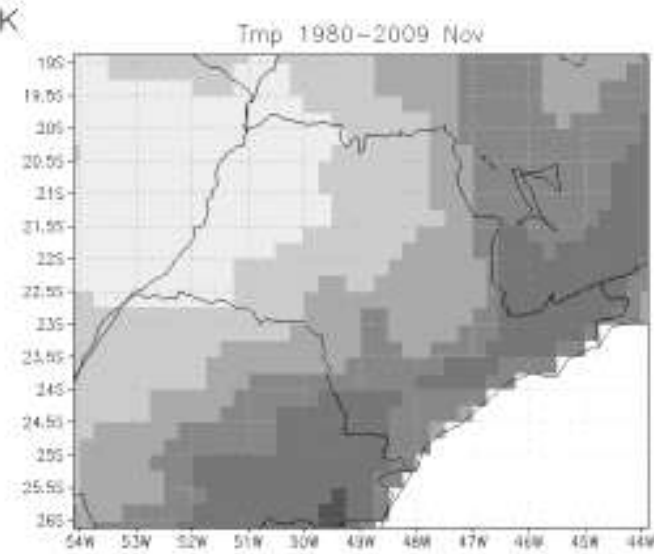

H

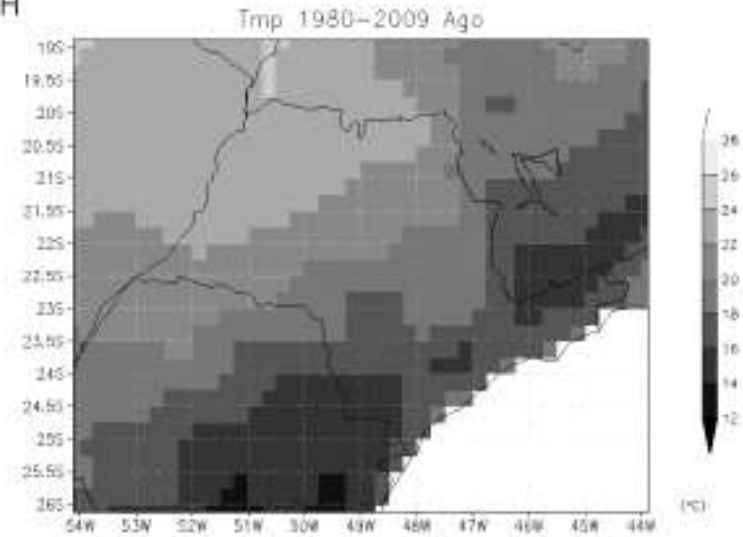

J

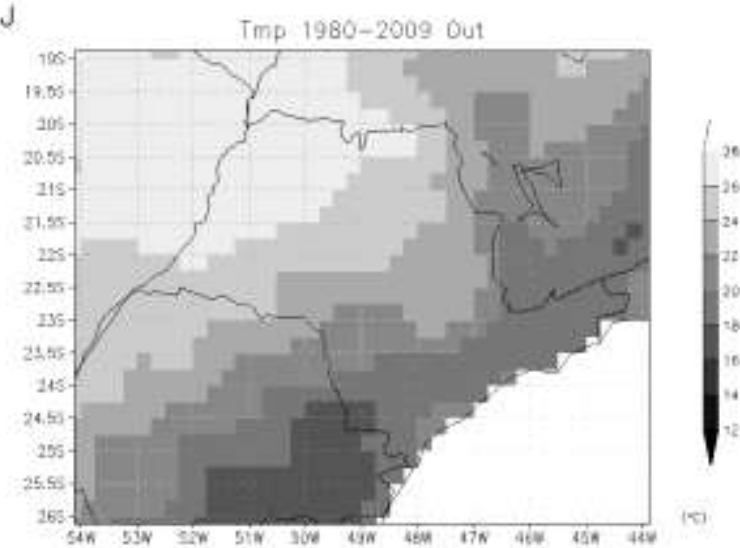

L

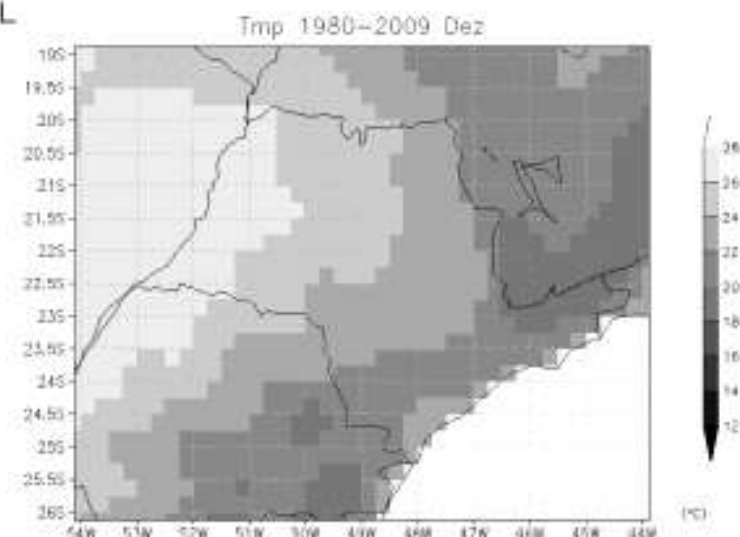

Figura B.4: Temperatura Média do Ar (Tmp) [ $\left.{ }^{\circ} \mathrm{C}\right]$. Médias mensais climatológicas entre 1980 e 2009. A) Janeiro; B) Fevereiro; C) Março; D) Abril; E) Maio; F) Junho; G) Julho; H) Agosto; I) Setembro; J) Outubro; K) Novembro; L) Dezembro. 
A

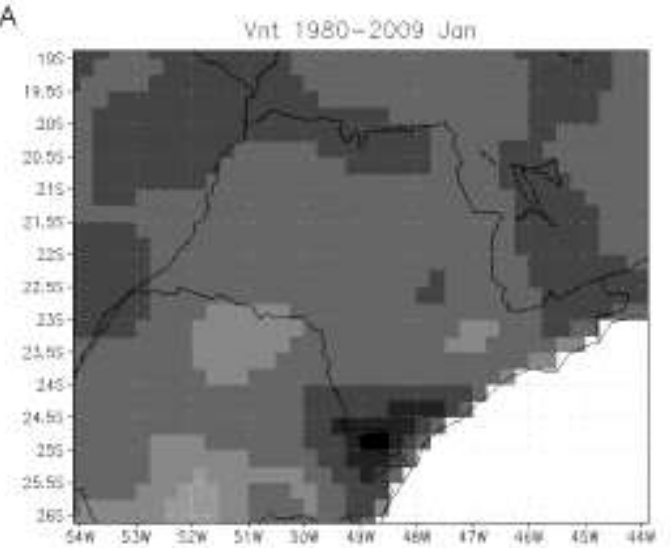

C

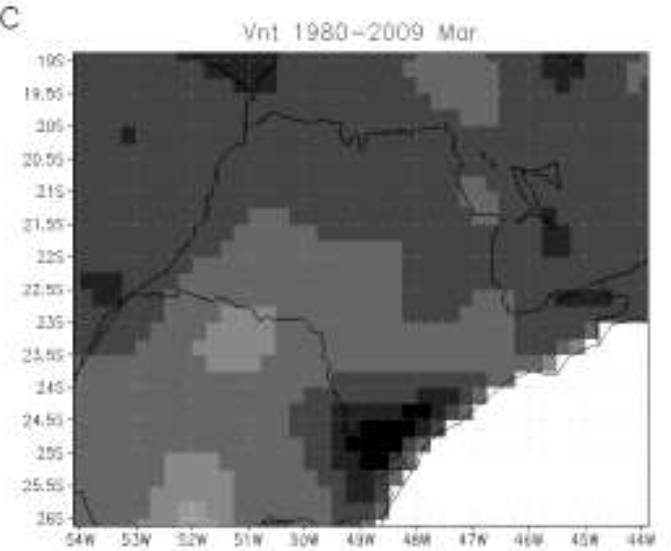

E

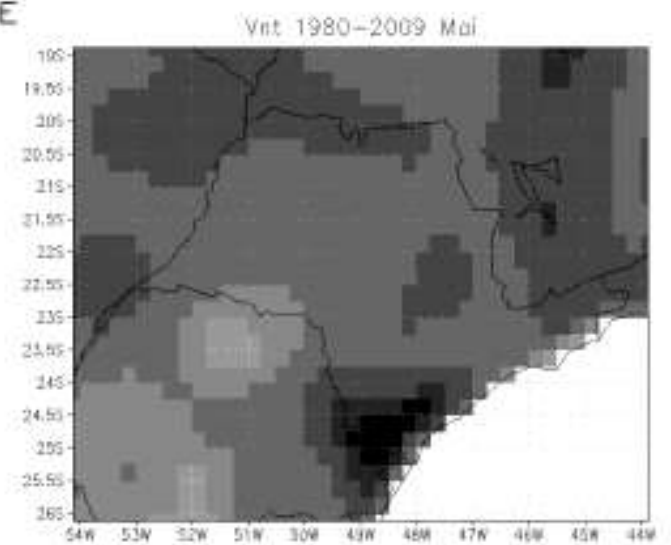

B

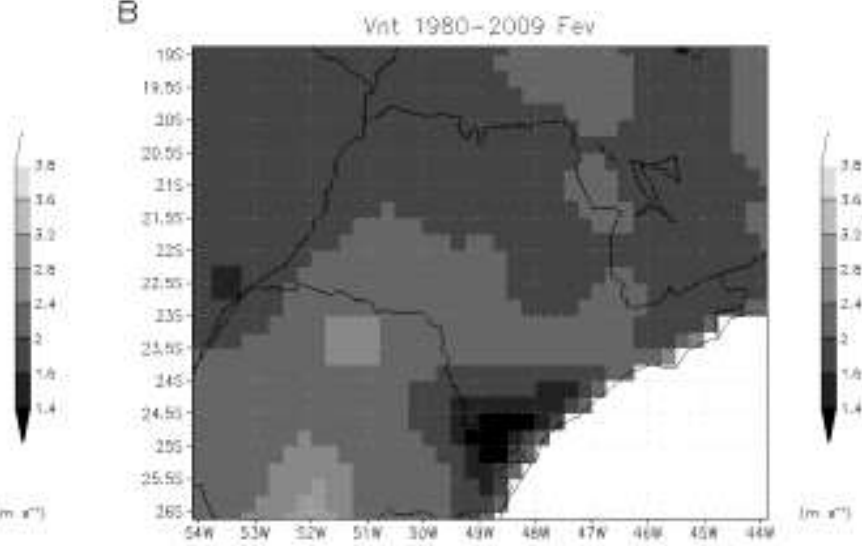

D

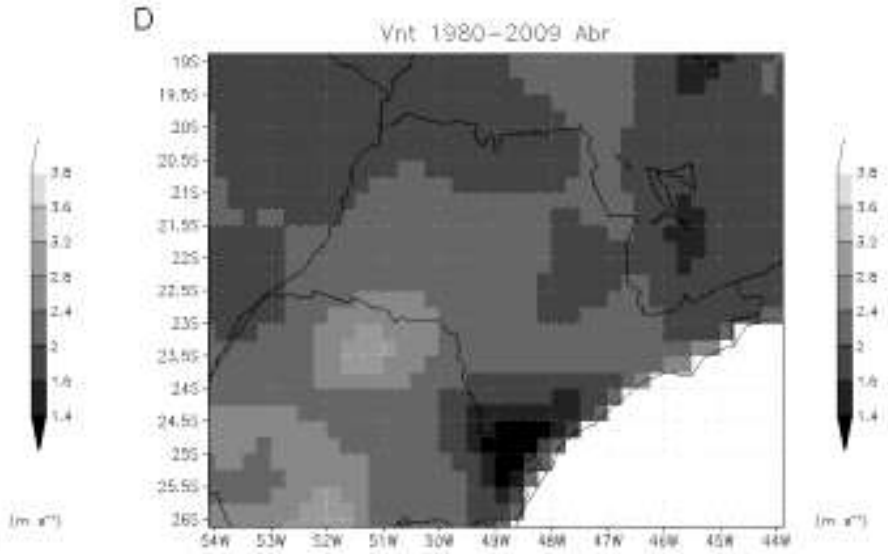

F

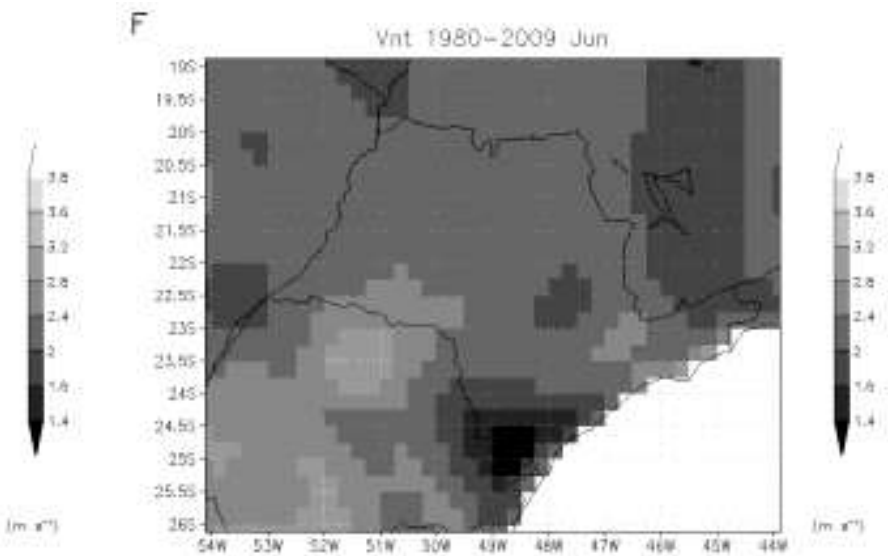


G

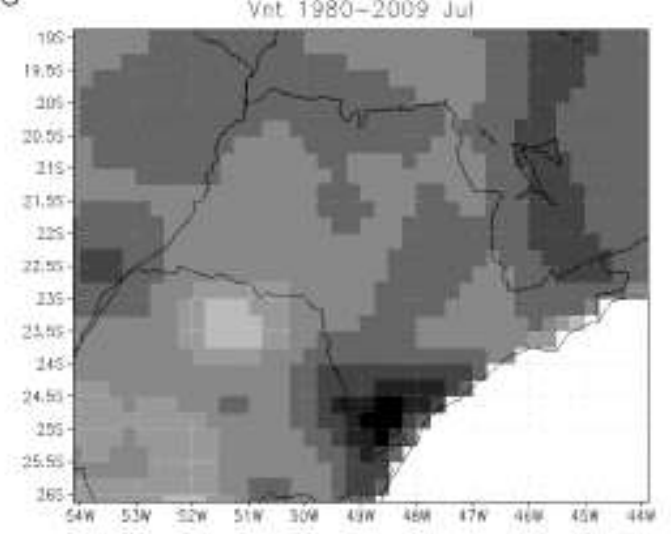

I

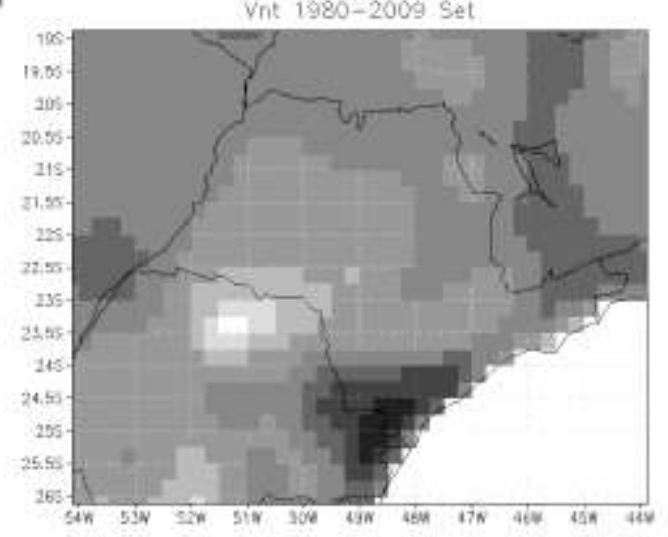

K

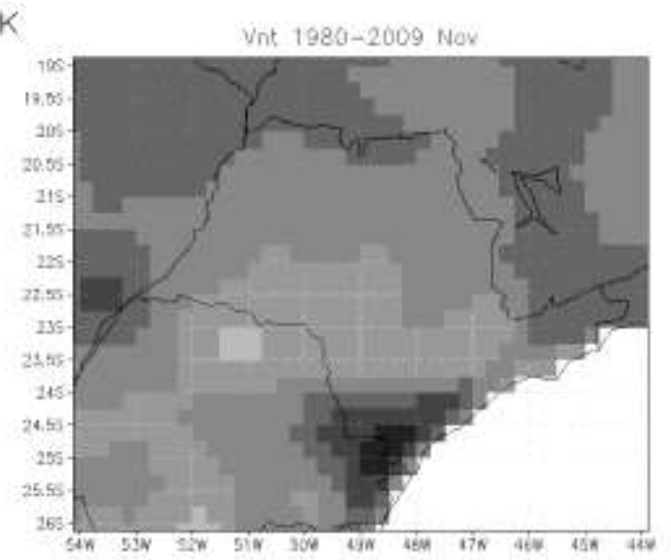

H

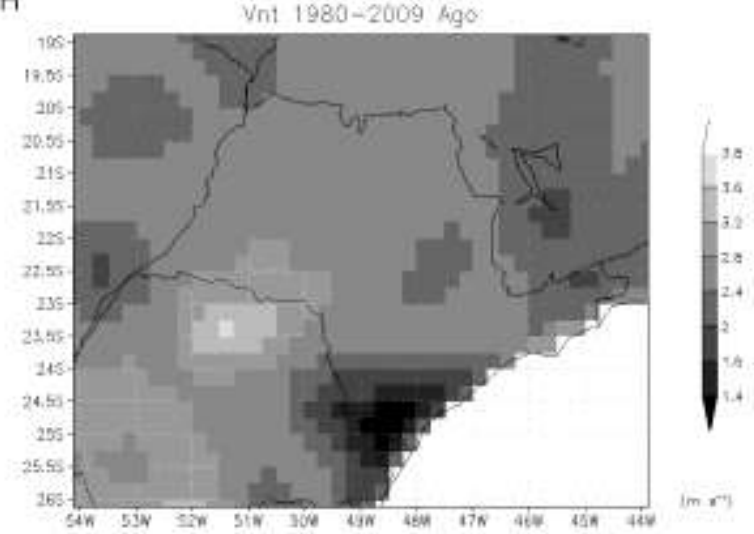

J

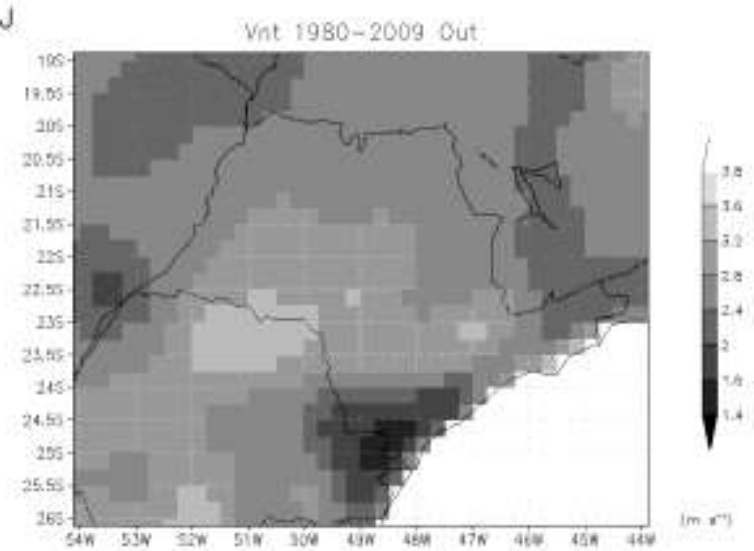

L

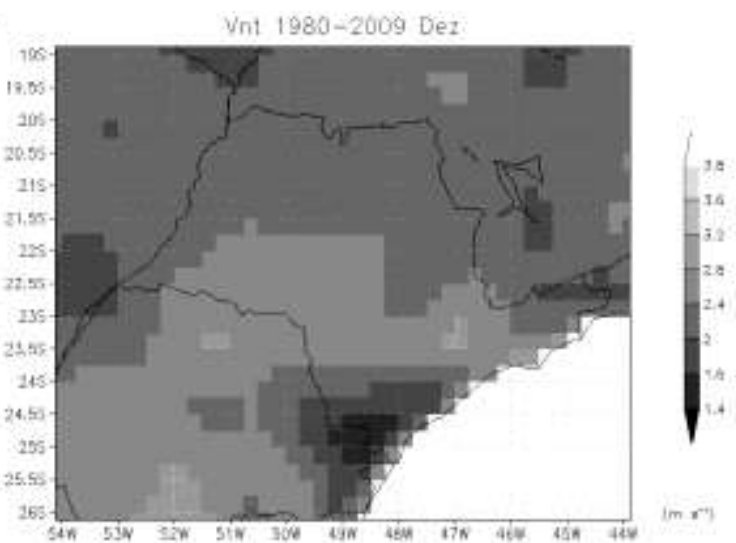

Figura B.5: Velocidade do Vento (Vnt) $\left[\mathrm{m} \mathrm{s}^{-1}\right]$. Médias mensais entre 1980 e 2009. A) Janeiro; B) Fevereiro; C) Março; D) Abril; E) Maio; F) Junho; G) Julho; H) Agosto; I) Setembro; J) Outubro; K) Novembro; L) Dezembro. 


\section{B.1.2 Comparação com observações}

A

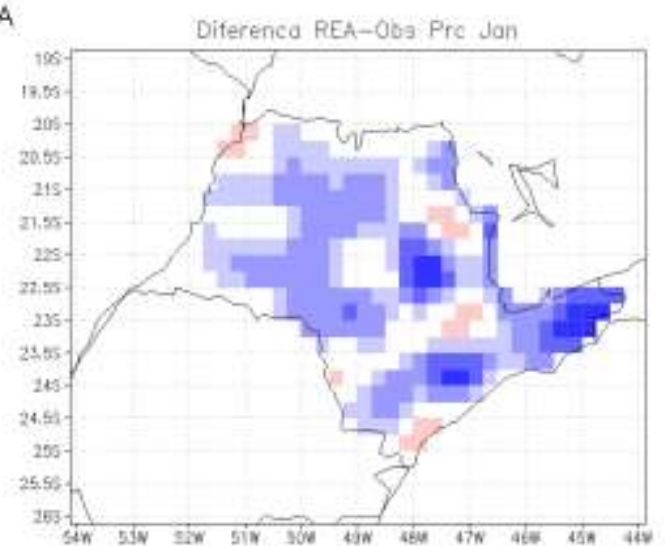

C

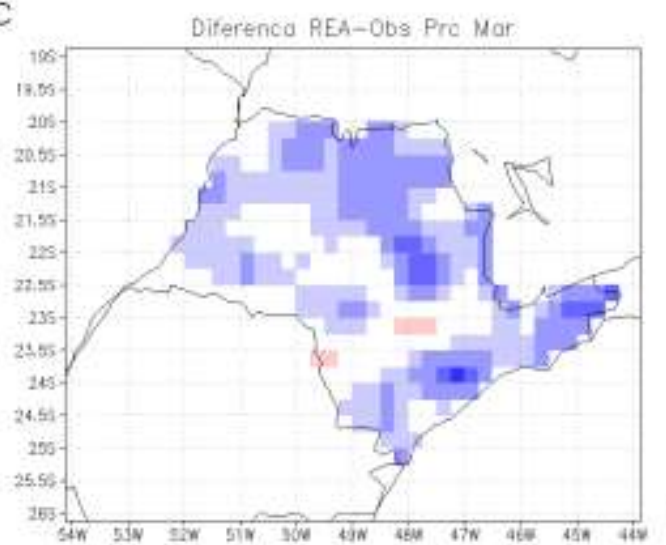

E

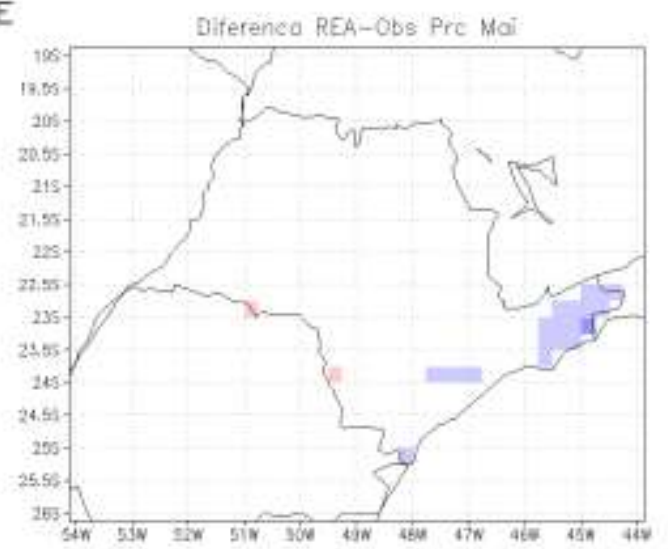

B

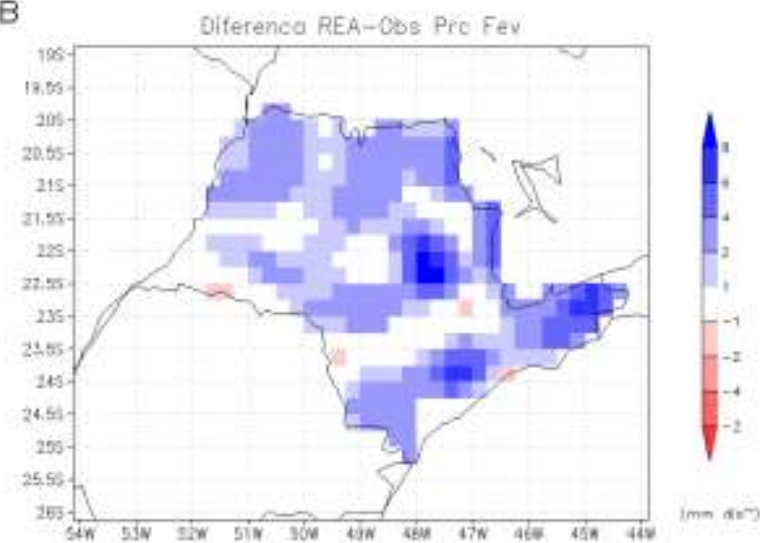

D

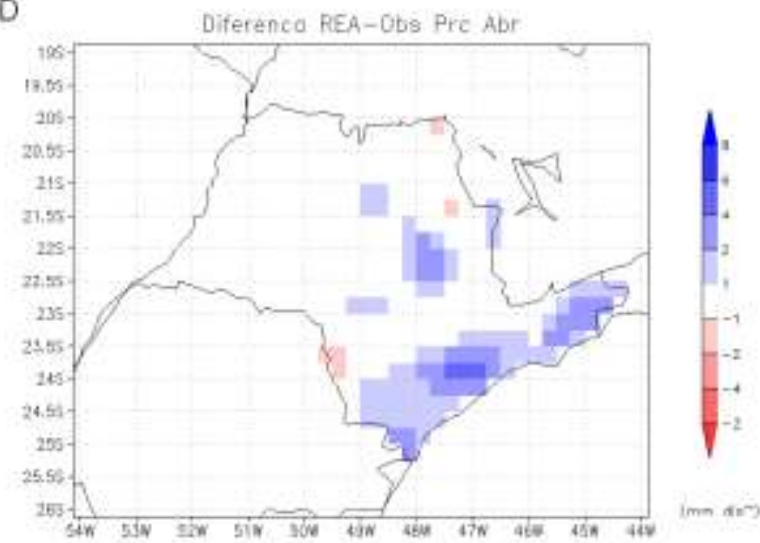

F

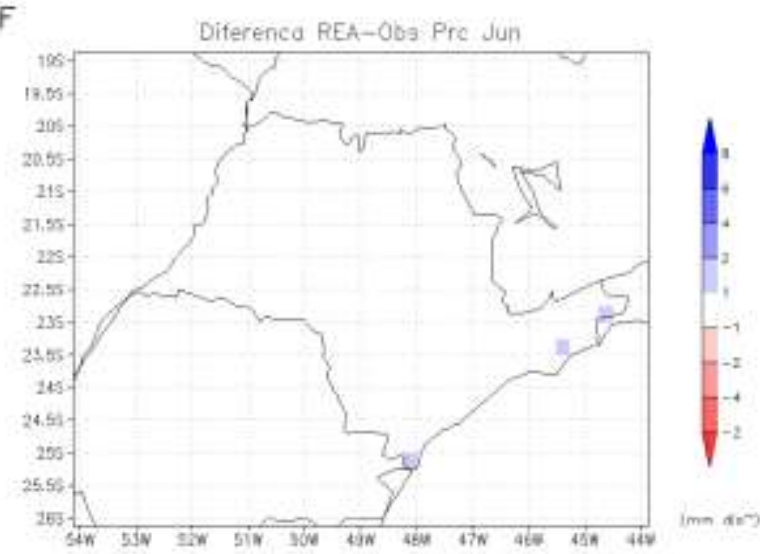


G

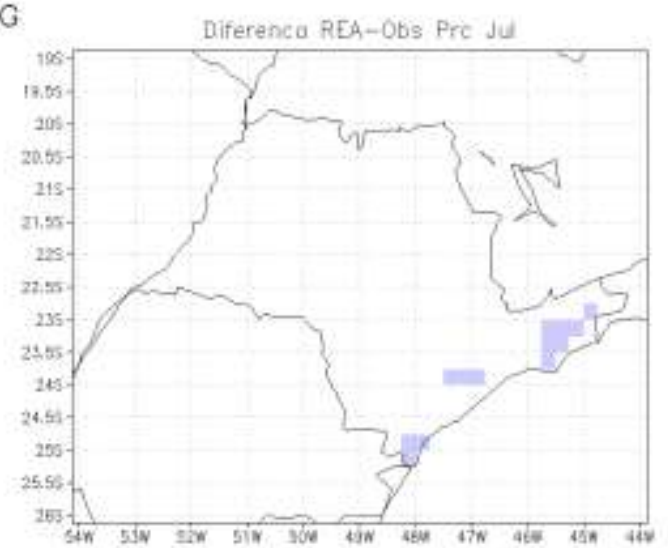

I

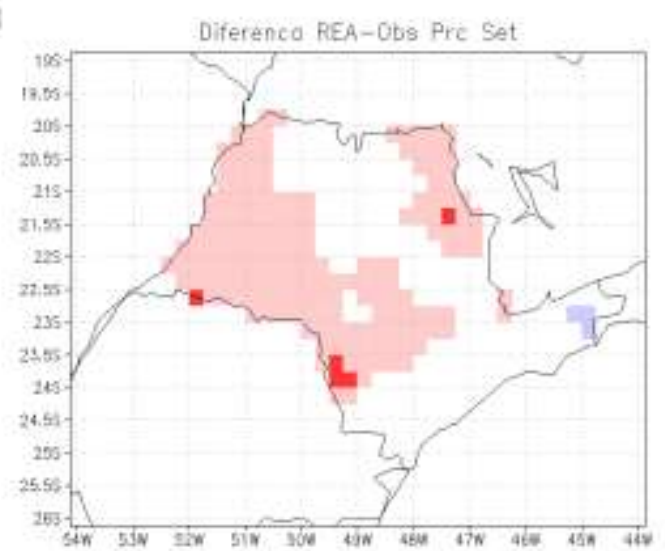

K

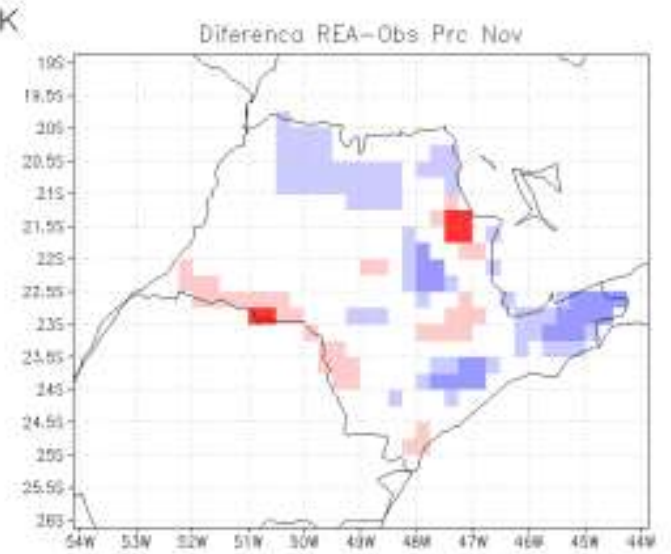

H
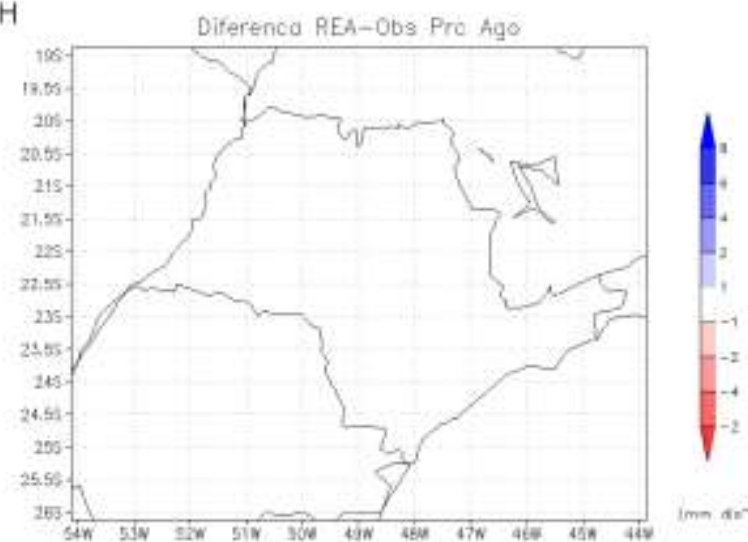

J

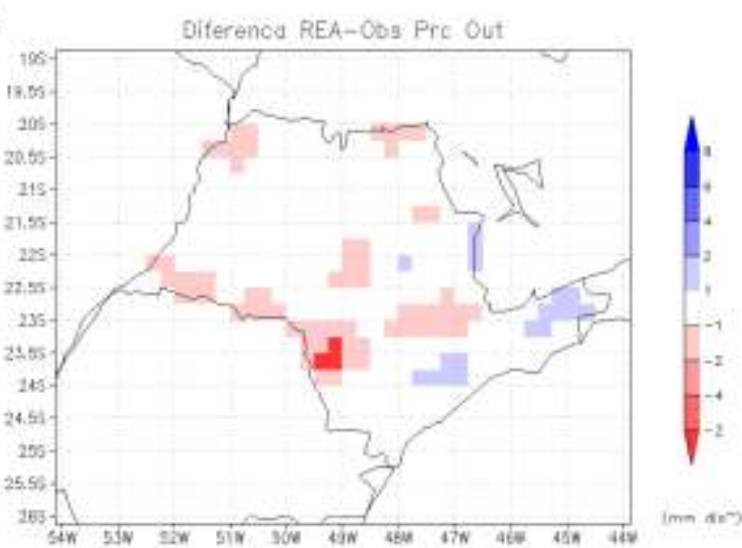

L

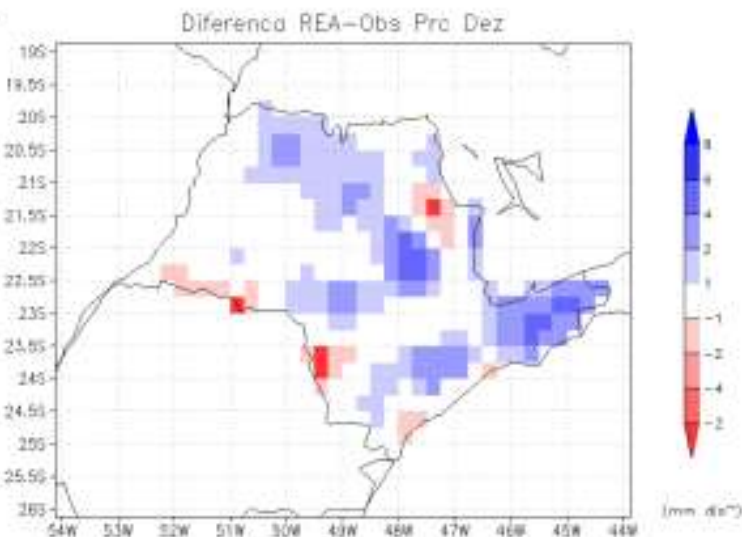

Figura B.6: Diferença entre a precipitação mensal acumulada da Reanálise e do conjunto de dados observados [mm dia ${ }^{-1}$ ]. Média no período entre 1980 e 2009. A) Janeiro; B) Fevereiro; C) Março; D) Abril; E) Maio; F) Junho; G) Julho; H) Agosto; I) Setembro; J) Outubro; K) Novembro; L) Dezembro. 
A

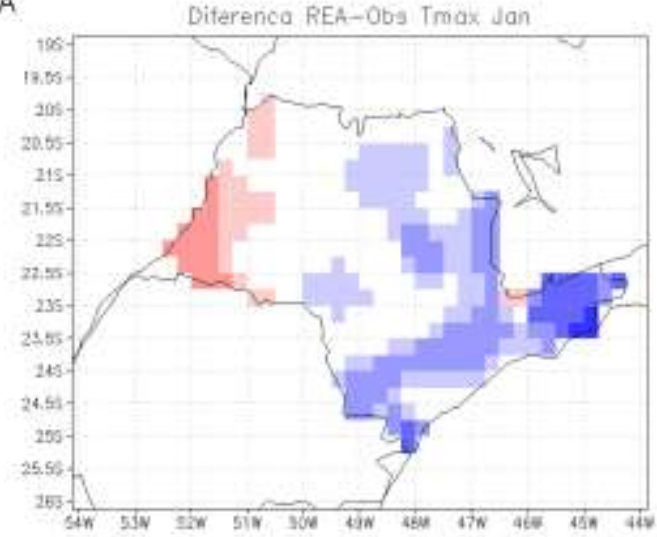

C

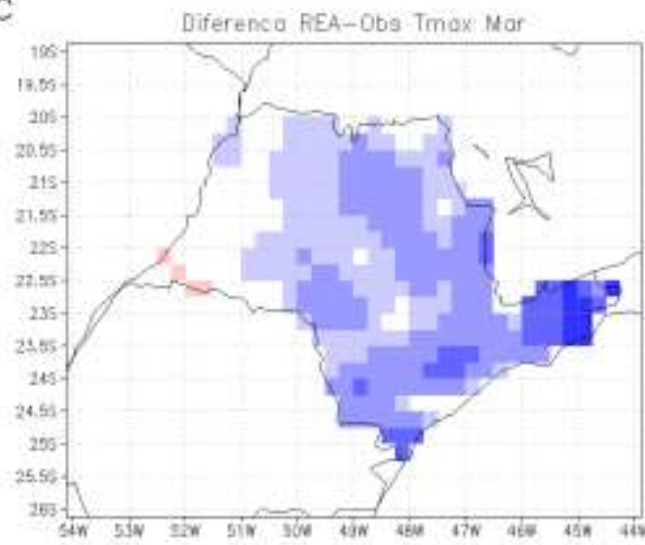

E

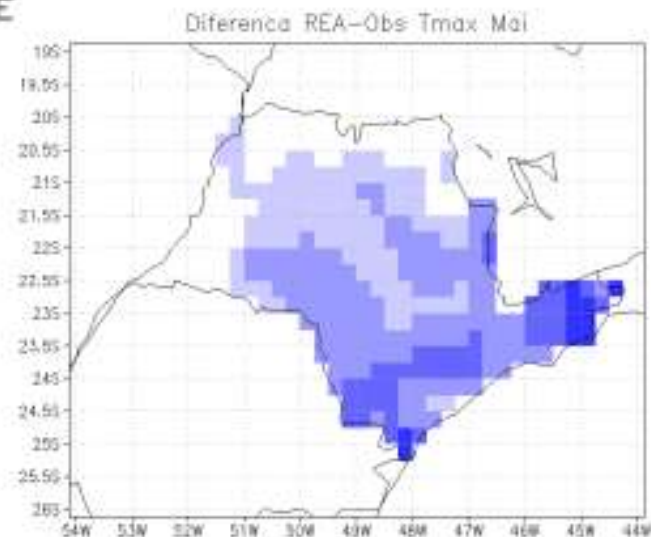

B

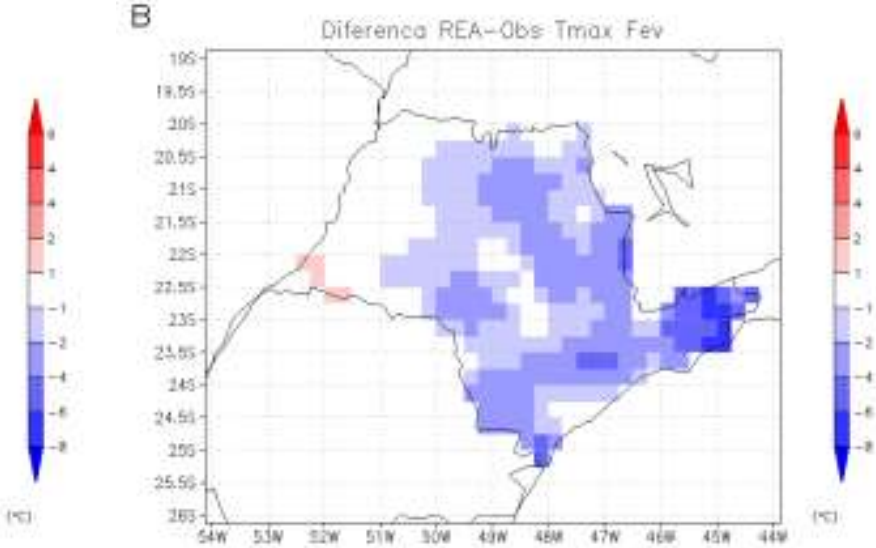

D

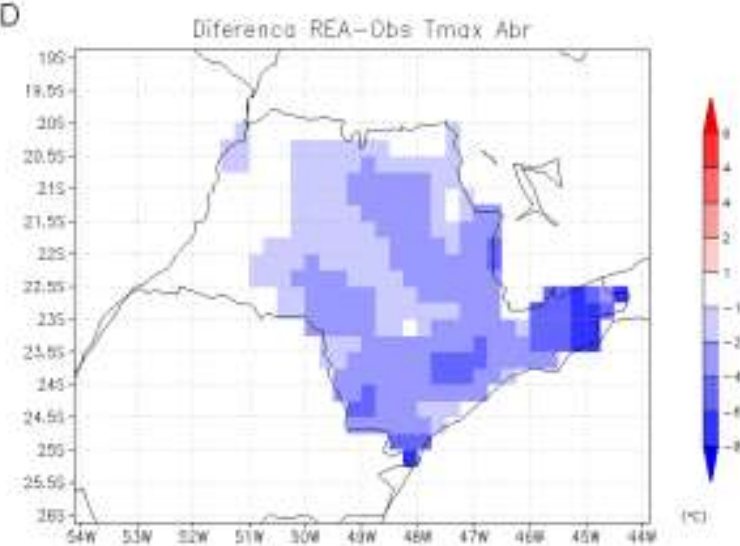

F

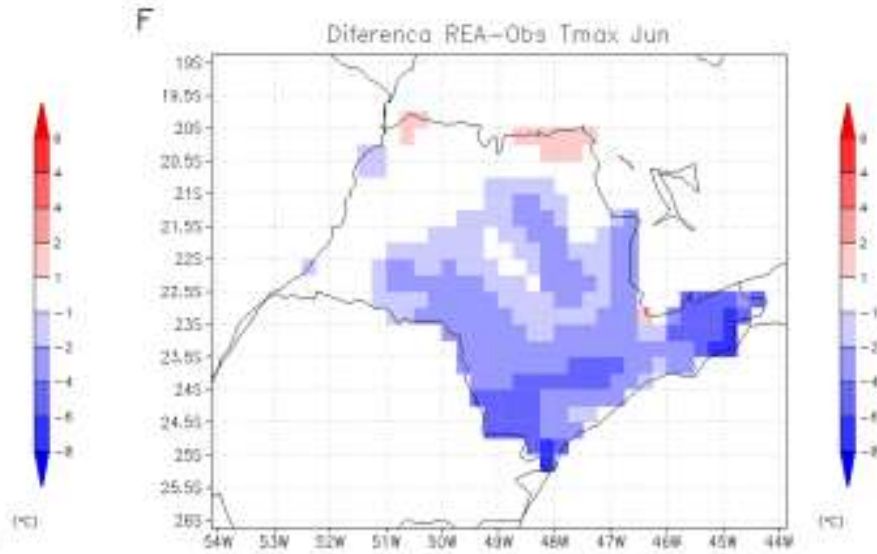


G

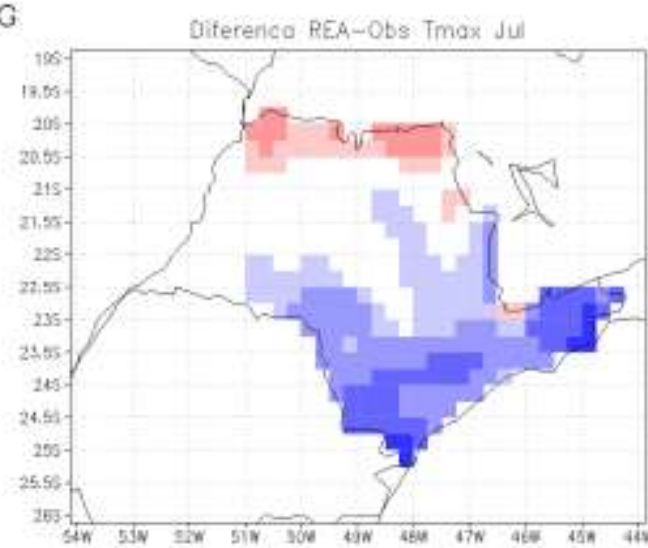

1

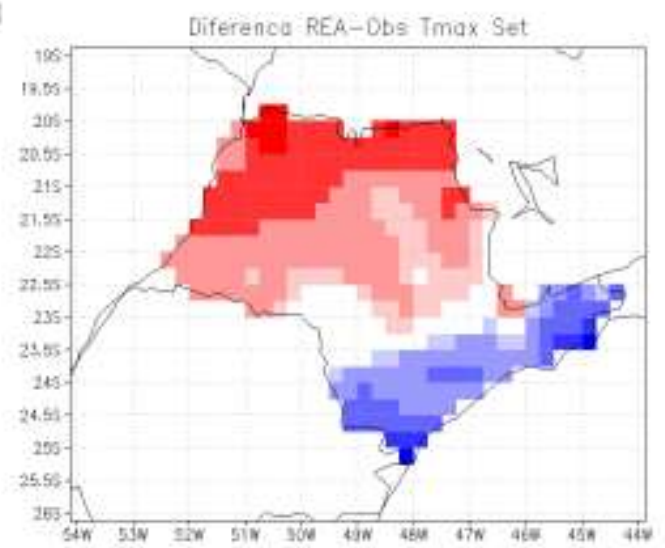

K

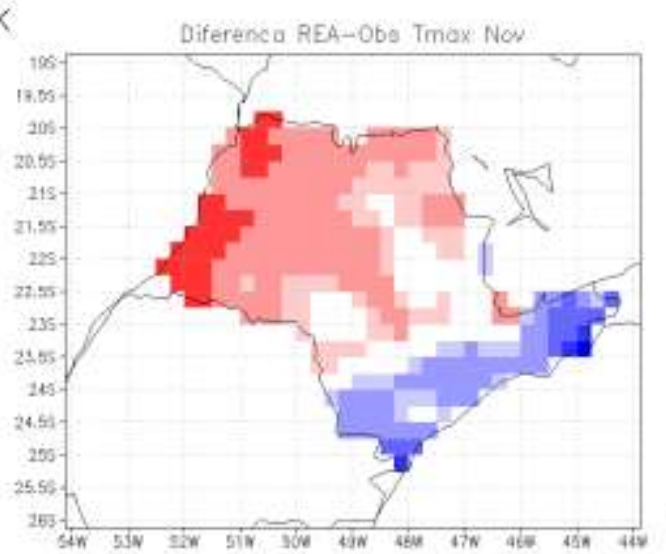

H

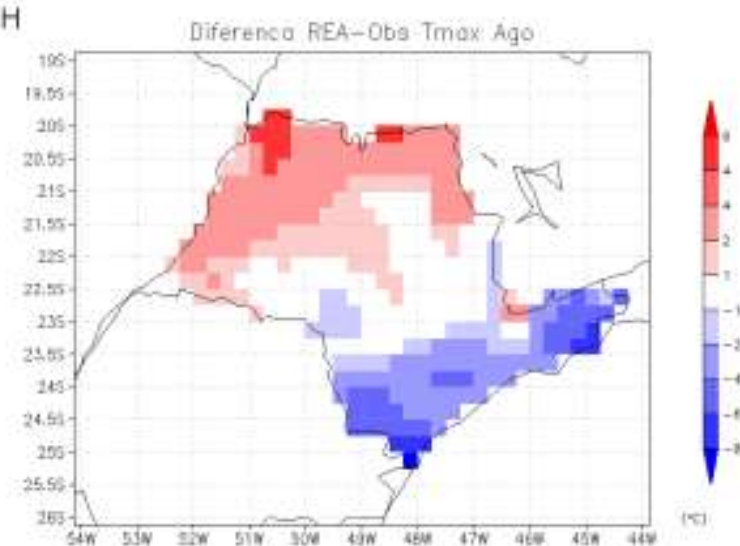

J

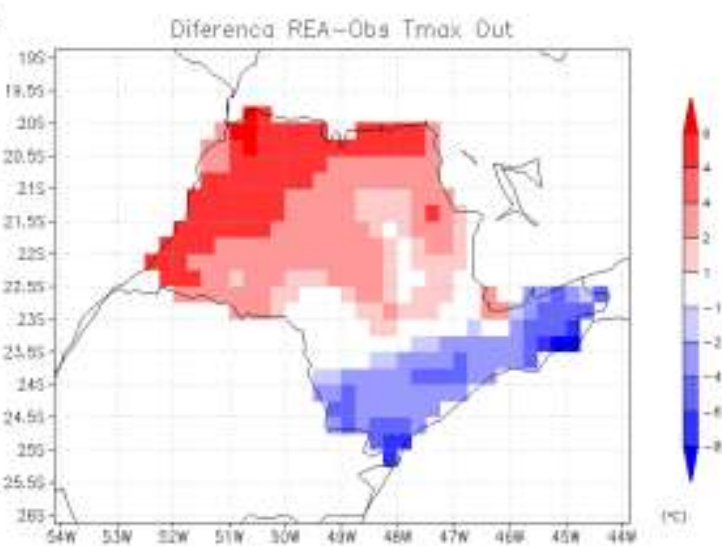

L

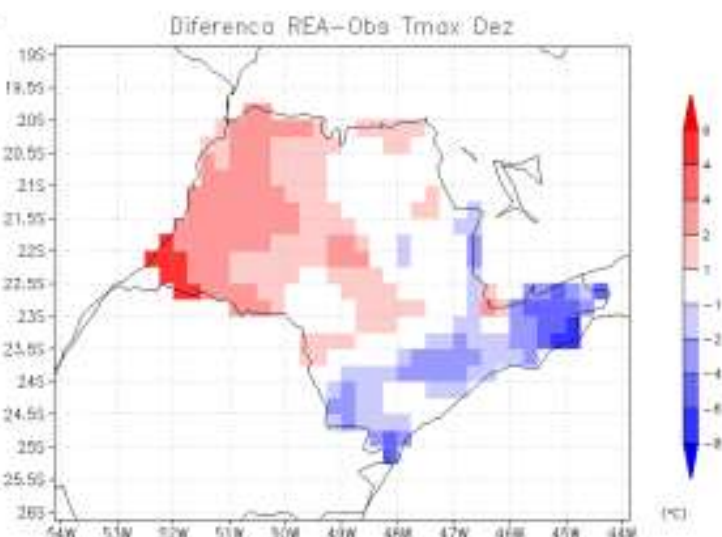

Figura B.7: Diferença entre a temperatura máxima média mensal da Reanálise e o conjunto de dados observados $\left[{ }^{\circ} \mathrm{C}\right]$. Média no período entre 1980 e 2009. A) Janeiro; B) Fevereiro; C) Março; D) Abril; E) Maio; F) Junho; G) Julho; H) Agosto; I) Setembro; J) Outubro; K) Novembro; L) Dezembro. 
A

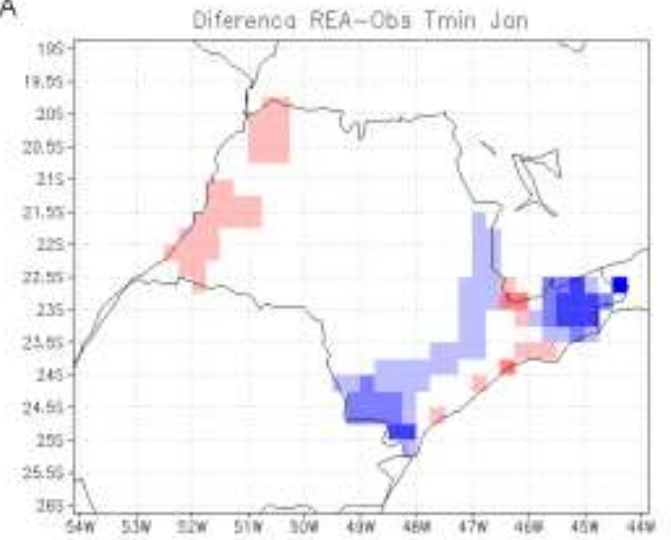

C

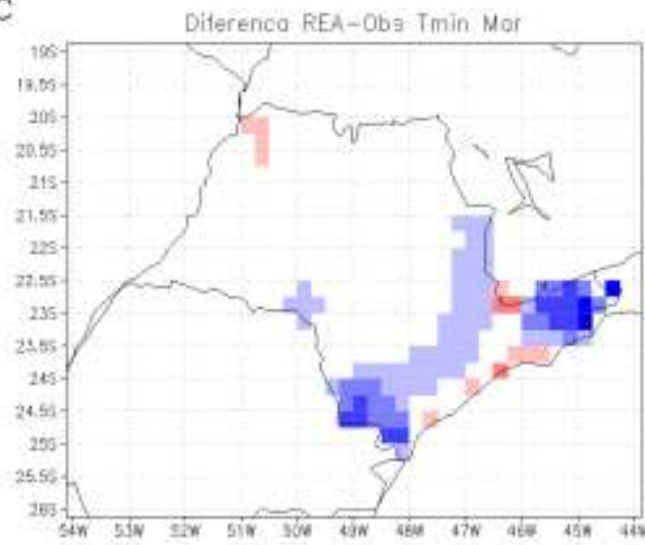

E

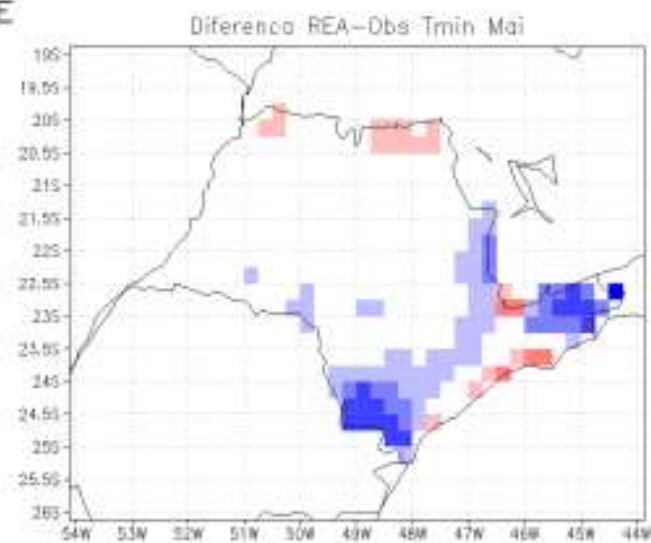

B

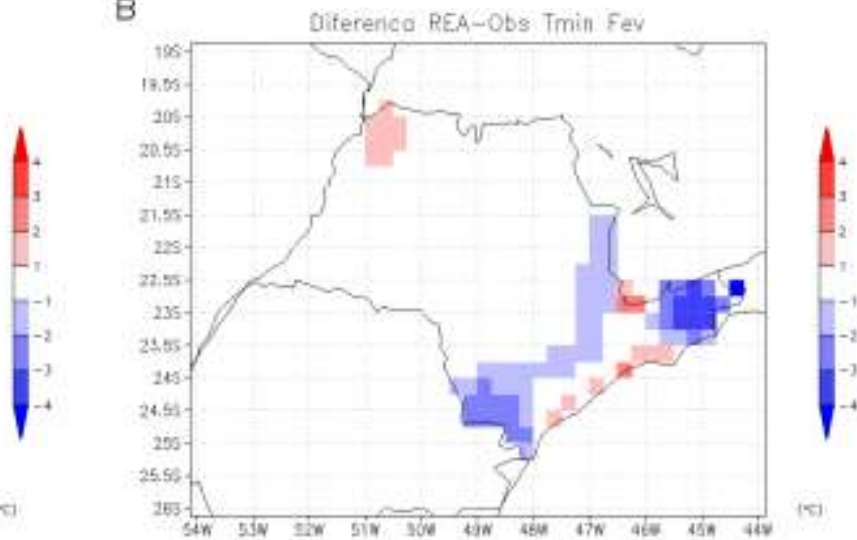

D

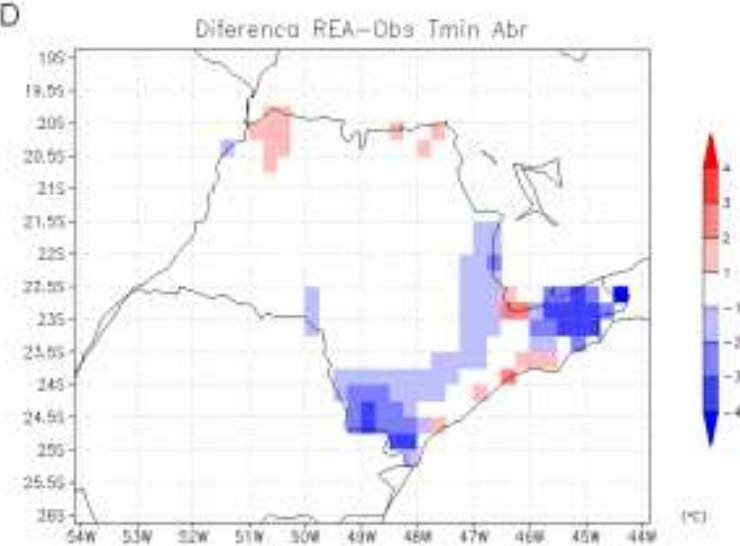

F

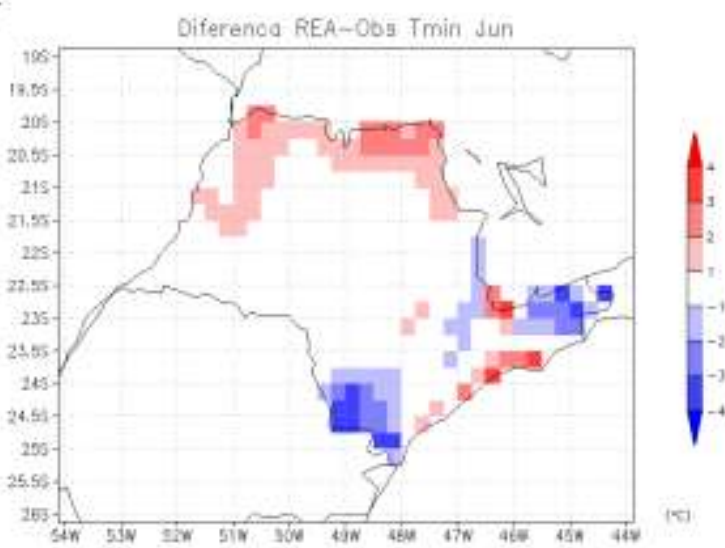


G

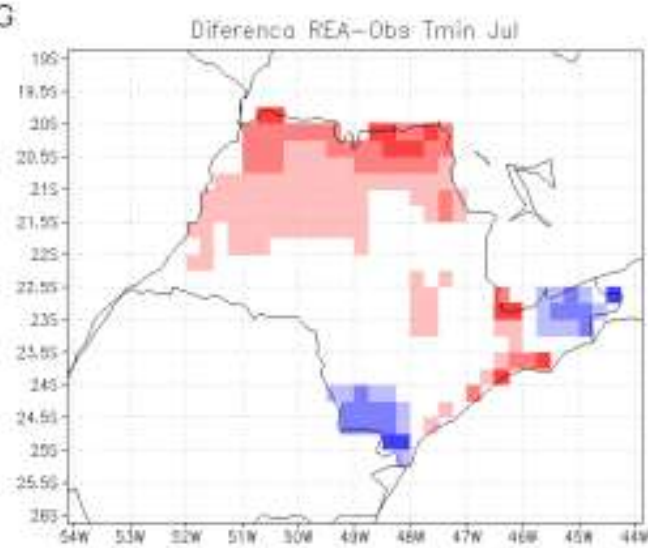

1

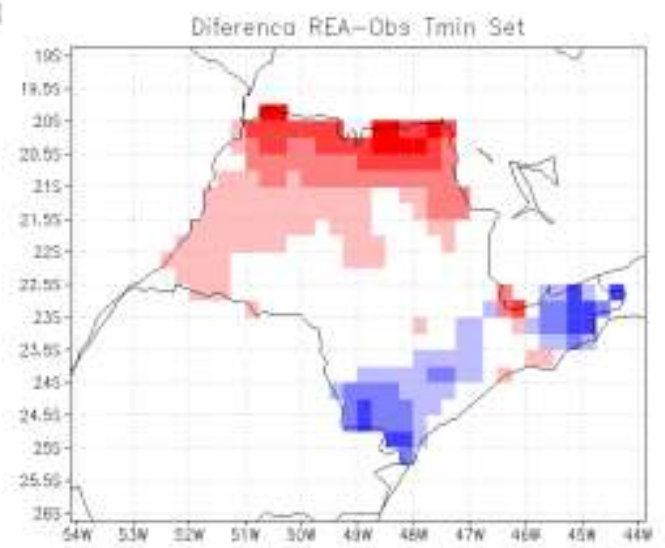

K

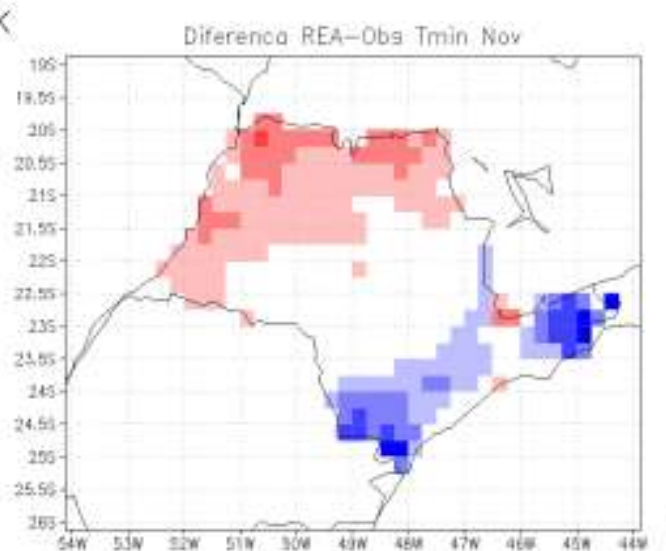

H

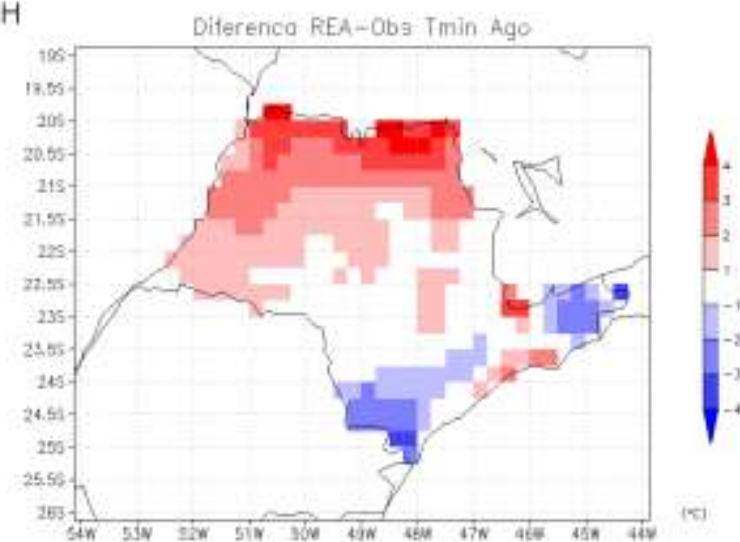

J

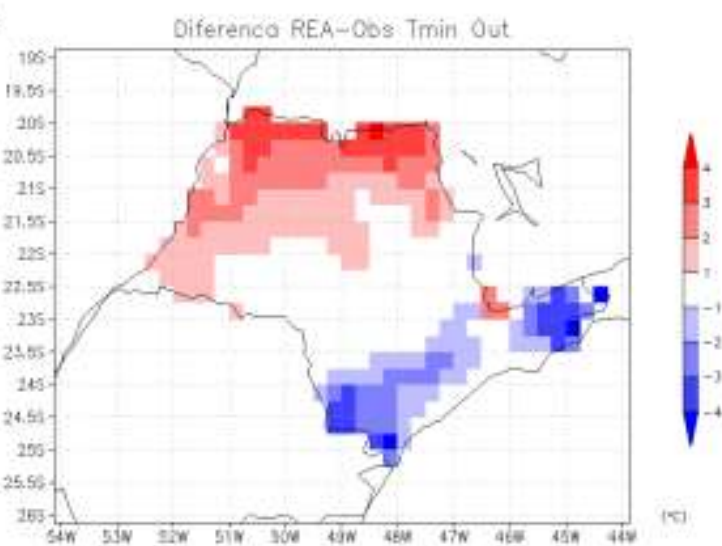

L

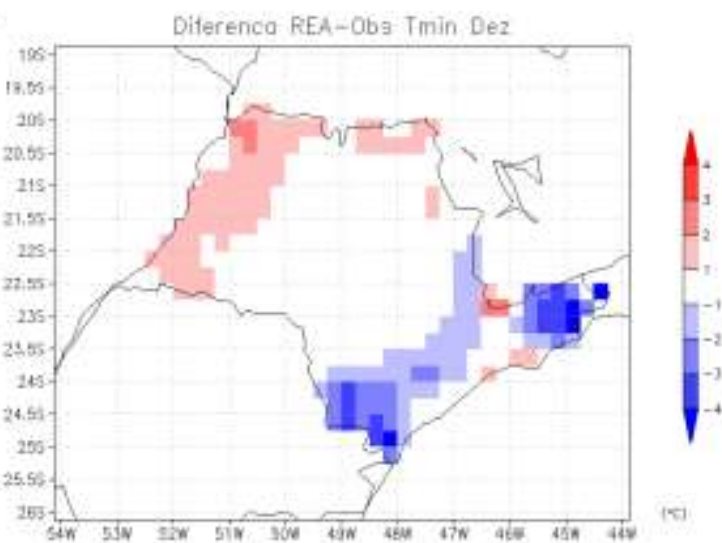

Figura B.8: Diferença entre a temperatura mínima média mensal da Reanálise e o conjunto de dados observados $\left[{ }^{\circ} \mathrm{C}\right]$. Média no período entre 1980 e 2009. A) Janeiro; B) Fevereiro; C) Março; D) Abril; E) Maio; F) Junho; G) Julho; H) Agosto; I) Setembro; J) Outubro; K) Novembro; L) Dezembro. 


\section{B.2 CENÁRIOS DE EVAPOTRANSPIRAÇÃO REGIONAL}

A

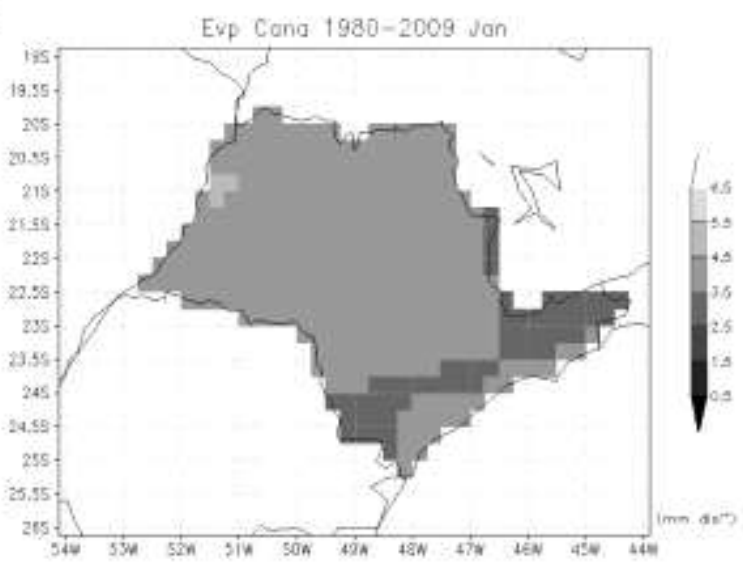

C

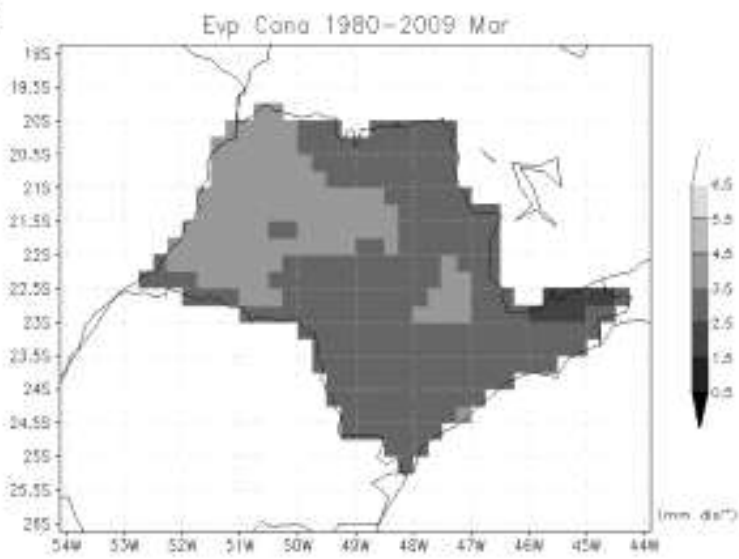

E

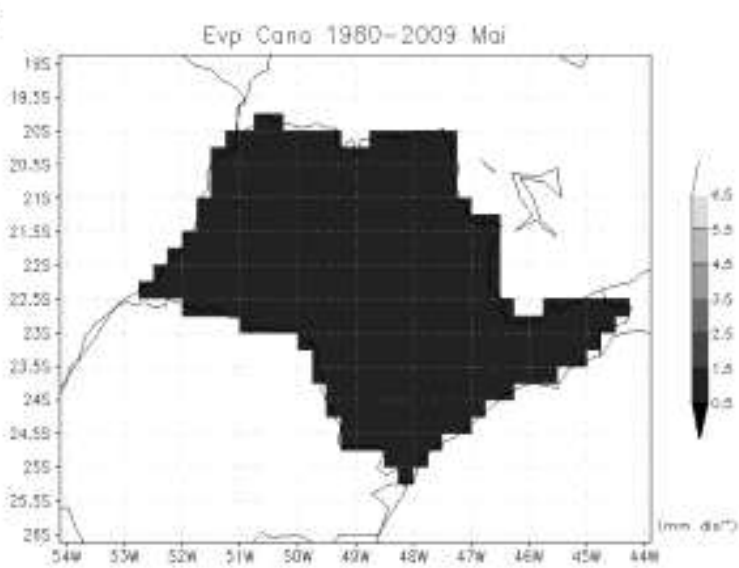

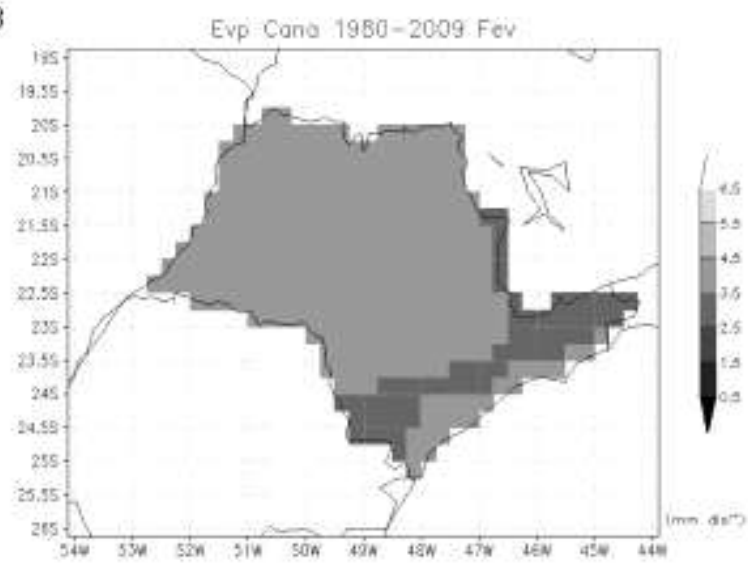

D

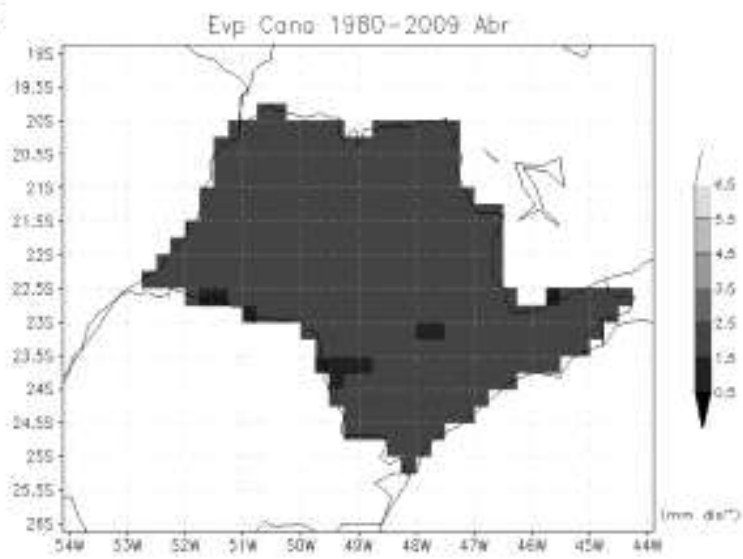

F

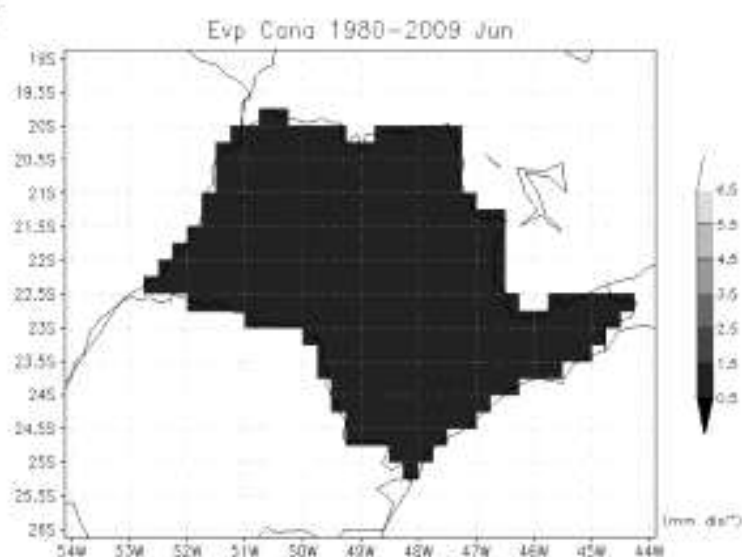


G
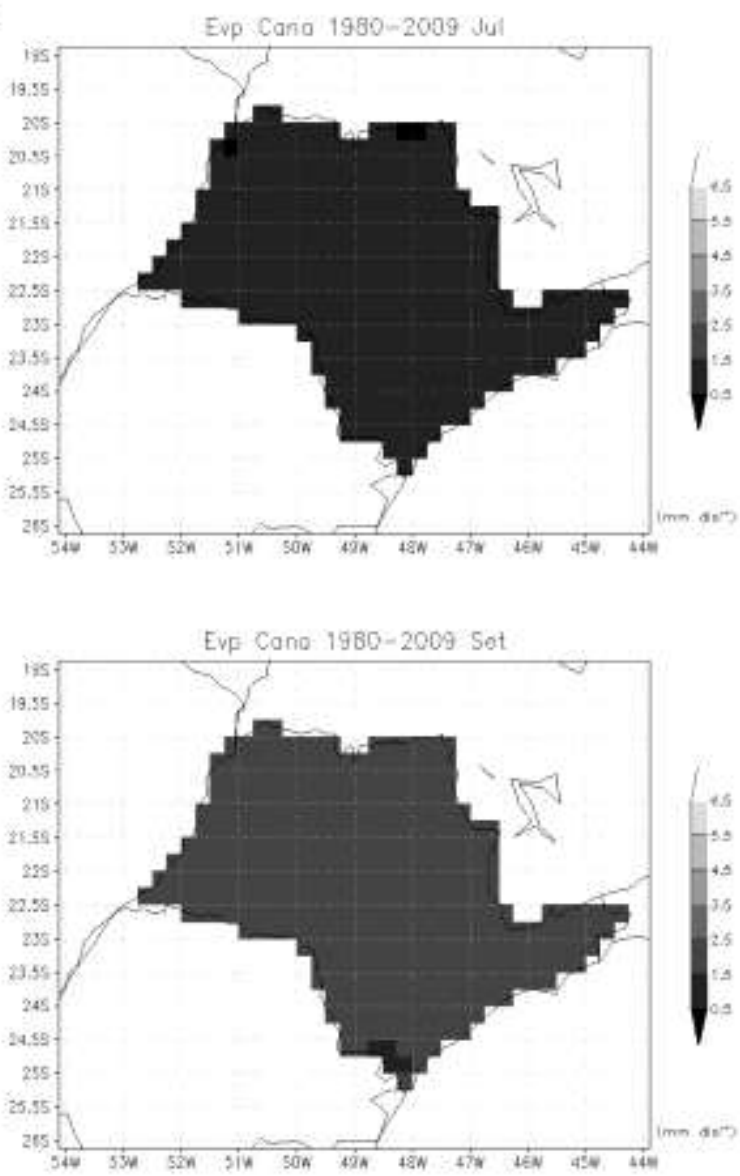

K

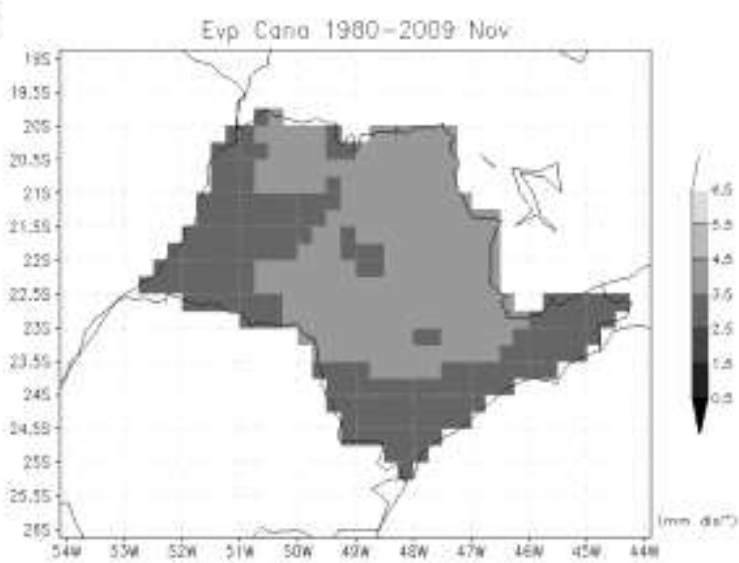

H

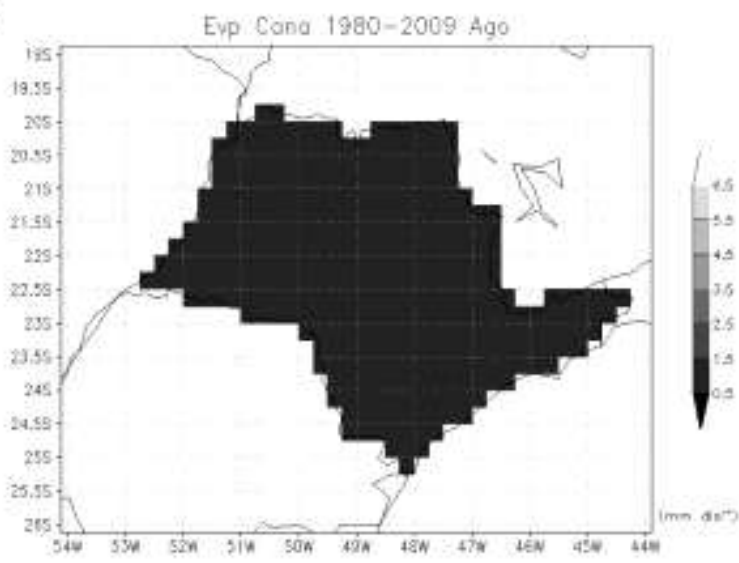

J

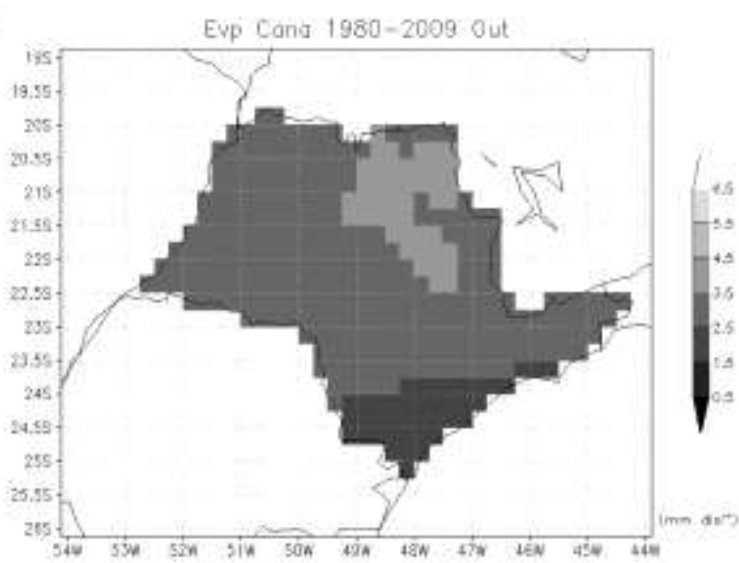

L

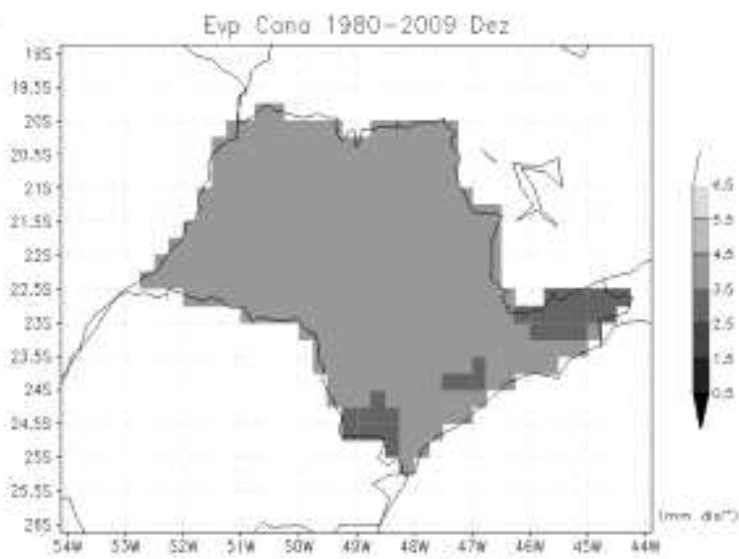

Figura B.9: Evapotranspiração para a cana-de-açúcar [mm dia-1]. Média no período entre 1980 e 2009. A) Janeiro; B) Fevereiro; C) Março; D) Abril; E) Maio; F) Junho; G) Julho; H) Agosto; I) Setembro; J) Outubro; K) Novembro; L) Dezembro. 
A

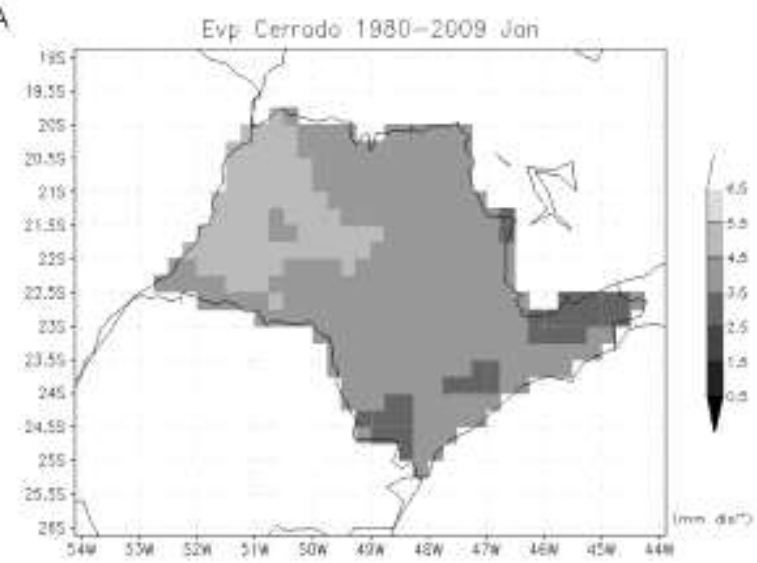

C

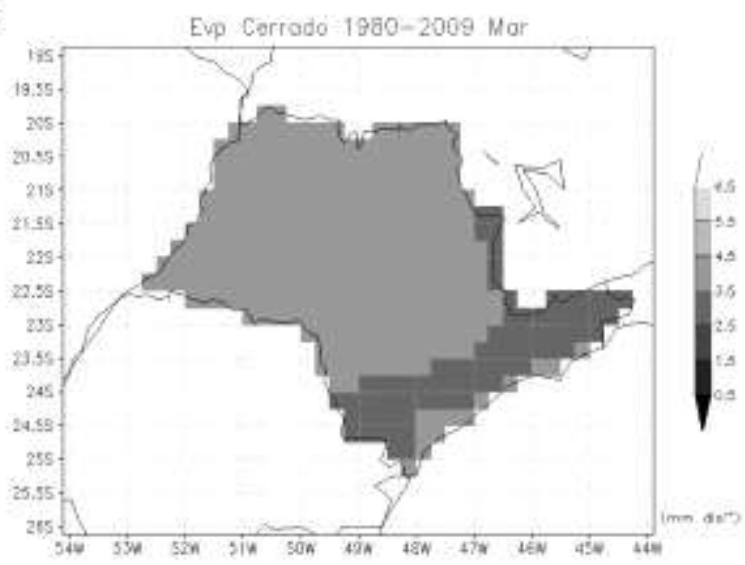

E

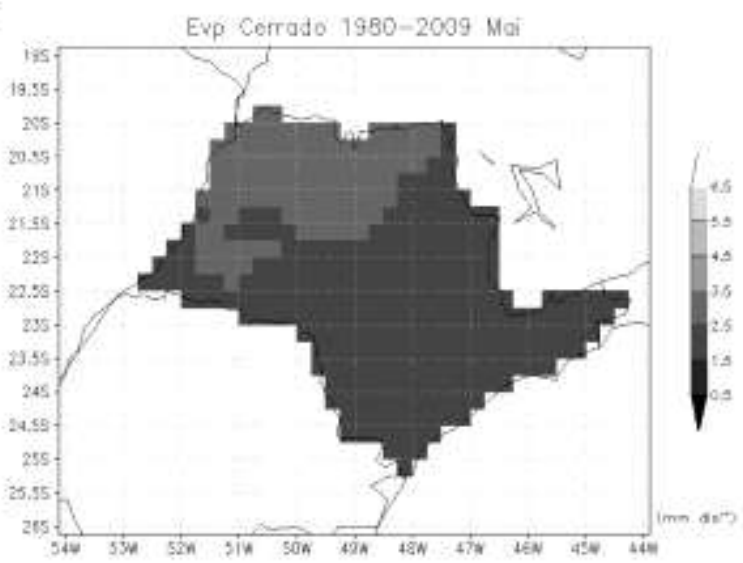

B

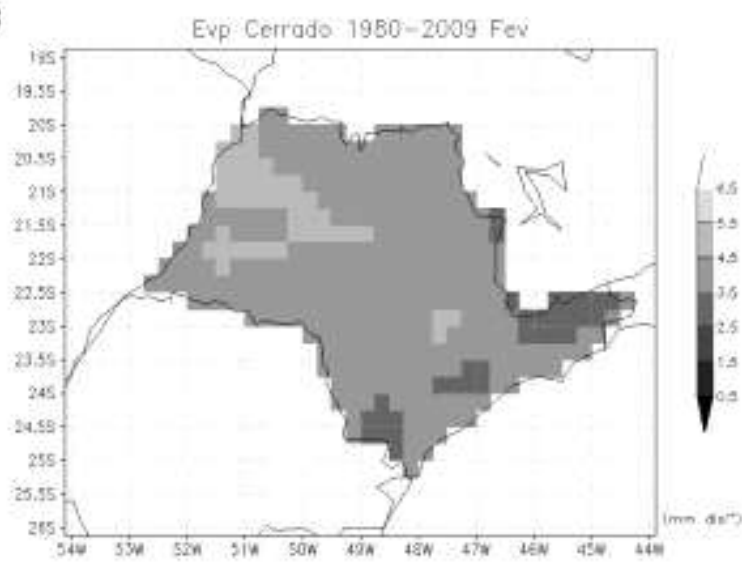

D

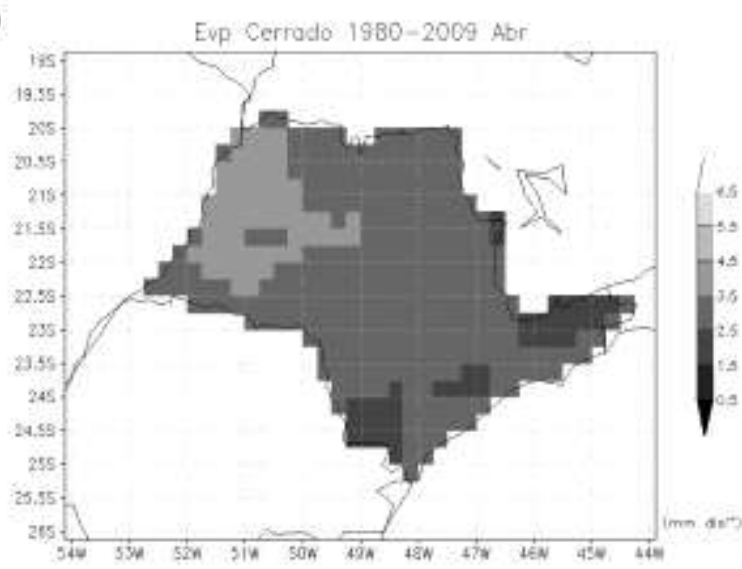

F

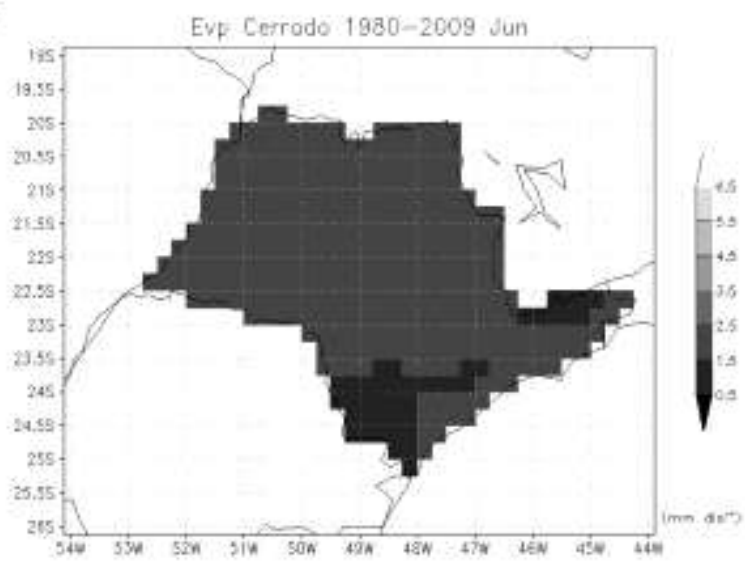


G
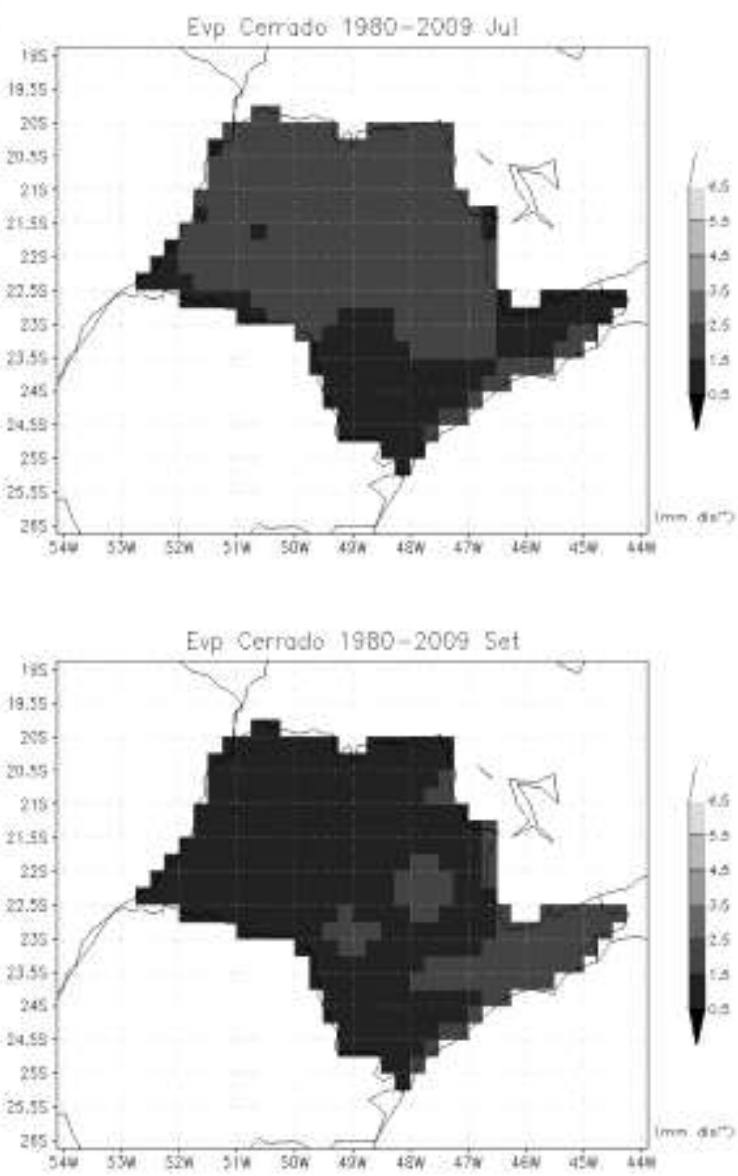

K

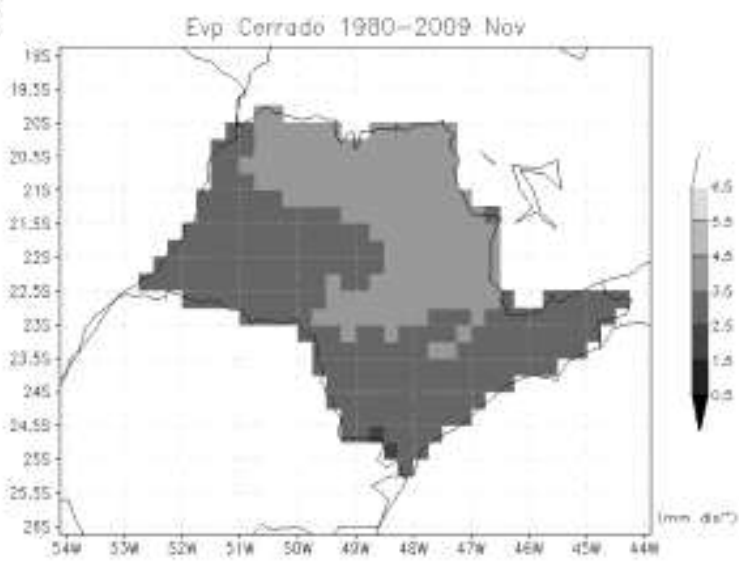

$\mathrm{H}$

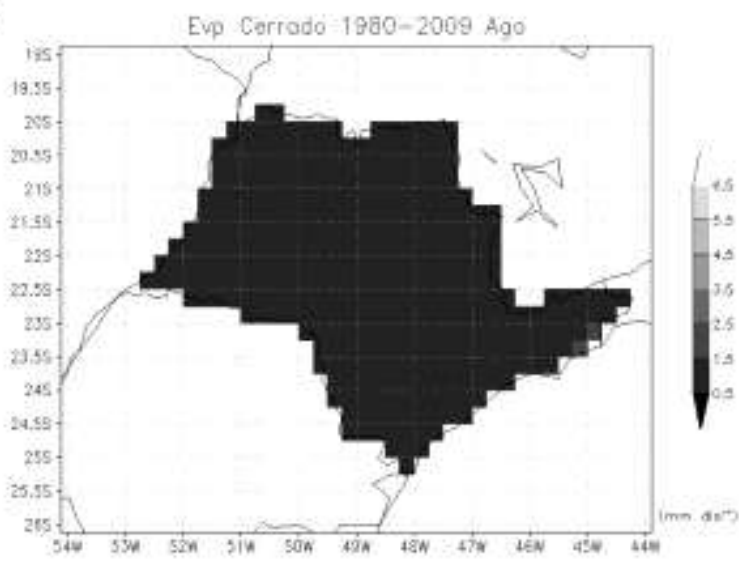

J

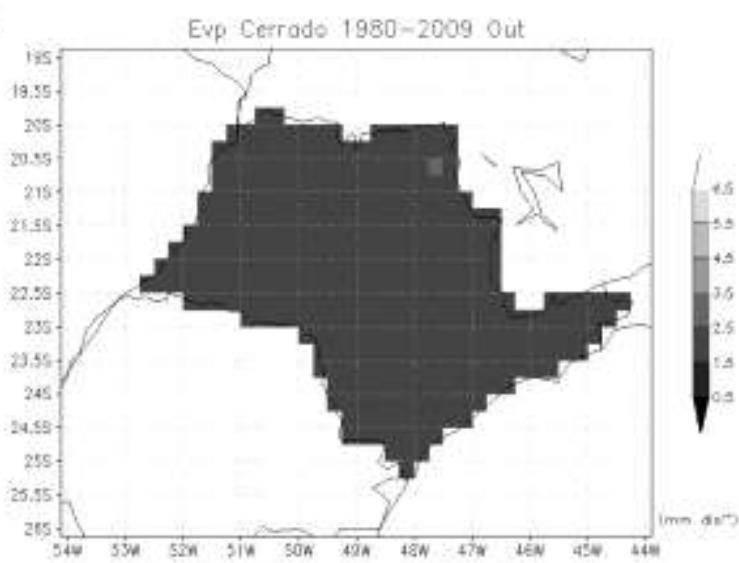

L

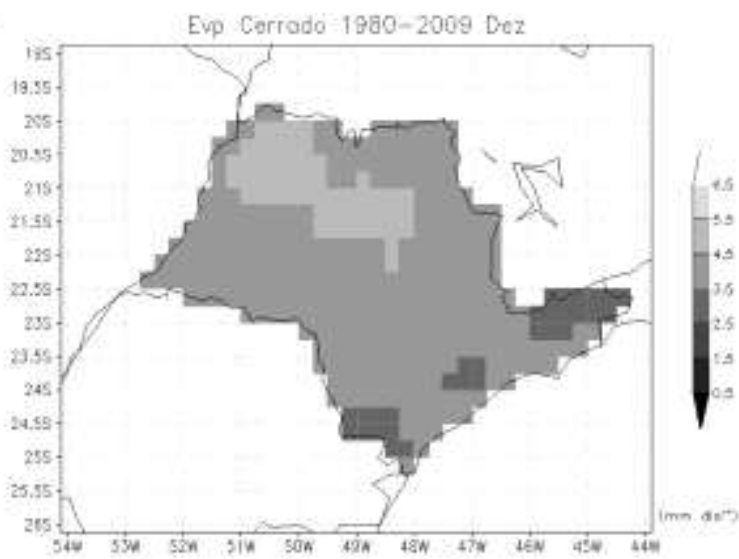

Figura B.10: Evapotranspiração para o cerrado [mm dia-1]. Média no período entre 1980 e 2009 . A) Janeiro; B) Fevereiro; C) Março; D) Abril; E) Maio; F) Junho; G) Julho; H) Agosto; I) Setembro; J) Outubro; K) Novembro; L) Dezembro. 
A

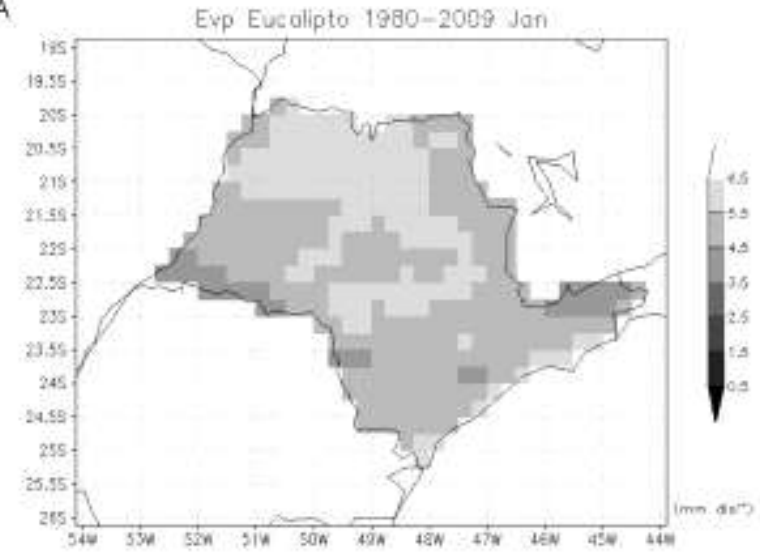

C

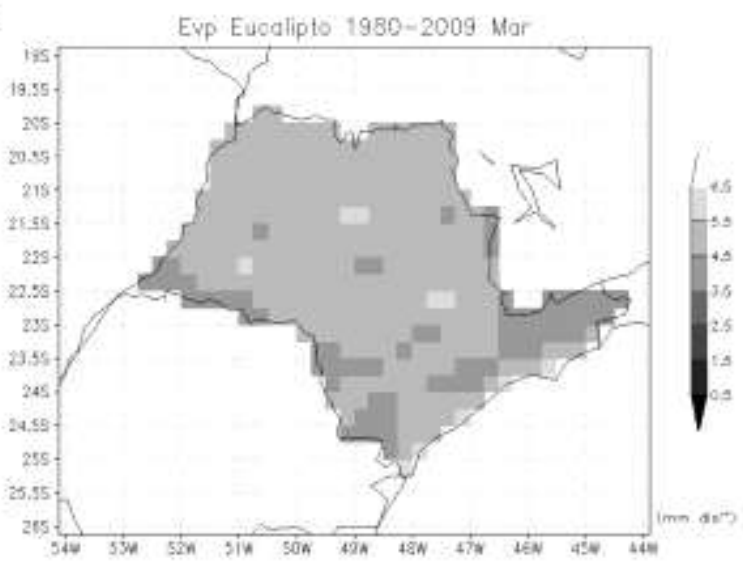

E

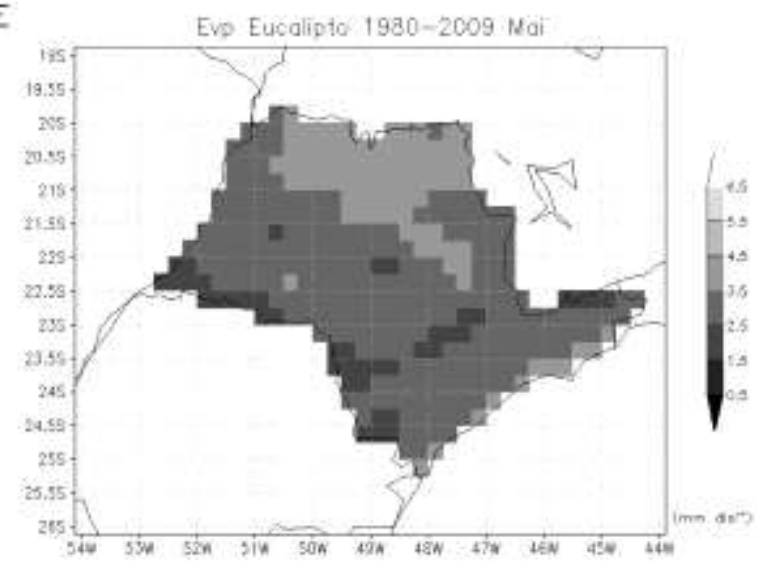

B

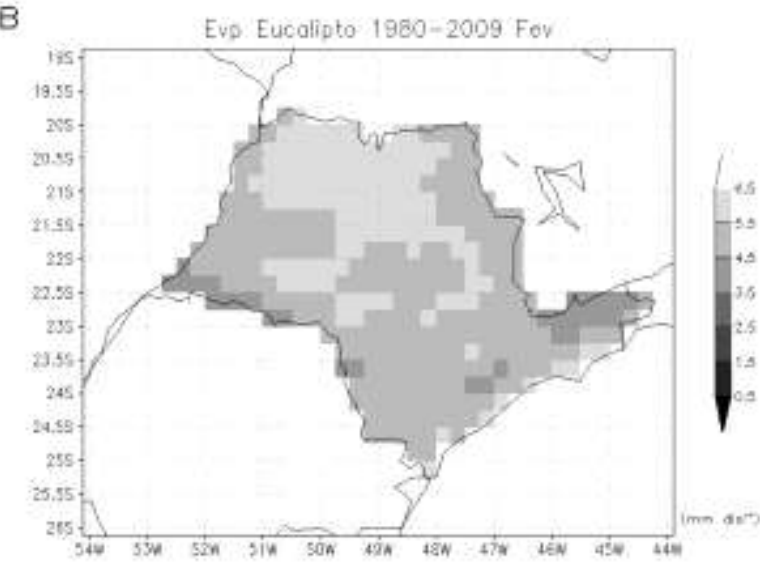

D

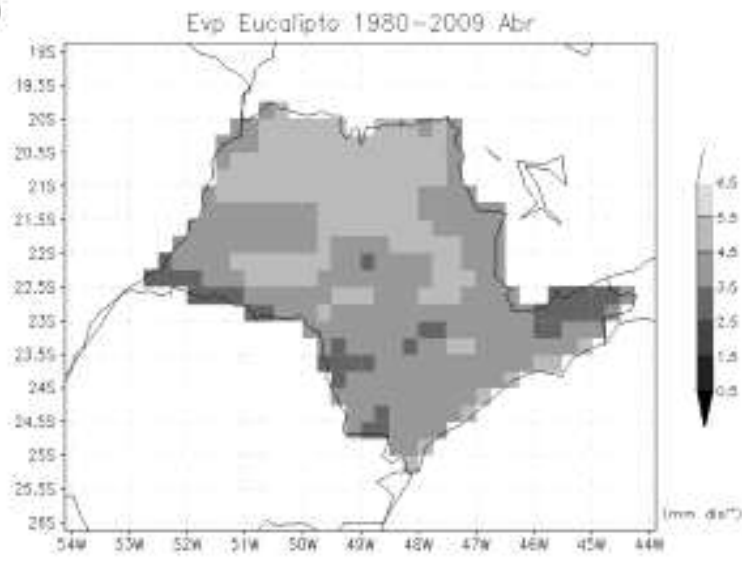

F

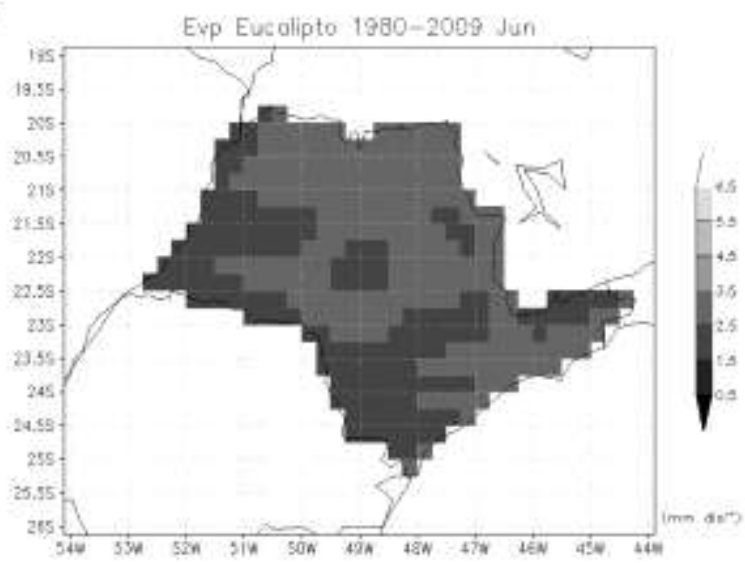


G

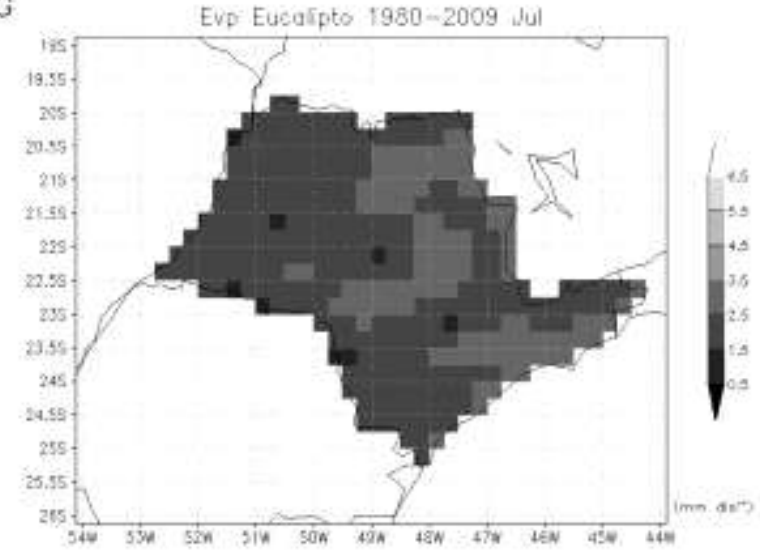

I

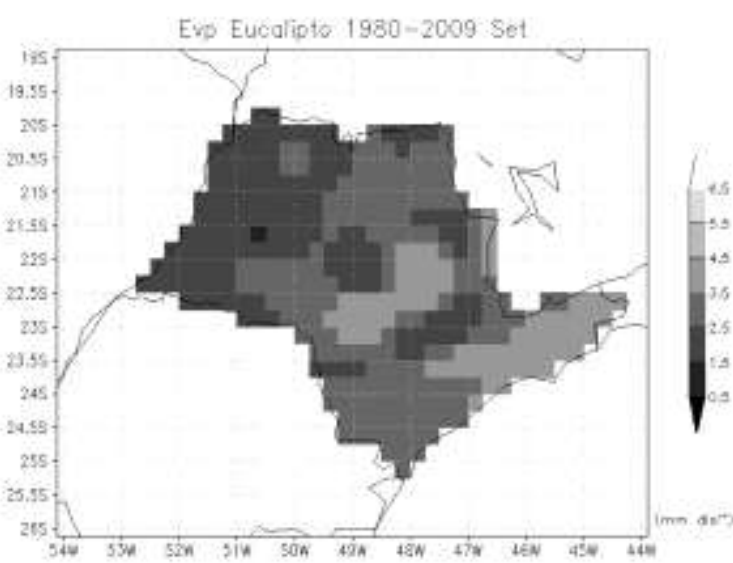

K

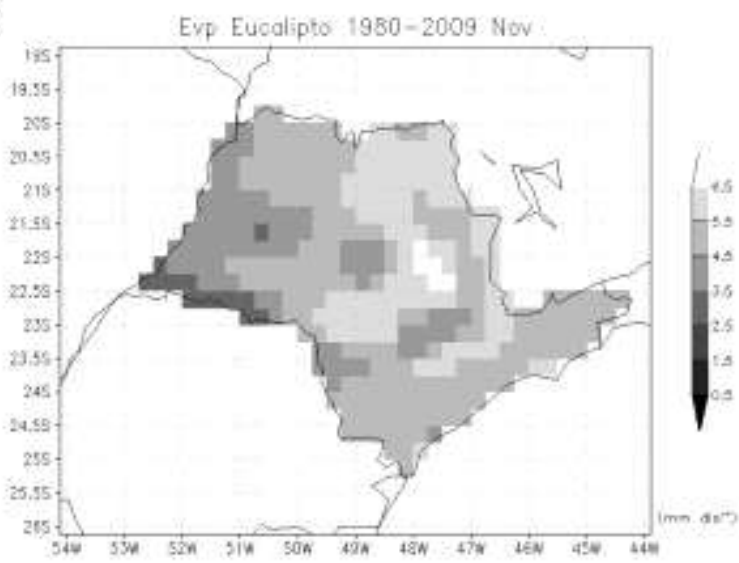

H

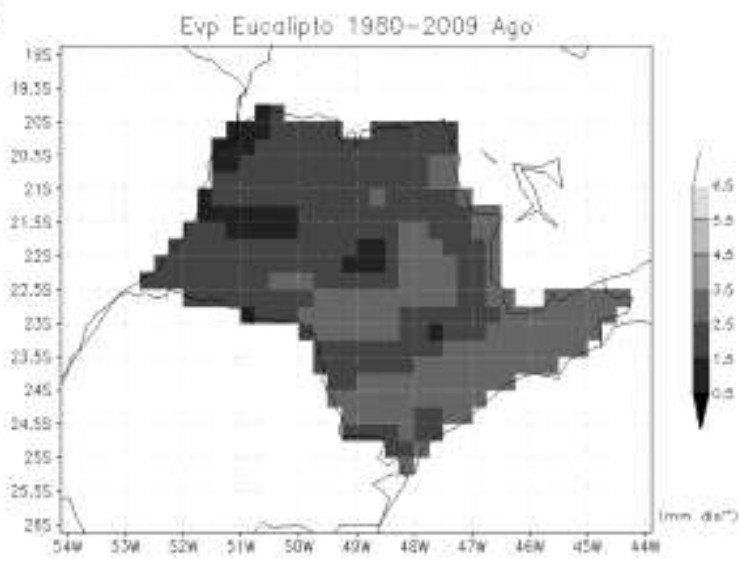

J

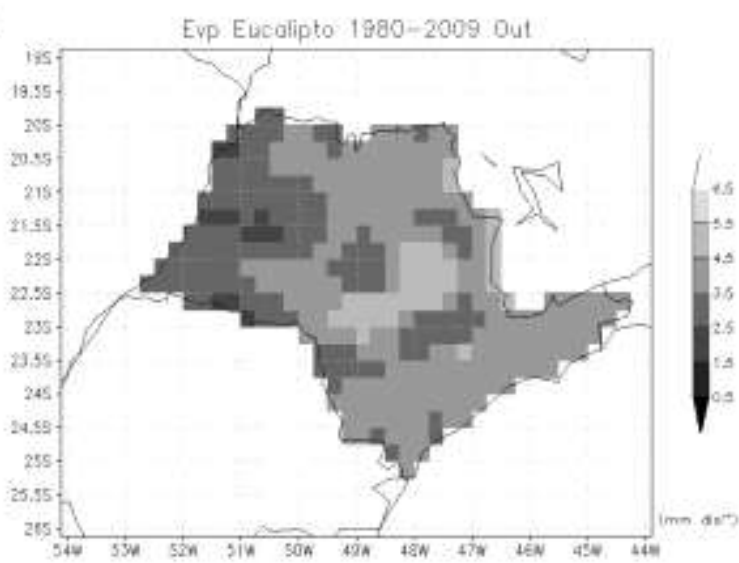

L

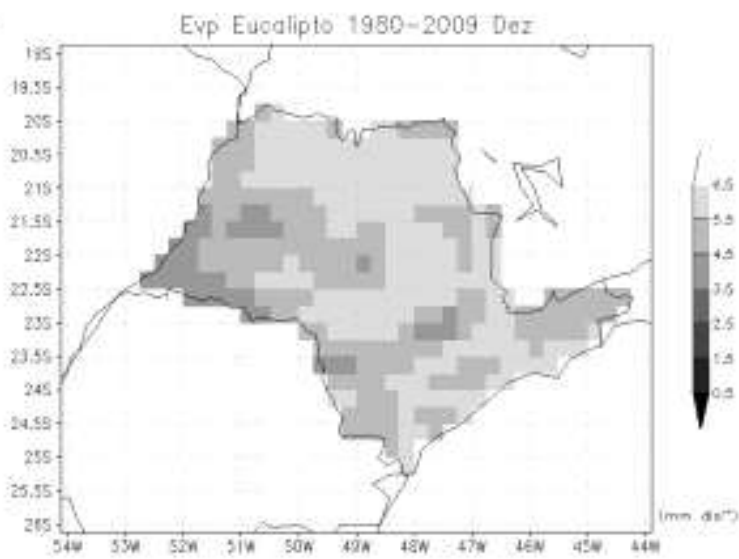

Figura B.11: Evapotranspiração para o eucalipto [mm dia-1]. Média no período entre 1980 e 2009 . A) Janeiro; B) Fevereiro; C) Março; D) Abril; E) Maio; F) Junho; G) Julho; H) Agosto; I) Setembro; J) Outubro; K) Novembro; L) Dezembro. 
A

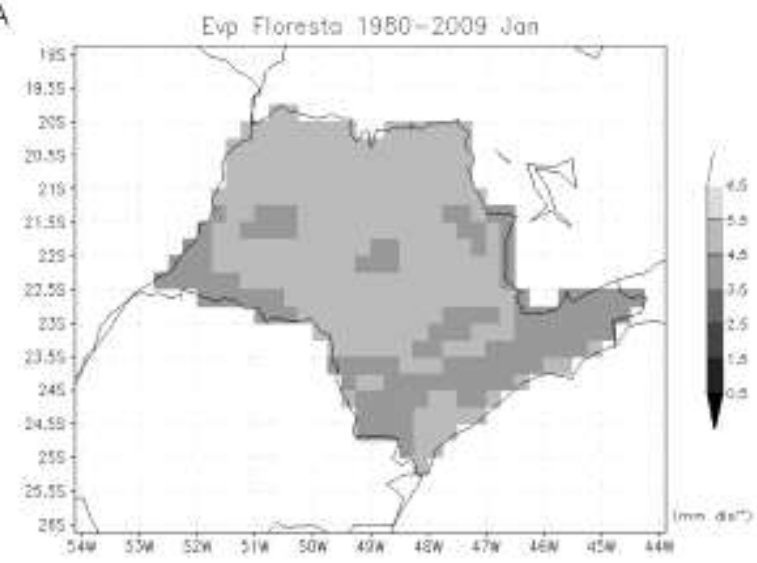

c

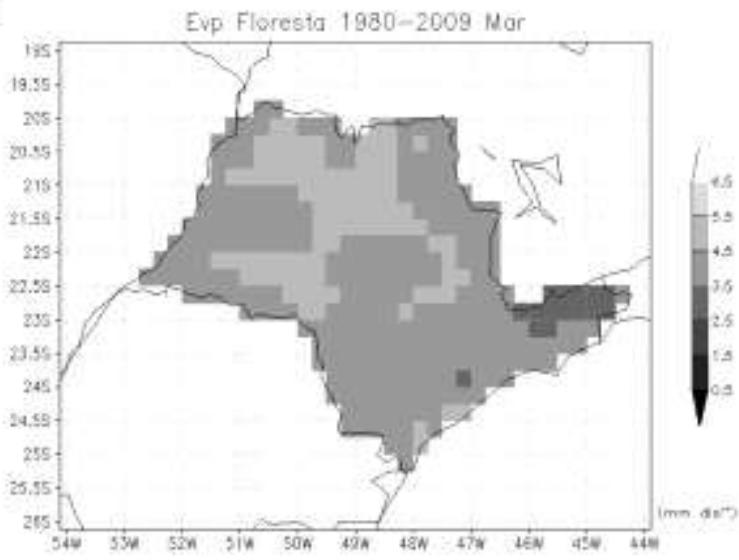

E

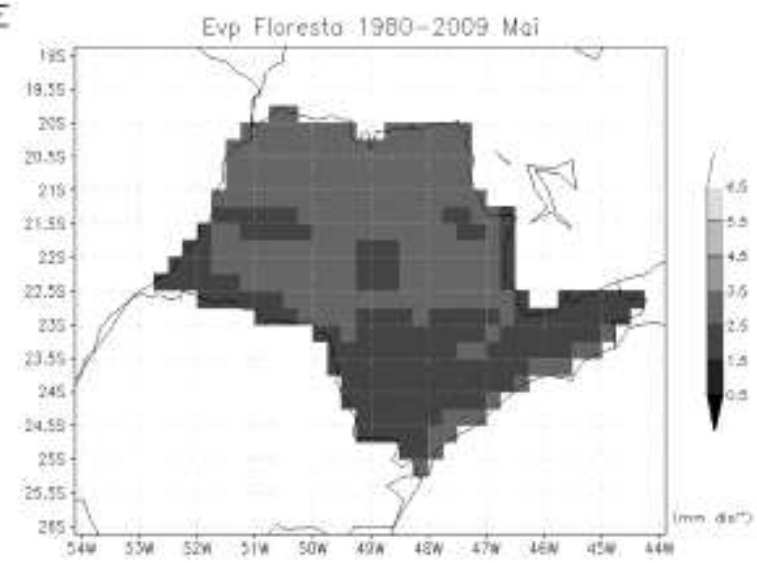

B

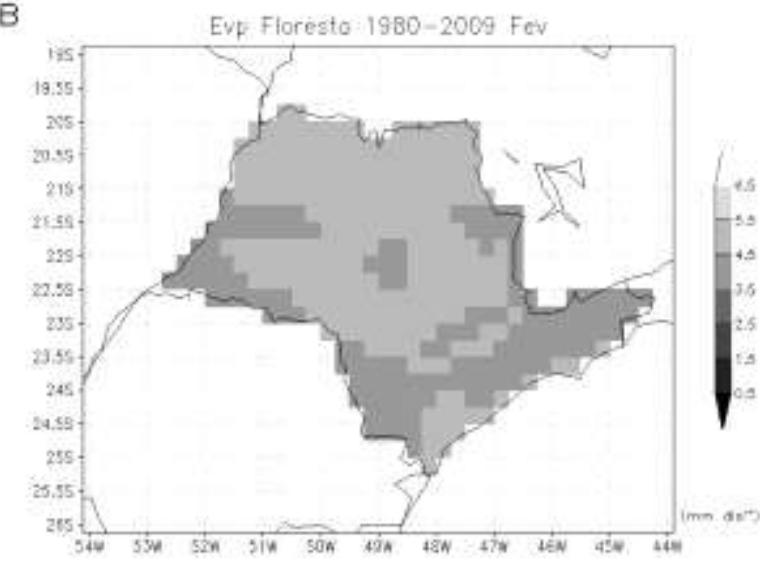

D

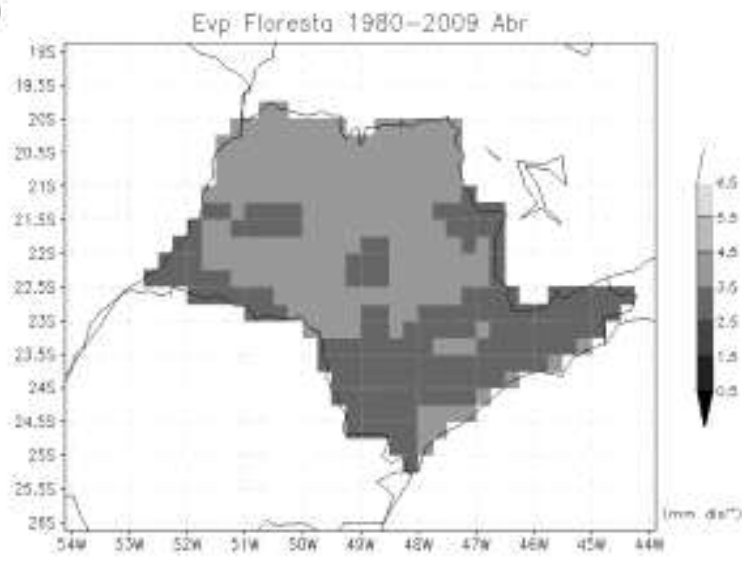

F

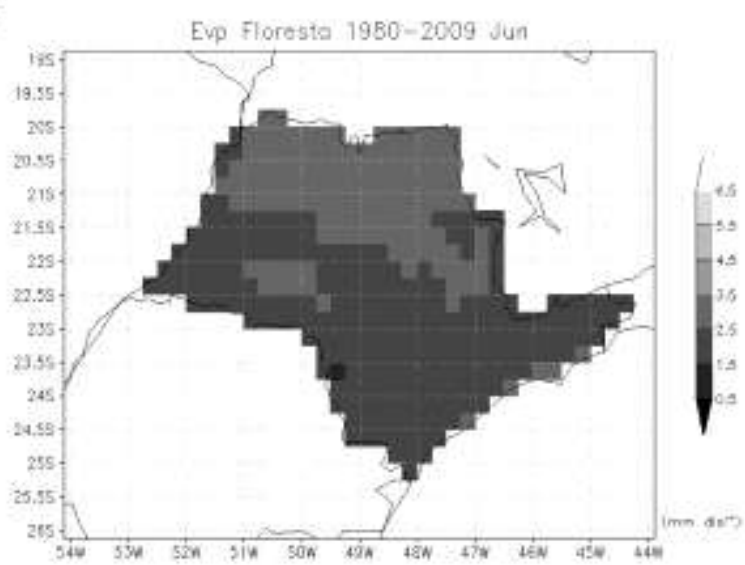


G
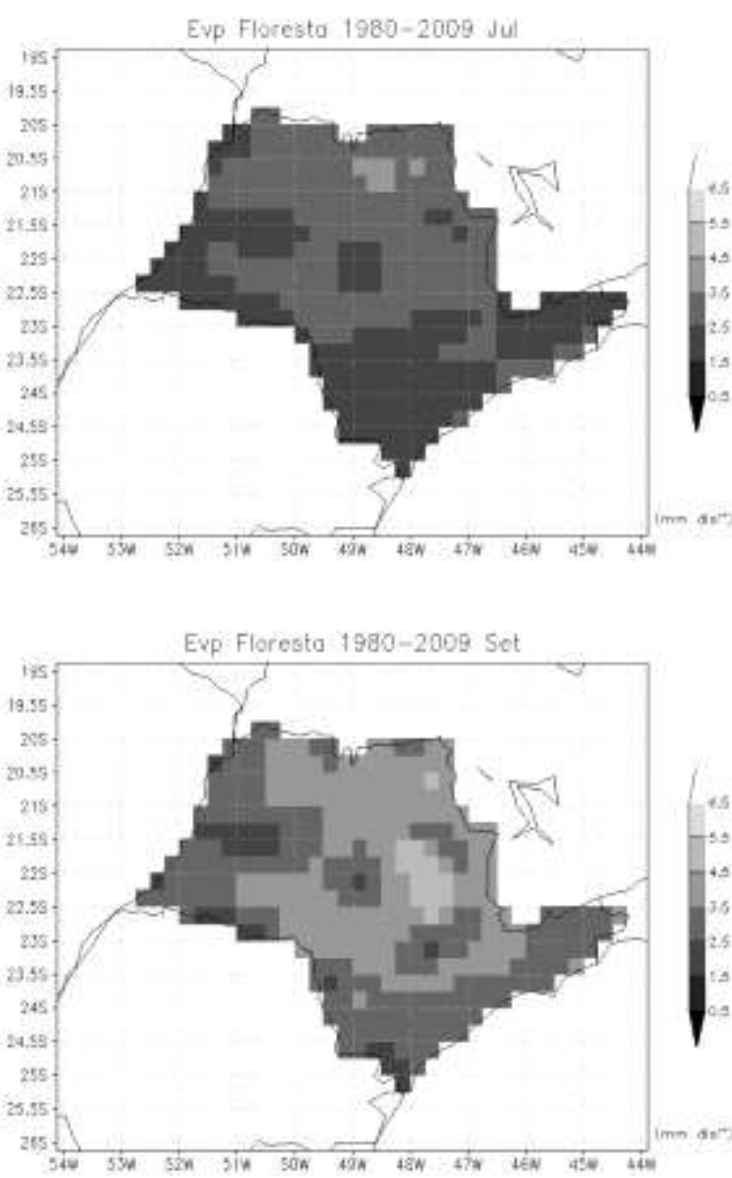

K

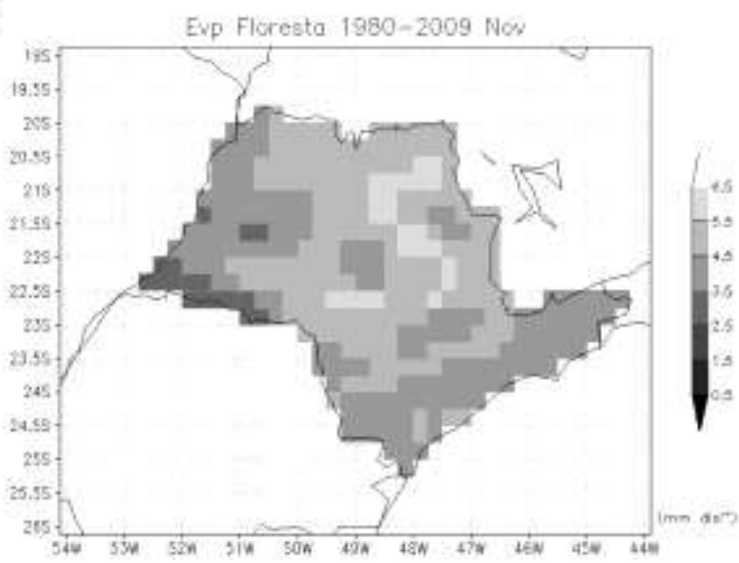

H

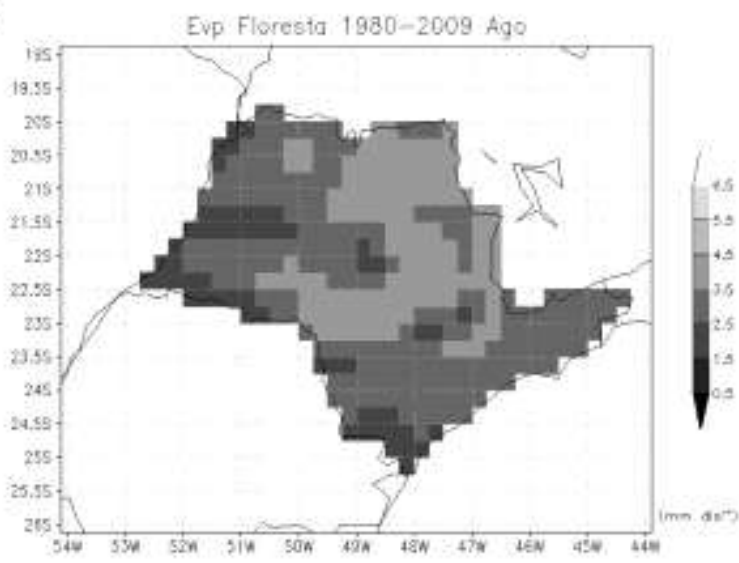

J

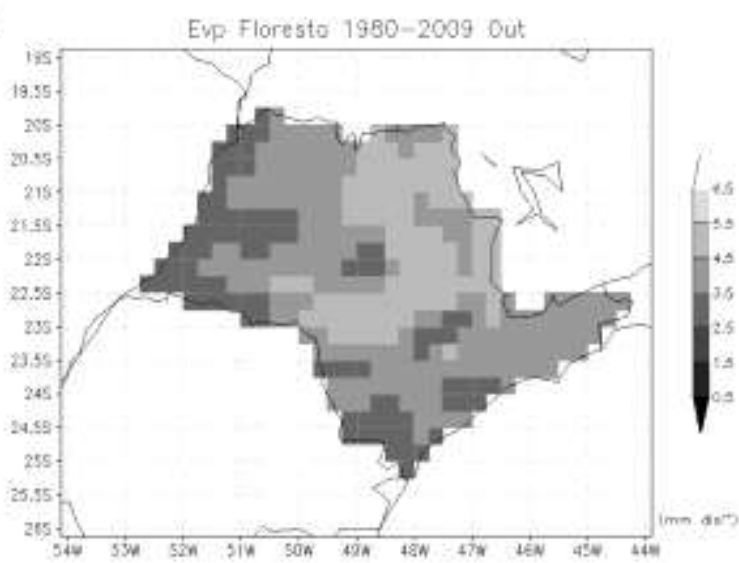

L

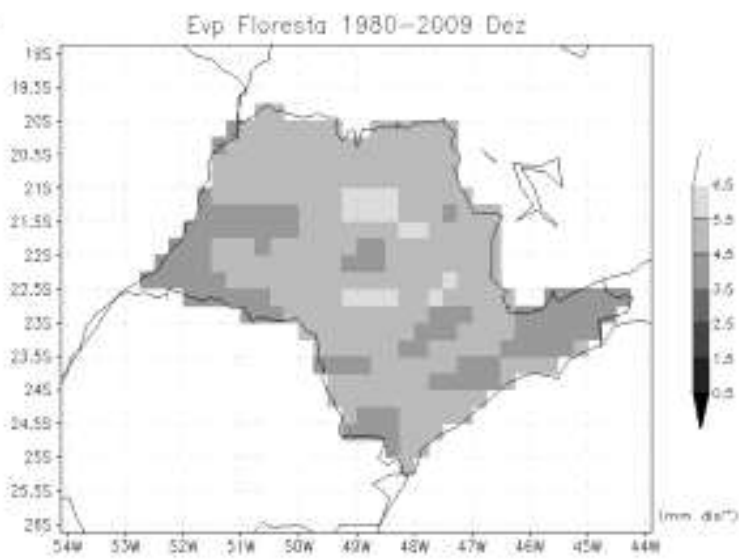

Figura B.12: Evapotranspiração para a floresta atlântica [mm dia $\left.{ }^{-1}\right]$. Média no período entre 1980 e 2009. A) Janeiro; B) Fevereiro; C) Março; D) Abril; E) Maio; F) Junho; G) Julho; H) Agosto; I) Setembro; J) Outubro; K) Novembro; L) Dezembro. 
A

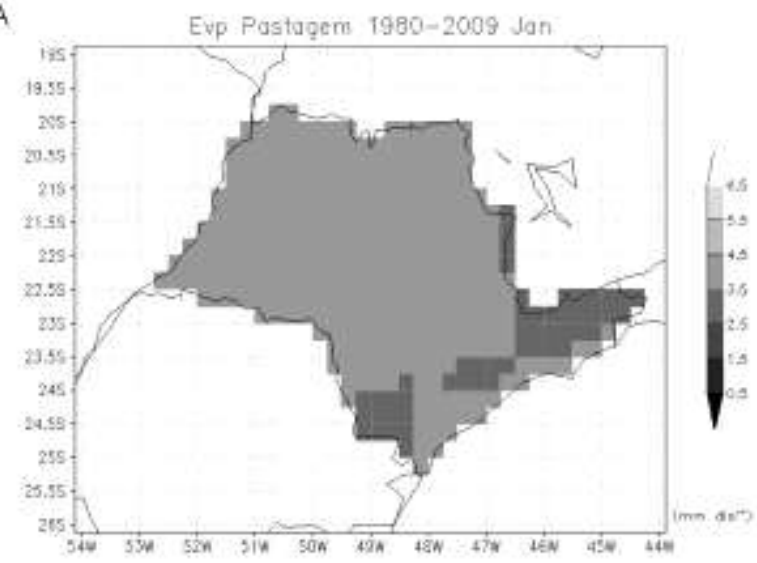

c

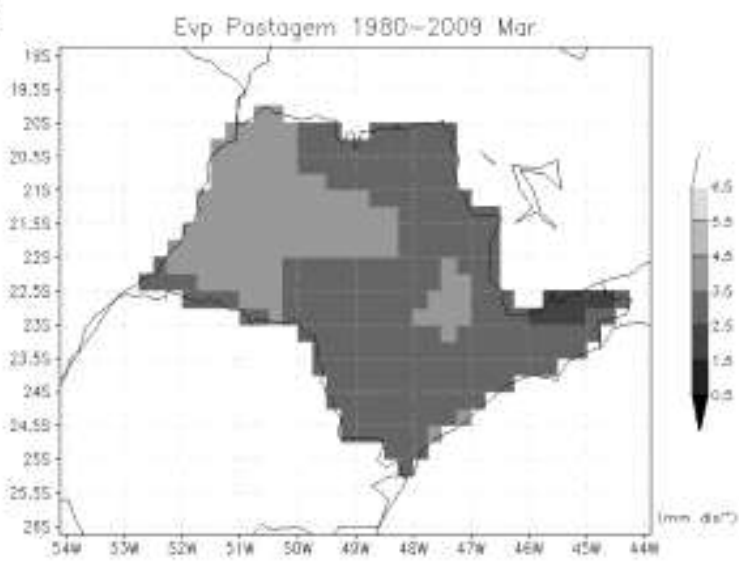

E

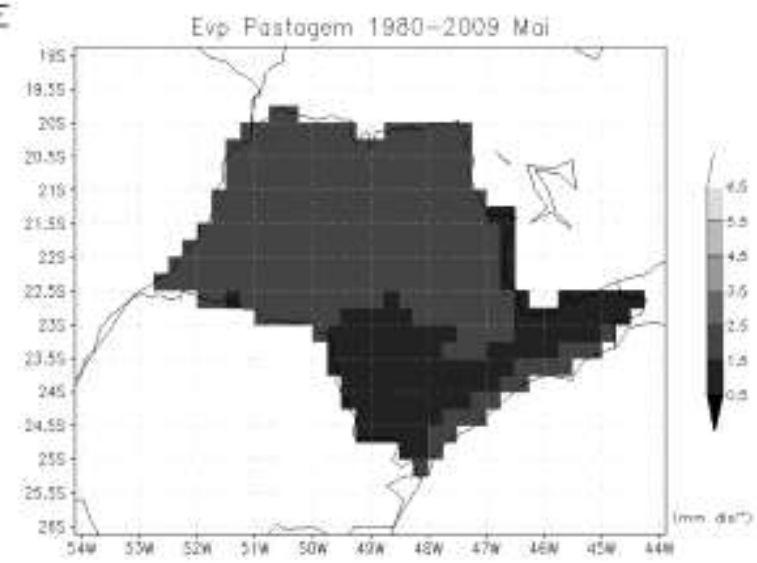

B

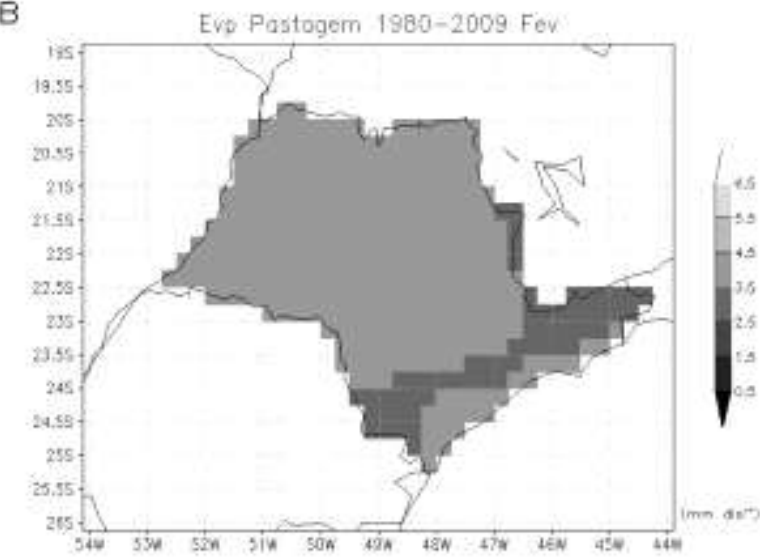

D

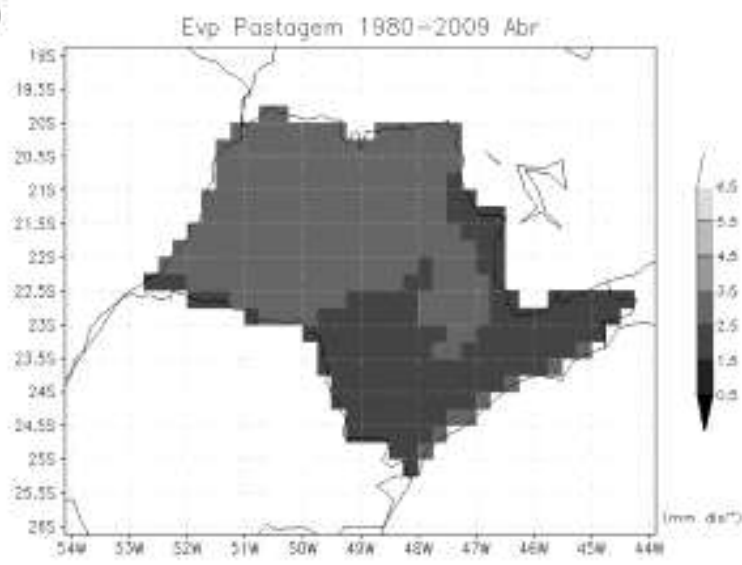

F

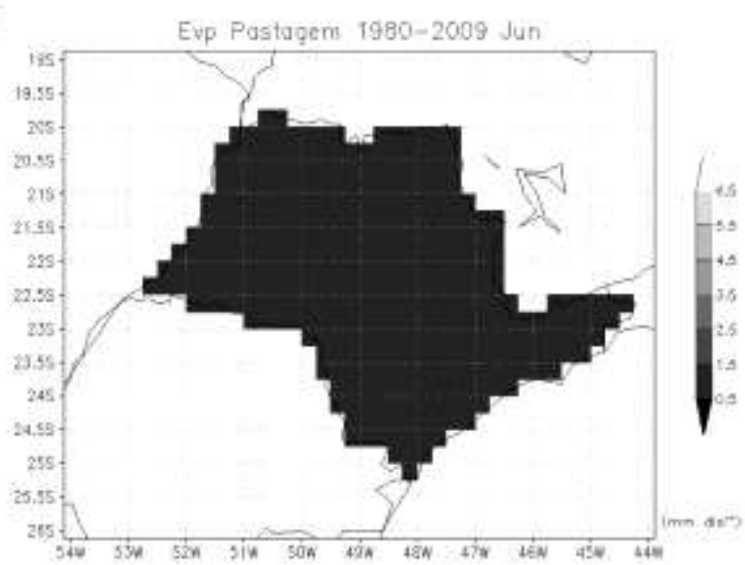


G
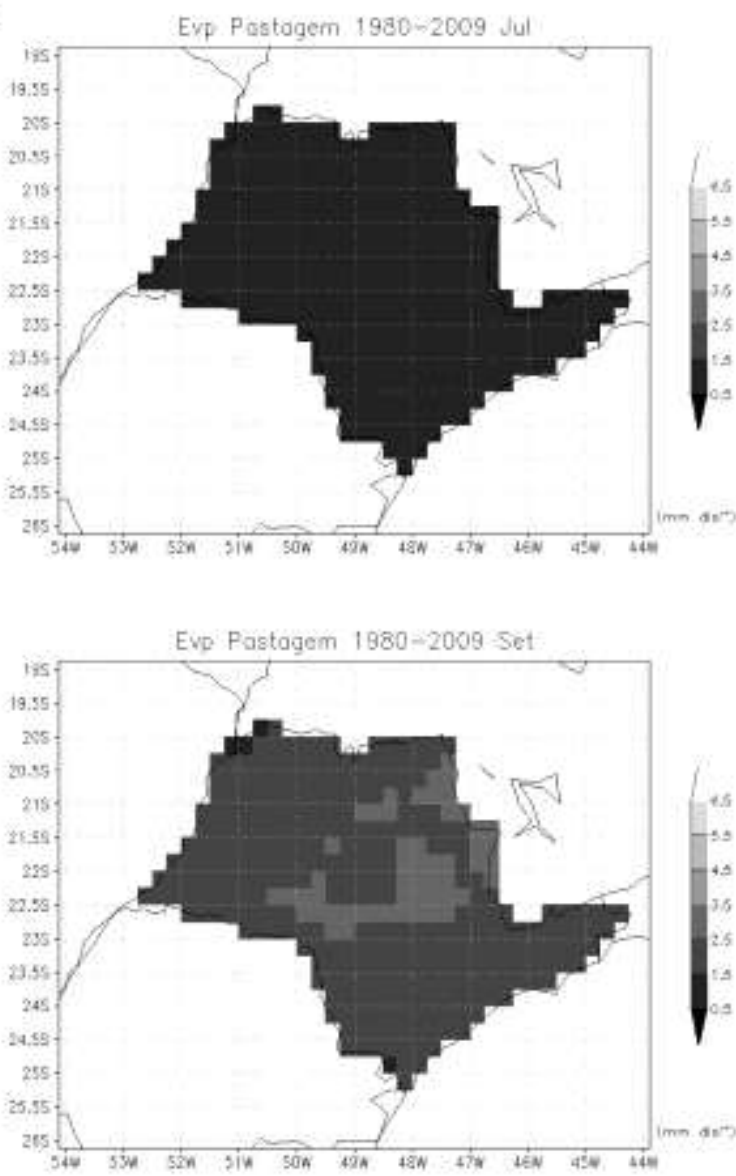

K

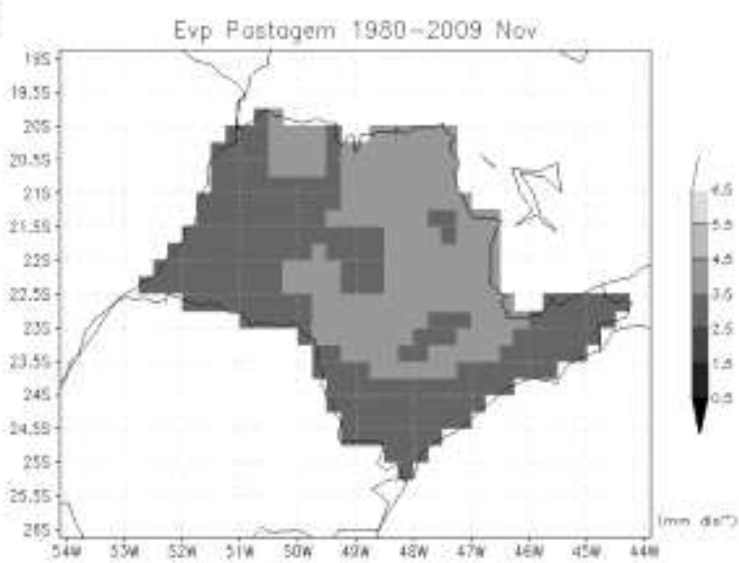

H

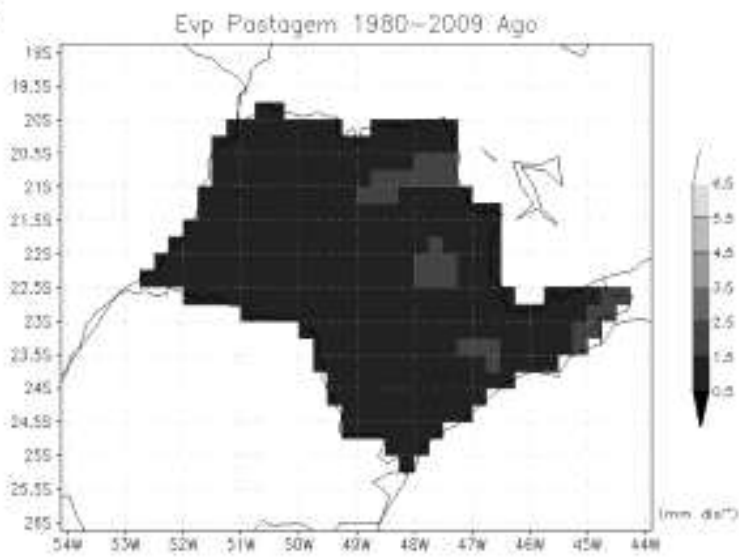

J

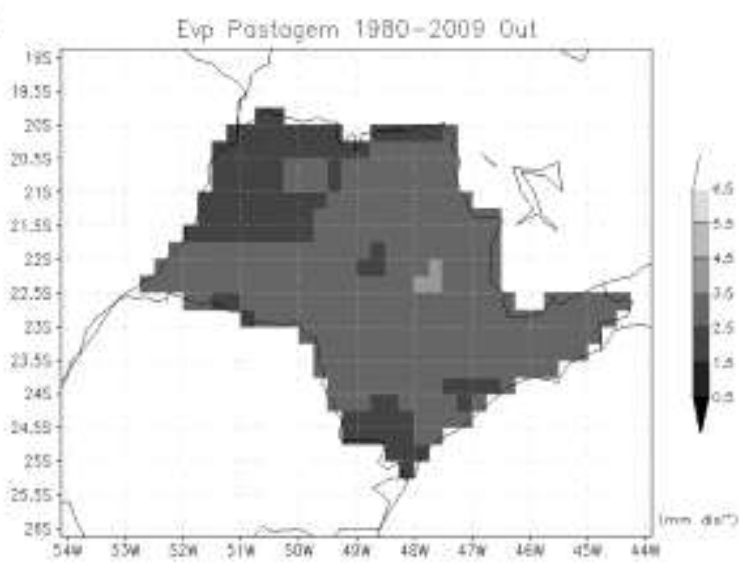

L

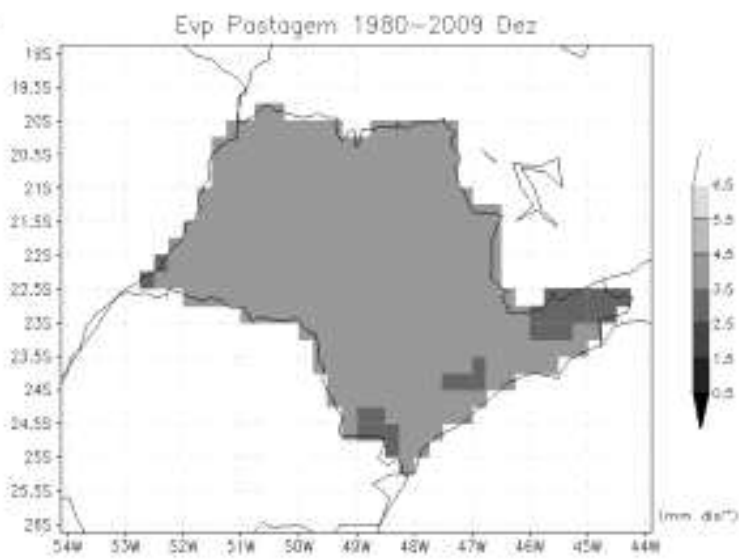

Figura B.13: Evapotranspiração para a pastagem $\left[\mathrm{mm}\right.$ dia $\left.^{-1}\right]$. Média no período entre 1980 e 2009. A) Janeiro; B) Fevereiro; C) Março; D) Abril; E) Maio; F) Junho; G) Julho; H) Agosto; I) Setembro; J) Outubro; K) Novembro; L) Dezembro. 
A

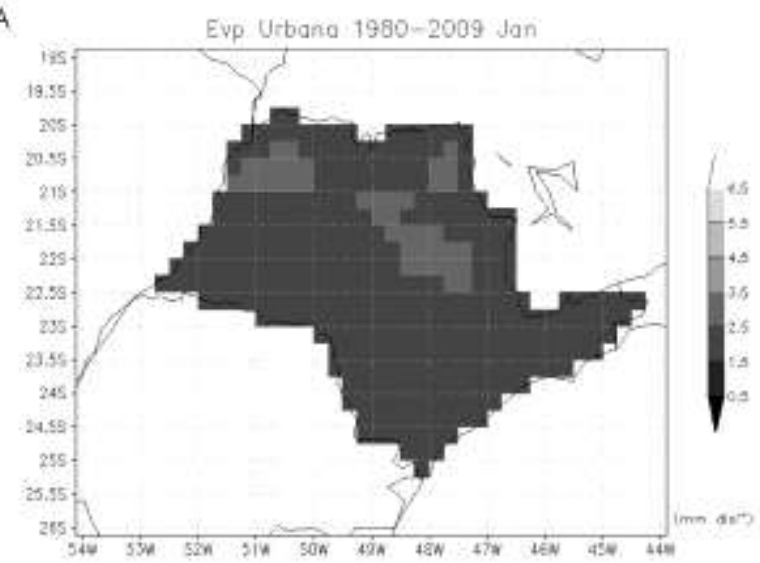

C

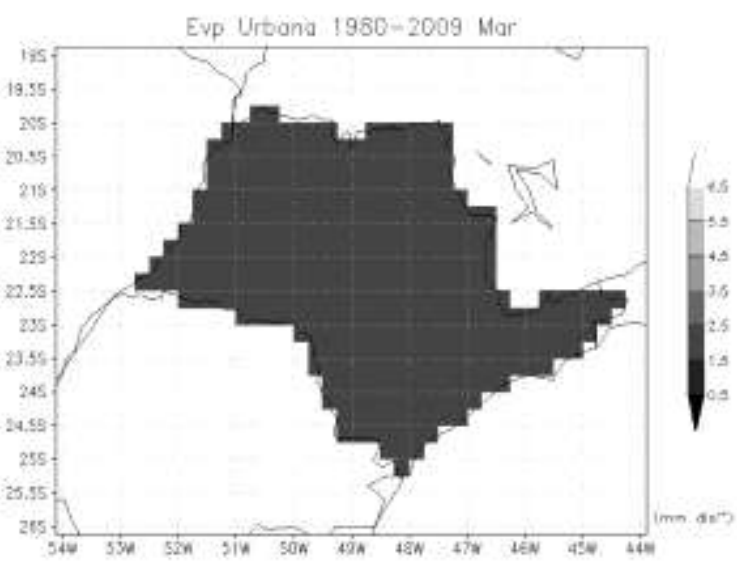

E

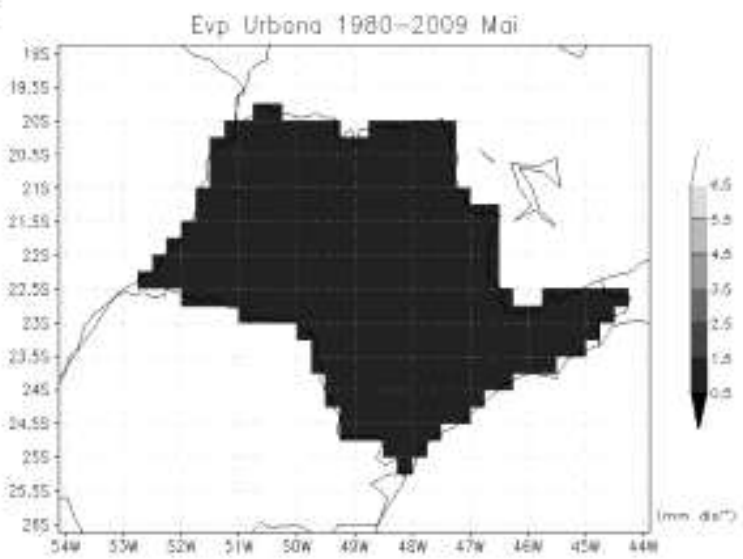

B

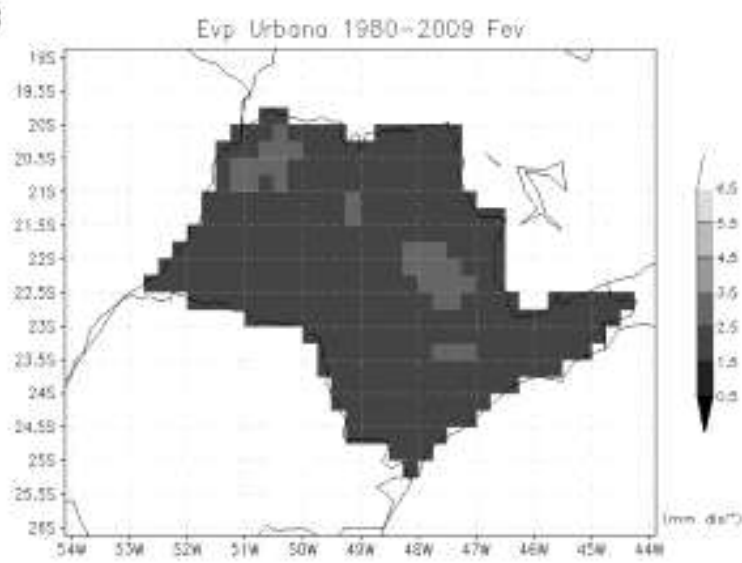

D

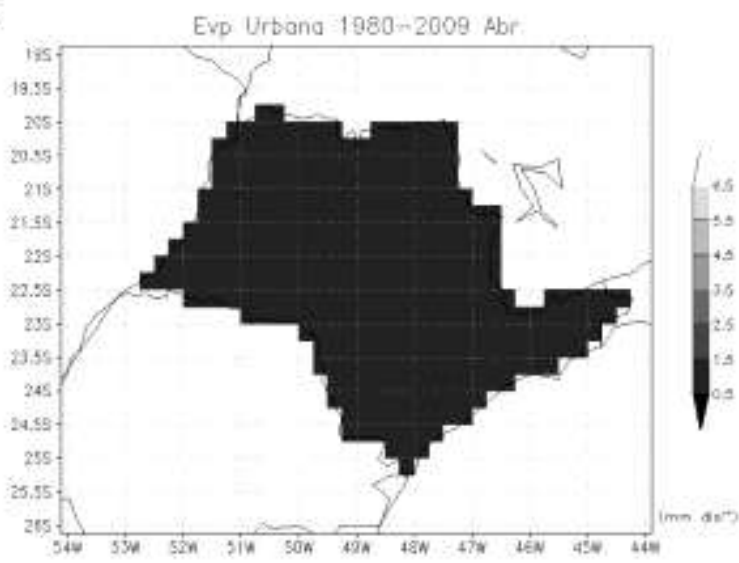

F

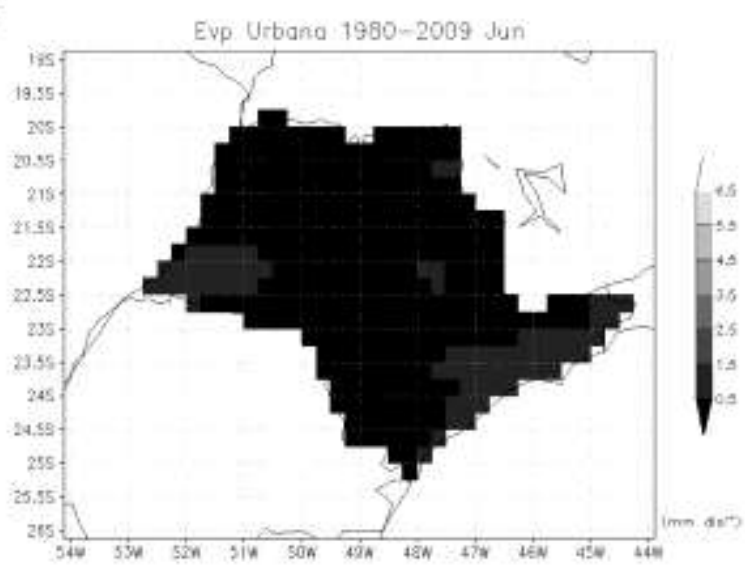


G
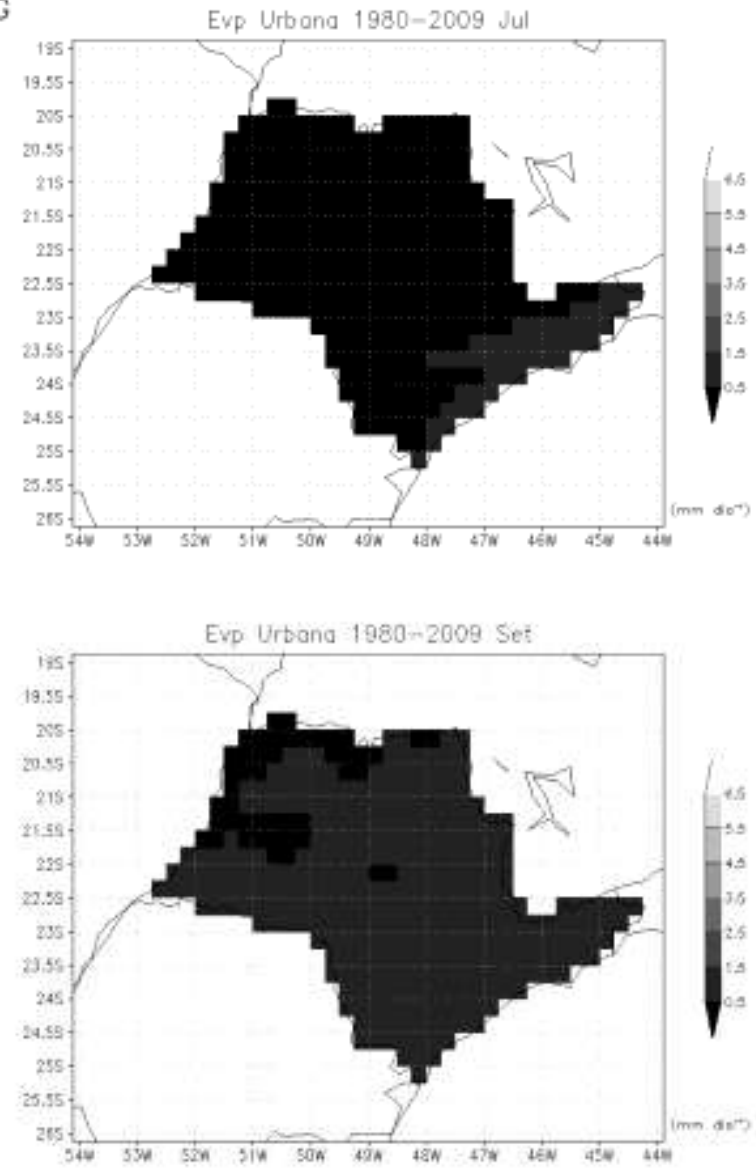

K

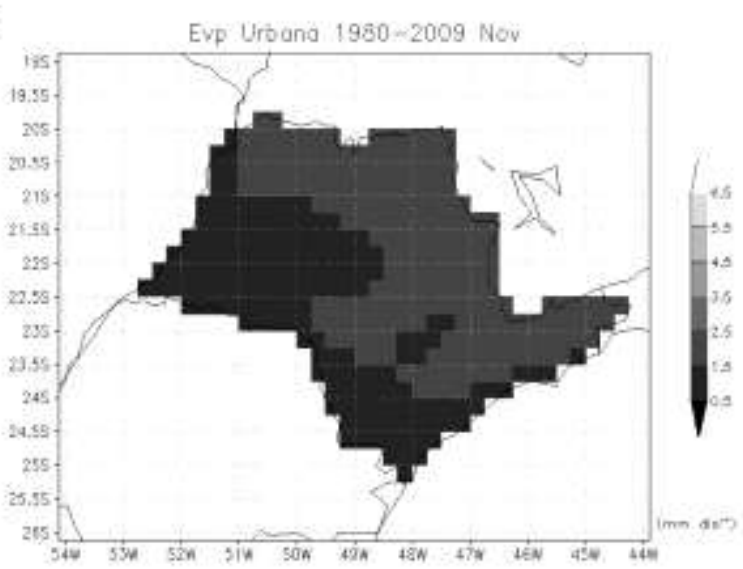

$\mathrm{H}$

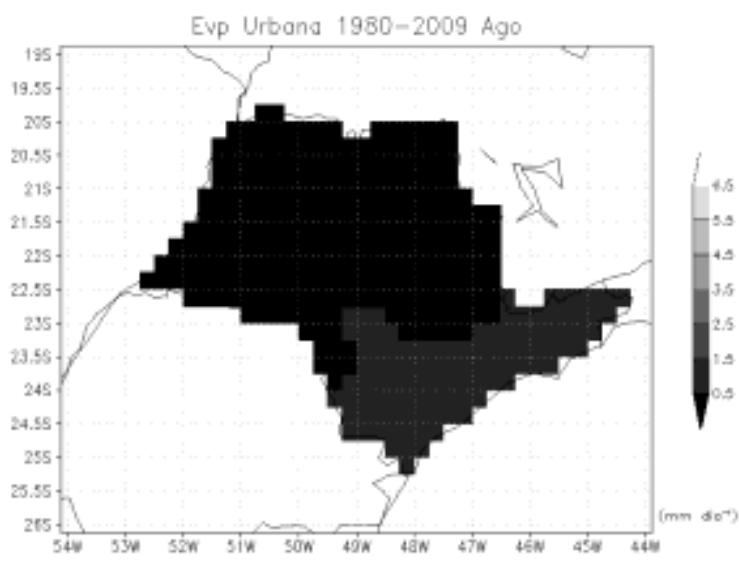

J

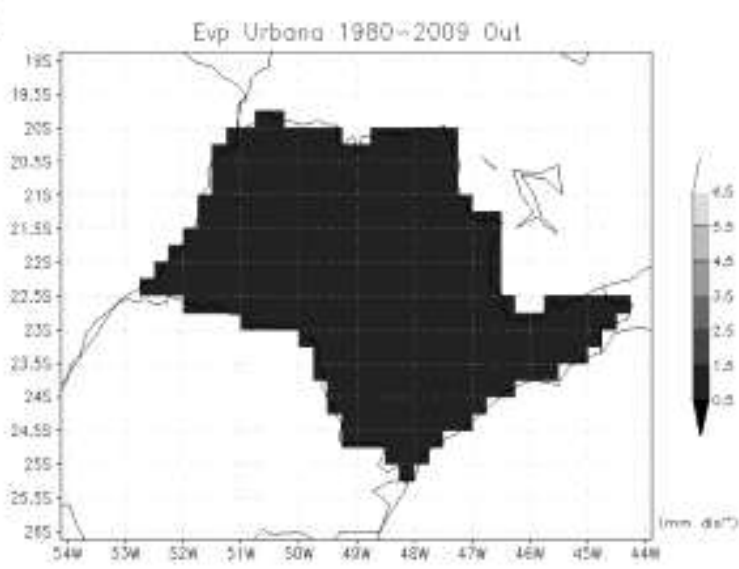

L

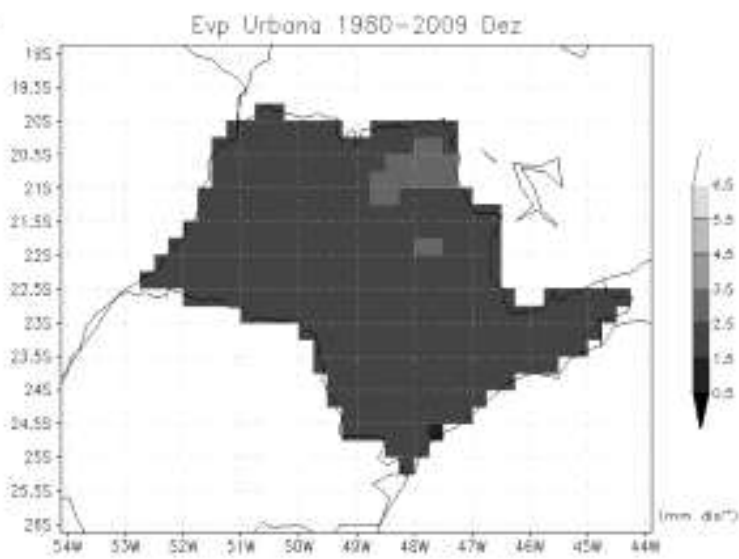

Figura B.14: Evapotranspiração para a área urbana $\left[\mathrm{mm} \mathrm{dia}^{-1}\right]$. Média no período entre 1980 e 2009. A) Janeiro; B) Fevereiro; C) Março; D) Abril; E) Maio; F) Junho; G) Julho; H) Agosto; I) Setembro; J) Outubro; K) Novembro; L) Dezembro. 
A

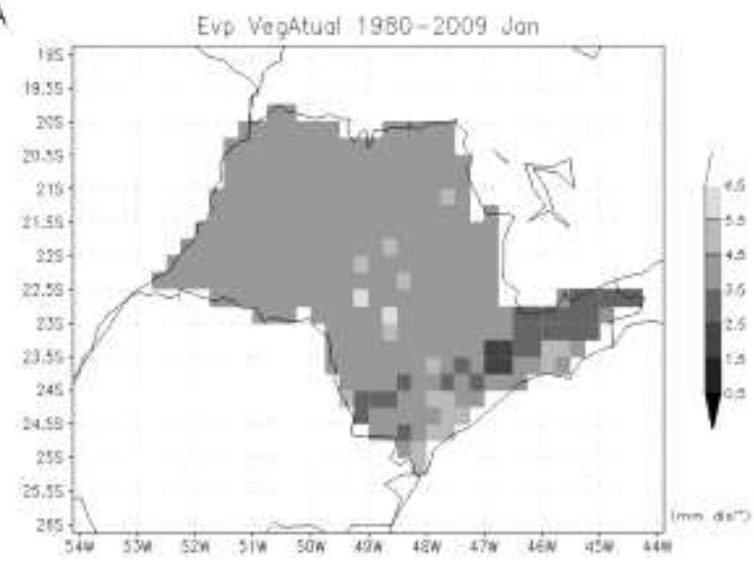

c

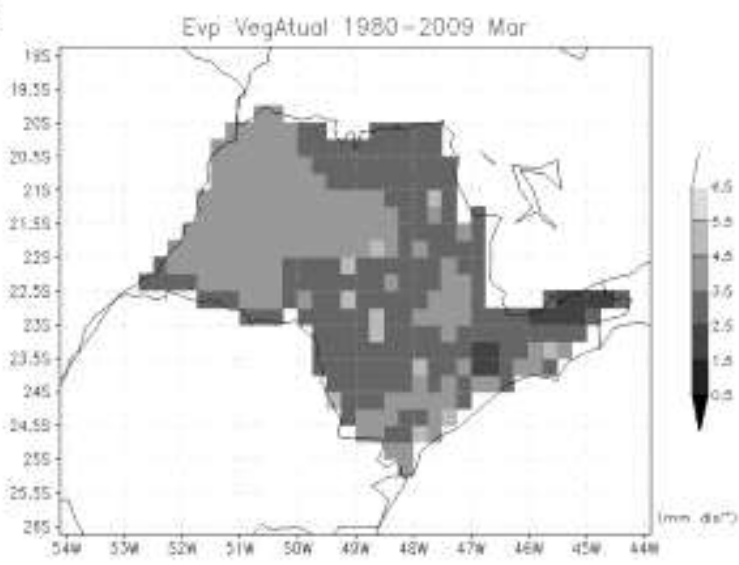

E

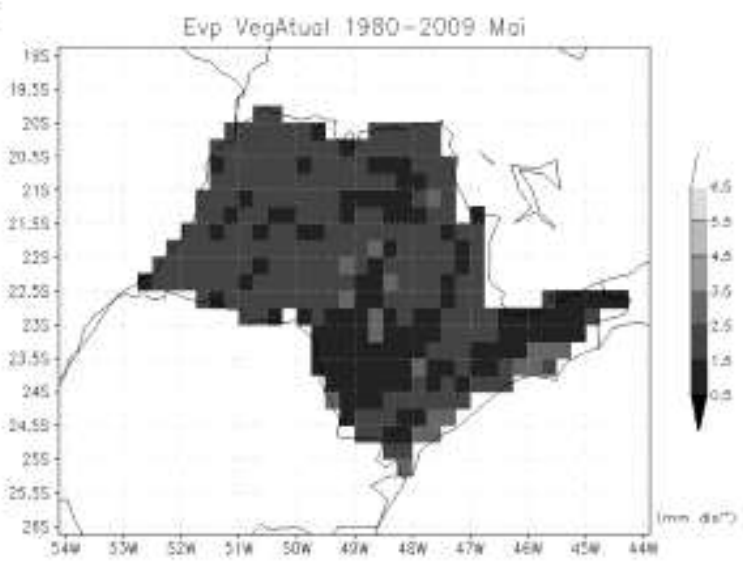

B

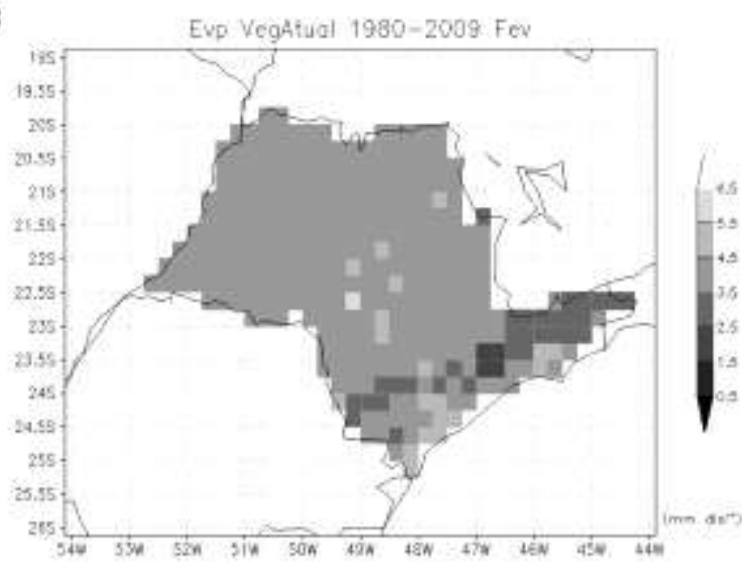

D

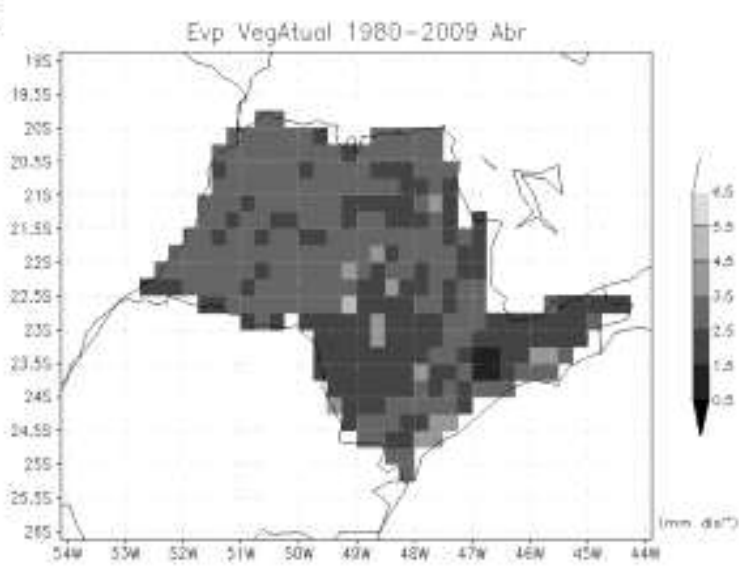

F

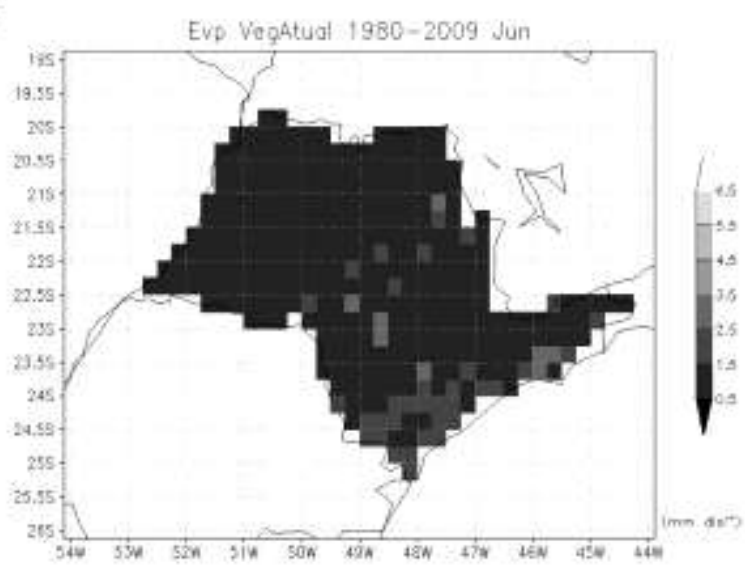


G
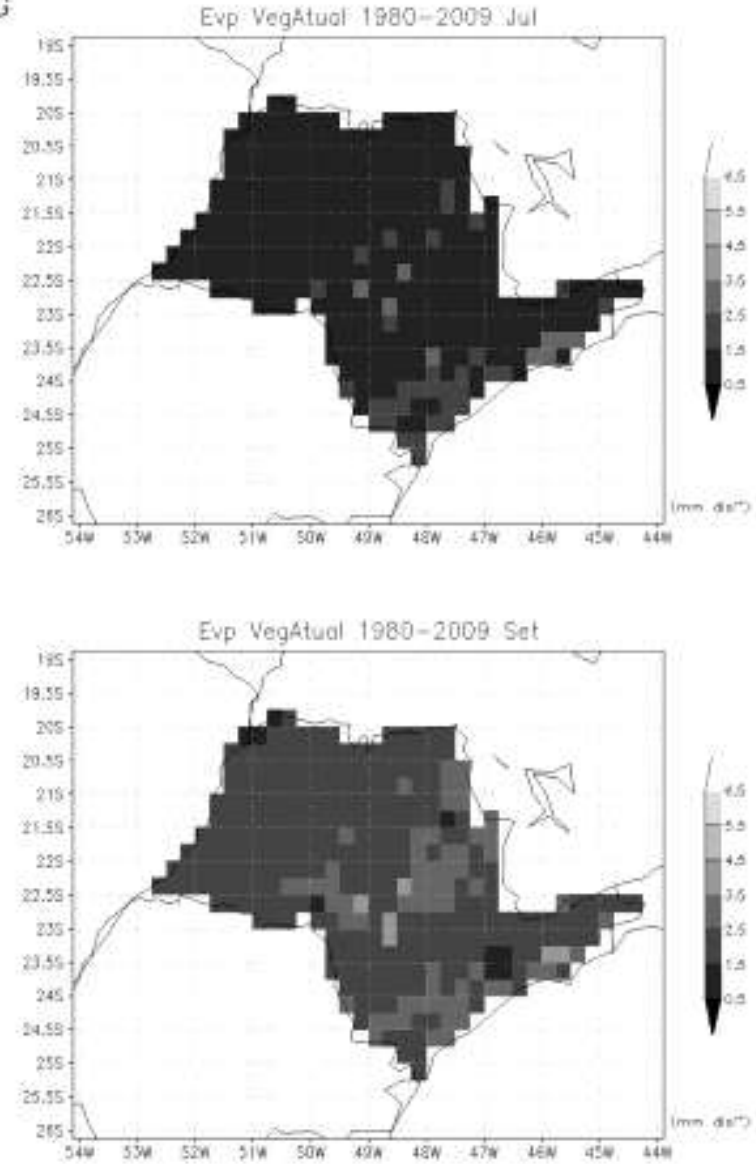

K

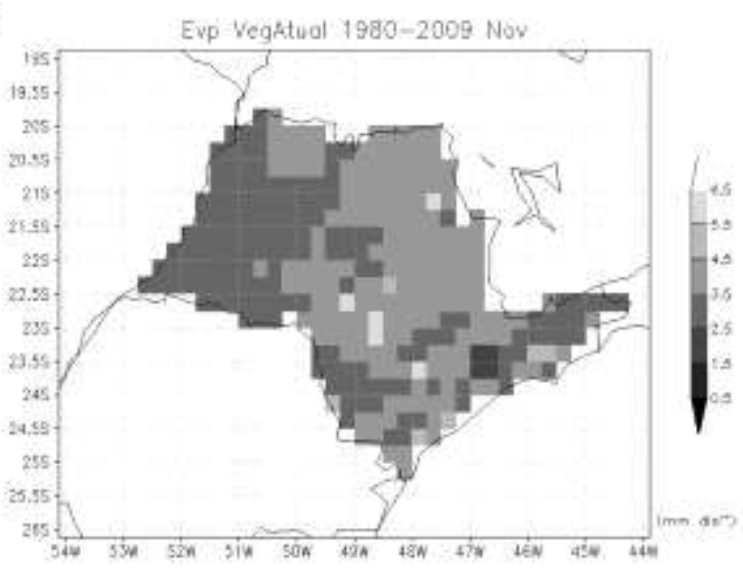

H

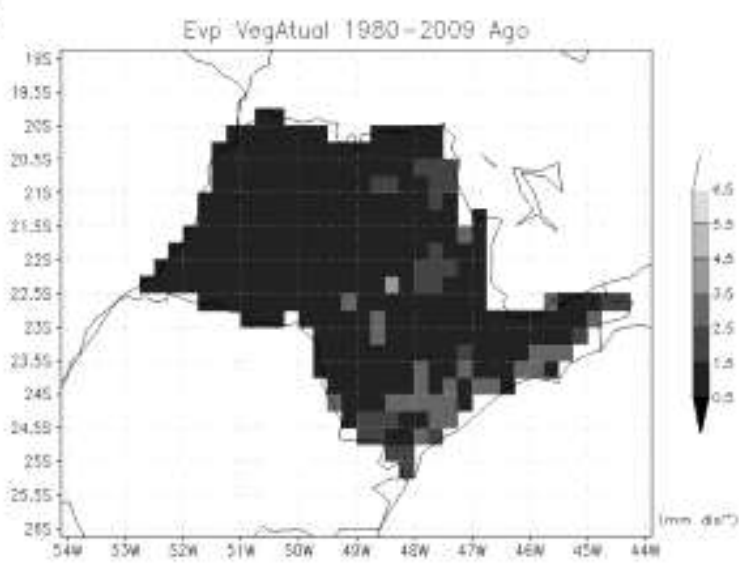

J

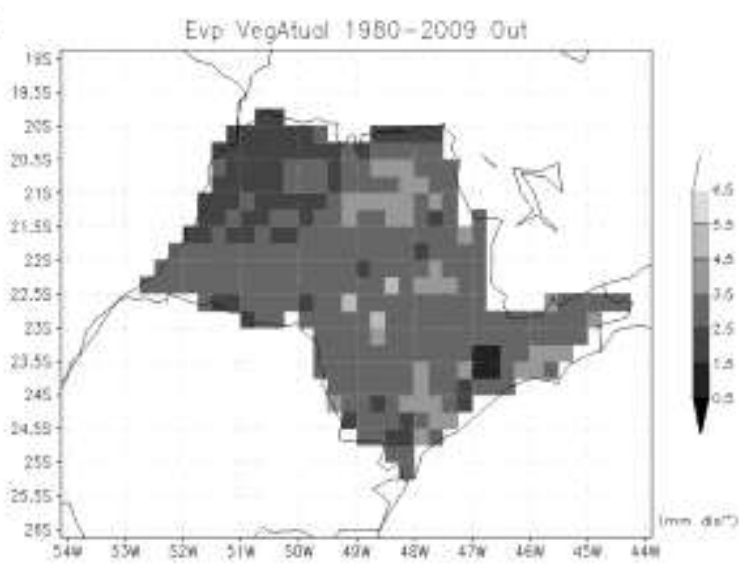

L

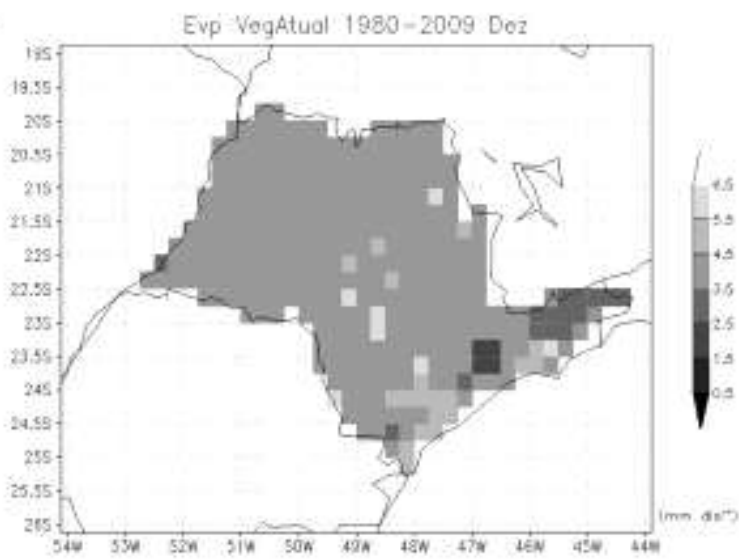

Figura B.15: Evapotranspiração para a vegetação atual [mm dia $\left.{ }^{-1}\right]$. Média no período entre 1980 e 2009. A) Janeiro; B) Fevereiro; C) Março; D) Abril; E) Maio; F) Junho; G) Julho; H) Agosto; I) Setembro; J) Outubro; K) Novembro; L) Dezembro. 
A

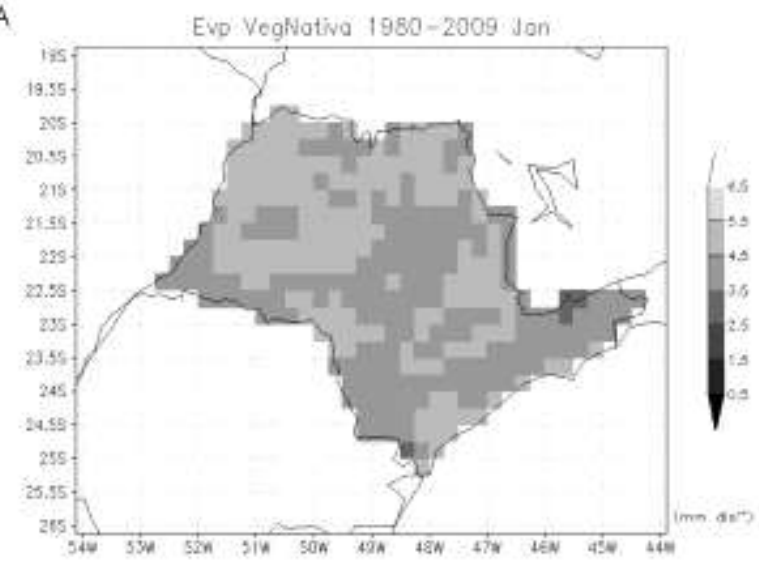

c

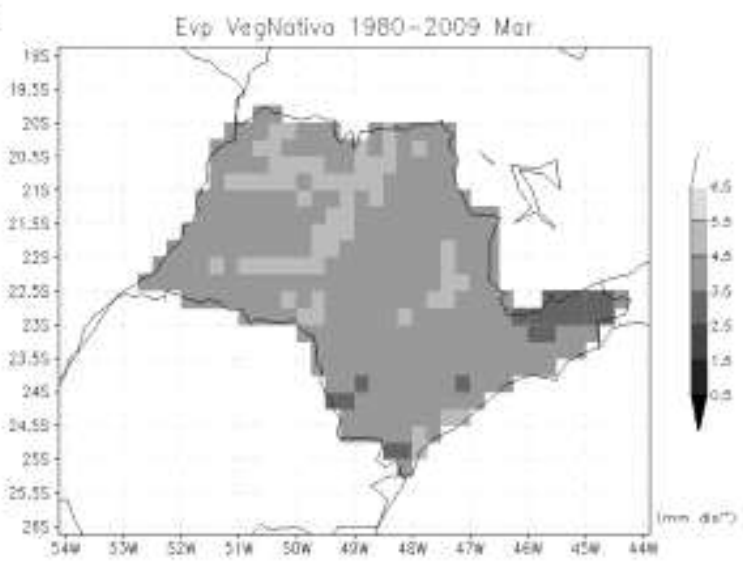

E

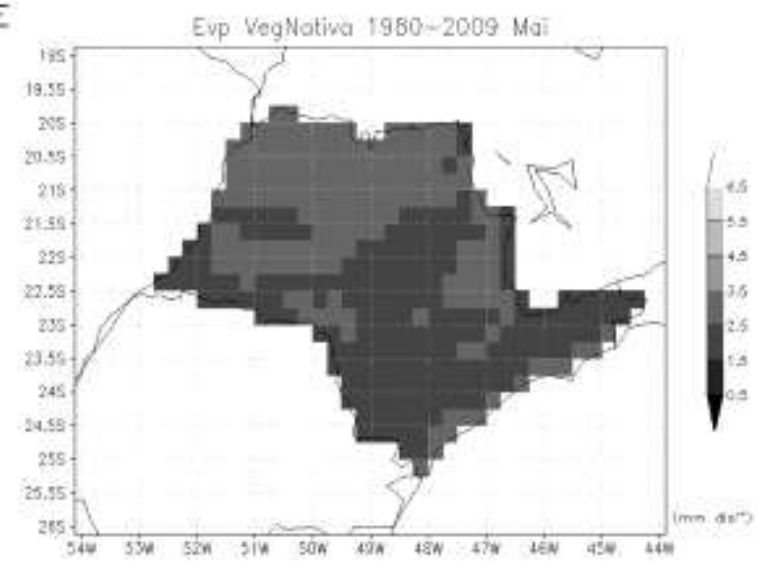

B

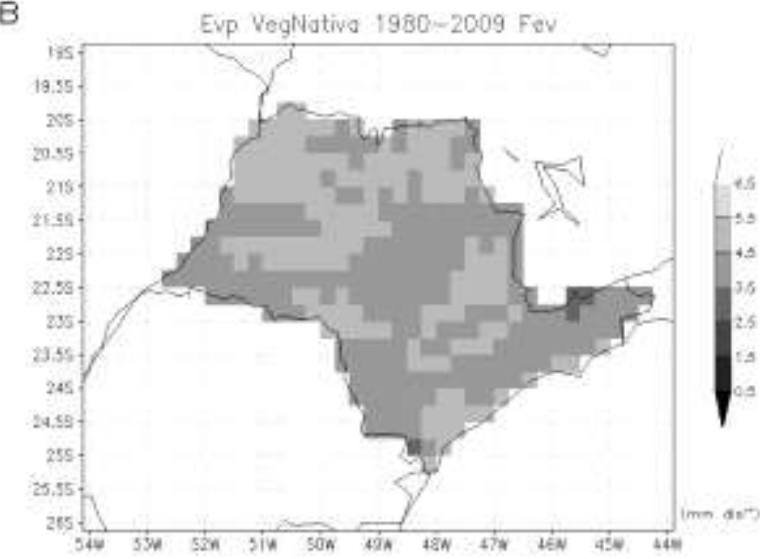

D

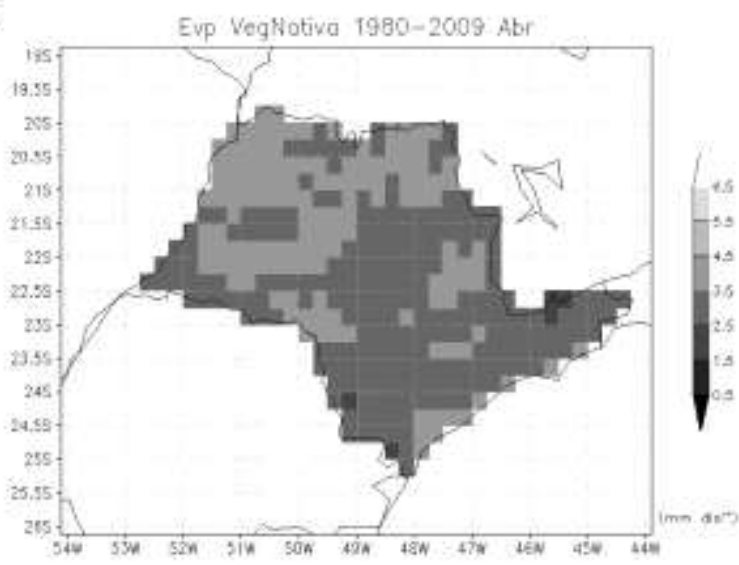

F

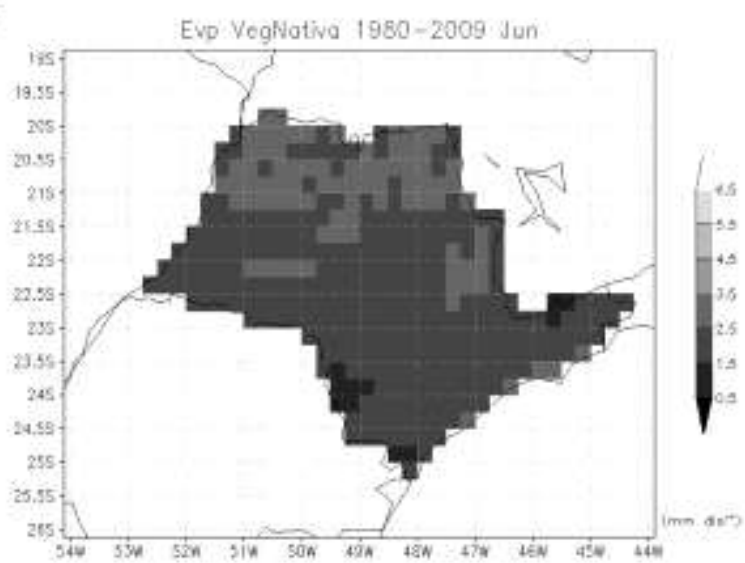


G
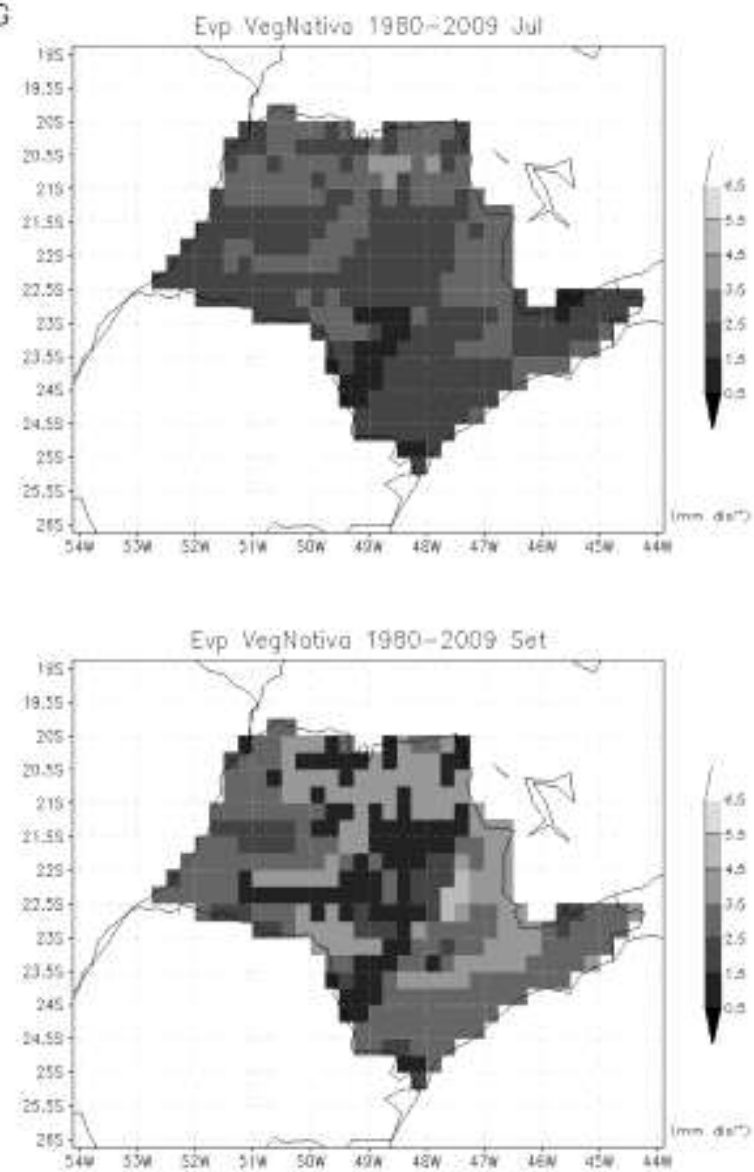

K

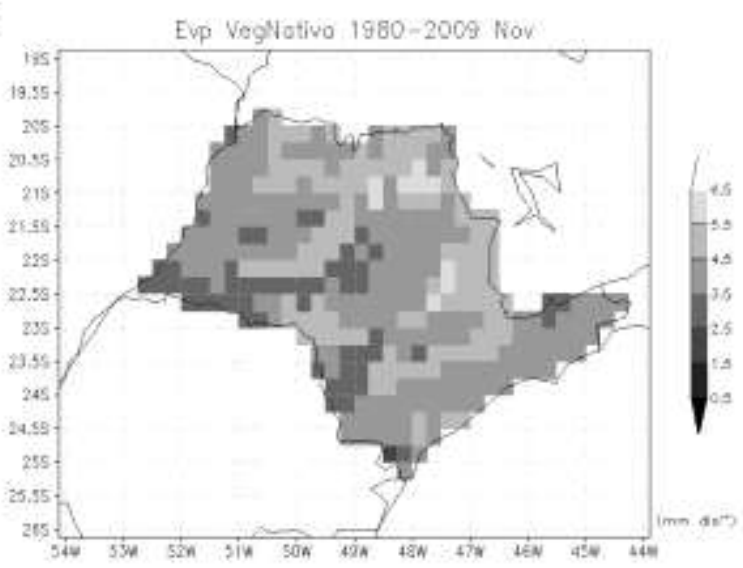

H

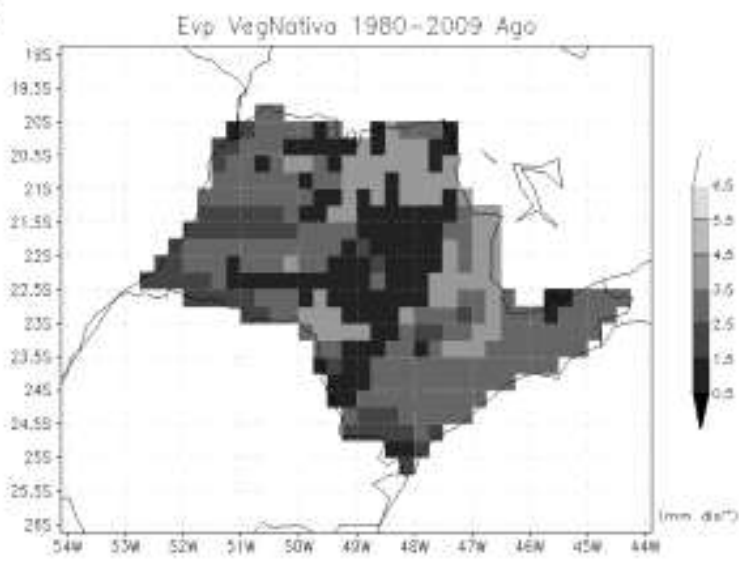

J

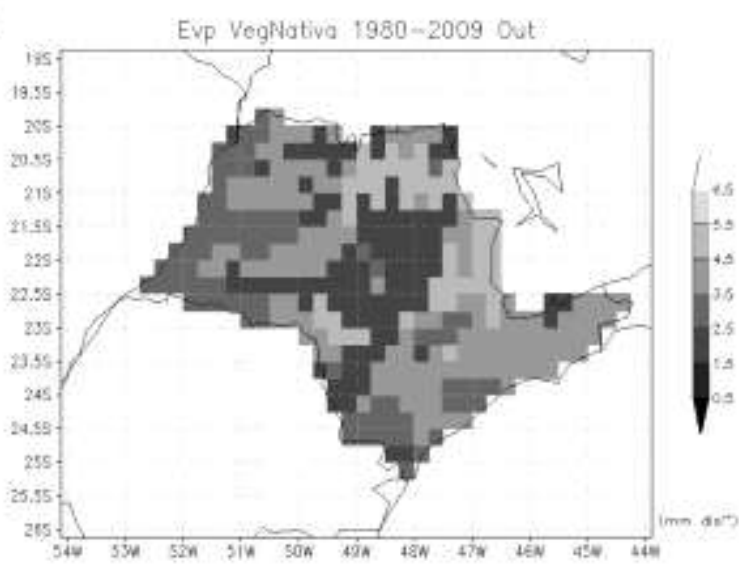

L

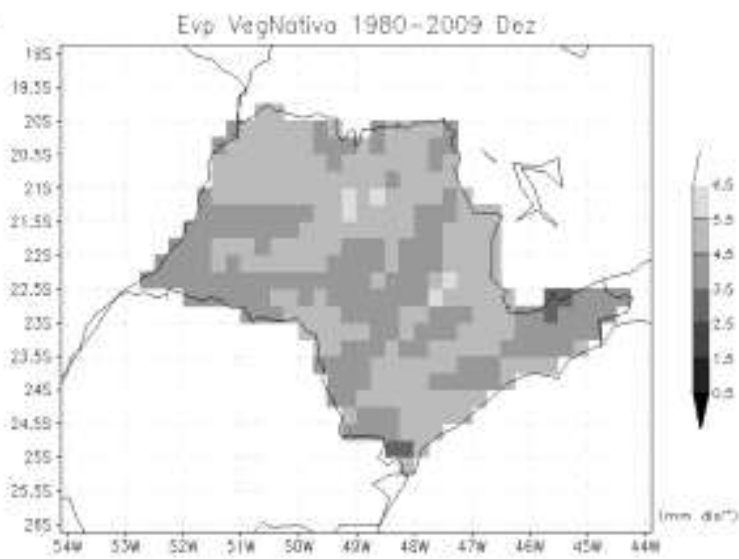

Figura B.16: Evapotranspiração para a vegetação nativa [mm dia ${ }^{-1}$ ]. Média no período entre 1980 e 2009. A) Janeiro; B) Fevereiro; C) Março; D) Abril; E) Maio; F) Junho; G) Julho; H) Agosto; I) Setembro; J) Outubro; K) Novembro; L) Dezembro. 


\section{APÊNDICE C CONJUNTOS DE PARÂMETROS (data1)}

\section{C.1 CANA-DE-AÇÚCAR}

O sítio experimental para a cana-de-açúcar está localizado na Fazenda São José do

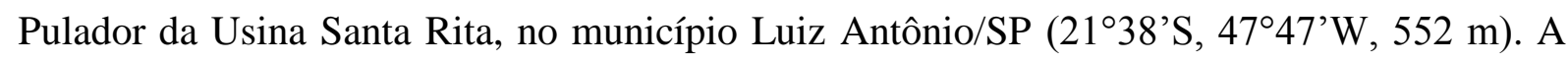
torre foi instalada no início de fevereiro de 2005, contendo a soca da cana-de-açúcar, plantada com espaçamento de $1,5 \mathrm{~m}$, com altura média de 3,5 m na época da colheita, realizada em 14 de abril de 2005 e 10 de maio de 2006.

Os parâmetros utilizados na simulação da cana-de-açúcar (Figura C.1) foram os mesmos da calibração da pastagem, com exceção do índice de área foliar, já que a cana tem um período, velocidade de crescimento e época de corte específicos. As simulações foram feitas com dados de torre localizada no município Luiz Antônio/SP, no período de 2006 a 2008. A data de corte da cana em 2005 foi dia 14/04/2005, de acordo com Tatsch (2006), e o perfil sazonal do índice de área foliar (IAF) estimado a partir de Negrón-Juárez (2004). 


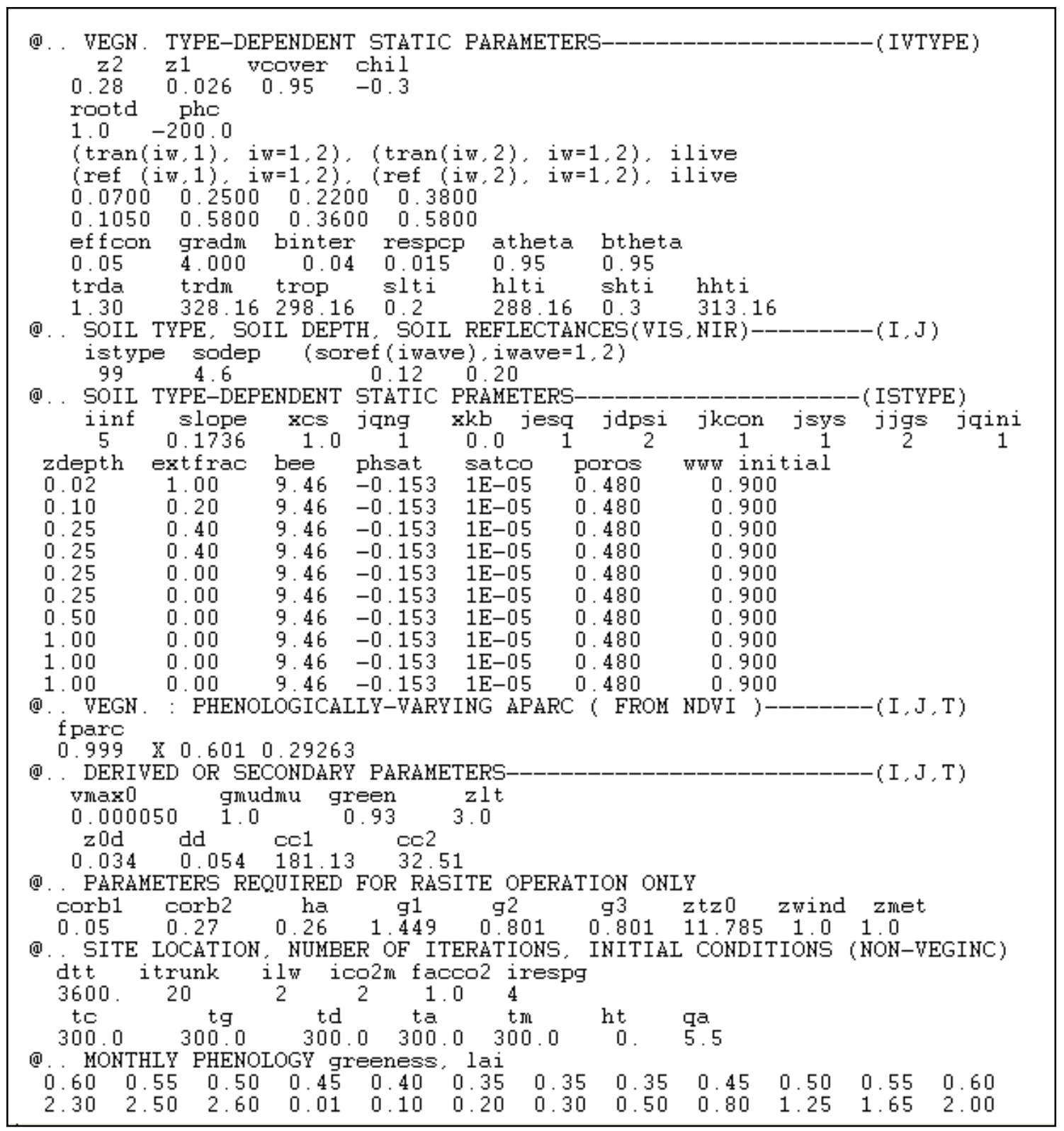

Figura C.1: Conjunto de parâmetros calibrados para a simulação da cana-de-açúcar no modelo SiB2.

\section{C.2 CERRADO}

As simulações para o cerrado foram feitas utilizando como entrada para o modelo dados de torre meteorológica localizada na Gleba Pé de Gigante, no município de Santa Rita do Passa Quatro, entre 2001 e 2003 e os parâmetros utilizados são os descritos em da Rocha et al. (2002) para a mesma região.

A torre foi instalada em janeiro de 2000 e tem $22 \mathrm{~m}$ de altura, fica localizada em $21^{\circ} 37^{\prime} \mathrm{S}, 47^{\circ} 38^{\prime} \mathrm{W}$, a $710 \mathrm{~m}$ de altitude. A fisionomia predominante é de cerrado sensu stricto e a altura média do dossel de $10 \mathrm{~m}$. 
Esta calibração teve o objetivo de encontrar a equação de onda longa que mais se aproximasse da observação (descrita no APÊNDICE B ) e reduzir a evapotranspiração, muito alta a princípio. Os resultados da calibração estão apresentados na Figura C.2.

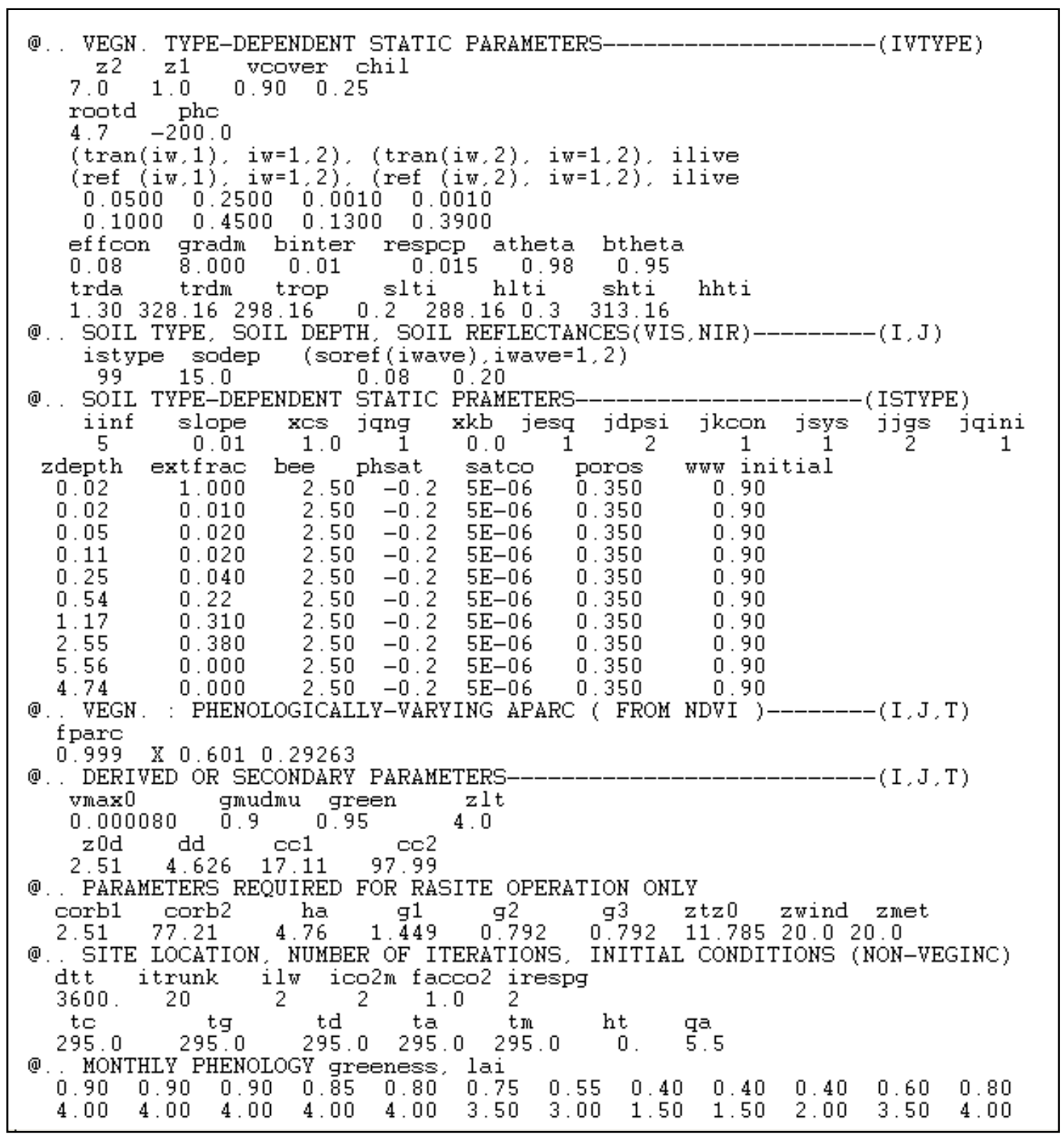

Figura C.2: Conjunto de parâmetros calibrados para a simulação do cerrado no modelo SiB2.

\section{C.3 EUCALIPTO}

As observações para o eucalipto foram feitas em torre localizada num talhão de

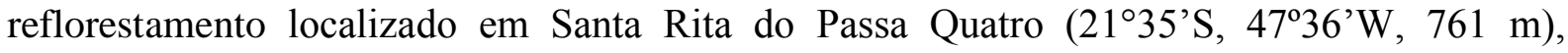
instalada em julho de 2003. O espaçamento de árvores adotado foi de $3 \mathrm{~m}$ e a altura das árvores em agosto de 2005 era de 11 m, e em fevereiro de 2006, 13 m (Tatsch, 2006). 
A simulação do eucalipto foi feita a partir dos parâmetros calibrados para a floresta, com exceção dos sazonais: índice de área foliar, parâmetros de folhas verdes no dossel e da máxima capacidade de fotossíntese. Os períodos de simulação foram os anos hidrológicos de 2006/2007 e 2007/2008, que começam no dia $1^{\circ}$ de setembro e termina no dia 31 de agosto de cada ano. A calibração entregou o conjunto de parâmetros listados na Figura C.3.

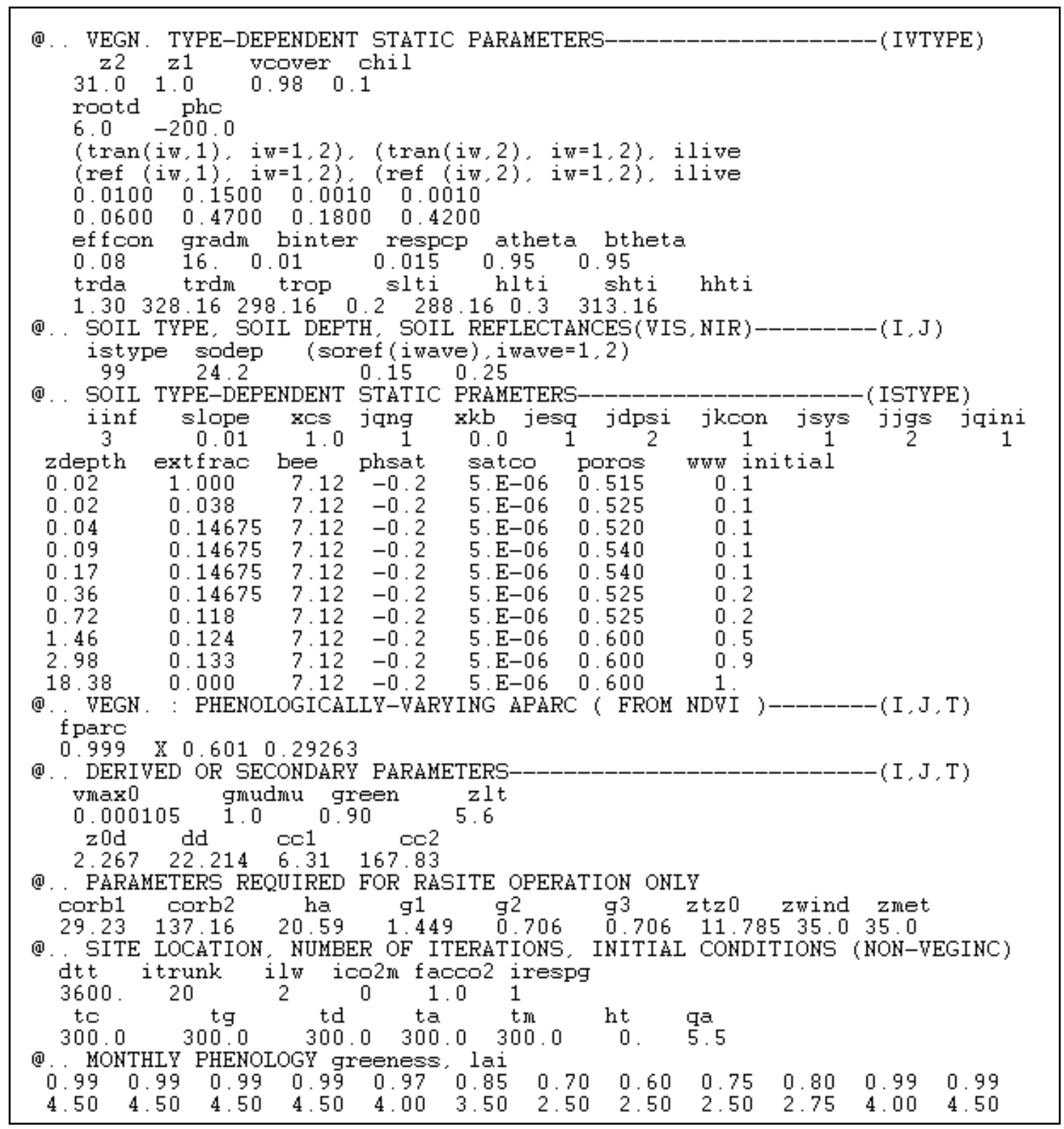

Figura C.3: Conjunto de parâmetros calibrados para a simulação do eucalipto no modelo SiB2. 


\section{C.4 FLORESTA ATLÂNTICA}

As simulações para floresta foram feitas com dados da torre localizada no Núcleo

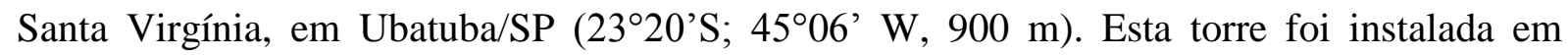
novembro de 2007 e os dados utilizados são do ano de 2008. Esta localidade é caracterizada por um dossel heterogêneo de aproximadamente $20 \mathrm{~m}$ de altura.

A parametrização foi resultada do estudo de Llopart (2009). Os parâmetros estão apresentados na Figura C.4.

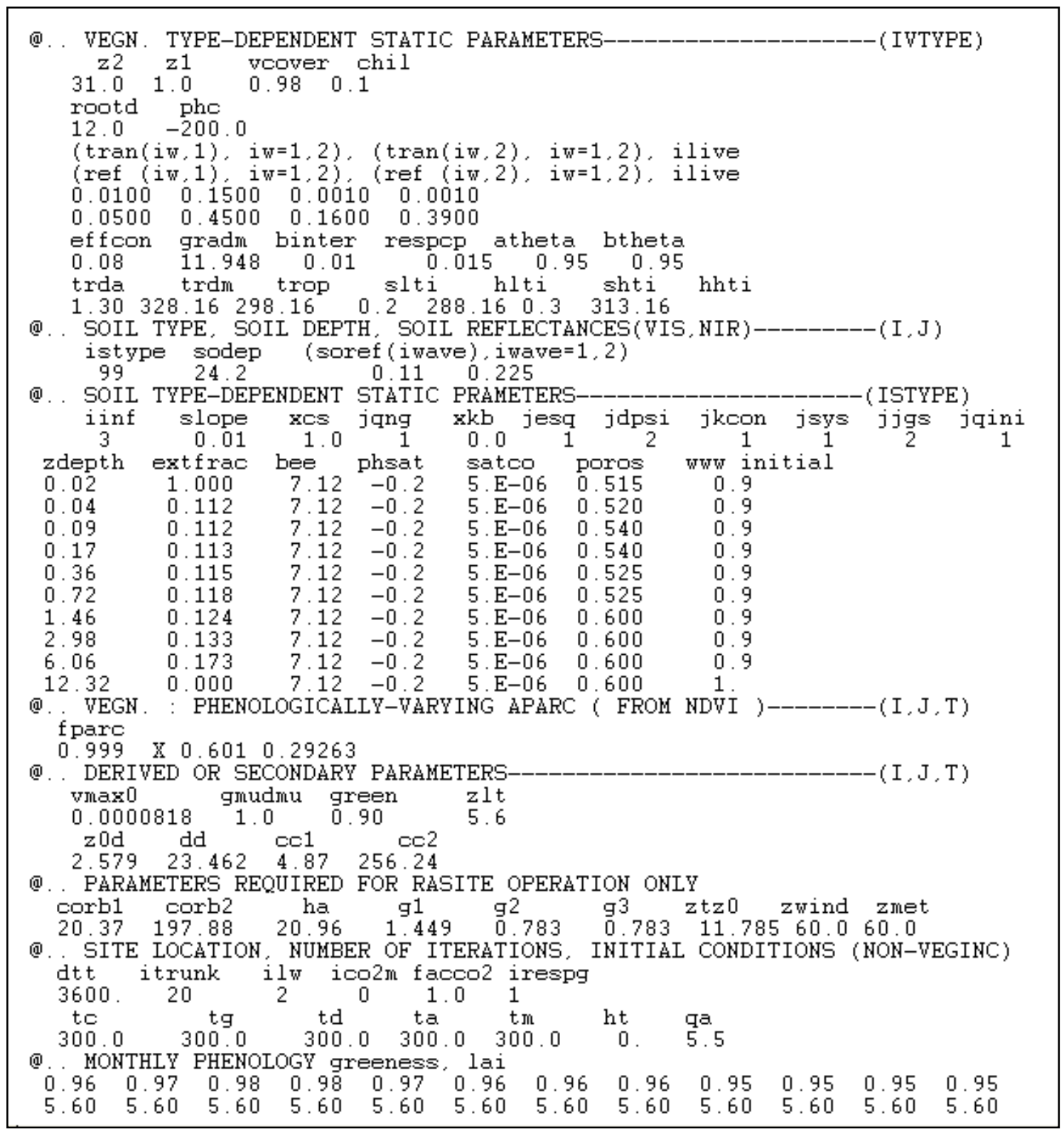

Figura C.4: Conjunto de parâmetros calibrados para a simulação da floresta atlântica no modelo SiB2. 


\section{C.5 PASTAGEM}

$\mathrm{Na}$ ausência de dados de torres de fluxos representativos da pastagem para São Paulo, os parâmetros utilizados nas simulações foram calculados para a Fazenda Nossa Senhora, Rondônia, durante o LBA Model Intercomparison Project (LBA-MIP). Os dados utilizados para as simulações foram obtidos gratuitamente a partir do site da ESALQ/USP, a estação automática localizada em Piracicaba reporta médias a cada 15 minutos. Foram feitas médias horárias para a montagem do arquivo de forçantes. O período de dados utilizado foi o de 2003 a 2004. As modificações feitas nos parâmetros durante a calibração se limitaram à profundidade das camadas do solo e aos valores de extração em cada camada (Figura C.5). 


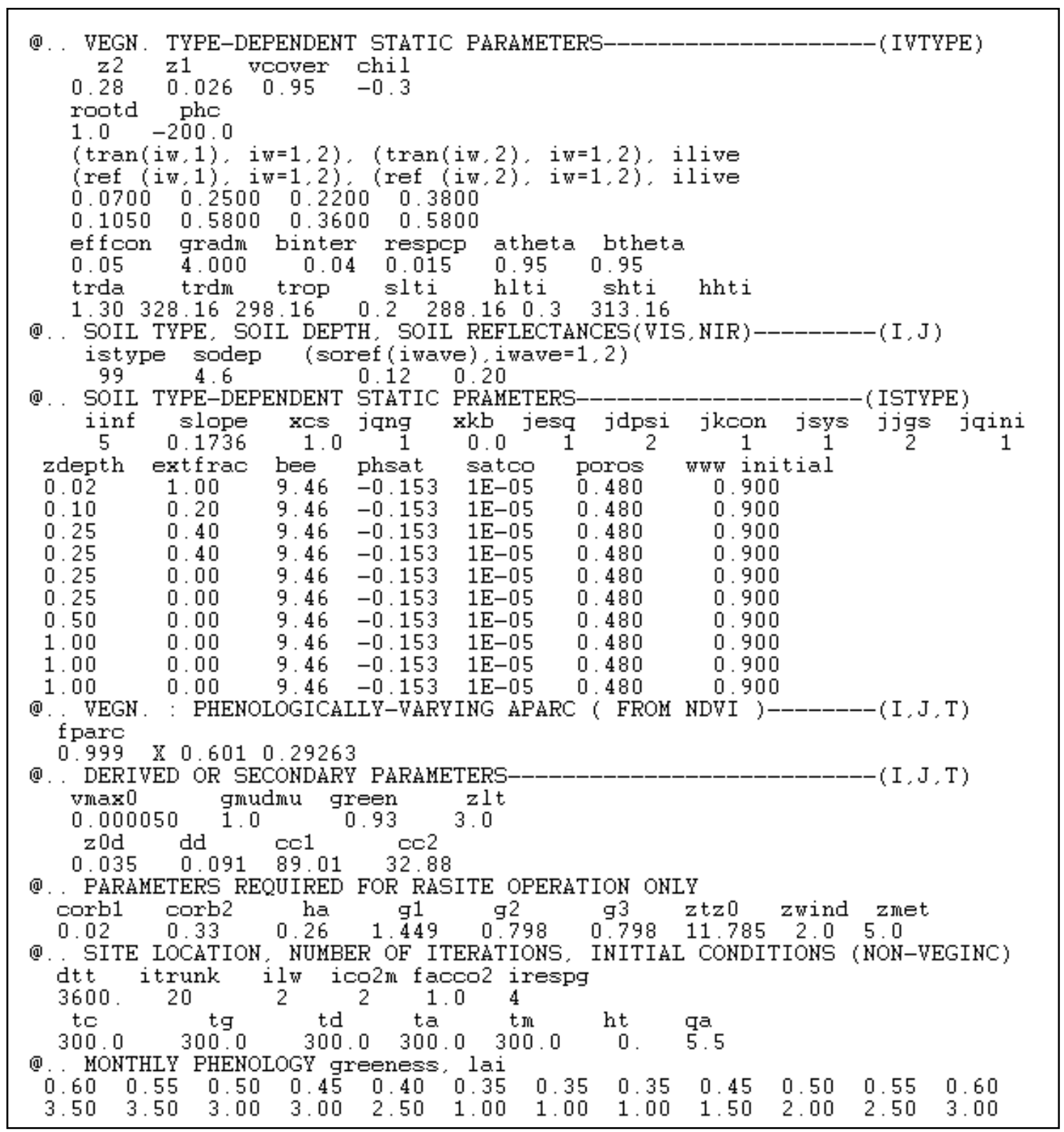

Figura C.5: Conjunto de parâmetros calibrados para a simulação da pastagem no modelo SiB2.

\section{C.6 ÁREA URBANA}

Para simular o comportamento dos fluxos de calor na área urbana procuramos alguns artifícios a fim de reduzir ao máximo a transpiração e, por consequência, a evapotranspiração (simulando uma área pobremente vegetada). A partir do conjunto de parâmetros para o cerrado, reduzimos o índice de área foliar ao valor de 10\%, o coeficiente angular estomático de 8 para 0,5 e a máxima capacidade de fotossíntese de 80 para 1 , além da resistência do solo 
(modificada diretamente no código do modelo) que passou a ter um valor muito elevado de 3000 s m-1. Os parâmetros estão listados na Figura C.6.

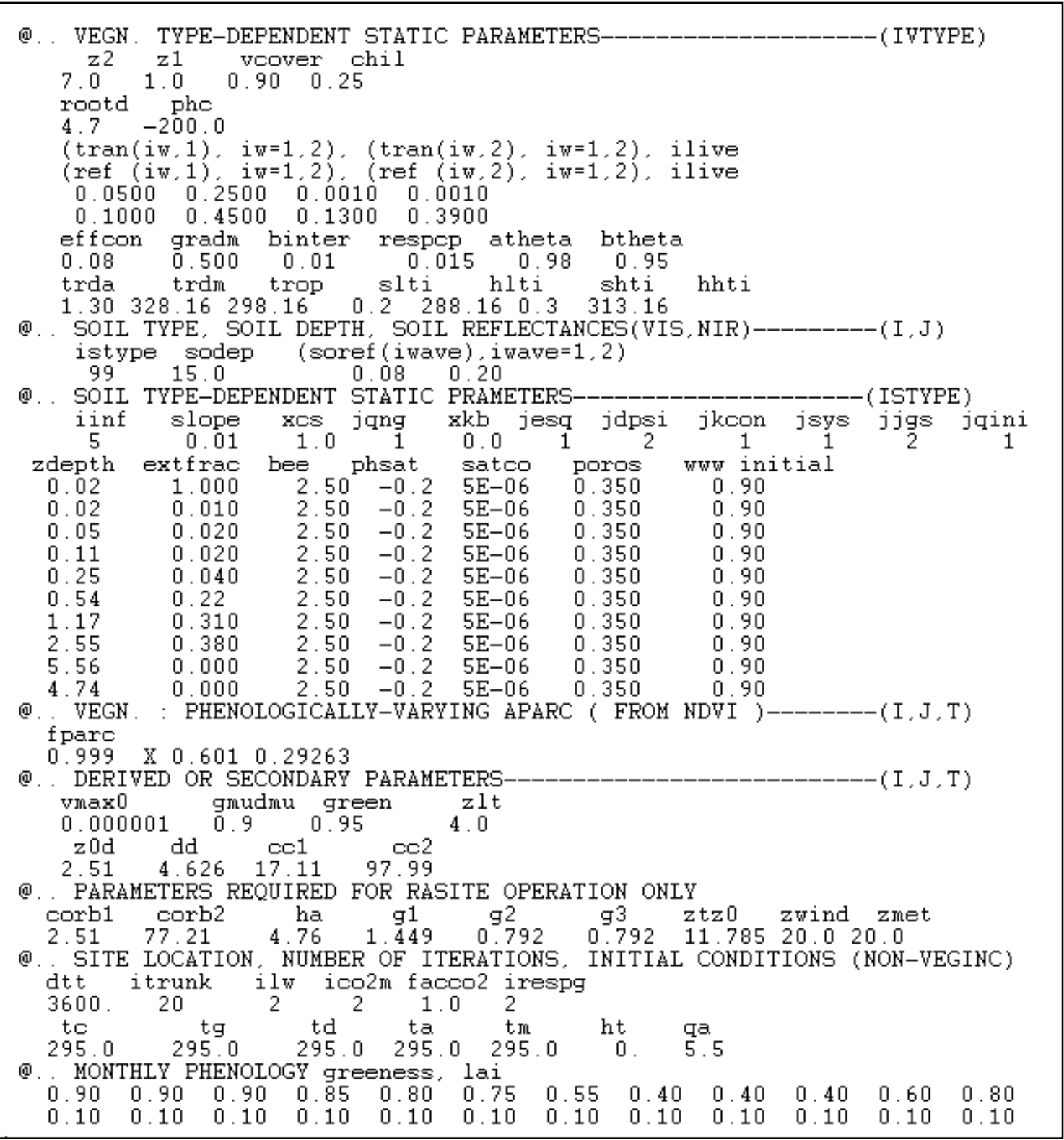

Figura C.6: Conjunto de parâmetros calibrados para a simulação da área urbana no modelo SiB2. 


\section{APÊNDICE D TESTE T-STUDENT}

Para avaliar a sensibilidade do modelo em resposta à caracterização da cobertura vegetal, os padrões do fluxo de calor latente médio mensal no cenário de vegetação nativa foram supostos como a referência, e os padrões nos demais cenários foram comparados com aquele. Na comparação da diferença dos padrões dos cenários, foi utilizado o teste t-Student (teste-t) para que apenas as diferenças estatisticamente significativas fossem destacadas. Este teste é utilizado para se verificar se duas amostras são estatisticamente diferentes, como, por exemplo, para campos de fluxos de energia e de precipitação, segundo Saad et al. (2010).

Com a estatística $t$ (Equação D.1), para 30 anos de simulação, resultado da série com um número de eventos (n) de 360 meses para cada amostra e grau de liberdade (Equação D.2) de 359 , calculou-se $t_{r}=1,9666$, com nível de significância de $5 \%{ }^{7}$. As duas amostras são estatisticamente distintas quando $t>t_{r}$. O teste foi feito no software GrADS, com script disponível na página do $\mathrm{CCR}^{8}$.

$$
\begin{aligned}
& t=\frac{\overline{X_{1}}-\overline{X_{2}}}{\sqrt{\frac{s_{1}^{2}}{n_{1}}+\frac{s_{2}^{2}}{n_{2}}}} \\
& d f=n-1=360-1=359
\end{aligned}
$$

$$
\begin{aligned}
\text { Onde: } \bar{X}_{\iota} & =\text { valor da amostra } i \\
n & =\text { número de dados de } \bar{X}_{\iota} \\
S_{i}^{2} & =\text { variância de } \bar{X}_{\iota} \\
d f & =\text { número de graus de liberdade }
\end{aligned}
$$

O teste-t foi feito tendo o campo de vegetação nativa como referência. Como o mapa de vegetação nativa é composto em sua maior parte por floresta atlântica, a comparação com o cenário fictício composto apenas por floresta é a que representa menor porção da figura estatisticamente diferente da referência. Obviamente, o mesmo ocorre com a figura para o cerrado, nas regiões originalmente cobertas por este padrão florestal.

\footnotetext{
${ }^{7} \mathrm{O}$ valor de $\mathrm{t}_{\mathrm{r}}$ foi obtido a partir da página: http://statpages.org/pdfs.html

${ }^{8}$ CCR - Center for Climatic Research: http://ccr.aos.wisc.edu/model/processing/grads/grads_statsig.php
} 
Os parâmetros utilizados para caracterizar o eucalipto são similares aos da floresta, sendo assim, encontramos algumas áreas em que o teste não foi válido, mas a maior parte da figura está sombreada.

A mesma comparação entre floresta e eucalipto pode ser feita entre cerrado e pastagem, com parametrizações semelhantes.

Os testes feitos para a cana e área urbana foram válidos para praticamente toda a área, o que é preocupante, pois são formas de uso da terra crescentes no estado.

Finamente, a comparação com o cenário de cobertura atual de vegetação mostra praticamente toda a área estatisticamente diferente das séries de referência (poucas exceções para regiões com vegetação nativa preservada). Desta forma, a evapotranspiração calculada se apresenta sensível às mudanças no uso da terra.

A

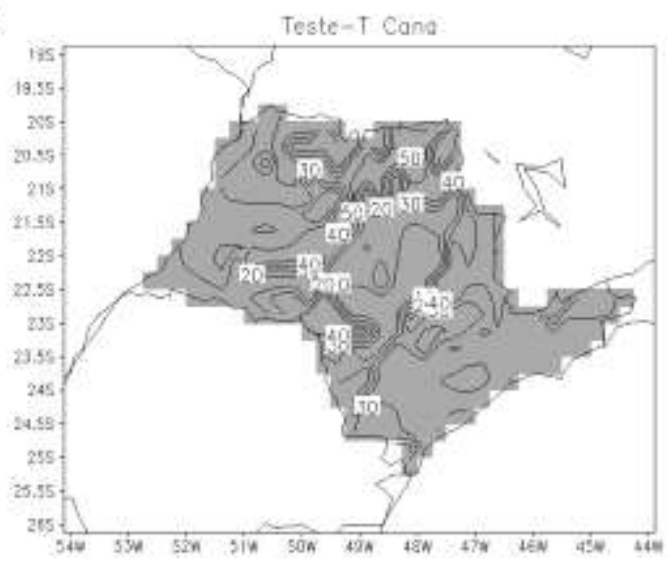

C

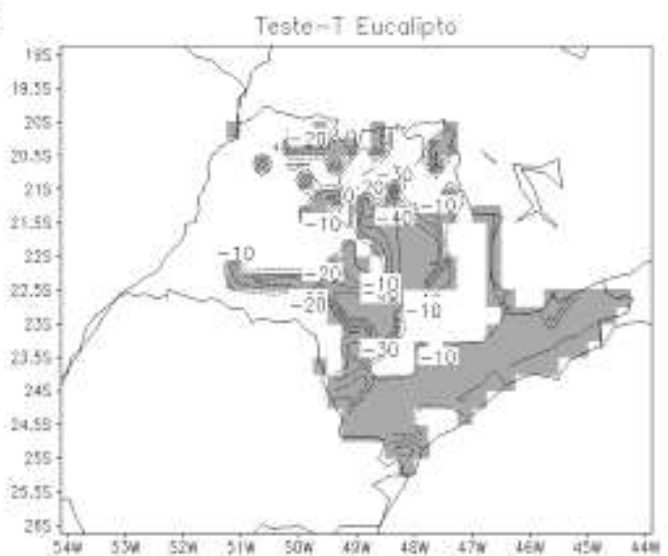

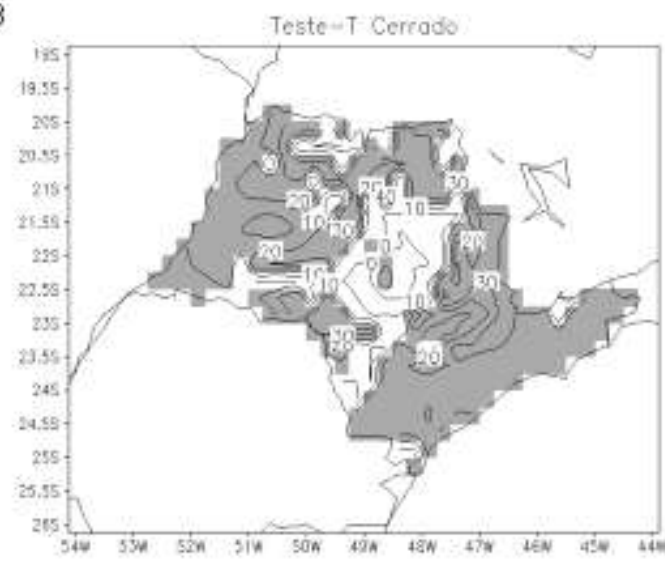

D

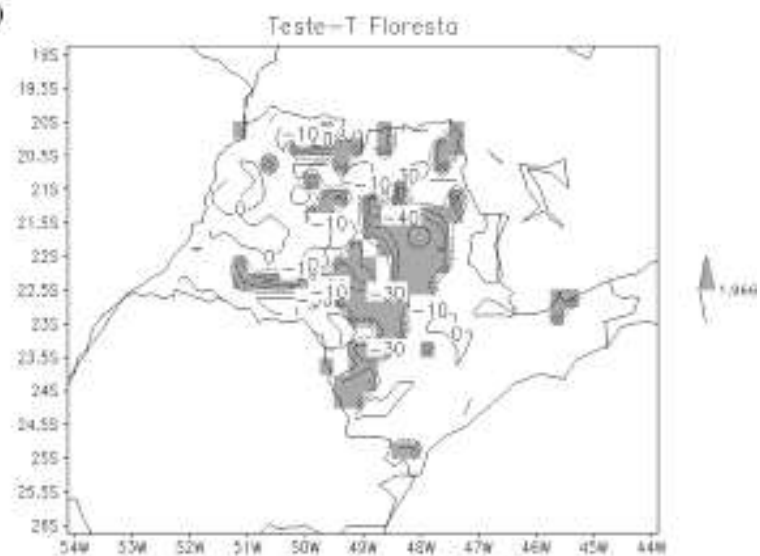


$E$

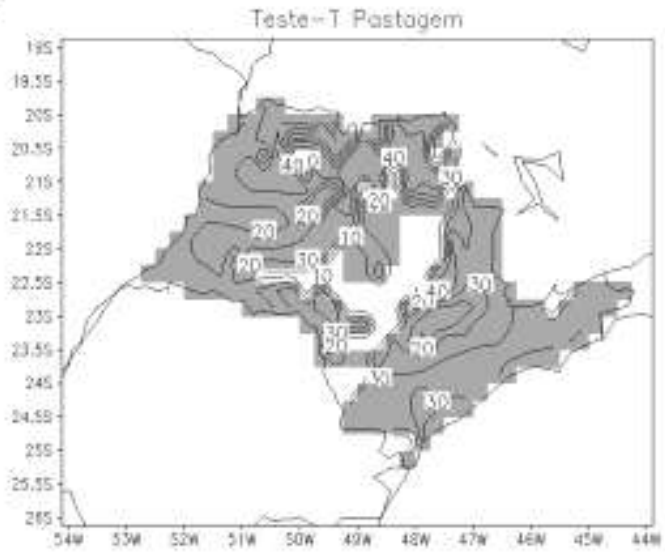

$\mathrm{F}$

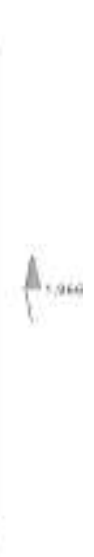

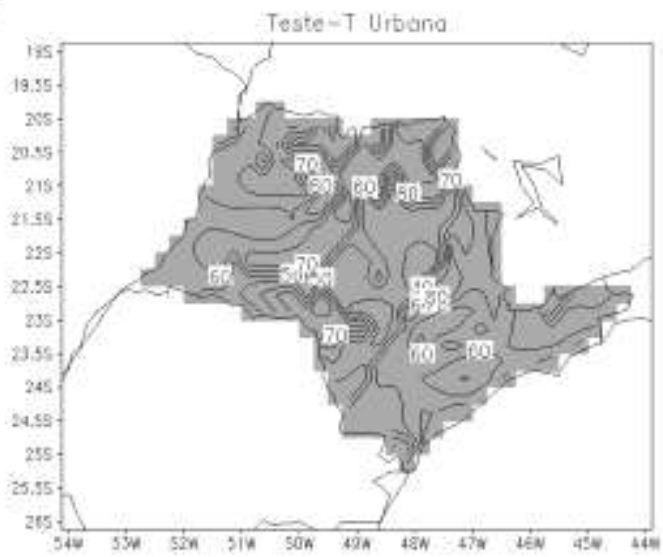

G

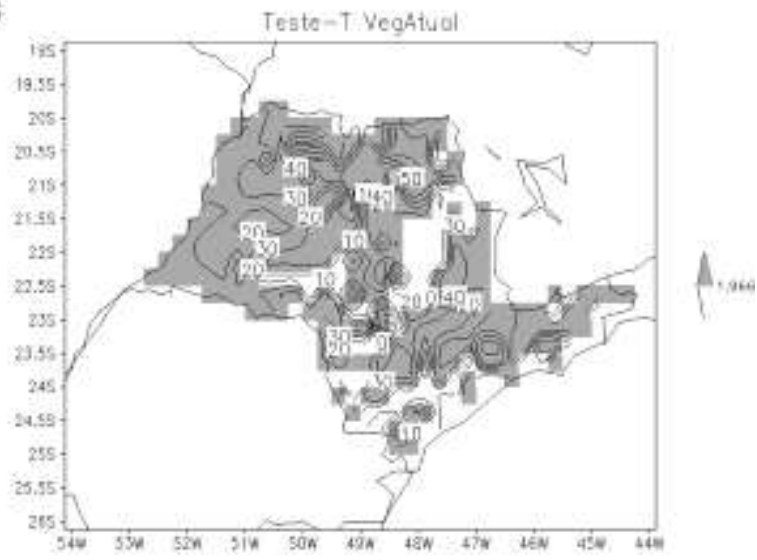

Figura D.1: Teste t-Student para com a vegetação nativa como referência. $A$ área sombreada indica onde o teste foi válido, séries compostas por 360 meses entre 1980 e 2009. A) cana-de-açúcar; B) cerrado; C) eucalipto; D) floresta atlântica; E) pastagem; F) área urbana; G) vegetação atual. 